\title{
Behavioral sequelae of perinatal hypoxia in the rat
}

Citation for published version (APA):

Hermans, R. H. M. (1994). Behavioral sequelae of perinatal hypoxia in the rat. [Doctoral Thesis, Maastricht University]. Rijksuniversiteit Limburg. https://doi.org/10.26481/dis.19941021rh

Document status and date:

Published: 01/01/1994

DOI:

10.26481/dis.19941021rh

Document Version:

Publisher's PDF, also known as Version of record

\section{Please check the document version of this publication:}

- A submitted manuscript is the version of the article upon submission and before peer-review. There can be important differences between the submitted version and the official published version of record.

People interested in the research are advised to contact the author for the final version of the publication, or visit the DOI to the publisher's website.

- The final author version and the galley proof are versions of the publication after peer review.

- The final published version features the final layout of the paper including the volume, issue and page numbers.

Link to publication

\footnotetext{
General rights rights.

- You may freely distribute the URL identifying the publication in the public portal. please follow below link for the End User Agreement:

www.umlib.nl/taverne-license

Take down policy

If you believe that this document breaches copyright please contact us at:

repository@maastrichtuniversity.nl

providing details and we will investigate your claim.
}

Copyright and moral rights for the publications made accessible in the public portal are retained by the authors and/or other copyright owners and it is a condition of accessing publications that users recognise and abide by the legal requirements associated with these

- Users may download and print one copy of any publication from the public portal for the purpose of private study or research.

- You may not further distribute the material or use it for any profit-making activity or commercial gain

If the publication is distributed under the terms of Article $25 \mathrm{fa}$ of the Dutch Copyright Act, indicated by the "Taverne" license above, 


\title{
BEHAVIORAL SEQUELAE OF PERINATAL HYPOXIA IN THE RAT
}

\author{
PROEFSCHRIFT \\ ter verkrijging van de graad van doctor \\ aan de Rijksuniversiteit Limburg te Maastricht, \\ op gezag van de Rector Magnificus, prof. dr. H. Philipsen, \\ volgens het besluit van het College van Dekanen, \\ in het openbaar te verdedigen \\ op vrijdag 21 oktober om 16.00 uur \\ door

\section{Raphaël Hubertus Maria Hermans} \\ geboren op 30 september 1964 te Kerkrade
}


Promotores: $\quad$ Prof. dr. J. de Haan

Prof. L. D. Longo, Loma Linda University, California U.S.A.

Co-promotor Dr. L. L. H. Peeters

Beoordelingscommisie: Prof. dr. H. M. van Praag (voorzitter)

Prof. dr. J. Jolles

Prof. dr. A. K. Slob, Erasmusuniversiteit, Rotterdam

Prof. dr. D. F. Swaab, Universiteit van Amsterdam

Prof. dr. J. Troost

CIP - DATA KONINIKLIJKE BIBLIOTHEEK, DEN HAAG

Hermans, Raphaël Hubertus Maria

Behavioral sequelae of perinatal hypoxia in the rat

Raphaël Hubertus Maria Hermans - Maastricht

Thesis maastricht - with ref. - with summary in Dutch

ISBN: 90 - 9007547 - $x$

Subject headings: hypoxia - testosterone - behavior

Layout: Out - line Eijsden

Druk: Uniprint RL To 043883970

(C) R. H. M. Hermans, Maastricht 1994 
aan Miriam 


\section{ABBREVIATIONS}

CNS

central nervoussystem

$\mathrm{CO}_{2}$

carbon dioxide

$\mathrm{CO}$

carbon monoxide

E

embryonic

$E_{2}$

$\mid 7$ - beta - estradiol

HPA - axis hypothalamic-pituitary-adrenal axis

HPG - axis hypothalamic-pituitary-gonodal axis

$\mathrm{O}_{2}$

oxygen

ODC

ornithine decarboxylase

P

postnatal

SDN

sexual dimorphic nucleus

$\mathrm{T}$

testosterone 
I. Hypoxia and behavior.

II. Prenatal stress and sexual differentiation of the brain.

III. Behavioral sequelae in young rats of acute, intermittent antenatal hypoxia.

IV. Decreased postnatal testosterone and corticosterone concentrations in rats following acute intermittent prenatal hypoxia without alterations in adult male sexual behavior.

V. Altered adult sexual behavior in the male rat following chronic prenatal hypoxia.

VI. The postnatal testosterone surge in the male rat: apparent lack of role of opioids and $\mathrm{N}$-methyl$\mathrm{D}$-aspartate excitatory amino acids.

VII. The postnatal testosterone surge is not preceded by a postnatal rise in plasma $L H B$ in the rat.

VIII. Altered catecholaminergic behavioral and endocrine responses in rats following early postnatal hypoxia.

IX. General discussion.

Summary, samenvatting, acknowledgement, curriculum vitae 


\section{HYPOXIA AND BEHAVIOR}

\section{INTRODUCTION}

It is well known that exposure of the fetus and neonate to a multitude of substances such as alcohol, methy/mercury, or radiation can alter brain morphology, function, and ultimately behavior. In the following chapters we will focus on the behavioral and endocrinologic effects of pre- and postnatal hypoxia. Hypoxia during the perinatal period is believed to be a cause of disturbed function of the central nervous system during childhood $(6,81)$. Studies in both humans and animals have demonstrated late neurological sequelae of perinatal hypoxia, in particular learning disabilities, motor disturbances, and behavioral abnormalities. Probably the first association of perinatal hypoxia to subsequent behavioral alterations was provided by W.J. Little who in 186 | reported the neurologic and behavioral sequelae of prolonged, difficult, or delayed parturition and of neonatal asphyxia in humans (42). Fetal and neonatal hypoxia is not infrequently encountered during pregnancy and parturition due to a wide variety of factors including anemia, pregnancy-induced hypertension, maternal smoking, maternal heart and lung disease, placental dysfunction, partial umbilical cord occlusion, and other factors (see 43 for review). In addition to these conditions a wide range of agents and conditions ranging from maternal ethanol ingestion $(61)$ to psychological stress $(58,59)$ induce fetal hypoxia by restricting oxygen delivery to the placental circulation and/or fetus.

In 1972 Ward first described the effects of prenatal maternal stress on sexual differentiation of the male rat (88). Maternal psychological stress (restraint, heat, bright illumination $45 \mathrm{~min}, 3 \times /$ day) resulted in failure of masculinized sexual behavior, and increased feminine potentials in male offspring. Prenatal hypoxia can be viewed as stress to both the mother and the dam. Thus, hypoxia during the perinatal period may result in altered sexual differentiation of the male rat. Male sexual differentiation is critically dependent on the occurrence of two perinatal testosterone surges. In the rat, the first plasma testosterone elevation occurs on day 18 of pregnancy, the second occurs $1-2$ hours after birth. No previous studies have examined the effect of prenatal hypoxia on the perinatal androgen status, or sexual differentiation of the male non- and reproductive sexually dimorphic behaviors. In addition, it is not clear which regulatory factors account for the rapid and significant rise in testosterone concentrations postnatally. For review see chapter 2 .

Few previous reports on perinatal hypoxia have employed longitudinal studies or an extensive test battery with foster procedures, to assess behavioral sequelae of perinatal hypoxia. In addition, previous studies by our group have shown marked neurochemical alterations in fetuses and neonates exposed to moderate prenatal hypoxia (44). Thus, we explored whether these hypoxic-induced neurochemical changes, affected subsequent functional development. 
In the present study we examined the following questions:

I.

To what extent does mild, acute, intermittent, prenatal hypoxia alter postnatal sensorimotor, locomotor, and cognitive development?

2.

Does mild, chronic, prenatal hypoxia alter postnatal sensorimotor, locomotor, and cognitive development, and if so to what extent do its effects differ from acute intermittent, prenatal hypoxia?

3.

Do either intermittent or chronic, prenatal hypoxia interfere with amplitude or onset of the postnatal testosterone surge, and thus interfere with the adult expression of nonreproductive and reproductive sexually dimorphic behaviors? If so, to what extent do the effects of chronic hypoxia differ from those of acute hypoxia?

4. Does acute, intermittent, postnatal hypoxia alter adult dopaminergic and noradrenergic behavioral and endocrinologic responsiveness?

5.

Does the fetal-neonatal hypothalamo-pituitary axis regulate the postnatal testosterone "surge" in the male newborn. To what extent are environmental and maternal factors involved in the regulation of onset and amplitude of the postnatal testosterone surge?

\section{Definitions}

Generally speaking, hypoxia refers to a relative lack of oxygen (e.g. low $\mathrm{O}_{2}$ content or tension) in the ambient air and/or tissues. Strictly speaking, hypoxia is $\mathrm{O}_{2}$-limited energy flux in mitochondria, rather than low $\mathrm{O}_{2}$ content or tension, per se. Asphyxia is synonymous with suffocation, i.e., hypoxia combined with increased $\mathrm{CO}_{2}$ tension and decreased $\mathrm{pH}$. Ischemia is insufficiency of blood flow.

\section{Background}

Probably the first description of an experiment on perinatal hypoxia were Boyle 's observations on newborn cats exposed hypobaric hypoxia (9). Boyle hypothesized that newborn animals would be more resistant to hypoxia compared to older animals. In his 1812 treatise "Experiences sur le principle de la vie", Legallois demonstrated that neonatal rabbits were more resistant to cerebral hypoxia than were adult animals (40). Gasping movements in decapitated newborn rabbits were much more prolonged then those in adults. Fazekas and colleagues (2I) showed that resistance to hypoxia was dependent on the relative maturity of the central nervous system at birth. For examp- 
le, the rat is relatively immature compared to the guinea pig, and consequently also more resistant to hypoxia (2I). The observation of increased resistance of the fetus and neonate to hypoxia lead to the early assumption that the developing mammal relied predominantly on anaerobic metabolism. The following factors have been considered to account for the resistance of immature neural tissue to hypoxia-induced cell death: I) lowered metabolic requirements for oxygen, 2) the sparseness of functional synapses, 3) relative electrical quiescence, and 4) a primitive state of differentiation $(18,39)$. Nonetheless, the developing brain is characterized by a high rate of increased cellular replication, differentiation, migration, axonal outgrowth, and synaptogenisis. Consequently, perinatal hypoxia has been shown to result in morphological and functional alterations. Therefore, despite increased survival rates, under certain circumstances the immature brain can suffer extensive hypoxic damage. Unique to the perinatal period is the concept of increased vulnerability. That is, the more rapid the development, the more vulnerable the organism is to disruptive influences.

In the rat, the third week of gestation (term $=21 / 22$ days) and early postnatal period is characterized by cellular migration, proliferation, differentiation, synaptogenisis, gliogenisis, myelination, and functional organization. Thus in the rat, the late gestational and early postnatal period is of critical importance for the developing brain. For example, the monoaminergic neurotransmitter system begins developing around gestational day 12, and continues rapid development during the perinatal period. Utilizing histofluorescence techniques, Golden (26) detected dopamine in the mouse brain beginning on day 13 of gestation. By day 16 the entire nigrostriatal tract could be visualized, and the adult fluorescence pattern was noted by day 18. In fetal rats, dopamine is detectable on day $15(13.2 \mathrm{pg} / \mathrm{mg}$ tissue) and the concentration increases to $193 \mathrm{pg} / \mathrm{mg}$ at birth (13). These data indicate the rapid development of the dopaminergic system during the perinatal period.

Exposure of the developing brain to exogenous substances which interfere with the balance of endogenous neuroactive compounds has been shown to alter cell number, migration, neural connections, and receptors. These compounds may alter brain development indirectly, for example by inducing hypoxia, or directly by altering cell acquisition, cell migration, formation, receptors, and ultimately by inducing cell death (84). In addition, during the perinatal period hormone imbalances associated with drug exposure and maternal stress have long-lasting effects on sexual differentiation and adult endocrine function. Thus, perinatal insults during the critical periods of the developing brain can induce perinatal neurotransmitter, peptide, and hormone imbalances, and alter adult behavior, endocrine responsiveness, and drug sensitivity.

\section{Physiological aspects of fetal oxygen delivery and hypoxia}

For the developing fetus, adequate respiratory gas exchange across the placenta is essential for normal growth and differentiation. Because the fetus requires an amount of oxygen per minute equal to more than half of its oxygen stores, its oxygen supply must be essentially continuous and not subject to major perturbations (43). Principal factors affecting placental $\mathrm{O}_{2}$ transfer include: maternal arterial $\mathrm{PO}_{2}$, fetal arte- 
rial $\mathrm{PO}_{2}$, maternal $\mathrm{Hb}-\mathrm{O}_{2}$ affinity, fetal $\mathrm{Hb}-\mathrm{O}_{2}$ affinity, maternal placental $\mathrm{Hb}$ flow rate, fetal placental $\mathrm{Hb}$ flow rate, placental diffusing capacity, spatial relation of maternal to fetal blood flow, and the amount of $\mathrm{CO}_{2}$ exchanged (43). Normal fetal arterial oxygen tension ( -25 Torr, $3.3 \mathrm{kPa}$ ) is relatively low compared to that of adult mammals ( $\sim 95$ Torr, $12.7 \mathrm{kPa}$ ). However, several characteristics unique to the fetus provide its tissues with adequate oxygen availability. For any given $\mathrm{pH}$ and temperature, the fetal oxygen dissociation curve lies to the left of that for maternal blood. Thus, at a given $\mathrm{O}_{2}$ tension, fetal blood has a higher affinity for oxygen than does maternal blood. Also, because of its steeper dissociation curve in comparison to the mother, fetal blood $\mathrm{O}_{2}$ tension must decrease less to release a given amount of oxygen. There are three principal reasons for the increased $\mathrm{O}_{2}$ capacity of fetal blood. Fetal hemoglobin $(\mathrm{HbF})$, has a greater $\mathrm{O}_{2}$ affinity than that of adult hemoglobin ( $\mathrm{HbA})$. Also, in many species, the fetal $\mathrm{Hb}$ concentration is 30 to $50 \%$ greater than that of the mother. In addition, the $\mathrm{CO}_{2}$ tension of fetal blood is somewhat greater than that of the mother. Thus, carbon dioxide in fetal blood entering the placenta will diffuse from fetal to maternal blood. Carbon dioxide loss makes the fetal blood more alkaline, while the increase of carbon dioxide makes the: maternal blood more acidic. By its effect on the $\mathrm{O}_{2}$ saturation curve these changes result in the ability of the fetal blood to have an increased oxygen content, while the reverse is true for the maternal blood (43).

\section{Previous studies on fetal and neonatal hypoxia and postnatal behavi- or}

For the developing fetus and newborn infant, hypoxia may be considered from several standpoints, namely: acute or short-term effects, long-term sequelae, mechanisms and pathophysiology, treatment, and prevention. In terms of long-term sequelae, hypoxia can result in physiologic, biochemical, morphologic, and functional changes in the central nervous system. The characteristics and severity of these effects are determined by a number of factors including: type of hypoxic-asphyxial-ischemic insult, its degree of severity, and its duration. In addition, factors such as species, ontogenic stage of maturity, and nutritional status play key roles in neurological sequelae.

\section{Experimental "models" of hypoxia/asphyxia/ischemia and the deve- loping brain}

During the past several decades a number of "models" of hypoxia and/or asphyxia and/or ischemia have been utilized to explore neurobiologic ramifications of these stresses. Chronically catheterized sheep have been used to study various physiologic and endocrinologic responses to acute and chronic hypoxia. However, because little of this work is directly relevant to behavior, most of these studies will not be considered further.

The first workers to examine systematically neurobiological responses to hypoxia in the fetus were Windle and Becker $(91,92,93)$, apparently stimulated by the association of children with cerebral palsy and other neurological deficits with asphyxia 
at birth or in the newborn period. In both near-term cats and guinea pigs these workers produced fetal asphyxia by clamping either the umbilical vessels or uterine arteries. Following resuscitation they then examined several behavioral sequelae during the next few hours to weeks $(91,92,93)$. Subsequently, Windle orchestrated a collaborative program which explored multiple aspects of acute perinatal asphyxia in mesus macaques. Specifically, in monkeys asphyxiated by complete placental separation with retention in the intact amniotic sac for 11 to 16 min, this group examined behavioral and neuropathologic sequelae for up to 10 years $(20,64,69,70,71,75$, see below).

As noted above, beginning in the 1950's several investigators used the hypoxia/asphyxiated fetal and newborn rat for behavioral studies. In pregnant rats (and their fetuses), and/or newborns, Meier and colleagues examined a number of behavioral and neurochemical responses following acute exposure to very low $\mathrm{O}_{2}$ concentrations i.e. hypoxic hypoxia $(52,55,56)$. In addition, several groups have examined the behavioral and neurochemical sequelae of both acute and chronic carbon monoxide hypoxia.

Beginning in the early 1980 's several groups commenced using a "model" of combined ischemia-hypoxia in the newborn rat for various behavioral-neurochemicalneuropathologic studies. In essence, this consisted of unilateral carotid artery ligation on postnatal day (P) 7 (or thereabouts) followed by inhalation of $8 \% \mathrm{O}_{2}$ for 1 to $4 \mathrm{~h}$, and recovery for several days. This was based on a similar approach which had been used in the adult rat (41).

\section{BEHAVIORAL SEQUELAE}

\section{General}

A number of studies have examined various behavioral sequelae of acute or chronic perinatal hypoxia-asphyxia-ischemia. However, few of these studies employed a relatively large battery of tests, or followed the pups over a period of several months. In addition, only in recent times have investigators used agonist or antagonists of neurochemical transmitter systems in an attempt to dissect out subtle alterations in these systems. Also, in few of the reports were the pups fostered at birth, or the experimenter blinded as to experimental group. In addition, little is known of the neurochemical, cellular, or molecular mechanisms responsible for hypoxia-induced functional changes.

Studies of the behavioral sequelae of either fetal or newborn hypoxia may be divided into several groups by exposure paradigm. The first is that of acute, relatively severe hypoxic exposure induced for a few minutes to several hours, and associated with a high maternal/fetal/newborn mortality. The second is more chronic, less severe hypoxic exposure for several hours per day, or continuously over 10 to 20 days of gestation or newborn life. Most of these studies are summarized in Tables $\mid$ and 2.

\section{Acute fetal hypoxia/asphyxia}

In decerebrate near-term cats, Windle and Becker removed the fetuses which 
they then asphyxiated by clamping the umbilical cord, measuring the time of gasping movements. Following resuscitation of the kittens, these workers followed evidence of central nervous system (CNS) damage for several days to weeks (92). Using a somewhat similar protocol in guinea pigs, these authors clamped either uterine or umbilical vessels until the fetuses gasped feebly. Following resuscitation, they demonstrated locomotor and behavioral abnormalities up to 8 weeks when they were sacrificed $(91,93)$. When tested for learning ability in a relatively simple maze at 2 to 8 weeks of life, the hypoxic/asphyxiated group made significantly more errors than did controls, demonstrated stereotypic behavior, and were much more docile and flaccid when handled (9I). These animals also showed several neuropathological deficits (93). Becker and Donnell $(4,5)$ replicated and extended this study, demonstrating a relative lack of activity and inquisitiveness among the experimental pups. At 6 to 12 weeks of age these animals had higher numbers of errors in negotiating an alternation maze. They also showed increased latency at decision points, and decreased response to electroshock for incorrect responses (5). In guinea pigs asphyxiated in utero until comatose, Becker $(3,5)$ demonstrated at P42 to P84 significantly retarded ability to solve a problem box. Other asphyxiated pups at P56 made more errors and repeated these errors more often than did either normoxic controls, or litter mates subjected to less prolonged asphyxia (5).

In near-term monkeys (Macaca mulatta) Windle and colleagues produced acute placental abruptio or asphyxia neonatorum followed by resuscitation. All animals which had been asphyxiated for 7 to 16 min and which experienced profound bradycardia prior to resuscitation, showed paralysis of facial muscles and limbs, tremors, and generalized seizures, hyperasthesia followed by hypersensitivity, somnolence, and reduced activity $(90,94)$. Most of these deficits persisted for only a few weeks following birth, during which time the infant monkeys showed hypoemotionality to environmental change, reduced startle response to loud noise, lethargic response to peripheral electroshock, and unusual docility. In referring to the movements of one of the monkeys, Windle recorded that "the progression efforts of the animal reminded one of those of a child with cerebral diplegia" ( 94 ).

Further studies at 6 month of age in these macaques, which sustained placental separation as fetuses, demonstrated hyperactivity, increased locomotion and exploration of their environment, and less "emotionality" or disturbance by a change in environment (69). At 10 to 14 months of age the asphyxiated monkeys were judged to be less emotional and demonstrated decreased responsiveness to their environment (70). However, their general activity level and exploratory activity were not different from controls. Asphyxiated monkeys also had deficient sensorimotor ability, e.g., they were less agile in tests of manual dexterity. In addition, they were less reactive and less emotional, and these changes correlated with the severity of neuropathology $(7 \mid)$.

In monkeys delivered at 156-159 gestational days ( 167 days=term), and asphyxiated by occlusion of the umbilical cord and then resuscitated, Sechzer. Windle and colleagues (76) reported a 10 to 11 day delay in the development of depth perception (from P3 to P5 for controls), visual placing (from P3 to P7 for controls), and independent locomotion (use of all four limbs to crawl from a control value of 3 days of age). Despite the presumptive neuropathologic damage in these animals, and in spite of the 
delays, these developmental behaviors were fully expressed and "normal" once they appeared (76). Even 8 to 10 year following the asphyxial insult, these monkeys demonstrated a marked deficit in remembering a visual cue (food location) beyond $5 \mathrm{sec}$ (75). These animals were also observed to be error prone, and commonly just "gazed into space" (75).

Subsequently, Hyman and colleagues $(35,36)$ asphyxiated monkeys at the time of birth in a manner similar to Windle's group. At 10 months of age, although these animals could perform a response task, when it was delayed $5 \mathrm{sec}$ they could no longer do it. As they didnot have a problem with visual discrimination, the authors concluded that their short-term memory was defective (35). In a subsequent study at 2 to 20 months of age, the asphyxiated animals received significantly more shocks than normal controls in an unsignaled avoidance test (36).

Becker and Donell (5) continued work along the line Becker had pursued with Windle, by asphyxiating in utero near-term ( $\sim 7$ days of gestation) fetal guinea pigs by uterine ligation either until their last gasp or until totally apneic and comatose. At $\sim P 84$ in a simple maze those animals which were most severely asphyxiated made significantly more errors, and repeated them more, than did their control mates. Two weeks later, in contrast to controls, these animals required "extensive retraining" to relearn the problem (5).

Behavioral studies in rats made acutely hypoxic or asphyxiated as fetuses or neonates commenced in the early 1950s. Near term (E|9.5) fetal rats asphyxiated for up to 20 min in utero, showed at P65 and P72 differences in negotiating the Hebb-Williams closed field maze, were slower in their rate of improvement over the testing sequence, and failed to reduce the number of errors (66). In an effort to simulate conditions associated with asphyxia at birth. Armitage (2) administered either of two barbiturates to pregnant rats just prior to parturition. The pups at $>90$ days of age (exact age not given) appeared handicapped in that they took longer to master two mazes, made more errors, and were less likely to solve a reasoning problem (2). No information was reported for other behaviors. Problems with this study include that 8 of 21 dams died from drug overdose, and the number of animals in the several experimental groups was small.

In contrast to these studies with asphyxia or ischemia, other workers have examined neurologic sequelae of hypoxia, per se. For instance. Meier and Bunch (55), Bunch ( 1 ), and Meier (52) examined acquisition and retention of learning of a water maze by rats (mixed breed) exposed to hypoxia (6.2\% equivalent) for $2 \mathrm{~h}$ during late gestation or the newborn period. In those pups made hypoxic as fetuses, maze acquisition learning at P70 was reported to be decreased compared to controls; however, little quantitative data was given (1 1). Scheidler (72) examined behavioral responses in rats (mixed breed) exposed to $6.2 \% \mathrm{O}_{2}$ equivalent for $2 \mathrm{~h}$ at several stages of gestation. The exposure was so severe that 12 of 42 dams died. Pups which were hypoxic in utero showed significantly inferior performance when tested for swimming speed (P59), complex maze learning (P60), maze memory retention (P90), and brightness discrimination ( $I$ I days after reaching criterion in the maze). Ability to learn the maze was related to fetal age at the time of hypoxic exposure. For instance, pups made hypoxic early in 
gestation ( $E||$ to $\mid 2$ ) required more trials to learn than those which were exposed late (E|5-|8). Also, male pups differed more from controls than did the females. Memory retention as measured by relearning was not significantly different in the hypoxic pups as compared to controls (72).

Using a similar paradigm (6.2\% $\mathrm{O}_{2}$ equivalent for $2 \mathrm{~h}$ ), Meier and colleagues ( 53. 56) exposed pregnant rats to hypoxia at various gestational ages ( 2 dams on each of the 2I days of pregnancy). With this severe hypoxia (as in Scheidler study), thirty percent of dams died. Surviving rat newborns demonstrated decreased learning and increased "emotionality". Also, as in Scheidler study, pups made hypoxic late in gestation, required the greatest number of trials and showed the longest latencies in maze performance. In contrast, those pups which were hypoxic early in gestation had the lowest number of trials and shortest latencies in maze performance (56). In CF/I mice Vierck and Meier demonstrated a similar inverse relation between severity of behavioral impairment and fetal age at which hypoxic stress was administered (86). These workers administered $0 \%$ $\mathrm{O}_{2}$ to pregnant mice at E6-10. E| I-15, and E6-20. Beginning at 42 days of life, the middle and late-exposed pups (EII-I5 and EI6-20) showed increased activity in relation to that of controls. In contrast, those exposed early in gestation (E6-10) had decreased activity. Within a given testing session, all hypoxic-exposure groups showed decreased activity (87). Subsequently, these workers reported conflicting results in rats exposed to $5.4 \% \mathrm{O}_{2}$ equivalent for $6 \mathrm{~h}$ at either $\mathrm{E} 8$ or E2O. Regardless of when in gestation they had been made hypoxic, at 30 to 94 days of life the experimental pups demonstrated decreased "emotionality" (which was even lower in the E8 group than in the E2O group), and from P90 to 94 were hyperactive and showed increased avoidance activity (87).

In other studies, Daughtry and Norton exposed on EI 5 pregnant rats to a single acute exposure $0.1 \%$ ( $1000 \mathrm{ppm}$ ) carbon monoxide for 2 or $3 \mathrm{~h}$ so that maternal carboxyhemoglobin concentration [ $\mathrm{HbCO}$ ], equaled $\sim 50 \%$ and the dames became comatose. This toxic exposure resulted in no behavioral alterations. Nevertheless, this paradigm resulted in gross morphologic changes in the caudate nucleus $(15,16)$.

\section{Chronic fetal hypoxia}

Reports in the literature show no unanimous picture of postnatal open field activity subsequent to prenatal hypoxia (Table I). For instance, following chronic intermittent hypoxia ( $13 \% \mathrm{O}_{2}$ for $2 \mathrm{~h} /$ day from E8 to term) McCullough and Blackman (50) observed no changes in open field behavior of male and female rats tested on P55. Intermittent hypobaric decompression ( $16.8 \% \mathrm{O}_{2}$ equivalent for $2 \mathrm{~min}, 7$ times/day from E2 to E20) was associated with decreased open field activity when tested on P35 (27).

To gravid Wistar rats, McCullough and Blackman (50) administered 13\% $\mathrm{O}_{2}$ for $2 \mathrm{~h}$ per day from E8 to E21. By P55 the offspring had displayed precocious eye opening, increased errors in a relatively complex maze, but no alteration in open field activity (50). Even with less severe hypoxia (16.8\% Oz equivalent for $14 \mathrm{~min}, 7$ times per day from E2 to E20). Graessle and coworkers (28) observed elevated neonatal mortality and a retardation in emotional development. Subsequently, with use of a similar hypoxia 
paradigm Graessle demonstrated significantly decreased open field activity at P35, but not at P78 or P83 (27). A second group of rats subjected to $16.8 \% \mathrm{O}_{2}$ for $110 \mathrm{~min} /$ day from E2 to 20 showed no significant differences in open field activity or active avoidance (27).

Lun and colleagues exposed pregnant rats to 9 to $12 \% \mathrm{O}_{2}$ for $10 \mathrm{~h} /$ day from $\mathrm{El} 6$ to E21, demonstrating in the offspring decreased conditioned avoidance learning (46); Avoidance activity was reported to be increased on $990-94$ following $5.4 \% \mathrm{O}_{2}$ equivalent for $6 \mathrm{~h}$ on either E8 or E20 (87). In contrast, in rats exposed to $150 \mathrm{ppm}$ CO from EI-2I Mactutus and Fechter (48) reported decreased acquisition and retention on P3031, and P300-360, while acquisition was not altered on PI20. Furthermore, active avoidance was not different from controls following prenatal hypobaric hypoxia ( $16.8 \% \mathrm{O}_{2}$ and $\left.11.8 \% \mathrm{O}_{2}\right)(27,45$ resp.).

In an effort to produce embryonic - fetal hypoxia without possible confounding maternal changes affecting the fetus, Meier and Menzel (54) made chick embryos hypoxic by immersion in water at E4, 8, 12, 16, and 19 of incubation. (The immersion duration was the LD50 based on percent hatching.) From days 4 to 13 of life, visually oriented behaviors, e.g., optokinetic reflex and vertical depth perception, were altered in the E8 hypoxic chicks (54). Subsequently, Meier (57) demonstrated deficiencies in locomotion, pecking, jumping, general activity, and maze learning in all exposure groups, although the E8-exposed chicks were most severely affected (57).

Relatively few studies have addressed the functional outcome of prenatal carbon monoxide exposure. Furthermore, none used a comprehensive longitudinal neurobehavioral evaluation. In an effort to "stress" the dopaminergic, catecholaminergic, or other neurotransmitter systems to uncover more subtle behavioral alterations, several groups have given dopamine/catecholamine agonists/antagonists. For instance, Fechter and Annau $(23,24)$ administered the dopamine precursor L-DOPA $(\mathrm{mg} / \mathrm{kg})$, which raises CNS catecholamine concentrations and behavioral activity. These animals were prenatally, from $\mathrm{El}$ to $\mathrm{E2} \mathrm{I}$ exposed to $150 \mathrm{ppm} \mathrm{CO}$ (maternal [HbCO] 15\%). Following $\mathrm{L}$-dopa treatment in the $\mathrm{PI}$ and $\mathrm{P} 4$ pups these authors demonstrated depressed locomotor levels in PI to 4 and PI4 rats associated with depressed dopamine levels. Fechter's group also reported a decreased performance of negative geotaxis and homing testing, with no pharmacological challenge. These authors found no correlation between reduced body weights and the neurobehavioral alterations (22). Mactutus and Fechter (48. 49 showed permanent learning and retention deficits in rats exposed to $150 \mathrm{ppm}$ $\mathrm{CO}$ from EI to E22. Later these rats were tested in a two-way avoidance task. With increasing age, P31, PI20, and P360, CO treated rats evinced deficient retention, with decreased acquisition on P30-31, and P300-360. Moreover, both juvenile (P3I) and aged (P360) rats showed impaired task acquisition $(48,49)$. These studies, which included multiple response measures, demonstrated long-term CNS dysfunction following this relatively mild hypoxic exposure. Singh (80) reported a retarded postnatal reflex neurological status in mice exposed to 65 or 125 ppm CO from E7 to |8. Exposure to 125 ppm significantly prolonged righting reflex time and negative geotaxis, respectively, measured on $\mathrm{PI}$ and $\mathrm{PIO}$. In addition, both 65 and $125 \mathrm{ppm} \mathrm{CO}$ reduced aerial righting performance (80). 
DiGiovanni and coworkers (17) exposed pregnant rats to either 75 or $150 \mathrm{ppm}$ $\mathrm{CO}$ from day 0 to 20 of gestation. Although no significant changes were noted following the lower exposures, the higher $\mathrm{CO}$ concentrations were associated with a $7 \%$ decrease in minimum frequency of ultrasonic calls in P5 pups. At 90 days, conditioned avoidance learning was also significantly decreased in these animals. The administration of the benzodiazepine derivate diazepam $(0.25 \mathrm{mg} / \mathrm{kg})$ failed to decrease the frequency of ultrasonic vocalization in CO-exposed pups, as compared with controls. The authors interpreted this finding as evidence for CO-impaired development GABA-receptor-chloride channel complex which mediates ultrasonic vocalization in the pup (I7).

In summary, following acute hypoxia/asphyxia with fetal survival, the early studies in mesus macaques showed various behavioral sequelae many of which (tremors, generalized seizures, and somnolence with reduced activity) were transient. Nonetheless, many of the changes (hyperactivity, spasticity, and decreased emotionality) persisted up to several years of age. In cats and guinea pigs, the post-asphyctic sequelae included: locomotor deficits, errors in problem solving, hypoactivity, and decreased active avoidance activity. In rats, despite a large number of acute experimental paradigms, a general theme of hyperactivity, decreased problem solving activity, and decreased emotionality is evident.

As a consequence of repeated or chronic prenatal hypoxia, again a general theme of decreased abilities in terms of righting and negative geotaxis responses, either hyperactivity or hypoactivity in open field tests, decreased ability to negotiate problem solving mazes, and decreased acquisition and retention of avoidance tests (i.e. altered learning and memory) prevails. In several studies behavioral effects were more severe or long-lasting following hypoxic exposure early in gestation rather then later, the age at which embryotoxicity and teratogenesis is maximal (67).

Overall, the several functional alterations appear to loosely follow a doseresponse relation. However, these changes were often associated with decreased body and brain weights, and altered growth rate of the animals. Thus, it is unclear whether such changes in behavioral development reflect nonspecific effects secondary to undernutrition or decreased muscle mass, rather than a specific effect of hypoxia on the developing CNS.

Also in accordance with findings in this thesis, following either acute or chronic hypoxia these locomotor, memory, and other behavioral deficits tended to improve with age, if not disappear entirely. This testifies to the neuroplasticity of the developing CNS.

\section{Acute neonatal hypoxia}

In 1928 Ford repeated Boyle's experiment in an effort to determine the relation of asphyxia to permanent brain damage. He asphyxiated kittens until their heart stopped, and then resuscitating them if possible. In four such kittens he observed no differences in "rate of development or general activity, and in 7 other such kittens noted no gross or microscopic brain lesions (25). A second group of kittens were exposed to 5.5 to $6 \% \mathrm{O}_{2}$ for up to $12 \mathrm{~h}$, and a third group to $3000 \mathrm{ppm}(0.3 \%)$ carbon monoxide or illuminating gas $(\sim 10 \% \mathrm{CO})$. Among the hypoxic-hypoxia group the kittens were "weak and tremulous" following resuscitation, while a kitten which survived illuminating gas 
showed "severe nervous disturbances ... was tremulous, ataxic, and could not walk, stand, or drink milk". Because brain lesions were not demonstrable in the kittens, Ford concluded that asphyxia neonatorum was not a common cause of cerebral birth injury (25). A study along somewhat similar lines in dogs less than $24 \mathrm{~h}$ old exposed to nitrogen until comatose, reported failure to suckle, opisthotonos, fore-limb extension, hind-limb flexion, and hypesthesia up to $48 \mathrm{~h}$ after resuscitation. Although no gross motor or behavioral abnormalities were noted, these pups' exhibited subtle differences in open field maze and auditory discrimination (12).

Meier and Bunch exposed newborn rats to $3.0 \% \mathrm{O}_{2}$ equivalent for $30 \mathrm{~min}$. At P75 to 100 the animals so exposed demonstrated deficiencies in learning position reversal in a water $T$ maze, although they performed better when the learned reversal was delayed 2 wk. They also demonstrated consistently decreased learning and relearning, although the differences from controls was not significant (55). Newborn cats which experienced a similar hypoxic exposure, at 6 to 14 months of age showed greater response latency in a puzzle box, delayed ability in simple or more complex problem solving in a water T maze, and increased stereotypy (52). Meier also reported "irritability ... frustration ... and lowered activity and reactivity" in the testing environment $(52,56)$. In contrast to these findings, Nolan (62) observed no differences in complex maze mastering or simple operant response in rats made hypoxic immediately after birth $\left(3 \% \mathrm{O}_{2}\right.$ equivalent for $30 \mathrm{~min}$ following birth). Also, Hurder and Sanders (34) found no behavioral sequelae as manifest in T-maze responses at $\mathrm{PlO0+}$ in those exposed as newborns to either $4.6 \% \mathrm{O}_{2}$ equivalent for $38 \mathrm{~min}$ or $5.2 \% \mathrm{O}_{2}$ equivalent for $3 \mathrm{~h}$. In addition, $\mathrm{P7}$ kittens exposed to $0 \% \mathrm{O}_{2}$ until breathing stopped $(\sim 5 \mathrm{~min})$ demonstrated no differences from controls from that time to $\mathrm{P} 50$ (7). In PI rats exposed to either $0 \% \mathrm{O}_{2}$ for 20 min or $6 \% \mathrm{O}_{2}$ for $4.5 \mathrm{~h}$, the latter group at P28 were inferior in conditioned avoidance response (2-way shuttle box) acquisition (32). Rats asphyxiated at birth for $45 \mathrm{~min}$ to 2 $h$ and then resuscitated (48\% mortality) demonstrated a I day delay in development of both forelimb grasp reflex and negative geotaxis (79).

Speiser and coworkers (82) exposed PI rats to $100 \% \mathrm{~N}_{2}$ for 25 minutes. In open field tests from PIO to P40, the anoxic pups increased ambulation (up to 100\%), and sniffling (up to $100 \%$ ), and rearing (up to $50 \%$ ) relative to controls, with maximum differences seen at P20-P25. In an extension of these studies (33), the hyperactivity in an open field test declined between P40 and P80. Also, at P20 the anoxic pups showed only 40 to $50 \%$ of the increase in motor response to 0.25 to $1.0 \mathrm{mg} / \mathrm{kg}$ D-amphetamine (dopamine receptor agonist) of controls. In addition, between 60 and 80 days of age they showed poorer performance in a complex 6-choice discrimination maze (33).

To investigate whether hypoxia without ischemia is an important contribution to the development of seizure disorders, Moshe and Albala (60) exposed PI and PIO rat pups to $6 \% \mathrm{O}_{2}$ for $4 \mathrm{~h}$ or less, and during the fourth week of life stereotaxically implanted a bipolar electrode in the left amygdala. Hypoxic pups showed no greater susceptibility to focally elicited (kindled) or generalized (flurothyl-induced) seizures (60). In addition, both PI5 and P20 pups made hypoxic (either $3.5 \% \mathrm{O}_{2}$ for 40 min or $4 \% \mathrm{O}_{2}$ for 6 h) showed better retention of brightness discrimination at 8 weeks of age than controls (68). Additional studies of hyperactivity following neonatal hypoxia were reported by 
Shimomura and Ohta (77). Wistar rat pups, $\mathrm{P} 4$, subjected to nearly $0 \% \mathrm{O}_{2}$ for 10 min displayed higher scores in startle response up to P28, increased open field locomotion, disturbed motor coordination on an inclined plane, and a greater susceptibility to pentylentetrazol-induced seizures (i.e., both myoclonic and generalized convulsions). At P25 the latencies for both these phenomena were shorter, and the seizures were more frequent and longer in the hypoxic animals (77).

\section{Repeated or chronic neonatal hypoxia}

Male rats exposed to postnatal hypobaric hypoxia ( $10.5 \% \mathrm{O}_{2}$ for $10 \mathrm{~h} /$ day from $\mathrm{P} 2$ to $\mathrm{P} 10$ ) were hyperactive on days 15 and 38 (29). No differences were seen on day 70. After exposing 5-day-old rats to $\mathrm{CO}$ until the onset of respiratory failure, Culver and Norton (14) reported similar results, i.e., hyperactivity in the open field at P7 to PI5. They observed hypoactivity in a residential maze at $\mathrm{P} 90$.

Rats subjected to electroconvulsive seizures (with $\mathrm{O}_{2}$ ventilation to prevent hypoxemia) between P2 and PII demonstrated delayed maturation of swimming ability, front paw activity, visual placing, auditory startle, and free-fall righting reflexes as well as reduced brain weight, DNA, RNA, and protein concentrations. This suggested that hypoxia and seizures had independent effects on subsequent outcome (89). Following $10.5 \% \mathrm{O} 2$ equivalent for $5 \mathrm{~h}, 5$ days/week from $\mathrm{PI}$ to $\mathrm{PI}$, male rat pups were reported to show more active avoidance, with enhanced retention after 2 months than controls. This was not seen in females, and the brevity of data prevents further analysis (51).

Gramatté, Lun, Schmidt, and co-workers have explored a number of aspects of perinatal hypoxia and its sequelae in a postnatal hypoxic preparation which they held correlates with hypoxic-asphyxic brain damage in children (47). For instance, in Wistar rats made hypoxic for $10 \mathrm{~h} / \mathrm{d}$ from $\mathrm{P} 2$ to P6 or P 10 , these workers correlated decreased learning capacity and decreased reaction to stimuli following stress at 8 to 10 weeks of age with altered striatal dopamine changes (45). Using the open field test, this group further reported marked hyperactivity at PI5 and P38, with a return to control activity level by day 70 and thereafter (29). In addition, spontaneous nocturnal activity was significantly increased in adult rats 70 and 100 days of age (29).

These workers also attempted to elucidate the role of the dopaminergic system in these responses. They reported significantly decreased apomorphine (dopamine receptor agonist) -induced locomotor and amphetamine (sympathomimetic amine) induced stereotypic behavior (30). Additionally, they reported that perinatal piracetam administration reduced hypoxia-induced open field hyperactivity to control values. Only minor effects on exploratory activity were observed following dimethylaminoethanol (a related nootropic drug) (3I). Lun and coworkers also demonstrated that L-dopamine administration during hypoxic exposure prevented both the augmented dopamine efflux and the decreased learning ability (46), as did pyritinol (47).

\section{Ischemia/hypoxia}

Beginning in the mid-1970's, several workers examined sequelae to bilateral carotid artery ligation or decapitation $(19,37,85)$. Shortly thereafter, several groups utilized in newborns the so-called "Levine" model of unilateral carotid artery ligation followed by hypoxia $(38,65,78,95)$. 
Behavioral sequelae of rats subjected to right common carotid artery ligation followed by hypoxia $\left(8 \% \mathrm{O}_{2}\right.$ for $4 \mathrm{~h}$ ) ischemia-hypoxia at $37^{\circ} \mathrm{C}$ on $\mathrm{P} 7$ included a delay in complex motor test performance (mid-air righting and bar walking) and spatial learning (Morris water maze). In addition, at day 31 avoidance learning was enhanced in the animals with cerebral infarction. In those pups which were hypothermic $\left(21^{\circ} \mathrm{C}\right)$ during hypoxic exposure only the Morris water test was abnormal (95).

Following neonatal (PO) asphyxia (delayed cesarian section) Bjelke (8), reported increased locomotor activity, but decreased rearing behavior when injected with apomorphine.

\section{Sexual dimorphism}

Furthermore, several studies point at a neonatal sex difference in the resistance to an acute hypoxic challenge $(10,83)$. For instance, Stupfel and colleagues (83) subjected newborn pups $(\mathrm{Pl})$ to acute $\left(100 \% \mathrm{~N}_{2}\right)$ or slow onset $\left(20.9\right.$ to $4.5 \% \mathrm{O}_{2}$ in $2 \mathrm{~h} \mid 8$ $\mathrm{min}$ ) hypoxia, and demonstrated significantly higher survival rates of the female pups following both treatments. Schellenberger (73) showed a similar dimorphism in 16- to 20 week-old rats exposed to $0.42 \%$ (4200 ppm) CO until the onset of respiratory arrest. Thirty nine percent of males died, in contrast to only $17 \%$ of females. Culver and Norton (14) obtained similar results.

\section{Carbon monoxide}

Several studies have examined behavioral changes following carbon monoxide hypoxia in the neonatal period. Culver and Norton (14) exposed P5 rats to $1 \% \mathrm{CO}$ ( $10,000 \mathrm{ppm})$ for about $2 \mathrm{~h}$, until the onset of respiratory failure. Following resuscitation, reflex neurological evaluation showed no significant changes. However, open field locomotor activity revealed a significant increase when tested on P7 to 9 in females. On days PIO to PI5, the males were also hyperactive. Postweaning circadian mythms were assessed in a residential maze. Hypoxic rats demonstrated hyperactivity at 3 to 8 wk of age. This effect was most prominent during the night, the active period for this nocturnal species. After 8 wk the hyperactivity disappeared. The authors pointed at the resemblance of these animals to the syndrome of minimal brain damage, associated with early hyperactivity which gradually decreases with increasing age. Subsequently Norton and Culver (63) demonstrated abnormal development of caudate nucleus neurons the developmental profile of which is correlated with the behavioral changes. Schellenberger and Norton (74) also exposed P5 pups to a somewhat lower CO concentration (4,200 ppm) until respiratory arrest (25\% died). CO-exposed animals also showed hyperactivity, which was significantly different in females.

In summary, both postnatal acute and chronic hypoxia may produce relatively profound behavioral and/or motor deficits. Despite a wide variety of hypoxic exposures, ages of subjects, and test paradigms, many aspects of learning and motor function (e.g., performance in mazes, open field et cetera) are sensitive to this stress. An additional generalization is that few, if any of the changes reported are specific for hypoxia. Rather, they are changes which have been reported following other stresses such as prenatal alcohol or nicotine exposure, and even maternal stress per se. 


\section{CONCLUSIONS}

Taken together, the above studies of hypoxia, asphyxia, and ischemia in fetal and newborn rats and several other species, for both relative brief periods as well as longer durations, demonstrate a wide spectrum of sequelae, particularly as regards subsequent learning and behavior. Unfortunately, little is known regarding the cellular and molecular mechanisms by which these changes occur. In addition, there has been no concerted study which examined a number of aspects of learning and behavior with well-defined, quantified testing protocols. Also, few studies have followed the animals longitudinally to adulthood to establish the permanency of observed changes. Finally, none of these studies use cross-fostering of newborns to eliminate postnatal effects of maternal hypoxia on lactation or care of the offspring.

In the following studies, we assessed the behavioral sequelae of moderate perinatal hypoxia in a longitudinal test battery with a foster paradigm. In addition we tested drug responsiveness following hypoxia.

In the next chapter, we will discuss previous studies on the effects of stress on sexual differentiation. 


\section{Table I. Behavorial effects following prenatal hypoxia}

Species I

Breed
Embryonic / Hypoxic Stress

Fetal Age

Test

\section{Acute Hypoxia}

rat

?

mixed breed

rat

$\mathrm{SD}$

11 to 19

hypobaric hypoxia

$6.2 \% \mathrm{O}_{2}$ equivalent for $2 \mathrm{~h}$

hypobaric Hypoxia

$5.2 \% \mathrm{O}_{2}$ equivalent

for $2 \mathrm{~h}$

multiple unit $T$ wate maze

acquisition

retention

swimming speed

multiple unit $T$ water maze

acquisition

retention

single unit $T$ water maze

acquisition

motor activity

until onset of

seizures $x=8.1 \mathrm{~min}$

$11-15$

or

$16-20$

rat

8 or 20

hypobaric hypoxia $5.4 \% \mathrm{O}_{2}$ equivalent for $6 \mathrm{~h}$

rat

15

SD

\section{Repeated or Chronic Hypoxia}

rat

$W^{*}$
$8-21$

$13 \% \mathrm{O}_{2}$

for $2 \mathrm{~h} /$ day
$\mathrm{CO}, 1000 \mathrm{ppm}$

for $2-3 h$ weight

eye opening,

righting reflex

reflex suspension

open field activity

eye opening open field maze problem solving 
decreased

100

59

72

60

decreased

90

$60-90$

$42-44$

increased activity

86

on repeated testing

initially hyperactive with

decreased activity on repeated testing

$90-94$

increased activity

87

decreased emotionality

16

1 - 8

$7-14$

21

55

I day earlier

50

80

increased number of errors 
Species I

breed

rat

mouse

rat

SD

rat

W

rat

LE

rat

LE

rat

LE

Embryonic I Hypoxic Stress

Fetal Age

$2-20$

( $16.5 \% \mathrm{O}_{2}$ equivalent )

$2-12$

$12-22$

for 14 min 6 times / day

hypobaric hypoxia

( $16.5 \% \mathrm{O}_{2}$ equivalent)

for 14 min 7 times / day

$1-20$

$100 \%$ CO for

$90 \mathrm{sec} /$ day

$[\mathrm{HbCO}]=6-11 \%$

$2-20$

hypobaric hypoxia

( $16.8 \% \mathrm{O}_{2}$ equivalent )

for $14 \mathrm{~min}, 7$ times / day

$2-20$

$16.8 \% \mathrm{O}_{2}$ for $110 \mathrm{~min}$

$|6-2|$

$|-2|$ 
0

$0-10$

$10-18$

$10-18$

decreased performance

32

16 decreased activity decreased

32 decreased activity

16

decreased

32

42

increased number of errors

।

decreased

increased activity following $L$ - DOPA

increased activity

decreased

increased latency decreased latency 
Species I

Breed

$\begin{array}{ll}\text { rat } & |-2| \\ \text { LE } & \\ \text { rat } & |-2| \\ \text { LE } & \end{array}$

mouse

CD

$7-18$

$0 \cdot 20$

W

$7-18$
Embryonic / Hypoxic Stress Fetal Age

$\mathrm{CO}, 150 \mathrm{ppm}$

$\mathrm{CO}, 150 \mathrm{ppm}$

$\mathrm{CO}, 65$ ppm

continuous

CO, 125 ppm

continuous

CO, 75 ppm

$\mathrm{CO}, 150 \mathrm{ppm}$
Test

active avoidance

acquisition

retention

active avoidance

acquisition

retention

acquisition

retention

righting reflex

negative geotaxis

righting reflex

negative geotaxis

ultrasonic calls active avoidance ultrasonic calls active avoidance

* $L E=$ Long Evans, SD = Sprague Dawley, SW = Swiss Webster, and W $=$ Wistar 
decreased

24h later decreased

increased latency increased latency

decreased

90 decreased

(1)

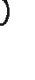

0 
Table 2. Behavorial effects following postnatal hypoxia

$\begin{array}{llll}\text { Species I } & \text { Newborn I Hypoxic Stress } & \text { Test } \\ \text { Breed } & \text { Age } & \end{array}$

\section{Acute Hypoxia}

rat (white) 0

hypobaric hypoxia water $T$-maze

( $3 \% \mathrm{O}_{2}$ for $30 \mathrm{~min}$ )

cat

0

puzzle box

water $T$ - maze

brightness discrimination

stereotypy

$\operatorname{rat}($ mixed ) 0

water $T$ - maze

Skinnerbox

$\operatorname{rat}(S D) \quad 0$

hypobaric hypoxia

T - maze

( $5.2 \% \mathrm{O}_{2}$ for $3 \mathrm{~h}$ )

( $4.6 \% \mathrm{O}_{2}$ for $38 \mathrm{~min}$ )

cat

7

I - $2 \% \mathrm{O}_{2}$ for $9.5 \mathrm{~min}$

air righting

after breathing ceased visual cliff

I - $2 \% \mathrm{O}_{2} 0.5 \mathrm{~min}$

after breathing ceased

( $20 \%$ of kittens died)

$\operatorname{rat}$ (Wistar) 2-11

electroconvulsive

swimming

seizures

free fall

$\pm \mathrm{O}_{2}$ respiration

righting 
Test day

$75-100$

$180+$

65

95

$150-160$

$100+$

10 to 50

$12+$

\section{5}

\section{Result}

Reference

decreased learning

55

decreased relearning

increased latency

52

response

decreased

increased

delayed

89

62

34

delayed

delayed 
Species I

breed

rat $(W)$

4

$0 \% \mathrm{O}_{2}$ for $10 \mathrm{~min}$

open field

open field

rat (SD)

$\operatorname{rat}(N R)$

0

rat (SD)

rat

$\operatorname{rat}(\mathrm{W})$

$\operatorname{rat}(\mathrm{SD})$

5

rat

$15-20$

5

aspyxiated

$45 \mathrm{~min}$ to $2 \mathrm{~h}$

$0 \% \mathrm{O}_{2}$ for $20 \mathrm{~min}$

$6 \% \mathrm{O}_{2}$ for $4.5 \mathrm{~h}$

CO, $6200-6400$ ppm

for $2 \mathrm{~h}$, until

respirarory failure

Test

open field

startle reflex

nest box emergence

open field

$\%$ of time awake

residential maze

forelimb grasp

negative geotaxis

conditioned avoidance

brightness discrimination

residential maze

$4 \% \mathrm{O}_{2}$ for $6 \mathrm{~h}$

$0 \% \mathrm{O}_{2}$ for $25 \mathrm{~min}$

open field

CO, 4200 ppm for $2 \mathrm{~h}$, residential maze until respiratory failure

$0 \% \mathrm{O}_{2}$ for $25 \mathrm{~min}$

open field amphetamine open field open field discrimination maze

$\operatorname{rat}(\mathrm{SD})$
$6 \% \mathrm{O}_{2} 4 \mathrm{~h}$

$6 \% \mathrm{O}_{2}<4 \mathrm{~h}$

( until 2 pupies died) susceptibility

to seizures

\section{Chronic Hypoxia}

rat $(W) \quad 2-10$

$10.5 \% \mathrm{O}_{2}$ equivalent open field $10 \mathrm{~h} / \mathrm{day}$ 

increased suscepttibility to seizures

56

15

$7-15$

$17-22$

90

$2-4$

$4-6$

28

56

$10-25$

$15-20$

$10-40$

42

20

40

80

$60-80$

$28+$
I d early

hyperactivity increased

hypoactivity

delayed Id

delayed Id

decreased

improved

68

increased ambulation

82

increased rearing increased sniffling

hyperactivity,

74

particulary in females

decreased

33

decreased

14

79

32

15

increased activity

$29,30,31$ 


\section{REFERENCES}

1. Abbatiello, ER and K Mohmann. Effects on the offspring of chronic low exposure carbon monoxide during mice pregnancy. Clin. Toxicol. 14:401-406, 1979.

2. Armitage, S.G. The effects of barbiturates on the behavior of rat offspring as measurd in leaming and reasoning situations. J. Comp. Physiol. Psychol. 45:1 46-152, 1952.

3. Becker, R.F. Behavioral changes produced by asphyxia at birth. Am. Psychol. 5:254-255, 1950.

4. Becker, RF. Leaming ability after aspyxiation at birth, especially as it concems the guinea pig. In W.F.Windle (Ed). Neurological and psychological deficits of asphyxia neonatorum. Springfield III.:Thomas, 44-54, 1958.

5. Becker, RF., and W. Donnell. Leaming behavior in guinea pigs subjected to asphyxia at birth. J. Comp. Physiol. Psychol. 45:I53-162, 1952.

6. Bergamasco, B., P. Benna, P. Ferrero, and R. Gavinelli. Neonatal hypoxia and epileptic risk: a clinical prospective study. Epilepsia. 25:131-136, 1984.

7. Berkson, G. Maturation defects in kittens. Am. J. Ment. Defic. 72:757-777, 1968.

8. Bjelke, B., K Andersson, 5.O. Ögren, and P. Bolme. Asphyctic lesion: proliferation of tyrosine hydroxylase-immunoreactive nerve cell bodies in the rat substantia nigra and functional changes in dopamine neurotransmission. Brain Res. 543:1-9, 1991.

9. Boyle, R New pneumatical experiments about respiration. Philos. Trans. Royal Soc. London. 5:201I-2031, 1970.

10. Britton, S.W. and RF. Kline. Age, sex, carbohydrate, adrenal cortex and other factors in anoxia. Am. J. Physiol. 145:190-202, 1945.

II. Bunch, M.E. The effects of pre- and postnatal anoxia upon leaming and memory ability at maturity. Science I 6:517-5 |8, 1952.

12. Cassin, S. and A.R. Fregly. Neurological sequelae of experimental anoxia in newbom dogs. (Abstract) Fed. Proc. 16:20, 1957.

13. Coyle, J.T., and D. Henry. Catecholamines in fetal and newbom rat brain. J. Neurochem. 21:6167. 1973.

14. Culver, B. and S. Norton. Juvenile hyperactivity in rats after acute exposure to carbon monoxide. Exp. Neurol. 50:80-98,1976.

15. Daughtry, W.C., M.B. Newby-Schmidt, and S. Norton. Fonebrain damage in chick embryos exposed to carbon monoxide. Teratology 28:83-89, 1983.

16. Daughtry, W.C. and S. Norton. Caudate morphology and behavior of rats exposed to carton monoxide in utero. Exp.Neurol. 80:265-278, 1983.

17. Di Giovanni, V., R. Cagiano, M.A De Salvia, A. Guistino, C. Lacomba, G. Renna, and V. Cuomo. Neurobehavioral changes produced in rats by prenatal exposure to carbon monoxide. Brain Res. 616:126-131, 1993.

18. Duffy, T.E., S.J. Kohle, and R.C. Vannucci. Carbohydrate and energy metabolism in perinatal rat brain: relation to survival in anoxia. J. Neurochem. 24:271-276, 1975.

19. Duffy, T.E. and RC. Vanucci. Perinatal brain metabolism: effects of anoxia and ischemia. In: Cerebral Vascular Diseases. J.P. Whisnant and B.A. Sandok (Eds.). New York. Grune \& Stratton, pp 231-235, 1975.

20. Faro. M.D. and W.F. Windle. Transneuronal degeneration in brains of monkeys asphyxiated at birth. Exp. Neurol. 24:38-53, 1969.

21. Fazekas, J.F., F.A.D. Alexander, and H.E. Himwich. Tolerance of the newbom to anoxia. Am. J. Physiol. 1 34:281-287, 194I.

22. Fechter, L.D. and $Z$. Annau. Prenatal carbon monoxide exposure alters behavioral development. Neurobehav. Toxicol. 2:7-11, 1980.

23. Fechter, LD, and Z. Annau. Toxicity of mild prenatal carbon monoxide exposure. Science 197:680-682, 1977.

24. Fechter, LD., Z. Annau. Effects of prenatal carton monoxide exposure on neonatal rats. In: Horvath, M. (Ed). Adverse effects of Environmental Chemical and Psychotropic drugs: Neurophysiological and Behavioral Tests. Vol. 2, Amsterdam, Elsevier Scientific, 1976. 
25. Ford, F.R An experimental investigation into the effects of asphyxia on the brain, with especial reference to asphyxia neonatorum. Bull. Johns Hopkins Hosp. 31:70-76, 1928.

26. Golden, G.S. Prenatal development of the biogenic amine systems of the mouse brain. Dev. Biol. 33:300-311, 1973.

27. Graessle, C.A. Prenatal influence of mild decompressions on hooded rats. Dev. Psychobiol. 13:399-407, 1980.

28. Graessle, C.A. K. Ahbel, and S.W. Porges. Effects of mild prenatal decompressions on growth and behavior in the rat. Bull. Psychon. 4:329-331, 1978.

29. Gramatte, T. and J. Schmidt. The effect of early postnatal hypoxia on the development of locomotor activity in rats. Biomed. Biochim. Acta 45:523-529, 1986.

30. Gramatté, T. and J. Schmidt. The effect of early postnatal hypoxia on the effectiveness of drugs influencing motor behaviour in adult rats. Biomed. Biochim. Acta 45:1069-1074, 1986.

31. Gramatté, T. C. Wustmann, J. Schmidt, and H.-D. Fischer. Effects of nootropic drugs on some behavioural and biochemical changes after early postnatal hypoxia in the rat. Biomed. Biochim. Acta 45:1075-1082, 1986.

32. Hedner, T., P. Lundborg, and J. Engel. Brain biochemical and behavioral changes in 4 weeks old rats after neonatal oxygen deprivation. Pharmacol. Biochem. Behav. 10:647-650, 1979.

33. Hershkowitz, M., V.E. Grimm, and Z. Speiser. The effects of postnatal anoxia on behaviour and on the muscarinic and beta-adrenergic receptors in the hippocampus of the developing rat. Dev. Brain Res. 7:147-155, 1983.

34. Hurder. W.P. and A.F. Sanders. The effects of neonatal anoxia on the maze performance of adult rats. J. Comp. Physiol. Psychol, 46:61-63, 1953.

35. Hyman, A., B. Parker, D. Berman, and A.J. Berman. Delayed response deficits in neonatally aphyxiated Rhesus monkeys. Exp. Neurol. 28:420-425, 1970.

36. Hyman, A., B. Parker, D. Beman, and A.J. Berman. Deficits in unsignaled avoidance behavior in Rhesus monkeys asphyxiated at birth. Exp. Neurol. 30:362-366, 197।.

37. Jilek, L., V. Janata, A. Londonova. Z. Makoc. S. Trojan, and F. Vorel. The influence of stagnant hypoxia on the activity of some dehydrogenases and aminotransferases in the brain of rats during ontogenesis. Develop. Psychobiol. 6:139-146, 1973.

38. Johnston, M.V. Neurotransmitter alterations in a model of perinatal hypoxic-ischemic brain injury. Ann. Neurol. 13:511-518, 1983.

39. Kreusser KL., and J.J. Volpe. The neurological outcome of perinatal asphyxia. Early Brain Dammage. $1: 151-168,1984$.

40. Legalois, M. Experiences sur le priciple de la vie, Paris: Hautel, 1812.

41. Levine, S. Anoxic-ischemic encephalopathy in rats. Am. J. Pathol. 36:1-17, 1960.

42. Little, W.J. On the influence of abnormal parturition, difficult labours, premature birth, and asphyxia neonatorum on the mental and physical condition of the child, especially in realtion to deformities. Trans Obstet. Soc. London 3:293-344,1861-1862.

43. Longo, LD. Respiratory gas exchange in the placenta. Handbook of physiology. Section 3: The respiratory system, Vol. IV, Gas Exchange. A.P. Fishman, L.E. Fahn, S.M. Tenney, S.R. Geiger, Eds. American Physiological Society, Bethesda, MD, 351-401, 1987.

44. Longo, L.D., S. Packianathan, J.A. McQueray, R.B. Stagg, C.V. Byus, and C.D. Cain. Acute hypoxia increases omithine decarboxylase activity and polyamine concentrations in fetal rat brain.

Proc. Natl. Acad. Sci. USA, 90:692-696, 1993.

45. Lun, A. J. Gross, M. Beyer, H.D. Fischer, C. Wustmann, J. Schmidt, and K. Hecht. The vulnerable period of perinatal hypoxia with regard to dopamine release and behaviour in adutt rats. 45:619-627, 1986.

46. Lun, A., C. Wustmann, C. Berndt, H.D. Fischer, J. Gross, K. Hecht, G. Stamminger, and J. Schmidt. Postnatal administration of L-DOPA normalizes hypoxia-induced long-term changes in dopamine release from striatum slices and in avoidance leaming. Biomed. Biochim. Acta 10:1277-1283, 1986. 47. Lun, A., H. Gruetzmann, C. Wustmann, L. Szuesz, B. Dominick, G. Horvath, H.D. Fischer, I Nagy, and J. Gross.Effect of pyritinol on the dopaminergic system and behavioural outcome in an animal model of mild chronic postnatal hypoxia. Biomed. Biochim Acta 48:5237-\$242, 1989. 
48. Mactutus, C.F. and L.D. Fechter. Moderate prenatal carton monoxide exposure produces persistent, and apparently permanent memory deficits in rats. Teratology. 31:1-21, 1985.

49. Mactutus, C.F. and LD.Fechter. Prenatal exposure to carbon monoxide: leaming and memory deficits. Science 223:409-41I, 1984.

50. McCullough, M.L and D.E. Blackman. The behavioral effects of prenatal hypoxia in the rat. Dev. Psychobiol. 9:335-342, 1976.

51. Meerson, F.C. and S.A. Radzievsky. [The influence of adaptation to the high altitude hypoxia in early ontogenesis on the parameters of the higher nervous activity.] Biull. Eksper. Biol. Med. 82:902-903, 1976.

52. Meier, G.W. Delayed effects of natal anoxemia upon behavior and electroencephalographic activity. Doctoral Dissertation, Washington University, St. Louis, MO, June 1953.

53. Meier, G.W. Prenatal anoxia and irradiation: Matemal-fetal relations. Psychol. Reports 9:417-424, 1961.

54. Meier, G.W. and E.W. Menzel. Prenatal oxygen deprivation and subsequent specific behavior dysfunctions. Science 22:419-420, 1955.

55. Meier, G.W. and M.E. Bunch. The effects of natal anoxia upon leaming and memory at maturity. J. Comp. Physiol. Psychol. 43:436-44I, 1950.

56. Meier, G.W., C.Y. Nolan, M.E. Bunch, and C.H. Scheidler. Anoxia, behavioral development and leaming ability. Psych.Mono. Gen. Appl. 74:1-48, 1960.

57. Meier, G.W. Prenatal anoxia in relation to behavioral phenomena. In W.F. Windle (Ed.),

Neurological and psychological deficits of asphyxia neonatorum. Sprinfield, Ill., T Thomas, 55-66. 1958.

58. Morishima, H.O., H. Pedersen, M. Finster. The influence of matemal psychological stress on the fetus. Am. J. Obstet. Gynecol. 131:286-290, 1978.

59. Morishima, H.O., Y. Ming-Neng. LS. James. Reduced uterine blood flow and fetal hypoxemi with acute matemal stress: Expenmental observation in the pregnant baboon. Am. J. Obstet. Gynecol. 134:270-275, 1979.

60. Moshé, S.L. and B.J. Albala. Perinatal hypoxia and subsequent development of seizures. Physiol. Behav. 35:819-823, 1985.

61. Mukherjee, A.B., and G. Hodgen. Matemal ethanol exposure induces transient impairement of umbilical circulation and fetal hypoxia in monkeys. Science. 218:700-702, 1982.

62. Nolan, C.Y. The effects of neonatal anoxia upon the leaming of rats at maturity. Doctoral Dissertation, Washington University, St. Louis, MO. August 1953.

63. Norton, S. and B. Culver. A golgy analysis of caudate neurons in rats exposed to cartoon monoxide. Brain Res.132:455-465, 1977.

64. Ranck J.B. Jr. and W.F. Windle. Brain damage in the monkey, Macaca mulatta, by asphyxia neonatorum. Exp.Neurol. I:I 30-154, 1959.

65. Rice, J.E., III, RC. Vannucci, and J.B. Brientey. The influence of immaturity on hypoxic-ischemic brain damage in the rat. Ann. Neurol. 9:131-141, 1981.

66. Richardson, J.W. Effects of neonatal anoxia on maze leaming in rats. Proc. Soc. Exp. Biol. Med, 86:341-343, 1954.

67. Rodier, P.M. Correlations between prenatally-induced alterations in CNS cell populations and postnatal function. Teratology 16:235-246, 1976.

68. Rüthrich, H.-L, G. Grecksch, and H. Matthies. Influence of postnatal hypoxia on leaming and memory formation of adult rats. Biomed Biochim. Acta 44:1119-1124, 1985.

69. Saxon, S.V. Differences in reactivity between asphyxial and nomal thesus monkeys. J. Genet. Psychol. 99:283-287, 1961.

70. Saxon, S.V. Effects of asphyxia neonatorum on behavior in the thesus monkey. J. Genet. Psychol. 99:277-282, 1961.

71. Saxon, S.V. and C.G. Ponce. Behavioral defects in monkeys aphyxiated during birth. Exp. Neurol. 4:460-469, 1961.

72. Scheidler, C.H. The effects of prenatal anoxia on leaming in white rats. Doctoral Dissertation, Washington University, St Louis, MO, 1953. 
73. Schellenberger, M.K. Persisting effects on adult brain monoamines of neonatal distress and carbon monoxide exposure. Neuroscience 7:667-671, 1982.

74. Schellenberger, M.K. and S. Norton. Factors influencing the persisting effects of acute carbon monoxide exposure on rat motor activity. Neurotoxocology 1:541-550, 1980.

75. Sechzer, J.A. Memory deficit in monkeys brain damaged by asphyxia neonatorum. Exp. Neurol. 24:497-507, 1969.

76. Sechzer, J.A., M.D. Faro, J.N. Barker, D. Barsky, S. Gutierrer and N.F. Windle. Developmental behaviours: delayed appearance in monkeys asphyxiated at birth. Science 171:1173-1175, 1971.

77. Shimomura, $\mathrm{C}$. and $\mathrm{H}$. Ohta. Behavioral abnomalities and seizure susceptibility in rat after neonatal anoxia. Brain Dev. 10:160-163, 1988.

78. Silverstein, F. and M.V. Johnston. Effect of hypoxia-ischemiaron monoamine metabolism in the immature brain. Ann. Neurol. 15:342-347, 1984.

79. Simon, N., and L. Volicier. Neonatal Asphyxia in the rat: greater vulnerability of males and persistent effects on brain monoamine systems. J. Neurochem. 26:893-900, 1976.

80. Singh, J. Early behavioral alterations in mice following prenatal carbon monoxide exposure. Neuro. Toxicol. 7:475-482, 1986.

81. Skov H., H. Lou, and H. Pederson. Perinatal brain ischemia: impact at four year of age. Dev. Med. Child.Neurol. 26:353-357, 1984.

82. Speiser, Z., AD. Korczyn, I. Teplitzky, and S. Gitter. Hyperactivity in rats following postnatal anoxia. Behav. Brain Res. 7:379-382, 1983.

83. Stupfel, M., A. Perramon, J.M. Gasc, M. Magnier, and M. Duriez. Body dimorphism and sex difference of resistance to an acute hypoxic challenge in rodents and birds of different ages. Comp. Biochem. Physiol. 59:347-354, 1978.

84. Swaab. D.F., G.J. Boer, and M.G.P. Feenstra. Concept of functional neuroteratology and the importance of neurochemistry. In: Biochemical basis of functional neuroteratology, permanent effects of chemicals on the developing brain. Eds, G.J. Boer, M.G.P. Feenstra, M. Mirmiran, D.F. Swaab, and F. Van Haaren. 73:3-14, 1988.

85. Trojan, S., L. jilek and M. Trojanová. Effect of high attitude hypoxia of different intensity on the. spinal cord and medulla oblongata during ontogenesis of the rat. Sbomik Lékarsky 78:6-9. 1976.

86. Vierck C.J.Jr. and G.W. Meier. Effects of prenatal hypoxia upon locomotor activity of the mouse. Exp. Neurol. 7:418-425, 1963.

87. Vierck C.J. Jr., F.A. King, and V.H. Ferm. Effects of prenatal hypoxia upon activity and emotionality of the rat. Psychon. Sci. 4:87-88, 1966.

88. Ward. I.L. Prenatal stress feminizes and demasculinizes the behavior of males. Science 175:82-84, 1972.

89. Wasterlain. C.G. Does anoxemia play a role in the effects of neonatal seizures on brain growth? An experimental study in the rat. Eur. Neurol. 18:222-229. 1979.

90. Windle, W.F. Asphyxia at birth, a major factor in mental retardation: Suggestions for prevention based on experiments in monkeys. In: Zubin, J. and G.A Jervis (Eds). Psychopathology of Mental Development, New York, Grune and Stratton, pp /40-147, 1967.

91. Windle, W.F. and R.F. Becker. Asphyxia neonatorum. An experimental study in the guinea pig. Am. J. Obstet.Gynecol. 45:183-200, 1943.

92. Windle, W.F. and R.F. Becker. Role of carbon dioxide in resuscitation at birth after asphyxia and after nembutal anesthesia. An experimental study in the cat and guinea pig. Am. J. Obstet. Gynecol. 42:852-858, 1941.

93. Windle, W.F., R.F. Becker, and A. Weil. Alterations in brain structure after asphyxiation at birth. An experimental study in the guinea pig. J.Neuropathol. \& Exper. Neurol. 3:224-238, 1944.

94. Windle, W.F., H.N. Jacobson, M.I. Robert de Ramirez de Arellano, and C.M. Combs. Structural and functional sequelae of asphyxia neonatorum in monkeys (Macaca mulatta). Res. Publ. Assoc. research Nervous Mental Disease 39:169-182, 1962.

95. Young, RS.K. J. Kolonich, C.L. Woods, and S.K. Yagel. Behavioral performance of rats following neonatal hypoxia-ischemia Stroke 17:1313-1316, 1986. 


\section{PRENATAL STRESS AND SEXUAL DIFFERENTIATION OF THE BRAIN}

\section{INTRODUCTION}

That males and females differ in many behaviors is widely recognized. During the past several decades it has become appreciated that sexual behavior, while in part genetically determined, is in great measure influenced by gonadal hormones during prenatal, as well as postnatal, development. During this same period, it has become apparent that prenatal influences such as maternal stress, exposure to chemicals such as ethyl alcohol and nicotine, or other factors can have profound effects on behaviors which are sexually dimorphic. For instance, considerable evidence indicates that following prenatal stress, alcohol exposure, et cetera, male rats may fail to masculinize and defeminize, and show altered adult sexual behavior.

The purpose of this review is to place in perspective those studies which have explored the role of prenatal influences on behavior that is sexually dimorphic. In addition, we consider the possible mechanisms by which prenatal stress, or other influences might affect adult sexual behavior. We do not consider the broad subject of the effects of prenatal stress on behavior in general.

\section{SEXUAL DIMORPHISM AND THE DEVELOPING BRAIN}

\section{Sex steroids and brain differentiation}

In the rat, the late gestational $(E \mid 4-21)$ and early postnatal $(\mathrm{P} \mid-10)$ periods appear to be critical for the sexual differentiation of the brain $(19,45,53)$. Foundation for the normal sexually dimorphic patterns of puberty, sexual behavior, gonadotropin secretion, and reproductive function in adult rats are established by the presence or absence of testicular steroids at precise times during this developmental period. In the rat, embryonic day 14 marks the beginning of testicular testosterone secretion (128). A surge in testosterone $(T)$ secretion occurs both on $E / 8(31,108)$ and 2 to $4 \mathrm{~h}$ following birth (E2I) $(20,104,11 \mathrm{I})$. Stahl and colleagues ( $1 \mathrm{I})$ demonstrated in the human male infant that $T$ peaked between 4 to $6 \mathrm{~h}$ post-partum. Forest and colleagues had originally reported that in human newborns, serum testosterone concentrations of males were significantly greater than that of females $(36,37,38)$, and that these elevated levels 5 to $9.75 \mathrm{~h}$ following birth (when they were first measured) and then declined (35).

The mechanism of the testosterone surge has been explored in several studies. In the fetal rat, testosterone secretion has been demonstrated as early as EI 4 (128). The fetal T surge is associated with increased plasma LH from El7.5 to El9.5 (105) and elevated pituitary $\mathrm{LH}$ concentration on $\mathrm{EI} 7$ and $\mathrm{EI} 8$ (93). Pituitary FSH and $\mathrm{LH}$ are first detectable on day 17 of gestation.

Serum $\mathrm{LH}$ and $\mathrm{FSH}$ peak on $\mathrm{E} 16$, decreasing rapidly thereafter (17). Testicular $\mathrm{LH}$ recep- 
tors appear around EI5, sharply increase at EI8 and continue to rise untill birth, while testicular FSH receptors first appear at E17, increasing sharply by $E 20$ (129). Decapitation of the fetus in utero after E 19.5 was associated with markedly recluced fetal basal plasma LH and testicular testosterone concentrations on E2O and E2I (49). Hypothalamic gonadotropin releasing hormone $(\mathrm{GnRH})$ appears around EI5 and hypothalamic regulation of gonadotrophin secretion is functional on El9 of fetal life (6). In addition, hypothalamic $\mathrm{GnRH}$ and pituitary $\mathrm{GnRH}$ receptors and $\mathrm{LH}$ concentrations increase from $\mathrm{E} / 9$ to term (6).

Administration of an $\mathrm{GnRH}$ antagonist decreased basal plasma [ $\mathrm{LH}]$ on $\mathrm{E} / 9$ and $[7$ from $E \mid 9(61)$. However, in these experiments fetuses treated with $\mathrm{GnRH}$ vehicle alone also had significantly decreased plasma testosterone concentrations.

In the newborn rat, the T surge may be associated with elevated $\mathrm{LH}$ and $\mathrm{FSH}$ concentrations $(20,22,104)$, although two groups reported only a minimal increase in $\mathrm{LH}(96,108)$. Unfortunately, most studies used pooled samples and $\mathrm{LH}$ radioimmunoassays not discriminating between alpha and beta subunits. Orchidectomy of the newborn male pup was associated with an absence of the $T$ surge (102). In newborn rats, the postnatal testosterone surge was retarded by environmental cooling (70), maternal separation (34), and ether anesthesia (70) (Table I).

There is also evidence for a placental testosterone surge; in vitro secretion of testosterone by placental tissue peaking at 18 days (69). Moreover, between day 14 and 22 of gestation elevated testosterone concentrations are detectable in the maternal uterine vein $(110)$. The placenta has also been shown to have bioactive capacities, increasing the $T$ secretion by fetal testis (50).

The rat brain, as the reproductive system, is believed to be inherently female. If androgens are not present in sufficient amounts at the appropriate time, the organism is feminized behaviorally, regardless of genetic or gonadal sex. Thus, for normal masculine differentiation of certain neuronally mediated functions, steroidogenic capacity in Leydig cells must be coordinated to that of the central nervous system to ensure the availability of appropriate amounts of testosterone during the critical period of masculine. differentiation. This androgen-mediated action is distinct from the activating functions of gonadal steroids from the time of puberty onward. Once the critical perinatal period of organization has passed, establishment or suppression of sexual behavior potential can be altered only with difficulty.

Pfeiffer (98) originally suggested that normal reproduction in male rats followed postnatal testicular function, while ovariectomy of the newborn female failed to alter normal female brain differentiation. Phoenix, Goy, and coworkers first demonstrated that androgens in the fetus permanently influence adult reproductive behavior (99).

Following administration of testosterone to pregnant guinea pigs, the adult female offspring displayed male-like mounting behavior, and their ability to perform typically female type behavior was impaired. Since this seminal contribution, several hundred studies have extended these observations to confirm that in both females and males the functional capacity of the adult brain depends upon the steroid hormonal environment during the perinatal period of sexual differentiation. Nonetheless, the specific mechanisms by which sexual behavior, and that which is sexually dimorphic, is altered remains 
to be demonstrated. Because of the huge literature in this field, we will consider only those papers which relate to the present topic. For more comprehensive reviews on various aspects of this subject, one may consult $\operatorname{Gorski}(5,44)$ and Döhler $(29)$ on sexual differentiation and dimorphism of the brain, Baum ( 10$)$ on sexual behavior, Beatty ( 11 ) on nonreproductive sexually dimorphic behavior, Archer and Blackman (4) and Montagu (82) respectively, on prenatal stress and behavior in general in rodents and humans, Goy and Goldfoot (46) on sexual differentiation in nonhuman primates, and McEwen (73) on cellular and subcellular mechanisms.

Castration of males during the perinatal period results in failure of masculinization of the neural substrate and feminizes the hypothalamo-pituitary axis. For instance, Corbier and colleagues (21) observed typical female type behavior (lordosis) in adult males which had been castrated at the time of birth. Those animals castrated 6 or $12 \mathrm{~h}$ after birth were less receptive to other males than those which were castrated at $0 \mathrm{~h}$. In contrast, those males castrated at $\mathrm{O}$ h, but which were injected with testosterone propionate failed to show lordosis or other feminized behavior. Subsequently, this group demonstrated that adult males castrated at birth displayed a lower frequency of female mounting behavior, but this effect was negated when castration was performed $24 \mathrm{~h}$ after birth or when testosterone replacement therapy was given following castration at time 0 (103). Chemical castration of male fetuses by injecting the dams with the testosterone antagonists cyproterone acetate or flutamide produced similar results. Moreover, the critical periods for "failure of masculinization" and "defeminization" differ. It is believed that prenatally, steroids act to virilize neural substrates destined to regulate male sexual behavior (31). Gonadotropin secretion patterns appear to be influenced by the absence of sex steroids during the early postnatal period. Although originally it was assumed that testosterone was the active hormone, intracellular estrogen may be more important in this regard. In both female and male rats, circulating estrogen is bound to feto-neonatal estrogen binding protein, which prevents its entry into the brain (74). (The corresponding binding affinity for testosterone is quite low.) In contrast, some have argued that alpha fetoproteins enter brain cells with estrogen, and in the liver act to protect estrogens from enzymatic metabolism and/or uptake (30, 134). Nonetheless, 17-beta-estra$\mathrm{diol}\left(E_{2}\right)$ is more potent than testosterone with respect to masculinization. During the perinatal period, testosterone readily passes the blood-brain barrier, and in the brain is aromatized to estradiol. Masculine differentiation of the brain is dependent upon this conversion $(75,89,91,92,116)$. For instance, the masculinization of behavior is attenuated if estrogen receptor blockers or compounds which prevent the aromatization process are given concomitantly with testosterone(71, 72).

Also, administration of 5 alpha reduced androgens were much less effective than either T or E2 in masculinizing the female brain (16). In addition, Tfm male rats (which have markedly reduced levels of androgen receptors, but normal CNS levels of estrogen receptors and aromatase) (87), undergo apparently normal brain sexual differentiation (66). Despite this, adult Tfm males demonstrate a female saccharin preference. Finally, injection of either androgen or estrogen in newborn females results in masculinization, with failure of feminization of their sexual behavior potential $(14,66)$. 
Both humans and rodents show sexual differences in central nervous system morphology $(1 \mid 2)$. Such differences include gross volume of defined cell groups and nucleii, differences in dendritic and synaptic organization, and ultrastructural differences in cellular and synaptic organelles $(66,88,90)$. In males the sexual dimorphic nucleus (SDN) in the hypothalamic preoptic area is larger than in females, and is sensitive to perinatal sex steroid exposure $(43,130)$. Prenatal alcohol exposure $(E 6-20)$ has been shown to significantly reduce the volume and average cell size of the SDN of male subjects at P70 (9). Despite considerable work on factors influencing SDN size, little is know of its function, either in regards to its role in regulating gonadotropin secretion, or its role in sexual activity and related behaviors. In addition, essentially nothing is known of the relation of this nucleus to the diffuse and more complex neural substrate involved in reproduction (44).

Other areas of cytoarchitectural sexual dimorphism exist in the brain and spinal cord (29). For instance, significantly larger volume or greater neuronal number in female, than in male, rat brain has been described in the lateral and medial anterior bed nuclei of the stria terminalis (27), the anterioventral periventricular nucleus (15), in the parastrial nucleus of the preoptic area (28), and in the anterior commissure of the corpus callosum (3).

In rodents, the endocrine status regulates the SDN met-enkephalin opioid system (60). Watson (130) observed a striking sexual dimorphism in the density of the met-enkephalin immunoreactive fibers in the periventricular region of the preoptic area, females having a more dense fiber system. The expression of female type fibers is regulated by the actions of neonatal and adult gonadal steroids. Moreover, there is a sexual dimorphism of mu-opioid receptor density in the medial preoptic area (51), which plays a central role in male and female reproductive behavior. Estrogen-induced neuronal differentiation may be important in the development of gonadotropin secretory patterns and sexual behavior. For instance, Matsumoto and Arai (68) showed that cells in arcuate nucleus, which is rich in estrogen receptors, responded to perinatally administered E2 with increased synaptogenesis. Garcia-Segura, Naftolin, and colleagues have shown that in rat arcuate nucleus, females have increased numbers of small particles on perikaryal membranes, compared to males (39). With synaptogenesis, the number of these intramembranous particles increased (94), and treatment of newborn females with testosterone resulted in a male-like phenotype of the arcuate nucleus (40).

As an aside, Reisert and Pilgram (100) have argued that sexual dimorphism of some systems in the nervous system may develop under primarily genetic, rather than sex hormone, control. Nonetheless, the cellular and molecular mechanisms whereby sex steroids modulate gene expression for development of brain structure and function remain unknown.

\section{Prenatal stress and sexual development}

During the past decade a number of studies have shown that sexual development in the rat, particularly the male, is affected by prenatal influences. For instance, prenatal maternal stress, exposure to ethyl alcohol, nicotine, and other compounds, can result in failure of masculinization in the male. In the rat, exposure to stress, ethanol, and other agents during this period of brain development has been shown to affect the hypo- 
thalamic-pituitary-gonad axis, as well as endogenous opiates and other neurochemicals. Males which are not or incompletly masculinized demonstrate a female type saccharin preference. In addition to reversing adult male saccharin preference, prenatal stress or drug administration can alter overt sexual behavior in both males and females. Some specifics of these alterations are detailed below.

\section{Stress}

Prenatal stress has been shown to affect both reproductive and non-reproductive behavior that is sexually dimorphic in male and female offspring (Table 2). In 1972. Ward first reported that the male offspring of dams, stressed by restraint and bright illumination for 45 min, 3 times per day, from days 14 to 21 of gestation displayed significantly decreased copulatory activity ( $26 \%$ vs $73 \%$ in controls) and ejaculatory behavior ( $21 \%$ vs $64 \%$ in controls). These males also showed increased lordotic behavior ( 8.8 lordosis quotient vs 2.7 lordosis quotient for control). Stress during the neonatal period (days I to 10) had no significant effect on these activities (119). Subsequently, Ward ( 1 18) demonstrated that this deficit in male copulatory behavior persisted ( $46 \%$ vs $77 \%$ of controls ejaculated) following castration and testosterone replacement therapy for 6 weeks. Nonetheless, castration of the prenatally stressed males followed by androgen treatment was associated with a somewhat paradoxical increase in lordotic behavior (62\% vs $0 \%$ in controls) (118). Ward later noted that androgen treatment of prenatally stressed males resulted in four distinct patterns of response, e.g., apparently normal male $(\sim 23 \%)$, female-like pattern with lordosis and failure to ejaculate $(\sim 38 \%)$, bisexual with their behavioral pattern appropriate to suit their sexual partner $(\sim 23 \%)$, and asexual $(\sim 15 \%)(117,1 \mid 8,122)$. In further studies using this paradigm, Ward and colleagues (81) reported decreased body weight, as well as weight of epididymis and testis. Also, they replicated the finding that prenatally stressed males showed increased lordotic behavior, although these males did not show a feminine-type pattern of active avoidance acquisition or open-field activity (81). Ward and Reed (123) confirmed an earlier report (33) that social isolation of the prenatally stressed males aggravated the decreased masculinization responses in these animals. This decrement in male sexual behavior was attenuated by raising the rat with a control male (or female) (123). Ward has cautioned that despite the lack of normal male copulatory activity and ejaculation, prenatally stressed males do not show the typical behaviors of an estrous female such as ear wiggling, hopping, and darting (117, 122).

Males with the "prenatal stress syndrome" (122) also demonstrated abnormalities in androgen metabolism. For instance, male pups stressed prenatally did not experience the day 18-19 T surge. Testosterone concentration was abnormally elevated on day 17 of gestation, but fell thereafter (125). In these pups, testicular Leydig cell $\Delta^{5}-3 \beta$ hydroxysteroid dehydrogenase (3B-HSD) activity also failed to show its normal increase on $E \mid 8-19$, although it was slightly higher than normal on El6 and E20 (95). In addition, steroid aromatase activity in combined hypothalamus and amygdala of stressed pups failed to increase at EI9, as is normal (132). Thus, prenatally stressed males demonstrated desynchronization in the rate of synthesis and release of testosterone, as well as in the development of enzymes and other elements in the central nervous system's target tis- 
sues which mediate sexual behavior: in a further report from this group, the prenatal stress syndrome was associated with elevated maternal and fetal corticosterone concentrations (in addition to the lack of testosterone surge on EI8-19 noted previously) (124).

Several other groups have examined the effects of prenatal stress on adult sexual behavior, with use of social crowding $(23,24)$, malnutrition ( 101$)$, or a conditioned emotional response (67) in addition to, or in place of, immobilization and intense illumination (Table 1). Dahlöf and colleagues confirmed that with either social crowding of dams or restraint with bright illumination, male offspring showed increased lordosis; however, their overt sexual behavior was not affected (24). In addition, these authors showed that at birth, body weight, testis and adrenal weights, and ano-genital distance were reduced (23). Ward has confirmed this finding; however, in the adults these measurements were not significantly different from controls (1 $\mid 7)$. Ward also reported that in adults other genital structures (penis and epididymis) did not differ in size, and the "stressed" males produced sperm (122). Prenatal stress was associated with female type behavior, e.g., lordosis, in males $(48,101,135)$, as well as increased number of mounts required before ejaculation ( $35 \pm 14$ vs $19 \pm 8$ in controls), increased number of intromissions before ejaculation ( $34 \pm 8$ vs $17 \pm 7$ ) ( 101 ). Some studies have reported decreased percent of ejaculation ( $31 \%$ vs $88 \%$ in controls) ( $10 \mathrm{I}$ ), or normal copulation and ejaculation (135). As noted above, others have reported that social isolation caused male rats to exhibit decreased copulatory activity, and such activity was absent in animals which also were prenatally stressed (33). In addition, treatment of the dams with the beta blocker propranolol (10 mg/ $/ \mathrm{gg}$ ) markedly decreased the number of demasculinized males (78).

In Ward's studies, the female offspring of prenatally stressed dams were normal in regards to sexual behavior, their ability to reproduce, and in manifesting maternal behavior $(12,122)$. In contrast, Herrenkohl and colleagues have reported several sexual alterations in females following prenatal stress. For instance, these authors noted significantly increased length of estrus cycle (55), decreased ovarian and uterine weights (57), fewer conceptions ( $64 \%$ vs $78 \%$ in controls), and increased spontaneous abortions ( $33 \%$ vs 14\%) (54). Herrenkohl and colleagues have reported gestational length to be either normal (56) or longer ( $24 \pm 3$ vs $22 \pm$ I days) (54). In addition, the offspring of prenatally stressed dams weighed less at birth $(6.6 \pm 0.2$ vs $7.4 \pm 0.1 \mathrm{~g})$, the stillbirth rate was elevated ( $45 \%$ vs $0 \%$ of controls), as was the neonatal deaths by 10 days of life ( 36 vs 0 ) (54). The birth weight decrement persisted through weaning on day 21 (56). Rhees and Fleming $(|0|)$ confirmed the effect of prenatal stress on increasing gestational length ( $22.9 \pm 0.6$ vs $22.0 \pm 0.7 \mathrm{~d}$ in controls), and in decreasing litter size and birth weight $(4.9 \pm 0.5$ vs $6.3 \pm 0.7 \mathrm{~g})$. The finding that in prenatally stressed males adrenal weights at birth were reduced $(1.7 \pm 0.1 \mathrm{mg}$, vs controls $2.5 \pm 0.1 \mathrm{mg})$, suggests that corticosteroids secreted by the stressed dam may suppress testosterone secretion in the male fetus (23). Although differentiation of sexual mechanisms continues after birth, stress during the newborn period appears to have little or no effect on males. Male pups exposed to stressful handling or vibration from PI to PIO showed normal adult sexual patterns. In addition, the combination of prenatal and postnatal stress produced no effect different 
from that of the prenatal treatment alone (119). Prenatally stressed males cross-fostered at birth to normal mothers also showed a failure to masculinize. This is further evidence that the behavioral alterations resulted from the prenatal stress, rather than from maternal influences during the neonatal period $(56,135)$.

\section{Ethyl alcohol}

One of the first chemicals shown to alter sexual behavior in adult rats was ethanol (Table 3). McGivern and colleagues (76) gave pregnant rats ethanol (35\% of total calories, $13.9 \mathrm{~g} / \mathrm{kg}$ body wt/day) either from days 7 to 21 of gestation (E7-E2I) or from El4 to E21. When tested for saccharin preference at 90 to 150 days of life, the males showed a significant preference for saccharin (to $16.4 \pm 2.0$ from $11.6 \pm 1.5 \mathrm{ml}$ of a $0.25 \%$ solution $/ 100 \mathrm{~g} \mathrm{bw} /$ day). In contrast, the females showed a modest decrease in saccharin preference (to $20.5 \pm 2.5$ from $25.4 \pm 3.4 \mathrm{ml} / 100 \mathrm{~g} / \mathrm{d}$ ). In addition, the ability of males to negotiate a Lashley III maze was decreased, the number of trials to reach criterion increasing to $45.5 \pm 4.3$ from $33.5 \pm 3.2$ in pair-fed controls. In contrast, the females required fewer trials (to $35 \pm 1.6$ from $50.0 \pm 5.5$ ) (76). Subsequently, these workers reported some physiologic basis for these changes in sexual dimorphism. Specifically, they noted that following a similar prenatal ethanol exposure, both male and female adult rats ( $120-170 \mathrm{~d}$ ) showed decreased circulating $\mathrm{LH}$ concentrations, with decreased pulse amplitude and frequency. Pituitary sensitivity to $\mathrm{GnRH}$, however, was not affected (52). Further studies with this experimental model, confirmed that adult males exposed to ethanol prenatally showed an increased saccharin preference, and this was not affected by testosterone propionate administration to the pregnant dams from $\mathrm{E} / 4$ to $\mathrm{E} / 7$ or EI8-E20 (77). This group also demonstrated that prenatal ethanol exposure resulted in an absence of the normal testosterone surge in males on days 18 to 19 of gestation (79). Such animals also showed a decreased number of testicular Leydig cells and increased vacuolization of seminiferous tubules. In males, but not females, McGivern and colleagues (80) also demonstrated an alcohol-mediated increase in hypothalamic aromatase activity on EI 8 and E19, and in the hypothalamic preoptic area 6 to $12 \mathrm{~h}$ after birth. These authors postulated that alcohol activated aromatase activity.

In humans, maternal alcohol ingestion is associated with lower concentrations of androstenedione, testosterone, and estradiol in amniotic fluid of male fetuses (133). In addition, acute ethanol treatment inhibits testicular steroidogenesis in the neonatal rat (59). With use of a similar ethanol exposure paradigm, Barron and colleagues (9) reported a significant decrease in size of the sexually dimorphic nucleus (SDN) in the hypothalamic preoptic area of males, but not of females (Table 3).

\section{Nicotine}

The offspring of nicotine-injected rats have been shown to have several growth and behavioral deficits, as well as neurochemical abnormalities (Table 4). In male pups of dams treated with nicotine tartrate from E12 onwards, Lichtensteiger and Schlumpf (64, 65) noted absence of the $T$ surge at E 8 . In addition, these workers observed significant increases in saccharin preference of the males: however, they did not correct fluid volu- 
me to animal weight (64). Following nicotine treatment of pregnant dams from E3 to E21. adult male animals (63-65 d) showed decreased number of mounts and intromissions, and decreased circulating testosterone concentrations. Although combined preand postnatal treatment resulted in a similar decrease in overt sexual activity, testosterone concentrations were similar to control levels, as was the case following postnatal treatment alone (106). Other workers have shown that prenatal nicotine administration resulted in decreased rearing activity in adult males (97). Following prenatal inhalation of cigarette smoke by the mother, mount latency and postejaculatory interval in adult male rats was decreased (13). Although these authors noted no effect of nicotine injection per se, it was given only twice a day rather than over an extended period (Table 4).

\section{Other compounds}

Several other chemical compounds have been noted to alter the $T$ surge at birth, and adult sexual activity of male rodents (Table 5). That the endogenous opioid system may be involved in the prenatal T surge is suggested by suppression of 3B-HSD activity (normally seen on EI8-EI9) by prenatal morphine administration (7). Prenatal exposure to morphine (opioid agonist) demasculinizes male sexual behavior, and also inhibits adult female sexual activity (122). Conversely, exposure to naltrexone (muopioid antagonist) enhances female sexual behavior (86). In addition, exposure of rat fetus to the synthetic opioid methadone from El 4 to $E 19$ markedly suppressed basal [T] on E2O (107). Maternal treatment with the synthetic estrogen mestranol (3-methoxy, 17 alpha ethynil estradiol) resulted in decreased in vitro testosterone production by 20-dayold fetal testis $(1 \mid 3)$. In the mouse, maternal cannabinol treatment reduced serum [1] on $\mathrm{E} / 6$ (26). Chronic maternal dexamethasone administration from $\mathrm{E} \mid 5$ to $\mathrm{E} 2 \mathrm{I}$ reduced plasma [T] in male rat fetuses between EI9 and E2I, and also suppressed the postnatal T surge (6I). Wilke (136) showed that maternal stress and exogenous ACTH significantly elevated maternal and fetal androstenedione and testosterone concentrations were decreased in males born to cocaine users (2). Despite the demasculinizing effect of prenatal haloperidol treatment on the male rat, it failed to alter prenatal T levels (58).

In mice, $\Delta^{9}$-tetrahydrocannabinol (THC) given on days 20 and 21 of gestation and days $\mid$ to 6 of the newborn period was associated in adults with decreased testis weight, increased body weight, and increased plasma LH concentrations ( $135.3 \pm 19.0$ vs $76.4 \pm 9.0 \mathrm{ng} / \mathrm{ml}$ in controls). In contrast, injection of the nonpsychoactive component cannabinol resulted only in decreased FSH concentrations (25). Both compounds were associated with increased latency to mount and decreased numbers of mounts. Only 4 of 9 THC exposed animals mounted females, as opposed to 7 of 7 controls (25).

The development of the hypothalamic-pituitary-gonadal axis and catecholaminergic pathways occur in concert during the perinatal period. Immediately before the fetal $\mathrm{LH}$ rise at E 17, the hypothalamic and preoptic area are innervated with ascending catecholaminergic neurons. It is postulated that these predominantly noradrenergic neurons facilitate $\mathrm{LH}$ secretion, as in adult rats norepinephrine does so. Lesion studies with 6 hydroxydopamine confirm the stimulation by central catecholamines of the male pituitary gonadal axis (65). In addition, evidence suggests that the alpha-adrenergic system may promote, and the beta-adrenergic system inhibit, failure of masculinization (32). 
Thus, alterations in norepinephrine content, which is predominantly bound by alphareceptors, may alter sexual differentiation. The neuroleptic and dopamine receptor antagonist: haloperidol given to pregnant or lactating rats also impaired masculine sexual behavior in the male offspring (58). For instance, the number of ejaculations was significantly reduced in prenatally \pm postnatally treated males, but not in those which received only postnatal treatment. In addition, treatment of pregnant dams with the dopamine agonist apomorphine or the dopamine synthesis inhibitor alpha-methyl tyrosine, either individually or in combination, resulted in significantly fewer ejaculations and increased latency to ejaculation. Plasma [1] did not differ among the groups (58). Cocaine acts centrally to inhibit the uptake of dopamine, norepinephrine, and serotonin. Prenatally cocaine-exposed female rats exhibit reduced adult lordosis behavior, whereas prenatally exposed males display normal or even facilitated sexual behavior (1 14).

Food restriction (50\% of the caloric intake of controls) and maternal ACTH injection improved male copulatory behavior and increased lordotic behavior, as compared with controls (101).

In addition, E. coli endotoxin given to pregnant dams on El 8, was associated with significantly increased latency of mounting, intromission, and ejaculation. However, no differences were noted in the Hebb-Williams maze test (137).

\section{Potential mechanisms of failure of masculinization}

Beyond the fascinating phenomenology of the changes in sexual behavior, a critical question regards the mechanisms by which prenatal stress or chemical exposure result in failure of masculinization and related changes. Considerable evidence indicates that the hormonal milieu, rather than the genome, determines sexual dimorphism in an inherently female brain (44). Normal patterns of sexual behavior and gonadotropin secretion are established by adulthood, on the basis of the presence or absence of androgens during critical periods of fetal and neonatal development. For instance, chemical or surgical castration of males during the perinatal period results in lack of masculinization, and/or feminization of reproductive functions. In contrast, exposure of females to androgens during a critical period masculinizes and defeminizes reproductive function, morphology, and behavior. The degree of these changes is a function of the amount and timing of the hormonal intervention.

Considerable evidence suggests that in the male rat, the absence of the fetal testosterone surge is followed by an absence of masculinized behavioral changes. Because the role of the GnRH system and LH in the T surge is not completely established, it cannot be inferred that stresses which result in failure of masculinization act centrally. Nonetheless, several studies have provided suggestive evidence for involvement of the opioid, catecholaminergic, and other systems in this phenomenon.

The neurotransmitters norepinephrine and dopamine have been implicated at several levels of regulation of hormonally-mediated behavior, such as copulation $(1,41)$. In addition, brain catecholamines modulate the regulation of anterior pituitary function (109). Moyer and colleagues (84) observed in maternal rats that stress during pregnancy was associated with decreased norepinephrine concentrations in the ventral ascending bundle in the medial preoptic nucleus, anterior hypothalamus, and median forebrain 
bundle, areas associated with gonadotropin secretion. These workers also observed decreased dopamine concentrations in these and related areas (84). This group also examined the effect of prenatal stress in altering catecholamine concentrations in the brains of both male and female offspring as adults. For instance, in males, norepinephrine concentrations were decreased in the median eminence and preoptic area. In contrast, in females, prenatal stress was associated with markedly increased dopamine levels in the arcuate nucleus of the hypothalamus (85). In addition, the behavioral alterations may be mediated in part by the adrenergic system. For instance, McGivern and colleagues (78) reported that prenatal stress increased the number of trials to criterion to learn a Lashley III maze (70.I \pm 9.2 vs $53.1 \pm 6.3$ ), as well as markedly increasing male saccharin preference. However, treatment with the beta adrenergic antagonist propranolol reversed these alterations (78). Additionally, and as noted above, the effect of propranolol administration in decreasing the incidence of failure of masculinization among prenatally stressed males, suggests that the noradrenergic/dopaminergic systems are important in this regard (78). Thus, prenatal stress may alter the neuroanatomical and neurochemical organization of the developing catecholaminergic neurotransmitter system, so that the unique characteristics of male brain do not develop.

That in males the endogenous opiate system may play a role in the failure of some aspects of masculinization following prenatal stress, is suggested by morphine's action, given to pregnant dams every $8 \mathrm{~h}$, to increase the percentage of "incompletly masculinized" male offspring, e.g., those exhibiting lordosis and reduced ejaculatory response $(117)$. The opiate antagonist naltrexone given to the prenatally stressed dam prevented this response (126). Also, prenatal morphine administration suppressed the rise in 3B-HSD activity normally seen on days $18-19$ of gestation (7). In addition, exposure of rat fetuses to the synthetic opioid methadone from EI4 to E19, resulted in markedly depressed testosterone concentrations on E20 (107). Behavioral studies were not performed in these animals. These observations suggest that exposure of the fetus to excess opiates inhibits testosterone synthesis, as it does in the adult (17). In the adult, stress triggers a release of beta endorphin (47). Thus, the "prenatal stress syndrome" may, in part, be mediated by endogenous opiates.

Taken together, these data provide evidence that the modification of sexually dimorphic behaviors which follow prenatal stress per se, alcohol, nicotine, cocaine, or other manipulations may result from failure to experience the normal surge in testosterone which occurs in the male fetus on days 18 and 19 of gestation and/or immediately after birth. Central nervous system components critical to adult sexual behavior which begin to differentiate at this time may do so without benefit of the $T$ surge which occurs under normal conditions. How these studies almost all of which are in the rat, relate to the human is unclear. Few studies have assessed the effect of prenatal influences on human sexual differentiation. For instance, Ward and colleagues (127) reported that boys prenatally exposed to methadone were significantly feminized in some aspects of two gender identity tests. However, no profound disturbances in gender identity (i.e. cross dressing, expressing wish to be a girl, preference for feminine toys) were found. 
In the following chapters, we will discuss the effect of prenatal hypoxia on the perinatal testosterone surge, and sexually dimorphic behaviors in the male rat. We also studied the physiology of the postnatal testosterone surge. 


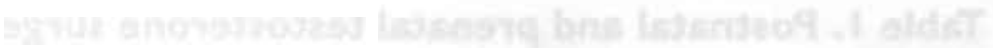


Table I. Postnatal and prenatal testosterone surge

\section{Species I}

breed

human

rat

rat

rat

human

rat

rat

rat

rat

rat

rat

rat

rat

sheep

rat

rat
F

N

F

N

Fetal / Newborn

Age

$N$

$N$

N

N

$F \& N$

$N$

N

$N$

F

F

N

F

F\&N

$N$

$N$ $N$

$N$

N

Stress 

at 5 to $9.75 \mathrm{~h}$

$\mathrm{LH}$ and $\mathrm{FSH}$ increased 2 to $6 \mathrm{~h}$ after

104 birth.

testicular weigth increased over first $24 \mathrm{~h}$

TS** associated with oncreased LH \& FSH and testicular weight

2

$4-6$

T elevated at $23-24$ wk gestation

$0.5-2$

LH \& FSH not significantly increased neuroanatomical, physiological, and behavioral sex differences

TS on EI8 - EI9

$T$ in males greater than in females on $\mathrm{PI}$

$T$ increased on $E 19$ increased on E20.5 - E2I.5. L

fetal descapitation decreased

$\mathrm{LH}$ and testicular

GnRH increased plasma LH from

EI7.5 - E19.5

castration at birth increased female type adult sexual behavior (lordosis)

$T$ increased near term

pituitary LH increased on EI7 - EI8 
Species I

breed

rat

rat

rat

rat

rat

human

ferret

rat

mouse

human

rat

rat

rat

F

$N$

F

N

$N$

N

N

F

$N$

N

N

F
Stress

Age

restraint \& illum

$F \& N$

nicotine tartrate

ethanol

* $\mathrm{T}=$ testosterone

** TS = testosterone surge chronic, prenatal

dexamethasone 
male $T$ increased on EI7

and decreased on EI9

$\mathrm{LH}$ receptors in testis peak E2I.5

6

hypothalamic $\mathrm{GnRH}$ pitutiary LH

and pituitary $\mathrm{GnRH}$ receptors

increase from EI9 to term

T decreased in males on EI7

elimination of TS at birth ( castration)

103

decreased adult mounting sexual behavior on days 2 and $5 \mathrm{~T}$ decreased in preterm

8 infants with cryptorchidism

abscene of TS on E18-19

TS associated with decreased testicular T

TS abolished by cooling or ether anesthesia

$\mathrm{GnRH}$ antagonist decreased plasma

$\mathrm{LH}$ on E 19 and T from E19 - E2I

decreased plasma T on E19 - E21 supressed TS 
Table 2. Prenatal stress and its effects on sexual behavior

Species I

Breed

rat

SD

$\mathrm{SD}$

$6-22$

$\mathrm{PI}-10$

$14-21 \&$

$\mathrm{PI}-10$

$|4-2|$

restraint \& bright

illumination

45 min. $3 x$ day

maternal separation

vibration

$"$

avoidance conditioning

restraint, heat

illumination

45 min, $3 x$ day

SD

$14-22$

SD

SD

Wistar
$|4-2|$

$14-22$

restraint, heat

illumination

$45 \min , 3 x$ day

restraint, \& bright

illumination

$45 \min , 3 x$ day

social crowding or

immobilization

with intense

illumination

14-22 restraint, heat

illumniation

$45 \min , 3 x$ day
Test

sexual behavior

sexual behavior

open field activity

nursing behavior

sexual behavior

sexual behavior

lordosis

sexual behavior

birth weight anogenital distance 


\section{Test day $^{\circ} \quad$ Result}

90

\section{$90+$}

$1+$

$60+$

$75+$

$190+$

decreased weight

56

male, decreased copulation \&

ejaculation

increased lordotic behavior

no significant change

similar to prenatal

decreased open field activity

67

male decreased copulation \&

ejaculation

male increased lordotic behavior bisexual behavior

increased lordosis

135

increased lordosis

24

no change

male decreased anogenitial distance

reduced body wt, testis, adrenal 
Species I

breed

rat

SD

$|4-2|$

heat immobolization

intense illumination

\pm social isolation

SD

$|4-2|$

$|4-2|$

$|4-2|$

immobilization,

illumination

SD

$14-22$

heat immobilization

intense illumination

Wistar

$|4-2|$

$|4-2|$

SD

SD

$45 \min 3 x$ day

restraint

$45 \min 3 x$ day

immobilization
Test

copulation

NE in brain

DA in brain

estrus cycle

weight

behavorial rests

sexual behavior

restraint \& illumination

[testosterone]

with bright illumination

illumination, heat

reduced caloric

ACTH to mother gestational length

birth weight

sexual behavior 
with prenetal stress and

social isolation various brain regions female increased or decreased NE \& DA in various regions

102 female increased length of estrus cycle

male decreased testis \& epididymus wt increased abortions, decreased birth wt

decreased liter size decreased birth wt male increased mounts before ejaculation

increased intromissions before ejaculation decreased percent ejaculation increased lordosis 
SD

immobilization

steroid aromatase

illumination in hypothalamus \& amygdala

SD

$\mid 4-2$

immobilization

illumination, heat

reproductive behavior

SD

$|4-2|$

restraint, $45 \mathrm{~min}$

$3 x$ day, with bright

illumination

heat, immobilization

[ $3 B$ HSD ]

SD

$|4-2|$

restraint \& illumination

[testosterone]

[progesterone]

[corticosterone]

SD

$|4-2|$

$"$

SD

$$
|4-2|
$$

\pm naltrexone

SD

$|4-2|$

restraint, illumination

saccharin preference

$45 \min 3 x$ day

lashley III maze

* Embryonic / fetal age; $P$ = postnatal age

- unless otherwise noted, refers to postnatal; $E=$ Embryonic 
EI7 - 21

male and female decreased

132

aromatase activity

especially E 8 - $2 \mid$

12

$E|6-2|$

male El 8 decreased activity

95

EI9 decreased activity

90

female increased length of

57

estrus cylce, decreased

weigth uterus, ovaries

$E|7-2|$

male EI 7 increased[test], no

124

difference in $\mathrm{P}_{4}$, corticosterone

El 8 decreased[test],

no difference in $\mathrm{P} 4$ corticosterone

$E$ I 9 decreased[test] no difference

in P4 corticosterone

60

increased latency of ejaculation

increased lordotic behavior

these decreased by raising with

female or male

60

male increased lordotic behavior

126

blocked by naltrexone

$100-110$

male increased saccharin

preference

increased number of trials to learn

maze

effects blocked by propranolol

( 3 blocker ) 
Species I

Breed

rat

SD

$$
7-21
$$

Age*

Stress

$35 \%$ of calories

$13.9 \mathrm{~g} / \mathrm{kg}$

body wt / day

$|4-2|$

SD

$|4-2|$

$35 \%$ of calories

I $1.6 \mathrm{~g} / \mathrm{kg} \mathrm{bw} / \mathrm{d}$

SD

SD

$14-20$

$14-17$

$18-20$

$\mid 4-21$

$35 \%$ of calories

$35 \%$ of calories

\pm testosterone prop

$0.3 \mathrm{mg} / \mathrm{kg}$

$1.0 \mathrm{mg} / \mathrm{kg}$

SD

$$
|4-2|
$$

$35 \%$ of calories

$35 \%$ of calories

pf controls

$$
6-20
$$

$$
E=\text { Embryonic }
$$

* $E=$ Embryonic/fetal age:

$\mathrm{P}=$ postnatal; ${ }^{\circ}$ unless otherwise noted refers to postnatal age
[ testosterone ]

testicular morphology

anogenital distance

Test

saccharin preference

lashley I I maze

pituitary sensitivity

to $\mathrm{GnRH}$

saccharin preference

brain aromatase activity

sexually dimorphic nucleus of preoptic area of hypothalamus 


\section{Saccharin} concentr.

0.25

0.5

1.0

0.25

0.25

0.5
Test day $^{\circ} \quad$ Result

$90-130$

male increased, female decreased

76

no significant difference

$90-150 \quad$ male increased, female decreased

$90-150 \quad$ male required more trials

female required fewer trials

$120-170 \quad$ male \& female decreased

LH concentration, pulse

ampl. \& frequent (however, not due

to pituitary sensitivity to $\mathrm{GnRH}$ )

male increased, but testosterone

had no effect

females no significant difference

but testosterone increased

52

77
Reference

79

testosterone surge

E18-19 male decreased number of Leyding

cells, increased vacuoles in

seminiferous tubulus

E21 no significant difference

E16-20 males, elevated aromatase

80

$\mathrm{PI}$

activity

$70-80$

male smaller SDN

female no siginificant difference 
Table 4. Prenatal nicotine and its effects on sexual behavior

Species I

Age*

Stress

Test

breed

rat

Wistar

$1-20$

cigarette smoke

sexual behavior

$15 \min / 2 x$ day

I - $8 \quad$ nicotine $2.0-0.5$

$9-20$

$\mathrm{mg} / \mathrm{kg} /$ day

$0.3 \mathrm{mg} / \mathrm{kg} / \mathrm{day}$

SD

$12-18$

nicotine tartrate

[ testosterone ]

$0.25 \mathrm{mg} / \mathrm{kg} / \mathrm{h}$

I. $13 \mathrm{LL} / \mathrm{L}$

$15-18$

SD

$|-2|$

$6 \mathrm{mg} / \mathrm{kg} / \mathrm{h}$

in water

( $40 \mathrm{lg} / \mathrm{ml}$ in blood)

rearing activity

SD

$\mid 2-21$

nicotine tartrate

[ testosterone ]

$0.25 \mathrm{mg} / \mathrm{kg} / \mathrm{h}$

by osmotic

minipump

saccharin preference

SD

$3-21$

$0.25 \mathrm{mg} / \mathrm{kg}$

sexual behavior

$2 x$ day

$3-21$

$+\mathrm{PO}-\mathrm{P}|4 \quad| x$ day

$\mathrm{PO}-\mathrm{P} \mid 4$

$12-20$

nicotine

brain aromatase

$6 \mathrm{mg} / \mathrm{kg} / \mathrm{d}$

activity

$8-20$

$2 \mathrm{mg} / \mathrm{kg} / \mathrm{d}$

[ testosterone ]

$6 \mathrm{mg} / \mathrm{kg} / \mathrm{d}$

*Embryonic / fetal age; $P=$ postnatal; ${ }^{\circ}$ unless otherwise noted, refers to postnatal age $E=$ Embryonic 
100

decreased mount latency

decreased post - ejaculatory

period

no effect

no effect

$E 17-18$

abolished EI 8 testosterone peak

65

"

male birth wt decreased

$60-85$

decreased rearing

activity in males

EI7

males decreased

64

$0.06,0.125,0.2590-150$

male increased saccharin

intake( not corrected

for animal wt )

female also increased at 0.06

although authors do not state so

$63-65$

male, decreased number of mounts

106

intromissions,

decreased testosterone

decreased number of mounts

intromissions, no difference in [testostorone]

mount latency decreased

no difference [testosterone ]

EI8, 19,22 male decreased aromatase

activity on $\mathrm{P} 6$

$P 2,6,15$ male decreased aromatase

activity on P6 
Table 5. Prenatal administration of other compounds and their effects on sexual behavior

Species I

Breed

mouse

Worcester

Fdn.

$$
20-21
$$

PI - 6

$\Delta^{9}$ tetrahydro-

cannabinol

rat

LE

$$
\begin{aligned}
& 7-21 \\
& P \mid-21
\end{aligned}
$$$$
\text { haloperidol }
$$$$
\text { ( } 2.5 \mathrm{mg} / \mathrm{kg} \text { ) }
$$

Wistar

18

E. coli endotoxin

( 0.2 or $2.01 \mathrm{~g}$ ) cannabinol

\section{Test}

mounting latency

$[\mathrm{LH}],[\mathrm{FSH}]$

ejaculation

[ testosterone ]

* Embryonic / fetal age; $P=$ postnatal age; ${ }^{\circ}$ unless otherwise noted, refers to postnatal $E=$ Embryonic; $P=$ postnatal 
$60-80$

increased body wt, decreased

25

testes wt

increased [ $\mathrm{LH}]$

increased latenct to mount

decreased proportion mounting

decreased [ FSH ] increased latency

to mount, decreased

number of mounts

$60-120$

decreased ejaculation

58

in prenatal and postnatal

decreased ejaculation with apomorphine, a mythel - $p$ - tyrosine

$84+$

increased latency for mounting

intromission, and ejaculation 


\section{REFERENCES}

I. Ahlenius, $S_{4}$ J. Engel, J. Erikson, K. Modigh, P. Sodersten. Involvement of monoamines in the media tion of lordosis behavior. In M. Sandler and G.L. Gessa (Eds). Esxual behaviour. Pharmacology and Biochemistry. New York Raven Press, 1975.

2. Ahluwalia, B.S., J.F. Clark L.S. Westney, D.M. Smith, M. James, S. Rajguru. Amniotic fluid and umbilical artery leveis of sex hormones and prostaglandins in human cocaine users. Reprod. Toxicol. 6:57-62, 1992.

3. Allen, L.S. and R.A. Gorski. Sexual orientation and size of the anterior commissure in the human brain.Proc. Natl. Acad. Sci. USA 89:7199-7202, 1992.

4. Archer, J.E. and D.E. Blackman. Prenatal psychological stress and offspring behavior in rats and mice. Develop. Psychobiol. 4:193-248, 1971.

5. Amold, A.P. RA. Gorski. Gonadel steriod induction structural sex differences in the central nervous system. Ann. Rev. Neurosci. 7:413-442, 1984.

6. Aubert, M.L, M. Begeot, B.P. Winiger, G. Morel, P.C. Sizonenko, and P.M. Dubois. Ontogeny of hypothalamic luteinizing hormone-releasing hormone $(\mathrm{GnRH})$ and pituitary $\mathrm{GnRH}$ receptors in fetal and neonatal rats. Endocrinology 116:1565-1576, 1985.

7. Badway, D. J. Orth, and J. Weisz. Effect of morphine on $\Delta 5$-3b-ol-steroid dehydrogenase in Leydig cells of fetal rats: A quantitative cytochemical study. Anat. Rec.199:15a, 1981.

8. Baker, B.A., R. Morley, and A. Lucas. Plasma testosterone in preterm infants with cryptorchi dism. Arch. Dis. Child. 63:1 198-1200, 1988.

9. Barron, S., S.B. Tieman, and E.P. Riley. Effects of prenatal alcohol exposure on the sexually dimorphic nucleus of the preoptic area of the hypothalamus in male and female rats.

Alcoholism: Clin. Exper. Res. 12:59-64, 1988.

10. Baum. M.J. Chifferentiation of coital behavior in mammals: A comparative analysis. Neurosci. Biobehav. Rev. 3:265-284, 1979.

I I. Beatty, W.W. gonadal hormones and sex differences in nonreproductive behaviors in rodents: Organizational and activational influences. Horm. Behav. 12:112-163, 1979.

12. Beckhardt, S. and I.L. Ward. Reproductive functioning in the prenatally stressed female rat. Develop. Psychobiol. 16:111-118, 1983

13. Bemandi, M. S. Genedani, and A. Bertolini. Sexual behavior in the offspring of rats exposed to cigarette smoke or treated with nicotine during pregnancy. Rivista di Farmacologia e Terapia 12:197-203, 1981.

14. Beyer, C., and H.M. Feder. Sex steroids and afferent input: Their roles in brain sexual differentiation. Ann. Rev. Physiol. 49:349-64, 1987.

15. Bloch, G.J. and RA. Gorski. Estrogen/progesterone treatment in adulthood affects the size of several components of the medial preoptic area in the male rat. J. Comp. Neurol. 275:613-622, 1988.

16. Brown-Grant, K. A. Munck, F. Naftolin, and M.R. Sherwood. The effects of the administration of testosterone propionate alone or with phenobarbitone and of testosterone metabolites to neonatal female rats. Horm. Behav. 2:173-182, 1971.

17. Chowdurry, M., and E. Steinbenger. Pituitary and plasma levels of gonadotrophins in foetal and newbom male and female rats. J. Endocr. 69:381-384, 1976.

18. Cicero, T.J. Effects of exogneous and endogenous opiates on the hypothalamic-pituitary-gonadal axis in the male. Fed. Proc. 39:255I-2554, 1980.

19. Clemens, L.G., B.A. Glaude, and L.P. Coniglio. Prenatal endogenous androgenicinfluences on masculine sexual behavior and genital morphology in male and female rats. Horm. Behav. 10:40-53, 1978.

20. Corbier, P., B. Kerdelhue, R Picon, and J. Roffi. Changes in testicular weight and serum gonadotropin and testosterone levels before, during, and after birth in the perinatal rat Endocrinology 103:1985-1991. 1978. 
21. Corbier, P., J. Roffi, and J. Rhoda. Female sexual behavior in male rats: Effect of hour of castration at birth. Physiol. Behav. 30:613-616, 1983.

22. Corbier, P., L. Dehennin, M. Castanier, A. Mebazaa, D.A. Edwards, and ]. Roffi. Sex differences in serum luteinizing hormone and testosterone in the human neonate during the first few hours after birth. J. Clin. Endocrin. Metabol. 71:1344-1348, 1990.

23. Dahlöf, L-G., E. Hård, and K Larsson. Influence of matemal stress on the development of the fetal genital system; Physiol. Behav. 20:193-195, 1978.

24. Dahlöf, L-G., E. Hård, and K. Larsson. Influence of matemal stress on offspring sexual behavior. Anim. Behav. 25:958-963, 1977.

25. Dalterio, S. and A. Bartke. Perinatal exposure to cannabinoids alters male reproductive function in mice. Science 205:1420-1422, 1979.

26. Dalterio, S. and A. Bartke. Fetal testosterone in mice: effect of gestational age and cannabinoid exposure. J. Endocr. 91:509-514, 1981.

27. Del Abril, A., S. Segovia, and A. GuillamAn. The bed nucleus of the stria terminalis in the rat: Regional sex differences controlled by gonadal steroids early after birth. Dev. Brain Res.

429:295-300, 1987.

28. Del Abril, A., S. Segovia, and A. GuillamAn. Sexual dimomhism in the parastrial nucleus of the rat pre-optic area. Dev. Brain Res. 52:11-15, 1990.

29. Dohler, KD. The pre- and postnatal influence of hormones and neurotransmitters on sexual differentiation of the mammalian hypothalamus. Int'l. Rev. Cytol. | 31:I-57, 1991.

30. Dohler, K-D., J.-L. Hancke, S.S. Srivastava, C. Hofmann, J.E. Shryne, and R.A. Gorski. Prog, Brain Res, 61:99-117, 1984.

31. Dömer, G. Hormones and Brain Differentiation.Amsterdam, Elsevier/North Holland Biomedical Press. 1976.

32. Dömer, $G$. Interactions between systemic hormones and neurotransmitters in brain development. In: Parvez et al (Eds), Progress in Neuroendocrinology, Vol. I, VNU Science Press, 167-189, 1985.

33. Dunlap, J.L., J.E. Zadina, and G. Gougis. Prenatal stress interacts with prepuberal social isolation to reduce male copulatory behavior. Physiol. Behav. 21:873-875, 1978.

34. Erskine, M.S., S.A. Tobet, and M.J. Baum. Effect of birth on plasma testosterone, brain aromatase activity, and hypothalamic estradiol in male and female ferrets. Endocrinology 122:524-530. 1988.

35. Forest, M.G. and A.M. Cathiard. Pattem of plasma testosterone and $\Delta 4$-androstenedione in normal newboms: Evidence for testicular activity at birth. J. Clin Endocrinol. Metab.

41:977-980, 1975.

36. Forest, M.G., A.M. Cathiard, and J.A. Bertrand. Evidence of testicular activity in early infancy. J. Clin. Endocrinol. Metab. 37:148-151, 1973.

37. Forest, M.G. A.M. Cathiard, and J.A. Bertrand. Total and unbound testosterone levels in the newbom and in nomal and hypogonadal children: Use of a sensitive radioimmunoassay for testosterone. ]. Clin. Endocrinol. Metab. 36: I | 32-1 | 42, 1973.

38. Forest, M.G., P.C. Sizonenko, A.M. Cathiard, and J. Bertrand. Hypophyso-gonadal function in humans during the first year of life. J. Clin. Invest. 53:819-828, 1974.

39. Garcia-Segura, L.M., D. Baetens, and F, Naftolin. Sex differences and maturational changes in arcuate nucleus neuronal plasma membrane organization. Dev. Brain Res. 19:146-149, 1985.

40. Garcia-Segura, L.M., J. Perez, P.A. Tranque, G. Olmos, and F, Naftolin. Sexual differentiation of the neuronal plasma membrane: Neonatal levels of sex steroids modulate the number of exo- and endocytotic images in the developing rat arcuate neurons. Neurosci. Lett. 91:19-23, 1988.

41. Gessa, G.L., and A Tagliamonte. Role of brain serotonin and dopamine in male sexual behavior. In M. Sandler (Eds), Sexual behaviour, Pharmacology and Biochemistry.

New York Raven Press, 1975.

42. Gogan, F., A. Slama, B. Bizzini-Koutznetzova, F. Dray, and C. Kordon. Importance of perinatal testosterone in sexual differentiation in the male rat. J. Endocr. 91:75-79, 1981.

43. Gorski, RA., J.H. Gordon, J.E. Shryme, A.M. Sondhan. Evidence for a morphological sex difference within the medial preopticarea of the rat brain. Brain Res. 148:333-346, 1978. 
44. Gorski, RA. Sexual differentiation of the brain. In: Krieger, D.T. and J.C. Hughes (Eds), Neuroendocrinology, Sunderland, MA, Sinauer Assoc., Inc., pp 215-222, 1980.

45. Goy, RW. and B.S. McEwen. Sexual Differention of the Brain. Cambridge, MA. MIT Press, 1980 , PP 1-12, 13-36, 64-73,152-156.

46. Goy, RW. and D.A. Goldfoot. Experiential and hormonal factors influencing development of sexual behavior in the male mesus monkey. In:Schmitt,F.O. and F.G. Worden (Eds), The Neurosciences: Third Study Program, Cambridge, MA, MIT Press, pp 57I-58I, 1974.

47. Guillemin, R, T. Vargo, J. Rossier, S. Minick N. Ling. C. Rivier, W. Vale, and F. Bloom. b-Endorphin and adrenocorticotropin are secreted concomitantly by the pituitary gland. Science 197:1367 1369. 1977.

48. Götz, F. and G. Dömer. Homosexual behaviour in prenatally stressed male rats after castration and oestrogen treatment in adulthood. Endokrinologie 76:1 15-117, 1980.

49. Habert, R and R. Picon. Control of testicular steroidogenesis in foetal rat: Effect of decapitation on testosterone and plasma luteinizing hormone-like activity. Acta Endocrinol. 99:466-473. 1982.

50. Habert, $R$ and $R$ Picon. Attempts for identification of a chorionicgo nadotrophin-like bioactivity in the rat placenta which stimulates the testosteron secretion of the fetal testis in vitro. Biol. Neonate 58:24-31, 1990.

51. Hammer R. Jr. Mu-opiate receptor binding in the medial preoptic a area is cyclical and sexually dimorphic. Brain Res. 515:187-192, 1990.

52. Handa, RJ., R.F. McGivem, E.P. Noble, and RA. Gorski. Exposure to alcohol in utero alters the adult pattems of luteinizing homone secretion in male and female rats. Life Sci. 37:1683-1690, 1985.

53. Harris, G.W. Sex hormones, brain development and brain function. Endocrinology 75:627-648, 1964.

54. Herrenkohl, L.R Prenatal stress reduces fertility and fecundity in female offspring. Science 206:1097-1099. 1979.

55. Herrenkohl, L..R and I.A. Politch. Effects of prenatal stress on the estrous cycle of female offspring as adults. Experentia 34:1240-1241, 1978.

56. Herrenkohl, L.R and J.B. Whitney. Effects of prepartal stress on postpartal nursing behavior, litter development and adult sexual behavior. Physiol. Behav. 17:1019-1021, 1976.

57. Herrenkohl, L.R and S. Scott. Prenatal stress and postnatal androgen: Effects on reproduction in female rats. Experientia 40:101-103, 1984.

58. Hull, E.M., J.K Nishita. D. Bitran, and S. Dalterio. Perinatal dopamine-related drugs demasculinize rats. Science 224:1011-1013, 1984.

59. Kelce, W.R. V.K Ganjam, P.K. Rudeen. Inhibition of testicular steroidogenesis in the neonatal rat following acute ethanol exposure. Alcohol. 7:75-80, 1990.

60. Kumar, M.S.A., C.L. Chen, R.F. Muther. Changes in the pituitary and hypothalamic content of methionine-enkaphalin during the estrous cycle in the rat. Life Sci., 25:1687-1696, 1979.

61. Lalau, J.-D. M. L. Aubert. D.F. Carmignac, I. Grégoire, and J.-P. Dupouy. Reduction in testicular function in rats. I. Reduction by a specific gonadotropin-releasing hormone antagonist in fetal rats. Neuroendocrinology 51:284-288, 1990.

62. Lalau, J-D. M. L. Aubert, D.F. Carmignac, I. Grégoire, and J.-P. Dupouy. Reduction in testicular function in rats. II. Reduction by dexamethasone in fetal and neonatal rats. Neuroendocrinology 51:289-293. 1990.

63. Lichtensteiger, W. and M. Schlumpf. Modification of early neuroendocrine development by drugs and endogenous peptides. In: Parvez et al (Eds), Progress in Neuroendocrinology, Vol. I, VNU Science Press, pp 153-166. 1985.

64. Lichtensteiger, $W$. and $M$. Schlumpf. Prenatal nicotine affects fetal testosterone and sexual dimorp hism of saccharin preference. Pharmacol. Biochem. Behav. 23:439-444, 1985.

65. Lichtensteiger, W. and M. Schlumpf. Steroids and neurotransmitter mechanisms in the prenatal period. In: Steroid Hormone Regulation of the Brain. Fux, K, J.-A. Gustafsson, and L. Wetterberg (Eds). Oxford, Pergamon Press, 1981, pp 161-172. 
66. Maclusky, N.J. and F. Naftolin. Sexual differentiation of the central nervous system. Science 211:1294-1303, 1981.

67. Masterpasqua, F., R.H. Chapman, and R.K. Lore. The effects of prenatal psychological stress on the sexual behavior and reactivity of male rats. Dev. Psychobiol. 9:403-411, 1976.

68. Matsumoto, A., Y. Arai. Morphologic evidence for intranuclear circuits in the hypothalamic arcuate nucleus. Exp. Neurol. 59:404-412, 1978.

69. Matt, D.W. and G.J. MacDonald. In vitro progesterone and testosterone production by the rat placenta during pregnancy. Endocrinology 115:741-747, 1984.

70. Matuszczyk, J.V., B. Silverin, and K Larsson. Influence of environmental events immediately after birth on postnatal testosterone secretion and adult sexual behavior in the male rat. Horm. Behav. 24:450-458, 1990.

71. McDonald, P.G. and C. Doughty. Inhibition of androgen-sterilization in the female rat by administration of an antioestrogen. J. Endocrinol. 55:455-456, 1972.

72. McDonald, P.G. and C. Doughty. Androgen sterilization in the neonatal female rat and its inhibition by an estrogen antagonist. Neuroendocrinology 13:182-188, 1973.

73. McEwen, B.S. Gonadal steroid influences on brain development and sexual differentiation. In: Greep, R. (Ed), Reproductive Physiology, Vol. 4. Bartimore, University Park Press, 1982.

74. McEwen, B.S., L Plapinger, C. Chaptal, J. Gerlach, and G. Wallach. Role of fetoneonatal estrogen binding proteins in the associations of estrogen with neonatal brain cell nuclear receptors. Brain Res. 96:400-406, 1975.

75. McEwen, B.W., I. Lieberburg, C. Chaptal, and L.C. Krey. Aromatization: Important for sexual differentiation of the neonatal rat brain. Horm. Behav, 9:249-263, 1977.

76. McGivem, R.F., A.N. Clancy, M.A. Hill, and E.P. Noble. Prenatal alcohol exposure alters adult expression of sexually dimorphic behavior in the rat. Science 224:896-898, 1984 .

77. McGivem, R.F., C. Holcomb, and RE. Poland. Effects of prenatal testosterone propionate treatment on saccharin preference of adult rats exposed to ethanol in utero. Physiol. Behav. 39:241-246, 1987.

78. McGivern, R.F., R.E. Poland, A.N. Taylor, B.J. Branch, and W.J. Raum. Prenatal stress feminizes adult male saccharin preference and maze leaming: Antagonism by propranolol. Monogr. Neura Sci. 12:172-178, 1986.

79. McGivem, R.F., W.J. Raum, E. Salido and E. Redei. Lack of prenatal testosterone surge in fetal rats exposed to alcohol: Alterations in testicular morphology and physiology. Alcoholism: Clin.and Exp. Res. 12:243-247, 1988.

80. McGivem, RF., C.E. Roselli, and R.J. Handa. Perinatal aromatase activity in male and female rats: Effect of prenatal alcohol exposure. Alcohol Clin. Exp. Res. 12:769-772. 1988.

81. Meisel, RL. G.P. Dohanich, and I.L. Ward. Effects of prenatal stress on avoidance acquisition. open-field performance and londotic behavior in male rats. Physiol. Behav. 22:527-530, 1979.

82. Montagu, A. Prenatal Influences. Springfield, IL, C.C. Thomas, 1962.

83. Motelica-Heino, I. M. Castanier, P. Corbier, D.A. Edwards, and J. Roffi. Testosterone levels in plasma and testes of neonatal mice. J. Steroid Biochem. 31:283-286, 1988.

84. Moyer, J.A., L.R Herrenkohl, and D.M. Jacobowitz. Effects of stress during pregnancy on catecholamines in discrete brain regions. Brain Res. 121:385-393, 1977.

85. Moyer, J.A., L.R. Herrenkohl, and D.M. Jacobowitz. Stress during pregnancy. Effect on catecholamines in discrete brain regions of offspring as adults. Brain Res. 144:173-178, 1978.

86. Myerson, B. and M. Berg. Neonatal exposure to naltrexone affects morphine sensitivity and facilitates sexual behavior in female rats. Neurosci. Lett. 72:323-327, 1985.

87. Naess, O., E. Haug, A. Attramadal, A. Aakvaag, V. Hansson, and F. French. Endocrinology 99:1295- 1976.

88. Naftolin, F., L.M. Garcia-Segura, D. Keefe, C. Leranth, N.J. MacLusky, R. Robbins, and J.R Brawer. Estrogen effects on the synaptology and neuroal membranes of the rat hypothalamic arcuate nucleus. Biol. Reprod. 1989 
Sexual Differentiation: Basic and Clinical Aspects. New York.

Raven Press, 1984, pp 97-91, 1984.

90. Naftolin F., N. MacLusky, C. Leranth, H.S. Sakamoto, and L.-M Garcia-Segura. The cellular effects of estrogen on neuroendocrine tissues. J. Steroid. Biochem.30:195-207, 1988.

91. Naftolin, F., K. Ryan, I. Davies, V. Reddy, F. Flores, Z. Petro, M. Kuhn, R White, Y. Takaoka, and L Wolin. The formation of estrogens by central neuroendocrinetissue.

Rec. Prog. Horm. Res. 31:295-319, 1975.

92. Naftolin, F, D. Keefe, R Apa, A. Palumbo, and LM. Garcia-Segura. The apparent paradox of sexual differentiation of the brain. In: Achievements in Gynecology 1989-90. Contrib. Gynecol.

Obstet. Basel, Karger, 18:24-32, 1991.

93. Nemeskéri, A, M. Kurcz, and B. Halász. Changes in hypophyseal luteinizing hormone (LH) con tent during fetal and early postnatal life, and capacity of fetal and early postnatal pituitaries to synthesize and release LH in vitro. Neuroendocrinology 38:393-396, 1984.

94. Olmos, G., P. Aguilera, P. Tranque, F. Naftolin, and L.M. Garcia-Segura. Estrogen induced synap tic modelling in adult rat brain is accompanied by the reorganization of neuronal membranes. Brain Res. 425:57-64, 1987.

95. Orth, J.M., J. Weisz, O.B. Ward, and I.L. Ward. Environmental stress alters the developmental pattem of $\Delta 5$-3b-hydroxysteroid dehydrogenase activity in Leydig cells of fetal rats: A quantitative cytochemical study. Biol. Reprod. 28:625-631, 1983.

96. Pang, S.F., A.R Caggiula, V.L. Gay, RL Goodman, and C.S.F. Pang. Serum concentrations of testosterone, oestrogens, luteinizing hormone and follicle stimulating hormone in male and female rats during the critical period of neural sexual differentiation. J. Endocr. 80:103-110, 1979.

97. Peters, D.A.V. and S. Tang. Sex-dependent biological changes following prenatal nicotine exposure in the rat. Phamacoi. Biochem. Behav. 17:1077-1082, 1982.

98. Pfeiffer, C.A. Sexual differences of the hypophyses and their determination by the gonads. Am. J. Anat. 58:195-225, 1936.

99. Phoenix. C.H. RW. Goy, A.A. Gerall, and W.C. Young. Organizing action of prenatally administered testosterone propionate on the tissues mediating mating behavior in the female guinea pig. Endocrinology 65:369-382, 1959.

100. Reisert, I. and C. Pilgrim. Sexual differentiation of monoaminergic neurons genetic or epigenetic? TINS 14:468-473, 1991.

101. Rhees, RW. and D.E. Fleming. Effects of malnutrition, matemal stress, or ACTH injections during pregnancy on sexual behavior of male offspring. Physiol. Behav. 27:879-882, 1981.

102. Rhoda, J. P. Corbier, and J. Roffi. Gonadal steroid concentrations in serum and hypothalamus of the rat at birth: Aromatization of testosterone to $17 \mathrm{~b}$ - estradiol. Endocrinology 114:1754-1760. 1984.

103. Roffi, J., F. Chami, P. Cortier, and D.A. Edwards. Testicular homones during the first few hours after birth augment the tendency of adult male rats to mount receptive females. Physiol. Behav. 39:625-628, 1987.

104. Roffi, J., P. Corbier, and B. Kerdelhué. Stimulation de la sécrétion de LH et de FSH et augmenta tion du poids testiculare È la naissance, chez le Rat. C.R Acad. Sc. Paris 284:1313-1316, Série D. 1977.

105. Salisbury, RL, S.D. Dudley, and]. Weisz. Effect of gonadotrophin-releasing hormone on circulating levels of immunoreactive luteinizing hormone in fetal rats. Neuroendocrinology 35:265-269, 1982.

106. Segarra, A.C. and F.L. Strand. Pennatal administration of nicotine alters subsequent sexual behavior and testosterone levels of male rats. Brain Res. 480:151-159, 1989.

107. Singh, H.H., V. Purohit, and B.S. Ahluwalia. Effect of methadone treatment during pregnancy on the fetal testes and hypothalamus in rats. Biol. Reprod. 22:480-485, 1980.

108. Slob, A.K. M.P. Ooms, and J.T.M. Vreeburg. Prenatal and early postnatal sex differences in plasma and gonadal testosterone and plasma luteinizing hormone in female and male rats.

J.Endocr. $87: 81-87,1980$ 

Wilkins, Baltimore, 1989.

110. Sridaran, R, R. Basuray, and G. Gibori. Source and regulation of testosteroen secretion in pregnant and pseudopregnant rats. Endocrinology 108:855-861, 1981.

111. Stahl, F., F. Götz, I. Poppe, P. Amendt, and G. Dîmer. Pre- and early postnatal testosterone levels in rat and human. In: Hormones and Brain Development. Dîmer, G. and M. Kawakami (eds), Elsevier/North-Holland Biomedical Press, 1978, pp 99-109.

112. Swaab, D.F. and M.A. Hogman. Sexual differentiation of the human hypothalamus: ontogeny of the sexual dimorphic nucleus of the preoptic area. Dev. Brain Res. 44:314-318, 1988.

113. Varma, S.K. E. Bloch. Effects of prenatal administration of mestranol and two progestins on testosterone synthesis and reproductive tract development in male rats. Acta Endocrin. Copenh. 116:193-199, 1987.

114. Vathy, I., L. Katay, and K. Nunn Mini. Sexually dimorphic effects of prenatal cocaine on adult sexual behavior and brain catecholamines in rats. Develop. Brain Res. 73:1 15-122, 1993.

115. Von Ziegler, N.I., M. Schlumpf, and W. Lichtensteiger. Prenatal nicotine exposure selectively affects perinatal forebrain aromatase activity and fetal adrenal function in male rats. Develop. Brain Res. 62:23-31, 1991.

116. Vreeburg, J.T.M., P.D.M. van der Vaart, and P. van der Schoot. Prevention of central defemization but not masculinization in male rats by inhibition neonatally of estrogen biosynthesis.

94:375-382, 1977.

117. Ward, I.L. Effects of matemal stress on the sexual behavior of male offspring. Monogr. Neural Sci. 9:169-175, 1983.

1 18. Ward, I.L. Exogenous androgen activates female behavior in noncopulating, prenatally stressed male rats. J. Comp. Physiol. Psychol. 91:465-47I, 1977.

119. Ward, I.L. Prenatal stress feminizes and demasculinizes the behavior of males. Science 175:82-84, 1972.

120. Ward, I.L. Sexual behavior differentiation: Prenatal hormonal and environmental control. In: Sex Differences in Behavior, Friedman, RC., R.M. Richart, and RL. Vande Wiele (Eds), New York, John Wiley \& Sons, 1974, pp 3-17.

121. Ward, I.L. Sexual diversity. In: Maser, J.D. and M.E.P. Seligman (Eds), Psychopathology. Experimental Models, San Francisco. W.H. Freeman and Co., 1977, pp 387-462.

122. Ward, I.L. The prenatal stress syndrome: Current status. Psychoneuroendocrinology 9:3-1 I, 1984.

123. Ward, I.L. and J. Reed. Prenatal stress and prepuberal social rearing conditions interact to determine sexual behavior in male rats. Behav. Neurosci. 99:301-309, 1985.

124. Ward, I.L. and J. Weisz. Differential effects of maternal stress on circulating levels of corticosterone, progesterone, and testosterone in male and female rat fetuses and their mothers. Endocrinology || 4:1635-1644, 1984 .

125. Ward, I.L. and J. Weisz. Matemal stress alters plasma testosterone in fetal males. Science 207:328-329, 1980

126. Ward, O.B., E.P. Monaghan, and I.L. Ward. Naltrexone blocks the effects of prenatal stress on sexual behavior differentiation in male rats. Pharmacol. Biochem. Behav. 25:573-576, 1986.

127. Ward, O.B., D.M, Kopertowski, L.P. Finnegan, D.E. Sandberg. Gender-identity variations in boys prenatally exposed to opiates. Ann. N.Y. Acad. Sciences. 562:365-366, 1989.

128. Wamen, D.W., G.C. Haldmeyer, and KB. Eik-Mers. Testosterone in the fetal rat testis. Biol. Reprod. 8:560-565, 1973.

129. Warren, D.W., I.T. Huhtaniemi, J. Tapanainen, M.L. Dufau, and K.J. Catt. Ontogeny of gonadotropin receptors in the fetal and neonatal rat testis. Endocrinology 114:470-476, 1984.

130. Watson, R.E. Ir., G.E. Hoffmann and S.J. Wiegand, Sexually dimorphicopioid distribution in the preoptic area: manipulation by gonadal steroids. Brain Res. 398:157-163, 1986.

131. Weisz, J. and I.L Ward. Plasma testosterone and progesterone titers of pregnant rats, their male and female fetuses, and neonatal offspring. Endocrinology 106:306-316, 1980.

132. Weisz, J., B.L. Brown, and I.L. Ward. Matemal stress decreases steroid aromatase activity in brains of male and female rat fetuses. Neuroendocrinology 35:374-379, 1982. 
133. Westney, L., Bruney, R; Ross, B.; Clark J.F; Rajguru. S.; Ahluwalia, B. Evidence that gonadal hormone levels in amniotic fluid are decreased in males bom to alcohol users in humans. AlcoholAlcohol. 26:403-407;1991.

134. Westphal, U. In: Pharmacological Modulation of Steroid Action, (E. Genazzani, F. Di Carol, and W.I.P. Mainwaring, eds), pp. 33-47, Raven, New York, 1980.

135. Whitney, J.B. and LR Herrenkohl. Effects of anterior hypothalamic lesions on the sexual behavior of prenatally-stressed male rats. Physiol. Behav. 19:167-169, 1977.

136. Wilke, D.L., S.R Tseu, RW. Rhees and D.E. Fleming. Effects of environmental stress or ACTH treatment during pregnancy on matemal and fetal plasma androstenedione in the rat. Horm. and Beh.16:293-303, 1982.

137. Wijkstra, S., N. Valkhof, J.M. Koolhaas, and G.A Schuiling. Endotoxin treatment of pregnant rats affets sexual behavior of the male offspring. Physiol. Behav. 49:647-649, 1991.

138. Yu, H.K., T. Cabalum, C.A.M. Jansen, J.E. Buster, and P.W.Nathanielsz. Androstenedione, testosterone, and estradiol concentrations in fetal and matemal plasma in late pregnancy in the sheep. Endocrinology | 13:2216-2220, 1983. 


\title{
III. BEHAVIORAL SEQUELAE IN YOUNG RATS OF ACUTE INTERMITTENT ANTENATAL HYPOXIA
}

\author{
Hermans, R.H.M., D.E. Hunter, R.F. McGivern, C.D. Cain and L.D. Longo. Neurotoxicology \\ and Terotology, 14:119-129, 1992.
}

\section{ABSTRACT}

Several studies have examined behavioral sequelae of acute or chronic pre- or postnatal hypoxia. However, few of these studied a large battery of behavioral functions, particularly those following relatively mild, intermittent hypoxia. Also, in few studies were the hypoxic pups cross-fostered or the experimenter blinded as to the experimental group. In addition, in almost no studies were concomitant hypoxic-induced brain biochemicals measured. The present study tested the hypothesis that mild, intermittent antenatal hypoxia can lead to long-term alterations in neurobehavioral development, as well as neurochemical changes.

\section{INTRODUCTION}

Hypoxia experienced by the fetus and/or newborn is believed to be a major cause of disturbed central nervous (CNS) system function during childhood. Numerous clinical and experimental studies have demonstrated neurological sequelae of hypoxia during the perinatal period. These include learning disabilities, motor disturbances, and behavioral alterations $(10,13,18)$. However, few studies have assessed a large battery of behavioral functions in a longitudinal manner following hypoxia. Additionally, little is known about the biochemical correlates of these behavioral changes. In addition, in few studies were the hypoxic pups cross-fostered or the examiner blinded as to experimental group.

Recently, we showed in fetal and newborn rat brain that ornithine decarboxylase (ODC) and the polyamines are markedly altered by relatively mild, acute hypoxic exposure, and thus may be useful markers for hypoxic effects on the brain (22). For instance, in response to acute hypoxia ( $10.5 \%$ inspired $\left.\mathrm{O}_{2}\right), \mathrm{ODC}$ activity in cerebral cortex, hippocampus, and cerebellum increased four- to five-fold, peaking at about $4 \mathrm{~h}$. This rise in ODC activity was accompanied by a striking increase in the concentrations of putrescine, and the polyamines spermidine and spermine. The increase in ODC activity, which was a function of inspired $\mathrm{O}_{2}$ concentration, was also associated with a significant increase in ODC mRNA, and was not a result of beta-agonist stimulation, or a result of maternal stress (22). ODC is the rate limiting enzyme in polyamine synthesis, catalyzing the formation of the diamine putrescine from ornithine. Putrescine and the polyamines 
spermine and spermidine are intimately associated with cellular growth and differentiation $(15,36)$. Critical periods of brain maturation and growth are accompanied by elevations of ODC and the polyamines. Presumably, perturbations of these maturational patterns in the developing brain may cause altered neurogenesis, synaptogenesis, and other brain dysfunctions (5). Functional outcome is apparently determined by time, duration, and severity of the hypoxic insult

We performed the following study to test the hypothesis that relatively mild, intermittent hypoxia, which resulted in increased brain biochemical changes, may have postnatal influences vis à vis learning, memory, and other sensorimotor and locomotor functions.

\section{METHODS}

Timed pregnant Sprague-Dawley rats (Charles River, Portage, MI) arrived in the laboratory on day II of gestation. From days 15 to 20 of gestation (EI5-E20), dams for behavioral studies were exposed to $4 \mathrm{~h}$ hypoxia $(0800-1200 \mathrm{~h}$ ) per day in an environmental chamber. In animals for biochemical study, the dams were exposed to hypoxia for either 4 h, 4 h/day $\times 6$, or 4 h/day $\times 5$ with biochemical analysis performed immediately thereafter or $24 \mathrm{~h}$ later. The inspired oxygen $\left(\mathrm{O}_{2}\right)$ concentration was maintained at $10.5 \%$ by infusing nitrogen gas into the chamber. $\mathrm{O}_{2}$ concentration was continuously monitored by use of an $\mathrm{O}_{2}$ analyzer (Model OM-14, Beckman instruments, Anaheim, CA). Moreover, we obtained maternal blood gas values in chronically catheterized rats. Control rats were maintained in the same room where the chamber was located (temp $23^{\circ} \mathrm{C}$, humidity $45-55 \%$, and $12 \mathrm{~h}$ light dark cycle, lights on at 0700 ). All rats were individually housed in translucent maternity cages, with free access to food and water. Nesting material was provided on day 18. Time of delivery was noted within $4 \mathrm{~h}$. Within $12 \mathrm{~h}$ after birth, 15 control $(\mathrm{C})$ and 15 hypoxic $(\mathrm{H})$ litters were cross-fostered to untreated lactating dams. Each foster dam received 4 male and 4 female pups, with each male and female pair originating from different litters. Because preweaning handling interferes with postweaning behavior, we allotted the litters to two groups for behavioral testing: one group for the preweaning studies (from $\mathrm{PI}$ to $\mathrm{P} 2 \mathrm{I}$ ) and the other for the postweaning studies (from P22 to PI 10). All testing was conducted during the light phase of the light/dark cycle, at a random sequence. During all behavioral studies the experimenter was blinded to the experimental group.

\section{Biochemical studies}

On day 20 of gestation we quantified ornithine decarboxylase activity and polyamine concentrations in fetal hippocampus, cerebrum, and cerebellum of 5 fetuses in each of 4 control and 12 hypoxic litters. Brain and body weights were recorded. ODC activity was measured by a modification of the method of Russell and Snyder (36). The polyamines putrescine, spermidine, and spermine were measured according to the method of Kabra et al (20). Protein content was determined by the method of Bradford (6). 


\section{Behavioral testing}

The test developmental battery used was based on the tests for neurobehavioral toxicity suggested by Vorhees and colleagues (49).

\section{Physical and sexual development}

In the preweaning group, we recorded the time of eye and ear opening and recorded body weights at regular intervals. In postweaning females we measured as onset of puberty the time of vaginal opening.

\section{Righting reflex}

The righting reflex is considered to be a reflection of subcortical maturation ( 4 , 39). Pups were placed on their backs, and the time measured to turn over on all 4 feet. A maximum of $60 \mathrm{sec}$ per trial was allowed. The criterion of the mature righting response was righting within $1 \mathrm{sec}$ on each of 3 consecutive trials on a given day. We measured the latency of the response daily from $\mathrm{P} 2$ to $\mathrm{PI} 4(\mathrm{n}: \mathrm{C}=6, \mathrm{H}=6)$, and the day of reaching criterion.

\section{Negative geotaxis}

This test is believed to test labyrinthine and cerebellar integration (19). Rats placed on an incline with their head pointing down the slope turn to face upward. Pups were tested for 1 min each on two inclines, $15^{\circ}(P 2-7)$ and $25^{\circ}(P 2-10)(n: C=6, H=6)$.

\section{Cliff avoidance test}

The performance of this test involves the integration of exteroceptive input (vibrissae), and locomotor output (3). Pups placed on the edge of a platform with their nose and forepaws over the edge, tend to move away by backing up or turning to the side. Avoidance was scored by reflex latency between being placed on the edge and first sign of an avoidance attempt. Studies were conducted from $P \mid$ to $P||(n: C=6, H=6)$.

\section{Wire hanging maneuver}

This maneuver tests neuromuscular and locomotor development (4). Rats suspended by their forelimbs from a horizontal rod $(2 \mathrm{~mm}$ thick, $70 \mathrm{~cm}$ long, between poles $50 \mathrm{~cm}$ high) tend to support themselves with their hindlimbs, preventing them from falling and aiding in progression along the rod. Suspension latencies (i.e., duration in sec of hanging) were recorded. All rats were tested from $P 10$ to $P 2 I$ ( $n: C=6, H=6$ ).

\section{Gait analysis test}

This test is believed to assess cerebellar integrity (29). Testing procedures and analysis were modified from Mullenix et al (3I) and Meyer et al (29). The hindpaws of each rat were smeared with Vaseline. Subsequently, the animal was allowed to walk up a runway $(80 \times 10 \mathrm{~cm})$ covered with white paper, which was inclined at an angle of $10^{\circ} \mathrm{C}$. with a darkened homing cage at the end. For motivational purposes, a white light (60 Watt) was placed at the beginning of the ramp. The experimenter prevented the ani- 
mal from back tracking during the test. Each animal was tested twice, and between each trial the paper cover was replaced. Subsequently, the record was dusted with charcoal revealing the footprint pattern. Measurements were made on 2 steps per trial. All measurements were made at the most proximal part of the second interdigital space. Six variables were measured using a distance scanner as follows: 1) distance between the successive placement of the same hindfoot, 2) distance between one hindfoot and the preceding print of the opposite hindfoot, 3) distance between one hindfoot and the succeeding print of the opposite hindfoot, 4) stride width, 5) step angle, and 6) gait symmetry (see Fig 8). As animal size differences interfere with results, the weights of the test pups were matched. Tests were conducted on P20, P36, and P80 ( $\mathrm{n}: \mathrm{C}=20, \mathrm{H}=20$ ).

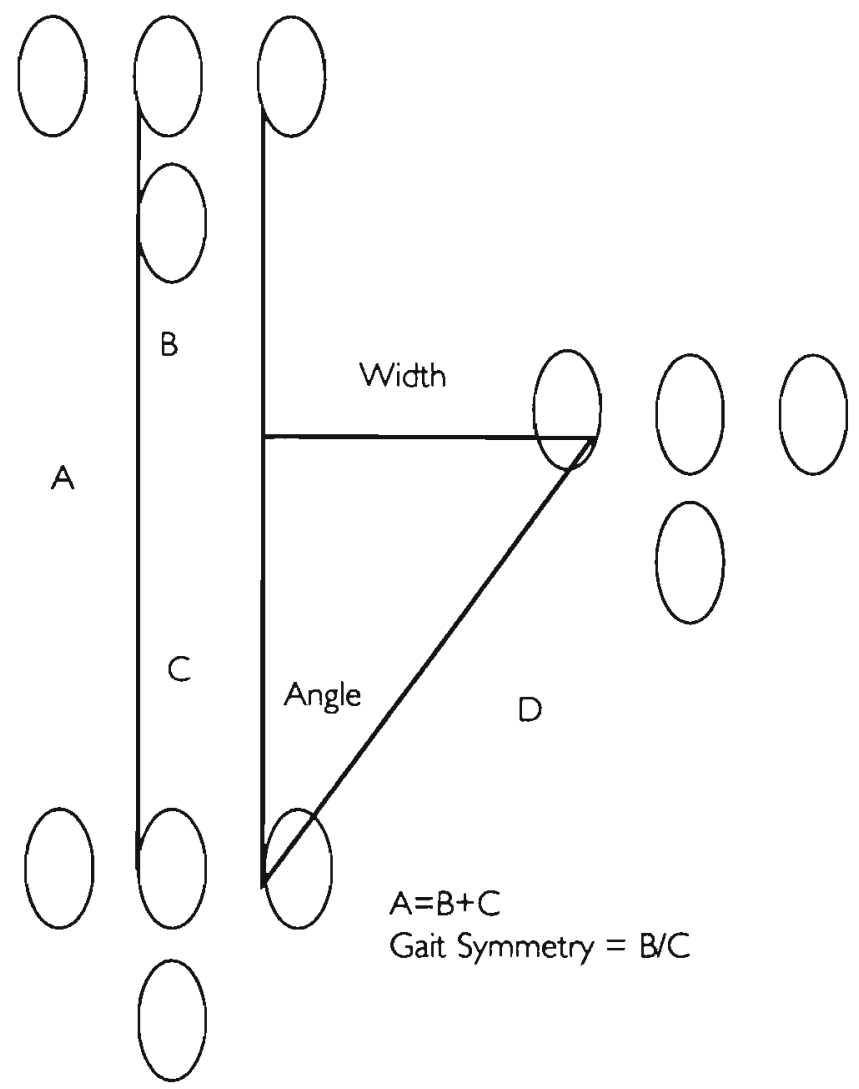

Fig 8. Schematic gait pattern of stained hindlimbs. $A=$ distance between the successive placement of the same hindfoot $D=$ distance between one hindfoot and the preceding print of the opposite hindfoot stride width, step angle, and gait symmetry. 


\section{Open-field test}

The open-field test measures the activity and habituation response of animals on placement in a novel environment. On days 19,27 or 28,43 or 44 , and 81 or 82 the animals were tested for open-field activity, according to procedures we have reported previously (27). Briefly, we used two age-dependent sized circular open fields $(90 \mathrm{~cm}$ on $P 19,27$, and 43 , and $180 \mathrm{~cm}$ on P80) enclosed by white plastic walls ( 25 and $37 \mathrm{~cm}$ high, respectively) and illuminated by red light. Each field consisted of 19 equal area segments. Adult female rats were tested during the anestrous phase of the estrous cycle. Each animal was subjected to a 6 min trial in which measures were calculated for successive 2 min intervals. Each animal was placed in the center of the open field and the following observations recorded: time to reach the field wall, the number of grids crossed, the number of rears, periods of grooming, and the number of boli excreted.

\section{Circadian activity rhythm}

Running wheel activity patterns reveal marked diurnal activity rhythms. We studied circadian activity hythm simultaneously in 24 males for 5 consecutive days, beginning at day 60 of life ( $\mathrm{n}: \mathrm{C}=12, \mathrm{H}=12)$. Running wheel activity was continuously monitored and recorded by a computer system (Mini Mitter Co, Inc., Sun River, OR). Animals were acclimatized to the apparatus for four days prior to beginning of testing.

\section{Passive avoidance}

Passive avoidance gives information about learning and memory capabilities as well as reflecting the maturation of inhibitory processes (34). On days 25 and 26 we measured passive avoidance acquisition and retention in $20 \mathrm{C}$ and $20 \mathrm{H}$ animals with equal numbers of both sexes. Experimental sessions were conducted in a one-way shutthe box consisting of two identical compartments $(22.2 \times 9.8 \times 15.6 \mathrm{~cm})$ covered by black painted plexiglass and separated by a manually operated guillotine door. The floor was made of stainless steel rods placed I cm apart. In the entrance of the darkened compartment a photocell light source and transducer were mounted. A solid state shocker (Coulborn Inst., Lehigh Valley. PA) was connected to the rods of this compartment. In the starting compartment a light was automatically activated on the rise of the guillotine door. Passive avoidance training began by placing the rat in the starting compartment, the guillotine door was raised, and the light activated. When the rat moved to the darkened compartment the door was closed, and following a $2 \mathrm{sec}$ delay, $0.6 \mathrm{~mA}$ was applied to the floor for I sec. Between each trial the rat was placed in a holding cage for I min. The acquisition trials were continued until the rat reached the criterion of two subsequent error free $(60 \mathrm{sec})$ trials. Acquisition was defined as the number of trials needed to reach criterion. A retention test was given $24 \mathrm{~h}$ later. During the first retention trial the rats were provided access to the shock compartment for $300 \mathrm{sec}$ and entrance latency was taken as retention measurement. Rats not meeting this criterion were subjected to re-acquisition trials $(60 \mathrm{sec})$ until they did so. 


\section{Morris water test}

The Morris water test has been shown to be a useful tool for the assessment of short-term memory (50). Eight rats from each treatment group were placed in a circular bath with a diameter of $180 \mathrm{~cm}$ and height of $70 \mathrm{~cm}$, half filled with opaque water at $22^{\circ} \mathrm{C}$. In this bath a small platform $\left(11 \mathrm{~cm}^{2}\right)$ was placed $2 \mathrm{~cm}$ below the water surface. The time to localize the platform was recorded for each rat up to a maximum of 120 sec. Rats failing to localize the platform within this period were removed and received a $120 \mathrm{sec}$ latency score. Each animal was given 6 trials. Tests were conducted on P29 and $\mathrm{P} \mid \mathrm{IO}$.

\section{Statistics}

Behavioral data obtained with the preweaning tests were analyzed with ANOVA using litter means. Postweaning data were analyzed with repeated measurements or single analysis of variance (ANOVA) with posthoc multiple comparison (Bonferroni). Biochemical results were analyzed with ANOVA.

\section{RESULTS}

\section{Maternal blood gas values, animal weights, and physical landmarks}

In other chronically catheterized dams $(n=7)$ which inspired $10.5 \% \mathrm{O}_{2}$, arterial $\mathrm{O}_{2}$ partial pressure averaged 37.6 1.4 Torr for hypoxic dams compared to $87.4 \pm 3.4$ Torr for normoxic controls. The corresponding $\mathrm{PCO}_{2}$ and $\mathrm{pH}$ values for the hypoxic and con-

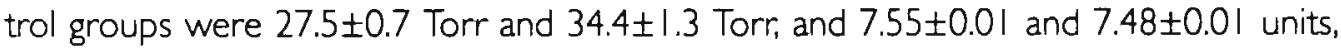
respectively. As shown in Table I, birth weights of hypoxic pups did not differ from controls, and the weights of both the control and hypoxic animals increased appropriately for their age. No differences between the groups were observed in day of eye opening, ear opening, or appearance of fur. Day of vaginal opening was similar for females in both groups.

\section{Table I. Animal weight and physical landmarks}

Test

Weight ( g )

$\begin{array}{lll}\text { birth } & 5.8 \pm 0.3 & 5.7 \pm 0.7 \\ \text { P2I } & 44.0 \pm 1.2 & 45.5 \pm 1.4 \\ \text { P90 } & 307.3 \pm 18.1 & 310.7 \pm 19.3\end{array}$

Eye opening $(d)$

$14.9 \pm 0.1$

$15.0 \pm 0.1$

Ear opening (d)

$13.9 \pm 0.1$

$14.1 \pm 0.2$

Vaginal opening (d) control

hypoxic
$38.1 \pm 0.5$ 
Table 2. ODC activity response to hypoxia

\section{Cerebrum \% Change Cerebellum \% Change Hippocampus \% Change}

$\begin{array}{lllllll}\text { control } & 0.314 \pm 0.025 & - & 0.281 \pm 0.031 & - & 0.217 \pm 0.024 & - \\ \text { 4h hypoxia } & 1.225 \pm 0.136 & 290^{* *} & 0.690 \pm 0.077 & 146 * * & 0.824 \pm 0.091 & 280 * * \\ \text { 4h hypoxia } \times 5 * & 0.370 \pm 0.041 & 18 & 0.324 \pm 0.036 & 15 & 0.303 \pm 0.034 & 40 \\ \text { 4h hypoxia } \times 6 & 1.232 \pm 0.137 & 292 * & 0.667 \pm 0.074 & 138 * * & 0.783 \pm 0.087 & 261 *\end{array}$

ODC Activity in $\mathrm{nm} / \mathrm{mg}$ protein $/ \mathrm{h}$

* ODC measurement performed $24 \mathrm{~h}$ following hypoxia

*** $p<0.05$ 


\section{Neurochemical studies}

Following $4 \mathrm{~h}$ hypoxia $\left(10.5 \% \mathrm{O}_{2}\right.$ to dam on E20) ornithine decarboxylase activity in the several fetal brain parts (cerebral cortex, hippocampus, and cerebellum) significantly increased up to $290 \%$ above control values in the hypoxic pups compared to the controls (Table 2). In addition, after repeated 4 h hypoxic exposures from EI5 to EI9 followed by $24 \mathrm{~h}$ normoxia the ODC activity was the same as control values. However, immediately after $4 \mathrm{~h}$ hypoxia was repeated on E2O (i.e., EI 5-20), the ODC activity increase was similar to that seen following a single $4 \mathrm{~h}$ exposure (Table 2). Also, following $4 \mathrm{~h}$ hypoxia the concentration of the polyamine putrescine almost doubled to $93 \pm 0.9$ $\mathrm{pm} / \mathrm{mg}$ protein from $45 \pm 3.0 \mathrm{pm} / \mathrm{mg}$ protein $(\mathrm{p}<0.05)$. By $6 \mathrm{~h}$ spermidine and spermine concentrations increased about 8 to 10 percent from the controls.

\section{Righting reflex}

The ontogeny of the righting reflex in hypoxic animals was somewhat delayed compared to controls. As shown in Fig. I, the mean latency of the righting reflex of control animals decreased from $19.7 \pm 3.6 \mathrm{sec}$ on $\mathrm{P} 2$ to $3.9 \pm 0.7 \mathrm{sec}$ on $\mathrm{P} 6$, after which it decreased further to $0.8 \pm 0.1 \mathrm{sec}$ by $\mathrm{P} / 4$. Hypoxic pups exhibited significantly longer mean latency times compared to controls on P4 (treatment, $F[1,10]=8.85, p<0.05$ ), and $P 9$ (treatment, $F[1,10]=4.7, p<0.05$ ). The day to reach righting criterion (e.g., righting in I sec on each of 3 consecutive trials) was not significantly different between the two groups.

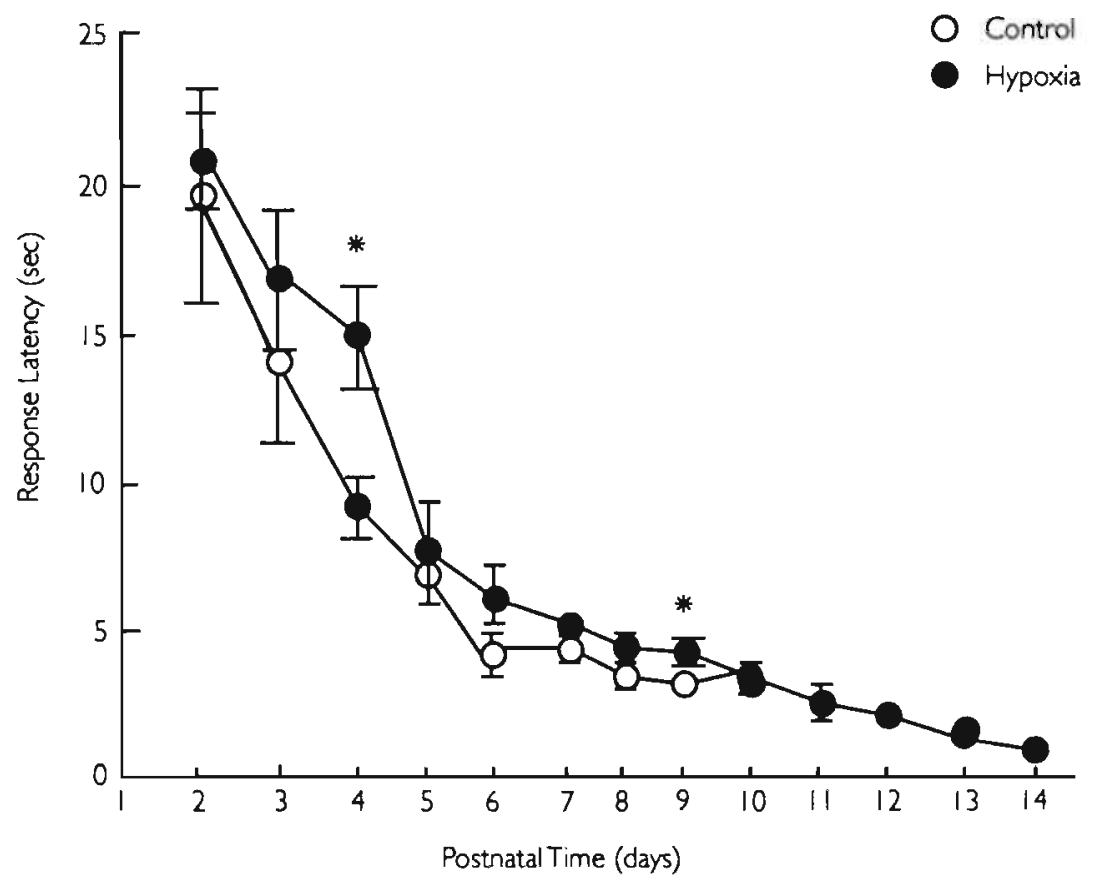

Fig 1. Development of the righting reflex from days 2 to 14 of life. Shown are mean \pm SEM response latencies in sec for control (0) and hypoxic pups ( $)$. * indicates $p<0.01$ by ANOVA. 


\section{Negative geotaxis}

Hypoxic pups reacted significantly more quickly than controls on the $25^{\circ}$ inclined planes on P3 to PIO, when analyzed with repeated measurement ANOVA (treatment $F[1,10]=4.664, p<0.05$ ) (Fig 2). No differences were observed between the treatment groups on the $15^{\circ}$ incline. With respect to the performance success rates, we observed no significant differences between the two groups on either inclined plane within the allotted $60 \mathrm{sec}$.

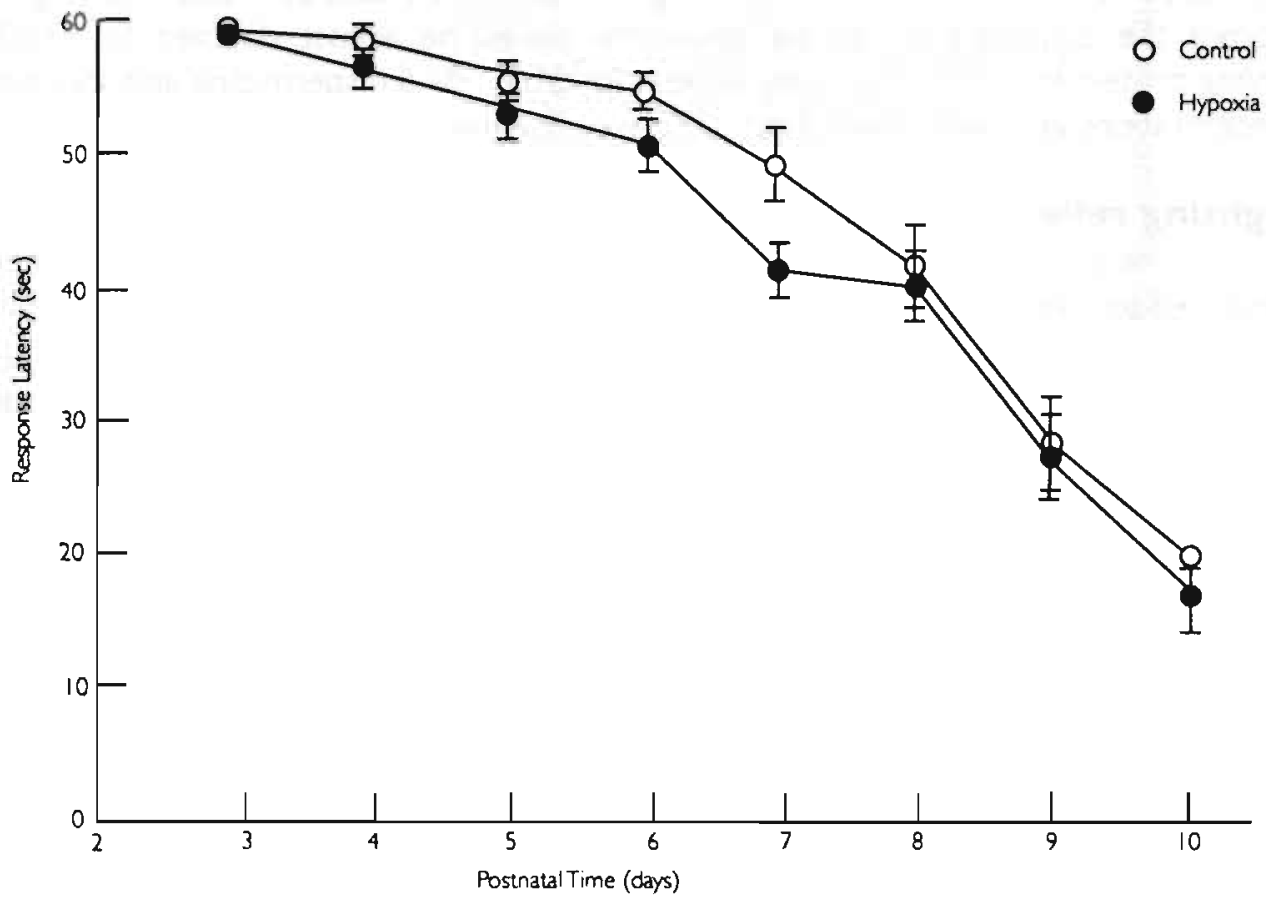

Fig 2. Development of the negative geotaxis test at $25^{\circ}$ from days 3 to 10 of life . Shown are the mean \pm SEM response latencies in sec for control (0) and hypoxic ( $(\bullet)$ pups. Significant increase latencies for hypoxic (ब) pups from P3 to PIO by ANOVA $p<0.05$.

\section{Reflex suspension}

For the wire hanging maneuver the median latency times of controls increased from $6.6 \pm 0.8 \mathrm{sec}$ at PIO to $23.8 \pm 3.5 \mathrm{sec}$ at PI6, thereafter (and following eye opening) declining to $6.0 \pm 7.3 \mathrm{sec}$ at P21. Hypoxic pups showed prolonged median latencies only on $\mathrm{P} / 8(12.9 \pm 2.6 \mathrm{sec})$ and $\mathrm{P} 20(7.3 \pm 3.2 \mathrm{sec})$. However, these differences were not significant when corrected for multiple tests.

\section{Cliff avoidance}

In the cliff avoidance reaction, mean latency for control litters decreased from $13.2 \pm 0.5 \mathrm{sec}$ at $\mathrm{P} 2$ to $4.3 \pm 0.5 \mathrm{sec}$ at $\mathrm{P} \mid \mathrm{I}$. The values for the hypoxic pups were not significantly different. Success rates for control pups increased from $20 \%$ at P2 to $95 \%$ on $P||$. Again, these values were not significantly different for the hypoxic animals. 
Table 3. Open field activity

\section{Test}

open field test crossings per $6 \mathrm{~min}$ rearings per $6 \mathrm{~min}$ groomings per $6 \mathrm{~min}$ thigmotaxis time (sec)

28

crossings per $6 \mathrm{~min}$ rearings per $6 \mathrm{~min}$ groomings per $6 \mathrm{~min}$ thigmotaxis time (sec)

crossing per $6 \mathrm{~min}$ rearings per $6 \mathrm{~min}$ groomings per $6 \mathrm{~min}$ thigmotaxis time (sec)

crossings per $6 \mathrm{~min}$ rearings per $6 \mathrm{~min}$ groomings per $6 \mathrm{~min}$ thigmotaxis time (sec)

44

80

\section{Day of life}

Overall

\section{Control}

Male

19

$95.9 \pm 7.9$
$20.9 \pm 2.4$
$3.5 \pm 0.8$
$19.5 \pm 4.5$

$\begin{array}{ll}106.4 \pm 9.2 & 85.4 \pm 12.6 \\ 24.4 \pm 2.7 & 17.4 \pm 3.8 \\ 2.0 \pm 0.3 \# \# & 5.1 \pm 1.4 \\ 14.4 \pm 2.4 & 24.6 \pm 8.5\end{array}$

$109.1 \pm 13.0$

$21.7 \pm 3.3$

$2.1 \pm 0.2 *$

$38.3 \pm 10.7$

$\begin{array}{ll}157.5 \pm 9.8 & 165.4 \pm 6.0 \\ 47.1 \pm 3.5 & 51.1 \pm 6.9 \\ 8.3 \pm 1.3 & 6.1 \pm 1.1 \\ 4.7 \pm 1.0 & 6.9 \pm 1.7\end{array}$

$152.5 \pm 7.8$
$42.8 \pm 3.9$
$7.6 \pm 0.7$
$4.6 \pm 0.6$

$147.1 \pm 13.7$ $40.4 \pm 4.5$

$8.2 \pm 0.9$

$3.5 \pm 0.7$

$157.7 \pm 15.0 * * 60.5 \pm 7.2$ $30.2 \pm 4.3 \#$

$13.3 \pm 3.7$

$1.4 \pm 0.2 \#$

$2.8 \pm 0.3$

$32.6 \pm 9.6$

$43.9 \pm 19.4$

$\begin{array}{llllll}132.1 \pm 15.1 & 80.4 \pm 15.0 \# & 184.9 \pm 9.8 & 105.1 \pm 12.7 & 78.9 \pm 14.7 \# \# & 133.8 \pm 13.3 \\ 31.3 \pm 6.4 & 11.0 \pm 3.5 & 54.1 \pm 6.9 & 16.7 \pm 3.7 & 7.8 \pm 3.3 & 24.9 \pm 4.4 \# \\ 3.2 \pm 0.7 & 2.1 \pm 0.8 & 4.4 \pm 1.2 & 3.8 \pm 0.7 & 2.6 \pm 1.0 & 4.9 \pm 0.7 \\ 4.0 \pm 0.7 & 3.3 \pm 0.9 & 5.0 \pm 1.2 & 2.4 \pm 0.4 & 2.1 \pm 0.3 & 2.6 \pm 0.6\end{array}$

* $p<0.05$ compared to controls, ** $p<0.01$ compared to controls

\# $p<0.05$ compared to controls, \#\#p $<0.01$ compared to controls

$\begin{array}{lll}151.4 \pm 9.6 & 136.9 \pm 8.2 & 165.8 \pm 16.6 \\ 24.1 \pm 2.6 & 21.4 \pm 4.0 & 26.8 \pm 3.4 \\ 1.8 \pm 0.3 & 1.3 \pm 0.3 & 2.3 \pm 0.4 \\ 7.9 \pm 1.2 & 9.2 \pm 2.1 & 6.7 \pm 1.2 \\ & \\ & \\ \text { ols, ** } p<0.01 & \text { compared to controls } \\ \text { ols, \#\#p<0.01 compared to controls }\end{array}$




\section{Open field behavior}

To examine habituation rates to the novel environment, we analyzed data in 2 min blocks using repeated measures ANOVA over the 6 min testing period. As shown in Fig. 3 and Table 3, open field locomotor activity at 19 days was significantly greater in hypoxic males, but significantly less in hypoxic females, compared to their untreated counterparts (treat $x$ sex, $F[1,44]=10.11, p<0.01$ ).

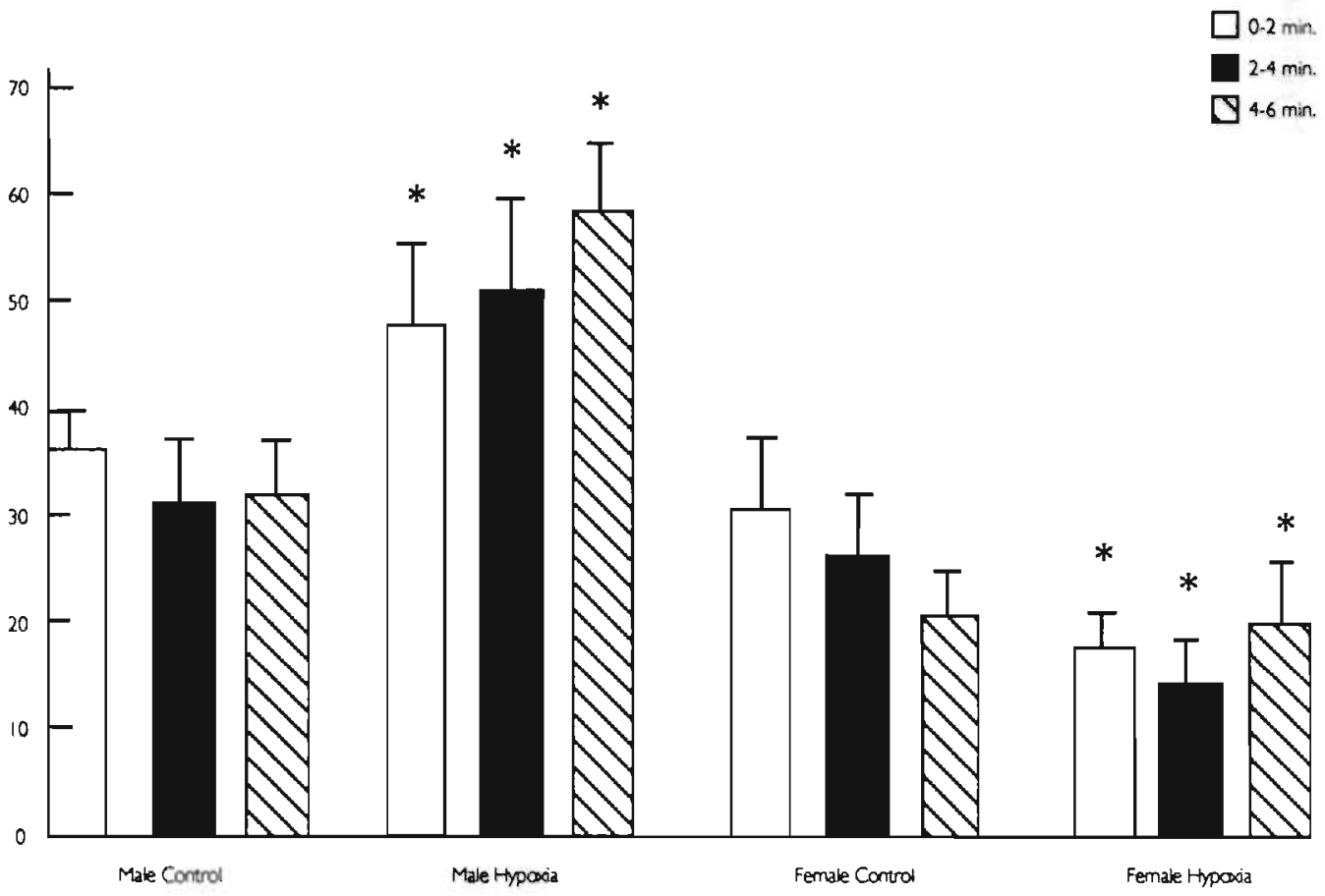

Fig 3. Open field locomotor activity at 19 days of age for males and females. Shown are the mean \pm SEM of the number of grids crossed during a given 6 min period in increments of 2 min. * indicates $p<0.05$ for treatment with linear component of orthogonal trend analysis.

A main effect for sex was also detected $(F[1,44]=24.90, p<0.0001)$. An orthogonal trend analysis revealed significant differences in the linear component for treatment $(F[1,44]=5.03, p<0.05)$, but no significant quadratic component was detected.

Rearing behavior at this age was not significantly influenced by prenatal intermittent hypoxia, although the response pattern was similar to that observed for locomotor activity (Fig. 4). Males were observed to exhibit significantly more rearing than females during the test session ( $\operatorname{sex}, F[1,44]=10.46, p<0.01$ ), as well as a greater rate of increase over the testing period (time $x$ sex, $F[2,88]=6.62, p<0.01$ ) (Table 3).

Grooming responses were significantly depressed in hypoxic animals (treatment, $F[1,44]=4.20, p<0.05)$. The analysis also yielded a significant main effect of sex $(F[1,44]$ $=9.45, p<0.01)$ as well as a time $\times$ sex interaction $(F[2,88]=5.95, p<0.01)$. No significant differences were observed for treatment or sex in either the thigmotaxic response (Table 3) or the number of boli excreted. 


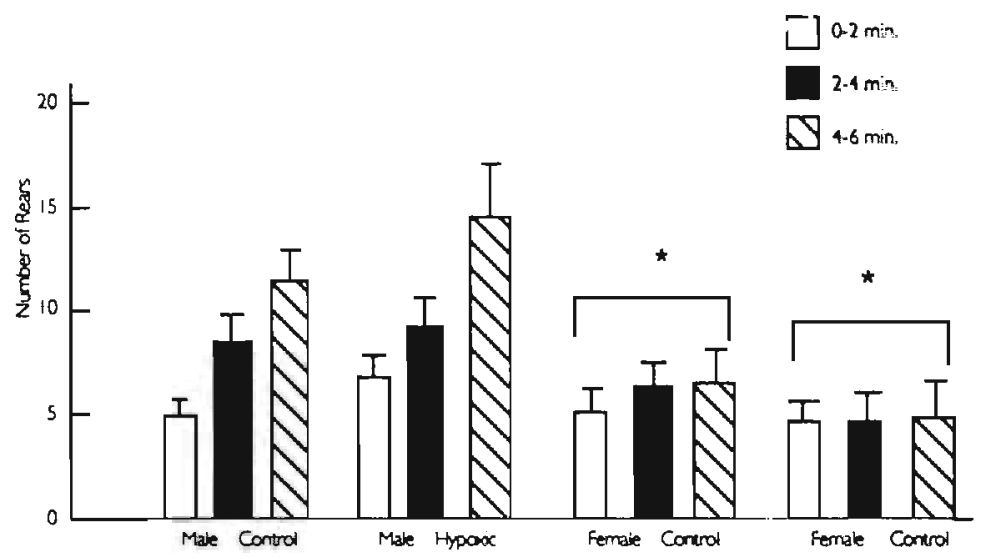

Fig 4. Open field rearing activity at 19 days of age. Shown are the mean \pm SEM of the number of rears during a given 6 min period with increments of 2 min. * indicates $p<0.01$ for sex.

At 28 days of life, the numbers of crossings, rearings, and groomings increased for both males and females, as compared with those activities at PI 9 (Table 3). However, there were no longer significant differences between either males and females, or between hypoxic and control pups in these functions.

At 44 and 80 days of life the numbers of crossings, rearings, and groomings were not significantly different between treatment groups (Table 3).

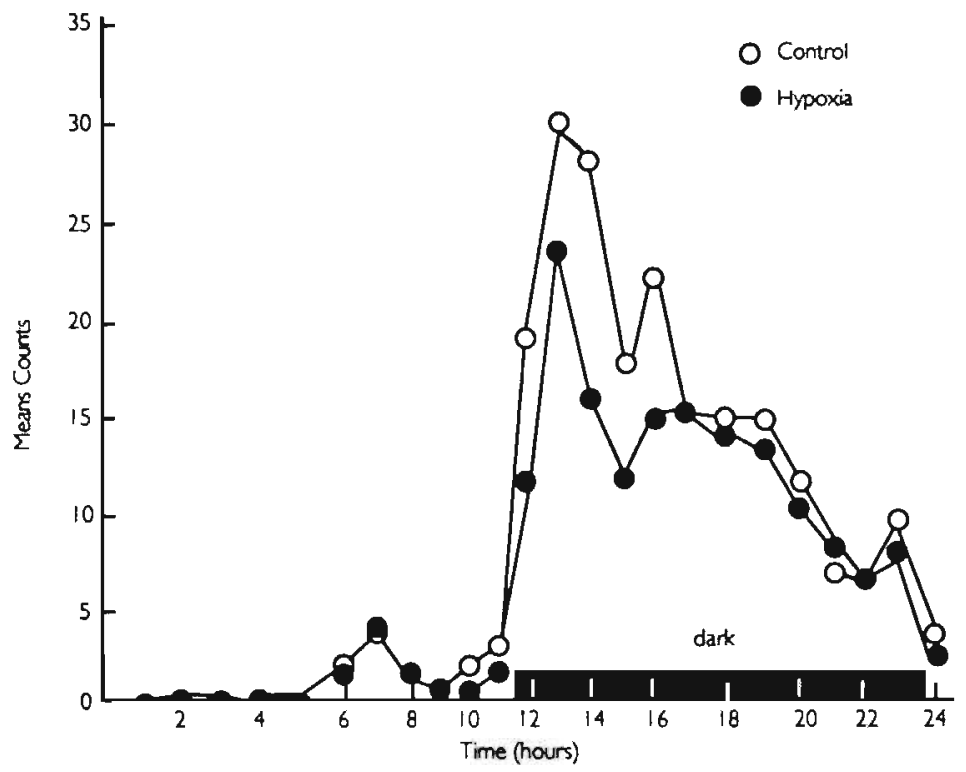

Fig 5. Circadian locomotor activity from 60 to 65 days of life. Shown are cumulated mean wheel revolutions per 60 min over 5 days of male control (0) and hypoxic ( $(\bullet)$ rats. 


\section{Circadian activity}

As shown in Fig. 5, male pup activity increased strikingly shortly after dark (1800 h), falling progressively to the end of the dark period $(0600 \mathrm{~h}$ ). Although the hypoxic pups tended to be less active at night, the differences were not statistically significant.

\section{Passive avoidance tests}

The number of trials to reach criterion for the acquisition of passive avoidance was significantly shorter for the hypoxic females $(p<0.05)$ (Fig. 6 upper panel). The hypoxic males showed a similar, but not significantly different trend. Twenty hours later the mean retention latencies showed no significant differences between the tested groups (Fig. 6, lower panel).

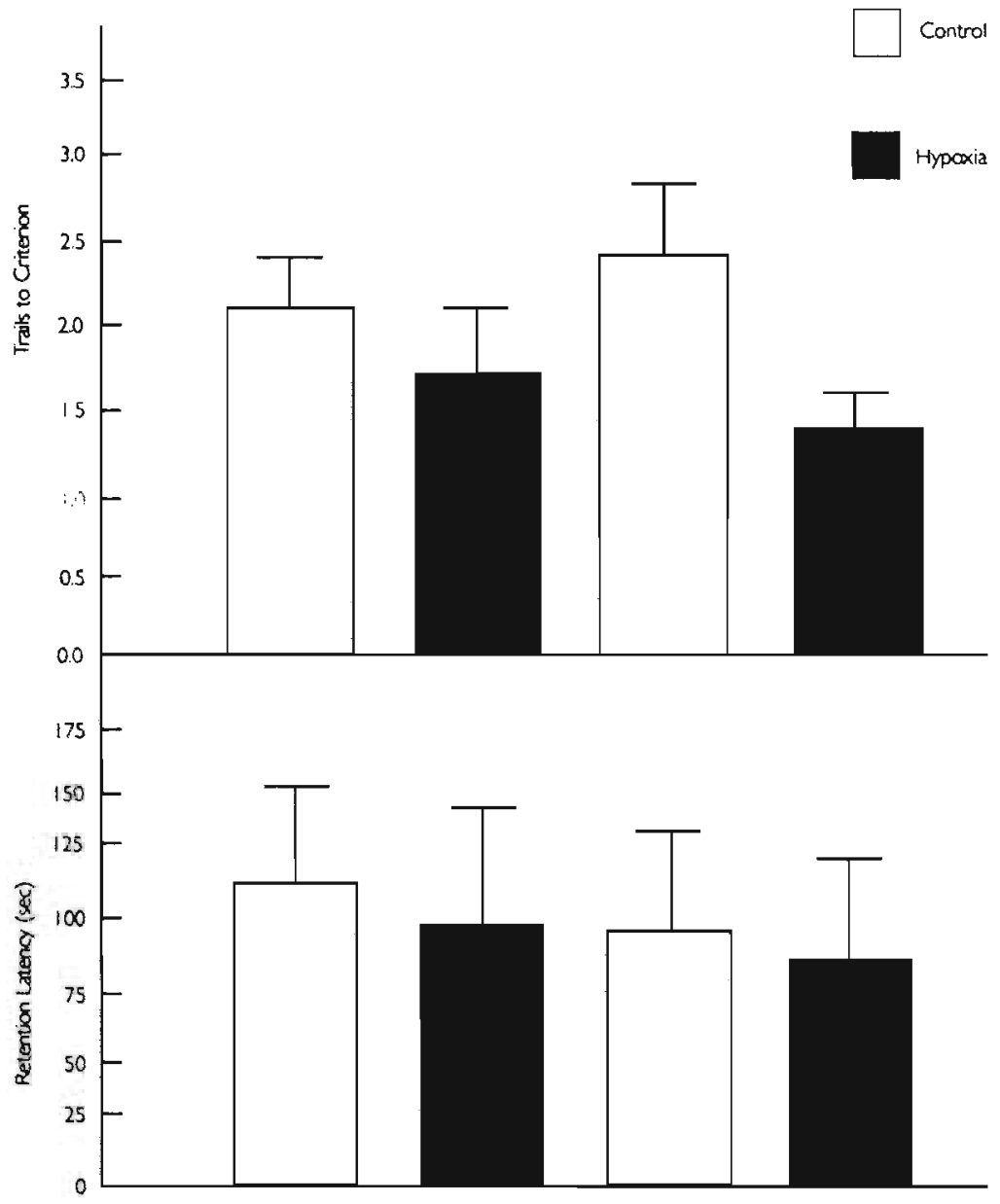

Fig 6. Passive avoidance test. Upper Panel. Acquisition of passive avoidance at 25 days for control and hypoxemic pups. Shown are mean \pm SEM number of trials to reach criterion by sex for both treatment groups. * indicates $p<0.05$ with painwise T-test. Lower Panel. Retention of possive avoidance at 26 days for both treatment groups by sex. 


\section{Morris water test}

On day 29 of life there was no significant difference between treatment and/or gender groups (Fig. 7). Data were analyzed over 6 trials using repeated measures ANOVA. On day 100 of life, mean latency times for control pups on the first trial was $138.3 \pm 57.7 \mathrm{sec}$, falling to $49.7 \pm 17.8 \mathrm{sec}$ on the second and subsequent trials. Mean latency values for hypoxic pups were not significantly different from controls.

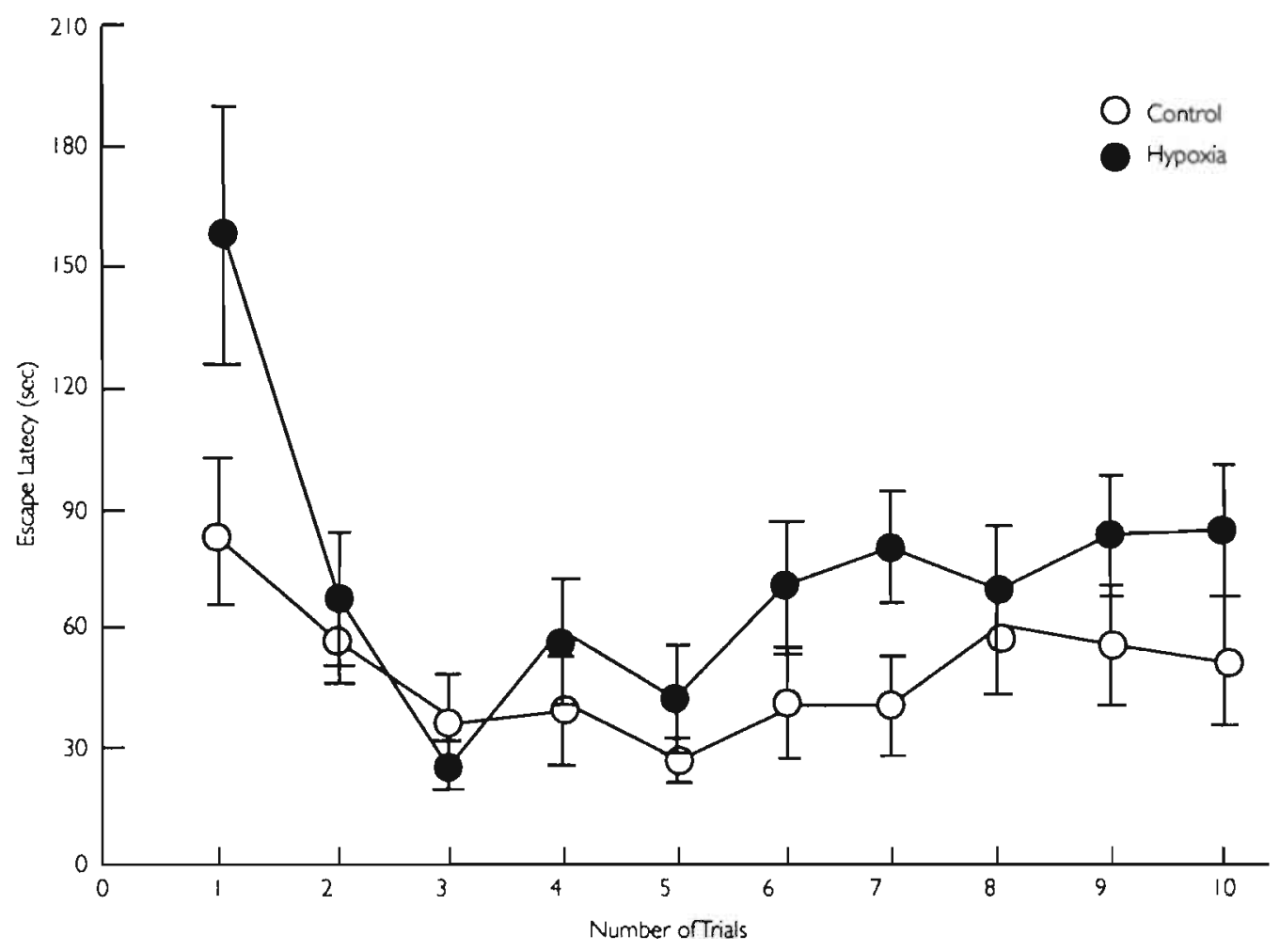

Fig 7. Morris water learning task at 29 days. Shown are the mean \pm SEM escape latencies in sec for a given trial for control (0) and hypoxic (O) rats.

\section{Gait analysis}

At all ages tested there were no significant effects of test weights on the gait analysis results. Furthermore, there were no significant treatment effects or interactions detectable on the stride length, stance width, step angle, gait symmetry, or interfeet distances (Table 4). However, analysis on days 36 and 79 revealed a significant effect of sex on body weight, $(F[1,35)=8.81, p<0.005$ and $F[1,36)=4338.8, p<0.0001)$, as males weighed more then females. 


\section{Control}

\section{Male}

Postnatal day 20

distance $A$

angle

width

gait symmetry

Postnatal day 36

distance $A$

angle

width

gait symmetry

Postnatal day 79

distance $A$

angle

width

gait symmetry

$\begin{array}{ll}9.2 \pm 0.1 & 8.9 \pm 0.2 \\ 32.1 \pm 0.8 & 32.5 \pm 0.9 \\ 3.0 \pm 0.1 & 2.8 \pm 0.1 \\ 1.0 \pm 0.01 & 1.0 \pm 0.03\end{array}$

female

male

$8.9 \pm 0.2$

$32.1 \pm 1.2$

$2.8 \pm 0.1$

$1.0 \pm 0.03$

Hypoxic

female

$8.9 \pm 0.2$

$29.4 \pm 1.3$

$2.6 \pm 0.1$

$1.0 \pm 0.05$

$13.0 \pm 0.3$

$23.4 \pm 1.4$

$2.9 \pm 0.2$

$3.3 \pm 0.1 \quad 2.9 \pm 0.2$

$1.0 \pm 0.02$

$13.5 \pm 0.2$

$25.9 \pm 1.1$

$3.4 \pm 0.1 \#$

$1.0 \pm 0.05$

* $p<0.05$ compared to females $\# p<0.01$ compared to females

$15.7 \pm 0.4$
$23.3 \pm 1.4 *$
$3.4 \pm 0.2 \#$
$1.0 \pm 0.02$

o females
females

$15.6 \pm 0.4$

$16.5 \pm 0.7$

$16.2 \pm 0.5$

$19.1 \pm 1.1$

$21.1 \pm 2.2$

$17.6 \pm 1.1$

$3.1 \pm 0.2$

$2.6 \pm 0.2$

$1.0 \pm 0.04$

$1.0 \pm 0.04$

\section{DISCUSSION}

Since Windle and Becker in 1941 first described behavioral and neurological consequences of acute asphyxia in cats, guinea pigs, and macaques $(51,52)$, several perinatal hypoxic, hypoxic/ischemic, and asphyxic models have been employed to assess subsequent function (Table 5). However, few if any of these studies employed a relatively large battery of tests over a period of several months. In addition, in few of these studies were the pups cross-fostered or the experimenter blinded. Additionally, in few studies were brain biochemical measurements made in an attempt to determine the mechanisms responsible for hypoxia-induced functional changes.

Several other studies of antenatal hypoxia have employed neurological tests similar to those used by us (Table 5). Depending upon the severity and duration of the insult, these studies demonstrated decreased performances in the early motor tests. The hypoxic exposures used in these studies were either relatively acute ( $2 \mathrm{~h}$ or less) and of 
severe degree $\left(6 \% \mathrm{O}_{2}\right.$ or less), or less severe and more prolonged. We regard the hypoxic stress used for our studies $\left(10.5 \% \mathrm{O}_{2}\right.$ for $4 \mathrm{~h}$ per day for 6 days from days 15 to 20 of gestation) as relatively mild (21). The inspired $\mathrm{O}_{2}$ concentration is equivalent to one-half atmosphere, i.e., breathing air at 5,490 m (18,000 ft). Our exposure paradigm was somewhat similar to that of Graessle (17) and Lun and colleagues (23).

Prenatal hypoxia is associated with changes in brain catecholamines and many other chemicals (44). In response to long-term hypoxia (>24h), brain ornithine decarboxylase activities significantly decreased, whereas in response to acute hypoxia ( $4 \mathrm{~h}$ ), it along with polyamine content, is markedly increased (22). This acute increase in ODC activity and polyamine concentrations may play a protective role against the acute hypoxic insult (14). Furthermore, polyamines are markers for increased cell growth and essential for various aspects of brain development. Whether the altered ODC activity and polyamine concentrations following acute hypoxia alter the normal orchestration of brain development, is not known. Nonetheless, the observed behavioral alterations were transient, disappearing by about one month of age. This probably demonstrates the plasticity of the developing nervous system.

The postnatal behavioral and reflex neurological studies showed a paradoxical response. Although the hypoxic pups had prolonged righting reflex latencies, they performed the negative geotaxis task better than did the controls. Several brain areas with different critical developmental periods are involved in both tests. The subcortex and cerebellum play a role in righting performance (35). The negative geotaxis task is dependent upon input from the cerebellum and labyrinthine system (2). In rats exposed to I 50 parts per million carbon monoxide (CO) throughout gestation, Fechter and Annau (13) noted increased latency in negative geotaxis on P2 to P6, but no alteration in righting reflex on PI. Following 1000 ppm CO for 2 to $3 \mathrm{~h}$ on $\mathrm{E} \mid 5$. Daughtry and Norton (I I) observed no alteration in righting reflex on $\mathrm{PI}-8$. Singh (42) reported increased latency in both righting and negative geotaxis following $125 \mathrm{ppm} \mathrm{CO}$, but not following $65 \mathrm{ppm} \mathrm{CO}$, on E7-I8 (Table 5). These results may point to a differential effect of hypoxia, depending upon its severity, duration, the time of the insult and related to the critical growth period of the particular brain region. Passive avoidance trials to criterion tended to be fewer in the hypoxic pups at day 25; however, thereafter there were no differences. Circadian activity in the males (only one sex tested) also tended to be lower when tested at days 60 to 65 .

Reports in the literature show no unanimous picture of postnatal open field activity after perinatal hypoxia (Table 5). For instance, following chronic intermittent prenatal hypoxia ( $13 \% \mathrm{O}_{2}$ for $2 \mathrm{~h} /$ day from E8 to term) McCullough and Blackman (26) observed no changes in open field behavior of male and female rats tested on day 55. Intermittent prenatal hypobaric decompression ( $16.8 \% \mathrm{O}_{2}$ equivalent for 2 min. 7 times/day from E2 to E20) was associated with decreased open field activity when tested on day 35 of life (I6). Following antenatal exposure (EI-E2I) of 150 ppm CO Fechter and Annau (12) reported increased open field activity in rats at several ages. On PI and P4, activity was increased following L-DOPA injection, as compared to controls. Activity was also increased on P/4 without drug challenge, however by $\mathrm{P} 2 \mathrm{l}$ activity was not different from controls (12). Male rats exposed to postnatal hypobaric 
hypoxia ( $10.5 \% \mathrm{O}_{2}$ for $10 \mathrm{~h} /$ day from $\mathrm{P} 2$ to $\mathrm{P} 10$ ) were hyperactive on PI5 and 38 , but no differences were seen on day 70 (18). After exposing 5-day-old rats to $\mathrm{CO}$ until the onset of respiratory failure, Culver and Norton (10) reported similar results, i.e., hyperactivity in the open field at P7 to PI5. They observed hypoactivity in a residential maze at $\mathrm{P} 90$.

Our results tend to agree with the results of Gramatte and Schmidt (18) and Culver and Norton (10). In the present study, activity patterns of 19-day-old hypoxic animals revealed a gender specific habituation and activity response on placement in a novel environment. Locomotor activity tended to be greater in hypoxic males and less so in the females. Rearing behavior tended to be lower in both sexes exposed to prenatal hypoxia. The development of locomotor activity in the rat is correlated with the maturation of neurotransmitter systems mediating inhibition and excitation (9). Neurotransmitter systems involved in the regulation of locomotor activity are known to develop differently in males and females. For instance, within 7 days after birth, female rats appear to have higher catecholaminergic and serotinergic neurotransmitter activity compared to the males (46). Additionally, neonatal asphyxia has shown to induce long lasting alterations in the serotonin metabolism of males, but not in the females (4I). Furthermore, several studies point at a neonatal sex difference in the resistance to an acute hypoxic challenge $(7,45)$. For example, Stupfel and colleagues (45) subjected newborn pups $(\mathrm{Pl})$ to acute $\left(100 \% \mathrm{~N}_{2}\right.$ ) or slow onset (from 20.9 to $4.5 \% \mathrm{O}_{2}$ in $2 \mathrm{~h} 18$ $\mathrm{min}$ ) hypoxia, and demonstrated with both treatments significantly higher survival rates of the female pups. Schellenberger (38) showed this dimorphism in 16-to 20-week-old rats exposed to $0.42 \%$ (4200 ppm) $\mathrm{CO}$ until the onset of respiratory arrest. Thus, hypoxia may have a sexual dimorphic effect on the maturation of locomotor activity in the rodent.

Our male hypoxic rats tested at 60 to 65 days exhibited a trend toward depressed nocturnal activity, though this difference was not significant. Culver and Norton $(10)$ obtained similar results. Furthermore, prenatal hypobaric hypoxia $\left(11.8 \% \mathrm{O}_{2}\right.$ for 10 h/day El6 to 21) did not appear to alter circadian activity at 8 weeks (23) (Table 5). Postnatal insults on $\mathrm{P} 2$ to 10 induced transient hyperactivity $(18,43)$.

The Morris water task performance was not altered in our hypoxic pups. The hippocampus plays a major role in spatial learning $(30,32)$, and is among the brain parts with particular vulnerability to hypoxia (40). By day 30 of life the hippocampus displays an adult metabolic activity pattern (28).

Our data do not indicate long-term effects of this hypoxic paradigm on hippocampal function.

Female hypoxic animals acquired the passive avoidance task significantly faster relative to the hypoxic males and controls.

Active avoidance has been reported to be increased, decreased, or unchanged following antenatal hypoxia (Table 5). For instance, avoidance activity was reported to be increased on P90-94 following 5\% $\mathrm{O}_{2}$ equivalent for $6 \mathrm{~h}$ from $\mathrm{E8}$ and $\mathrm{E2O}$ (48). In contrast, rats exposed to $150 \mathrm{ppm}$ CO from EI-2I demonstrated decreased acquisition and retention on P30-31, and P300-360, whereas acquisition was not altered on PI20 (25). Furthermore, active avoidance was not different from controls following either $16.8 \% \mathrm{O}_{2}$ 
Gait analysis showed no significant differences between treatment groups at all test ages. This test is thought to be a sensitive indicator of cerebellar function, which structure undergoes a critical growth spurt in the immediate postnatal period (53). Chronic prenatal $\mathrm{CO}$ exposure (150 ppm during the entire gestation) has been reported to interfere with the postnatal ontogeny of cerebellar norepinephrine content (44). Acute, intermittent, antenatal hypoxia in the present study induced no detectable functional expressions of cerebellar damage.

\section{CONCLUSIONS}

Overall, we observed several functional alterations following relatively mild, intermittent, antenatal hypoxia. However, with maturation these abnormal behaviors disappeared, which testifies to the neuroplasticity of the developing nervous system. These behavioral changes may have reflected the neurochemical alterations which occurred in association with hypoxia, and which may have affected brain development. Nonetheless, this remains to be established. Extrapolation of the present data obtained in rats to humans is difficult. However, it would suggest that mild, antenatal, hypoxic events may result in behavioral alterations of the developing child.

\section{SPECULATION}

Although mild, intermittent, prenatal hypoxia resulted in only minor, transient behavioral changes, more subtle alterations may have occurred. For instance, there may have been changes in the dopaminergic or noradrenergic neurotransmitter systems. Additionally, there may have been alterations in other behavioral or learning functions not examined in these studies. Currently we are investigating these possibilities. 


\section{Table 5. Behavorial effects following prenatal hypoxia}

\section{Species I Embryonic I Hypoxic Stress Test \\ Breed \\ Fetal Age}

\section{Acute Hypoxia}

rat

mixed breed

rat

SD

rat

SD mouse

CF - I

rat

SD

$6-10$

$11-15$

or

$16-20$

rat

8 or 20

15

\section{5}

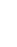

\section{Chronic Hypoxia}

rat

$8-21$

$W^{*}$

hypobaric hypoxia multiple unit $T$ wate maze

( $5.2 \% \mathrm{O}_{2}$ equivalent acquisition

for $2 h$ )

retention

hypobaric hypoxia swimming speed

( $6.2 \% \mathrm{O}_{2}$ equivalent multiple unit $\mathrm{T}$ water maze for $2 h$ ) acquisition retention single unit $T$ water maze acquisition

motor activity

until onset of

seizures $(x=8.1 \mathrm{~min})$

hypobaric hypoxia $\left(5.4 \% \mathrm{O}_{2}\right.$ equivalent for $6 \mathrm{~h}$ )

CO, 1000 ppm

for $2-3 h$ avoidance shuttle box activity

longitudial study

weigth

eye opening

righting reflex

reflex suspesion

open field activity

circadian motor activity

circadian motor activity

$13 \% \mathrm{O}_{2}$ for $2 \mathrm{~h} /$ day eye opening open field maze problem solving 


\section{Reference}

8

70

decreased

100

59

37

60

decreased

90

$60-90$

$42-44$

increased activity

47

on repeated testing

initially hyperactive with

decreased activity on repeated

testing

$90-94$

increased activity

decreased emotionality

1
7
2
30

120 and 180

increased exploratory activity

55

I day earlier

26

80

increased number of errors 
Table 5. ( Cont ' d)

Species I

breed

rat

LE*

rat

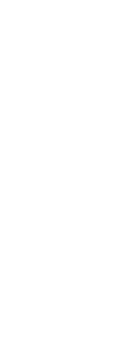

mouse

SW*

rat

LE*

rat

SD

$2-20$

$2-12$

( $16.5 \% \mathrm{O}_{2}$ equivalent

for 14 min 6 times / day)

( $16.5 \% \mathrm{O}_{2}$ equivalent

for 14 min 6 times / day)

$100 \% \mathrm{CO}$ for

$90 \mathrm{sec} /$ day

$[\mathrm{HbCO}]=6-11 \%$

CO, 150 ppm

+ cross-foster procedure

for weight

$2-20$

hypobaric hypoxia

( $16.8 \% \mathrm{O}_{2}$ equivalent

for 14 min. 7 times / day)

$2-20$

$16.8 \% \mathrm{O}_{2}$ for $110 \mathrm{~min}$

CO. 150 ppm

\section{Test}

weight

weight

open field activity

open field activity

open field activity

weight

grasping reflex

righting reflex

inclined plane task

climbing task

open field

weight

open field

weight

open field

Y - maze

weight

righting reflex

negative geotaxis

homing test

longitudinal study open field activity open field activity active avoidance

open field activity open fieldactivity active avoidance active avoidance acquisition retention 
Test Day Result

12

4-21 decreased

I, 4

14

21

24

0

$0-10$

$10-18$

$10-18$

32

16

32

16

32

42

1

$2-6$

$3-8$

35

78

83

35

78

83

30

31 increased activity following $L$ - DOPA

incrased activtity

decreased

17

decreased performance

decreased activity

decreased

decreased activity

decreased

decreased

13

increased latency

decreased latency

16

decreased activity

24 


\section{Table 5 ( Cont'd )}

\section{Species I Embryonic I Hypoxic Stress Test}

Breed Fetal Age

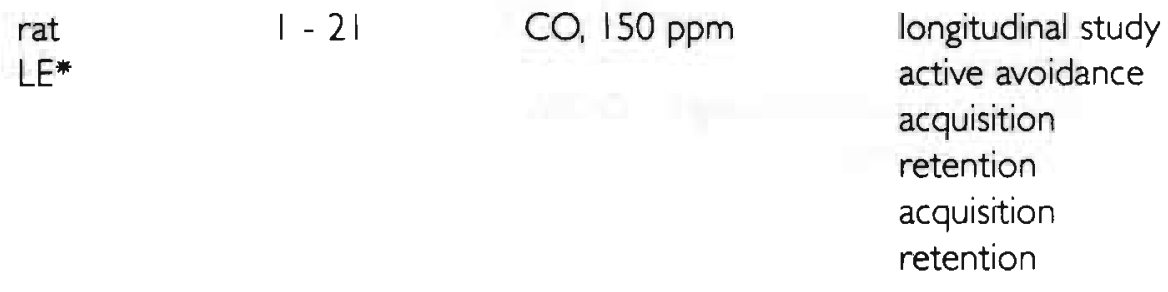

$\begin{array}{llll}\text { mouse } & 7-18 & \begin{array}{l}C 0,65 \mathrm{ppm} \\ \text { continuous }\end{array} & \text { righting reflex } \\ \mathrm{CD}-1 & & \text { negative geotaxis }\end{array}$

$\begin{array}{lll}7-18 & \mathrm{CO}, 125 \mathrm{ppm} & \text { righting reflex } \\ \text { continuous } & \text { negative geotaxis }\end{array}$

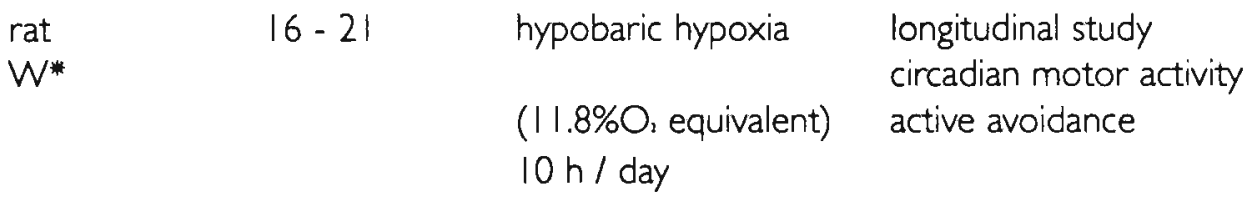

* $\mathrm{LD}=$ Long Evans, $\mathrm{SD}=$ Sprague Dawley, $\mathrm{SW}=$ Swiss Webster, and $W=$ Wistar 
25

120

$24 \mathrm{~h}$ later $300-360$ decreased

$24 \mathrm{~h}$ later decreased decreased

1

10

increased latency increased latency

56

84 


\section{REFERENCES}

1. Abbatijilo, E.R. and K Mohmann. Effects on the offspring of chronic low exposure carbon monoxide during mice pregnancy. Clin. Toxicol.14:401-406. 1979.

2. Adams, J. J. Buelcke-Sam, C.A. Kimmel, C.J. Nelson. Collaborative behavioral teratology study: protocol design and testing procedures. Neurobehav. Toxicol. Teratol. 7:579-586, 1985.

3. Altman, J. and $\mathrm{K}$ Sudarshan. Postnatal development of locomotion in the laboratory rat. Anim. Behav. 23:896-920, 1975.

4. Altman, J., K. Sudarshan, G.D. Das, N. McCormick. D.Bames. The influence of nutrition on neural development: 3. Development of some motor, particularly locomotor pattems during infancy. Develop. Psychobiol. 4:97-114, 1970.

5. Bell, J.M. and T.A. Slotkin. Coordination of cell development by the omithine decarboxylase (ODC) polyamine pathway as an undenying mechanism in developmental neurotoxic events. In: Boer, G.J.. M.G.P. Feenstra, M. Mirmiran, D.V. Swaab, F. Van Haaren., eds. Progress in Brain Research, Vol. 73. Amsterdam: Elsevier Science Publishers; 349-362, 1988.

6. Bradford, M.M. A rapid and sensitive method for the quantitation of microgram quantities of protein utilizing the principle of protein-dye binding. Anal. Biochem. 72:248-254; 1976.

7. Britton, S.W. and R.F. Kline. Age, sex, carbohydrate, adrenal cortex and other factors in anoxia. Am. J. Physiol. 145:190-202, 1945.

8. Bunch, M.E. The effects of pre- and postnatal anoxia upon leaming and memory ability at maturity. Science. $116: 517-518,1952$.

9. Campbell, B., L.D. Lytle. H.D. Fibiger. Ontogeny of adrenergic arousal and cholinergic inhibitory mechanisms in the rat. Science. 166:635-636, 1969.

10. Culver, B and S. Norton. Juvenile hyperactivity in rats after acute exposure to carbon monoxide. Exp. Neurol. 50:80-98, 1976.

11. Daughtry, W.C. and S. Norton. Caudate morphology and behavior of rats exposed to carbon monoxide in utero. Exp. Neurol. 80:265-278, 1983.

12. Fechter, L.D. and Z. Annau. Toxicity of mild prenatal carbon monoxide exposure. Science 197:680-682, 1977.

13. Fechter, L.D. and Z. Annau. Prenatal carbon monoxide exposure alters behavioral development. Neurobehav.Toxicol. 2:7-11, 1980.

14. Gilad, G.M. and V.D. Gilad. Polyamines can protect against ischemia-induced nerve cell death in gerbil forebrain. Exp Neurol. I11:349-355, 1991.

15. Goyns, M.H. The role of polyamines in animal cell physiology. J. Theor. Biol. 97:577-589, 1982.

16. Graessle, C.A. Prenatal influence of mild decompressions on hooded rats. Develop. Psychobiol. 13:399-407, 1980.

17. Graessle, C.A., K. Ahbel, S.W. Porges. Effects of mild prenatal decompressions on growth and behavior in the rat. Bull.Psychon. 4:329-331, 1978.

18. Gramatté, T. and J. Schmidt. The effect of early postnatal hypoxia on the development of locomotor activity in rats. Biomed. Biochem. 45:523-529, 1986.

19. Grozier, W.J., and G. Pincus. The geotropic conduct of young rats. J. Gen. Physiol. 10:257-269. 1926.

20. Kabra, P.M., H.K. Lee, W.P. Lubich, L.J. Marton. Solid-phase extraction and determination of danzl derivates of unconjugated and acetylated polyamines byreversed-phase liquid chromatography. Improved separation systems for polyamines in cerebro spinal fluid, urine and tissue. J. Chromatog. 380:19-32. 1986.

21. Longo, L.D. Respiratory gas exhange in the placenta. In: Fishman, A.P., L.E. Farhi, and S.M. Tenney, eds. Handbook of Physiology. Section 3: The Respiratory System, Vol. IV. Gas Exchange. Bethesda MD: American Physiological Society, 1987:351-401.

22. Longo, L.D., S. Packianathan, J.A. McQueary, C.V. Byus, C.D. Cain Acute hypoxia increases omithine decarboxylase activity and polyamine concentrationsin fetal rat brain.

Proc. Nat. Acad. Sci. 90:692-696, 1993. 

period of peninatal hypoxia with regard to dopamine release and behavior in adult rats. Biomed. Biochem 45:619-627; 1986.

24. Mactutus, CF. and L.D. Fechter. Prenatal exposure to carbon monoxide: leaming and memory deficits. Science 223:409-411; 1984.

25. Mactutus, C.F.and L.D. Fechter. Moderate prenatal carbon monoxide exposure produces persistent, and apparently permanent, memory deficits in rats. Teratology. 31:1-21; 1985.

26. McCullough, M.L.and D.E. Blackman. The behavioral effects of prenatal hypoxia in the rat. Develop. Psychobiol. 9:335-342; 1976.

27. McGivem, R.F., G. Rose, C. Berka, A.N. Clancy, C.A.Sandman, B.t. Reckwith. Neonatal exposure to a high level of ACTH4-10 impairs adult learning performance. Pharmaco. Biochom Rehav 27:133-142; 1987

28. Meibach, RC., D.A. Ross, D.C. Russelt, S.D. Glick The ontogeny of hippocampal energy metabolism. Brain Res. 204:413-435; 1981.

29. Meyer, L.S., L.E. Kotch, E.P. Riley. Alterations in gait following ethanol exposure during the brain growth spurt in rats. Alcohol. Clin. Exp.Res. 14:23-27; 1990.

30. Morris, RG.M., P. Gassud, J.N.P. Rawlins, J. O'Keefe. Place navigation impaired in rats with hippocampal lesions. Nature 297:681-683; 1982.

31. Mullenix, P., S. Norton, S. Culver. Locomotor damage in rats after X-irradiation. Exp. Neurol. 48:310-324: 1975.

32. Otton, D., J.T. Becker, G.E. Handelmann. Hippocampus,space and memory. Behavior. Brain Sci. 2:313-365; 1979.

33. Oton, D.S. Shock-motivated avoidance and the analysis of behavior. Psych. Bull. 4:243-251; 1973.

34. Riley, E.P., E.A. Lochry, N.R Shapiro. Lack of response inhibition in rats prenatally exposed to alcohol. Psychopharmacology 62:47-52; 1979.

35. Rodier, P.M. Correlations between prenatally-induced alterations in CNS cell populations and postnatal function. Teratology 16:235-246; 1976.

36. Russell, D.H. and S.H. Snyder. Amine synthesis in rapidly growing studies: omithine decarboxylase activity in regenerating rat liver, chick embryo, and various studes. Proc. Nat. Acad. Sci. USA 60:1420-1427; 1969.

37. Scheidler, C.H. The effects of prenatal anoxia on leaming in white rats. Dissertation at Washington University, St Louis, MO; 1953.

38. Schellenberger, M.K Persisting effects on adult brain monoamines of neonatal distress and carbon monoxide exposure. Neuroscience 7:667-67।: 1982.

39. Schönfelder, J. The postnatal development of rabbits air-righting reflex. Agressologie. 19:5-6; 1978.

40. Siesjö, B.K. Oxygen deficiency and brain damage: localization, evolution in time, and mechanisms of damage. Clin. Toxicol. 23:267-280; 1985

41. Simon, N., and L. Volicer. Neonatal asphyxia in the rat: greater vulnerability of males and persistent effects on brain monoamine synthesis. J. Neurochem. 26:893-900; 1976.

42. Singh, I. Early behavioral alterations in mice following prenatal carbon monoxide exposure. Neuro. Toxicol. 7:475-482; 1986.

43. Speiser, Z., S. Reicher, S. Gitter, S. Cohen. Tacrine or arecoline mediates reversal of anoxia- or AF64A-induced behavioural disorders in the developing rat.Neuropharmacol. 28: 1325-1332; 1989.

44. Storm, J.E. and L.D. Fechter. Alteration in postnatal ontogeny of cerebellar norepinephrine content following chronic prenatal carbon monoxide. J. Neurochem. 45:965-969: 1985.

45. Stupfel, M., A. Perramon, J.M. Gasc, M. Magnier, M. Duriez. Body dimorphism and sex difference of resistance to an acute hypoxic challenge in rodents and birds of different ages. Comp. Biochem. Physiol. 59:347-354; 1978.

46. Vaccari, A Sexual differentiation of monoamine neurotransmitters. In: Parvez, $\mathrm{H}$. and 5. Parvez. (eds), Biogenic Amines in Development New York Elsevier, 1980.

47. Vierck, C.J. and G.W. Meier. Effects of prenatal hypoxia upon locomotor activity of the mouse. Exp. Neurol. 7:418-425; 1963. 
48. Vierck, CI. F.A. King, V.H. Ferm. Effects of prenatal hypoxia upon activity and emotionality of the rat. Psychon. Sci. 4:87-88; 1966.

49. Vorhees, C.V., R.E. Butcher, RL Brunner, T.J. Sobotka. A developmental test battery for neurobehavioral toxicity in rats: a preliminary analysis using monosodium glutamate, calcium carrageenan, and hydoxyurea. Toxicol. Appl. Pharmacol. 50:267-282; 1979.

50. Whishaw, I.Q. Formation of a place leaming set by the rat: A new paradigm for neuro-behavioral studies. Physiol. Behav.35:139-143; 1985.

51. Windle, W.F., R.F. Becker. Role of carbon dioxide in resuscitation at birth after rasphyxia and after nembutal anesthesia. An experimental study in the cat and guinea pig. Am. J. Obstet. Gynecol. 42:852-858; 1941.

52. Windle, W.F. and R.F. Becker. Asphyxia neonatorum. An experimental study in the guinea pig. Am. J. Obstet. Gynecol. 45:183-200; 1943.

53. Yu, M.C. and W-H. Yu. Effect of hypoxia on cerebellar development: morphologic and radioautographic studies. Exp. Neurol. 70:652-664; 1980. 


\section{DECREASED POSTNATAL TESTOSTERONE AND CORTICOSTERONE CONCENTRATIONS IN RATS FOLLOWING ACUTE INTERMITTENT PRENATAL HYPOXIA WITHOUT ALTERATIONS IN ADULT MALE SEX BEHAVIOR}

Hermans, R.H.M., L.D. Longo, and R.F. McGivern. Neurotoxicology and Teratology, 16:201-206, 1994.

\section{ABSTRACT}

The prenatal and postnatal testosterone surges in the male rat are associated with neurobehavioral sexual differentiation of the brain. Both surges can be attenuated by maternal stress or other environmental factors which activate the maternal and/or fetal hypothalamic-pituitary-adrenal (HPA) axis during the last week of gestation. Since hypoxia is known to activate the HPA axis, we studied its effect during gestation on sexual differentiation in the male rat. We examined the influence of intermittent hypoxic exposure during gestation with respect to the postnatal testosterone surge and corticosterone levels, and subsequent development of adult reproductive and non-reproductive sexually dimorphic behaviors. We measured plasma testosterone and corticosterone concentrations of male neonates after maternal exposure to acute, intermittent, prenatal hypoxia ( $9 \% \mathrm{O}_{2} \mathrm{~h} /$ day from day 15 to 21 of gestation). Relative to normoxic controls, acute, intermittent, prenatal hypoxia significantly attenuated the postnatal testosterone surge. Postpartum plasma corticosterone levels in these animals were also suppressed. In adulthood, prenatally hypoxic animals exhibited normal masculine sex behavior. Lordosis behavior in response to estrogen and progesterone priming was not significantly different between treatment groups. Saccharin preference, a non-reproductive, sexually dimorphic behavior, was not significantly influenced by prenatal hypoxic exposure. These results demonstrate that in the male acute intermittent prenatal hypoxia attenuates the postnatal testosterone surge, and that such exposure failed to result in significant alterations of neurobehavioral sexual differentiation.

\section{INTRODUCTION}

In the male rat, both reproductive and nonreproductive sexually dimorphic behaviors have been demonstrated to be critically dependent on the neural organizational activity of perinatal androgen levels $(2,11)$. Masculinization of the rat brain requires elevated circulating testosterone concentrations, with aromatization of testosterone to estradiol $(17,24)$. Two perinatal testosterone surges in the male provide the primary source of estrogen for masculinization of the brain during this period. In the rat fetus, the first significant increase in circulating testosterone $(T)$ concentration occurs on days 
18 and 19 of gestation $(12,34,35)$. In several species including humans, rats, mice, and horses a second T surge occurs 2 to 12 hours after birth $(5,6,8,28)$. In human male infants, a postnatal T surge has been observed between 4 and 6 h post partum (29). These results confirmed earlier work by Forest and Cathiard (9) in male infants demonstrating elevated $T$ levels in males $5 \mathrm{~h}$ after birth, which subsequently declined.

Environmental factors such as stress (32), alcohol (14), or nicotine (25), which elevate HPA activity, have been shown to decrease the amplitude or alter the timing of these perinatal $T$ surges. Maternal restraint stress shifts the prenatal T surge to day 17 instead of day 18 of gestation (32). Both alcohol (23) and nicotine (18) attenuate the prenatal $T$ surge. In addition, the postnatal $T$ surge has been observed to be significantly smaller in magnitude in male rats prenatally exposed to alcohol (26). The behavioral consequences are consistent with the reductions in perinatal testosterone levels, as prenatal exposure to alcohol $(18,20,22)$, or stress $(31)$ demasculinizes or feminizes adult sex-related behavior in the male offspring.

In many respects, hypoxia can be viewed as a stress to the pregnant dam and fetus. Hypoxia is associated with elevated fetal levels of opioids (33), glucocorticoids (I), and monamines (4). Fetal hypoxia is not infrequently encountered during pregnancy and parturition due to a wide variety of factors including anemia, pregnancy-induced hypertension, umbilical cord occlusion, maternal smoking, heart and lung disease, and other factors (see Longo (19) for review). Lalau et al (16) have reported that high levels of dexamethasone suppress the postnatal testosterone surge, indicating a potential suppressive effect of elevated glucocorticoids on fetal T secretion. The possibility thus exists that perinatal hypoxia can alter perinatal androgen status, and therefore modify aduit male sexual activity. The present studies were designed to test the hypothesis that in male rats hypoxia during the prenatal period decreases the postnatal $T$ surge and increases corticosterone concentrations in the pup, with subsequent alteration of adult expression of sexually dimorphic behaviors.

\section{METHODS}

Sixty six Sprague Dawley rats were time mated on the same evening by the breeder (Charles River, Portage, MI) and arrived in our laboratory on day $\mid$ I of gestation. All the rats were individually housed in translucent maternity cages with free access to food and water. We allotted these dams to two treatment groups. The hypoxic $(H)$ group was subjected to $9 \% \mathrm{O}_{2}$ for $6 \mathrm{~h}$ a day (0830 to 1430) from days 15 to 21 (EI5 to $E 21$ ) of gestation. The inspired $\mathrm{O}_{2}$ concentration was maintained at $9 \%$ by infusing nitrogen gas into the chamber. $\mathrm{O}_{2}$ concentration was continuously monitored by use of an $\mathrm{O}_{2}$ analyzer (Beckman Inst. Model OM 14, Anaheim, CA). Control (C) dams were maintained in the same room with hypoxia treated dams under normoxic conditions (temp $=23^{\circ} \mathrm{C}$, humidity $=45-55 \%$, and a $12 \mathrm{~h}$ light dark cycle, lights on at 0700). The remainder of the dams served as foster dams.

We used a separate group of adult Sprague-Dawley nonpregnant female rats from the same breeder to determine arterial oxygen partial pressure under these conditions. These animals were implanted with arterial catheters placed in the carotid arte- 
ry, using a procedure we have described previously (10). Following two days of recovery. some animals $(\mathrm{N}=2)$ were placed in the hypoxic chamber and a blood sample $(0.5 \mathrm{ml})$ was taken $4 \mathrm{~h}$ later: Eight other animals served as controls and were sampled from their home cage. Blood gas values were subsequently measured using a respiratory blood gas analyzer (Radiometer, ABL2, Copenhagen, Denmark).

Nineteen additional pregnant dams were used to determine fetal oxygen levels. Dams were exposed to intermittent, acute hypoxia as described above, and subsequently sacrificed by cervical dislocation 6h following the beginning of hypoxic exposure on day 21 of gestation. Fetuses were quickly harvested and blood of two fetuses was pooled and blood gas values were measured for partial oxygen pressure $\left(\mathrm{PO}_{2}\right)$, hemoglobin $(\mathrm{Hb})$, saturation and oxygen content $\left(\mathrm{O}_{2}\right.$ cont).

\section{Postnatal testosterone surge and corticosterone concentrations}

On the morning of E2I (0800 to I200 h), we sacrificed I 4 pregnant female rats per treatment group by cervical dislocation. Pups were delivered by hysterotomy and the animals were sexed by visual assessment of anogenital distance. We then placed the male pups in cups in a covered shaking water bath (Precision Scientific, Chicago, $U$ ) to maintain the temperature at $30^{\circ} \mathrm{C}$. At $0,60,120,240,360$, and 480 min after delivery, we decapitated the pups (8-14 pups / time point / group) and collected trunk blood of each fetus in heparinized capillary tubes. At all times tubes were kept on ice. Subsequently, we centrifuged the samples and stored plasma samples at $-70^{\circ} \mathrm{C}$ until the time of assay.

\section{Testosterone radioimmunoassay}

The primary antibody was raised against testosterone-19-carboxymethylesterBSA (ICN Biomedicals, Costa Mesa, CA). After incubation of the sample with primary antibody and 20,000 cpm of [I- I25]-testosterone (ICN; cat \#07-189/26) at 40C overnight, $0.5 \mathrm{ml}$ of a $1: 9$ dilution of goat-anti-rabbit gammaglobulin (Henninger, Provo, UT) which contained $5 \%$ PEG, was added to each tube. The tubes were subsequently vortexed, and then centrifuged at $2000 \times \mathrm{g}$ for $20 \mathrm{~min}$ at $4^{\circ} \mathrm{C}$. The supernatant was aspirated and the pellet counted in a 4/600 gamma counter (Micromedic, ICN) with automatic data reduction software (RIA-AID; Robert Maciel and Assoc., Inc., Arlington, MA). Standard curves were calculated using the four parameter logistic option.

All samples displaced within the 80 to $20 \% \mathrm{~B} / \mathrm{Bo}$ and were run in one assay. The within-assay coefficients of variation for pools reading at the 80,50 and $20 \% \mathrm{~B} / \mathrm{Bo}$ were $4.8,6.5$, and $6.7 \%$, respectively. All quality control pools were within the two standard range of the $\mid C N$ published concentrations.

\section{Corticosterone radioimmunoassay}

We measured corticosterone concentrations in plasma, using [125|]-corticosterone radioimmunoassay. Specific rabbit antiserum (ICN Biomedicals), raised against corticosterone-3-carboxymethyloxime:BSA, was used. This antiserum binds $50 \%$ of corticosterone-3-carboxymethyloxime:BSA at equilibrium. Corticosterone antiserum crossreactivity is less than $0.01 \%-0.3 \%$ with deoxycorticosterone, progesterone, testosterone, 
aldosterone, and cortisol. ED50 was $156.8 \mathrm{ng} / \mathrm{ml}$, and the intra-assay coefficient of variation was $1.6 \%$.

\section{Saccharin preference}

In the rat, saccharin preference is sexually dimorphic, with females drinking significantly more of a given concentration of a saccharin solution than males when presented with the choice between a saccharin solution and plain water (37). We measured saccharin preference beginning at 70 days of age in male rats $(n=15$ per treatment group). All animals were individually housed and simultaneously tested during 10 consecutive days.

During the first 5 days of testing, we measured daily baseline water intake by presenting the animals with a $250 \mathrm{ml}$ bottle containing tap water. The last two days were used for analysis of baseline water intake. Subsequently for the next 6 days, we presented the animals with a two-bottle choice between saccharin and tap water. The bottle positions of the two fluids were alternated daily. Saccharin solutions at three concentrations $(0.125 \%, 0.25 \%$, and $0.50 \%)$ were presented successively in ascending order. Each concentration was presented for two days. Saccharin and water consumption were determined by measuring the difference in bottle weight over a $24 \mathrm{~h}$ period, and subsequently dividing both saccharin and water consumption by body weight. Body weights were measured every two days.

\section{Male sexual behavior}

Beginning at 130 days of age, we tested 15 males from each treatment group 3 times at weekly intervals for masculine sexual behavior, using procedures which we have published previously ( $2 \mathrm{I}$ ). Animals represented I- 2 animals from a litter. Tests were conducted in the presence of a receptive female for $20 \mathrm{~min}$ in a circular Plexiglass arena under red light illumination. Sexual behavioral tests were conducted between the 4th and 7 th hour of the dark cycle. After each animal was tested, the bedding was changed and testing arena cleaned with an alcohol/acetic acid solution (50\% alcohol(95\%)/water $\mathrm{v} / \mathrm{v}$, $0.1 \%$ acetic acid).

Receptivity was induced in previously ovariectomized females chronically implanted with a silastic capsule containing slow releasing estrogen ( $2 \mathrm{~mm}$ ß-estradiol-3benzoate, Sigma, St. Louis, MO). Four hours before testing, these females were injected with $500 \mathrm{mg}$ progesterone dissolved in $0.25 \mathrm{ml}$ sesame oil. Before testing female rats were scored for lordosis response, and only animals displaying adequate receptive behavior were used. The males were allowed to adapt to the mating arena for $5 \mathrm{~min}$ before the receptive female was introduced. During each test, the following behavioral parameters were recorded: 1) number of mounts, 2) number of intromissions, 3) ejaculation, 4) mount latency (time to the first mount), 5) intromission latency (time to first intromission), 6) time to first event (time to first mount or intromission), 7) ejaculation latency (time to first ejaculation after first intromission), and 8) postejaculatory interval (time after ejaculation to the first intromission of a new series). 


\section{Female sexual behavior potentials}

Female sexual behavior potentials were measured in a random selection of animals used in the male sex behavior study. Following the last test for masculine sexual behavior, we orchidectomized males of each treatment group $(N=5 \mathrm{C}$, and $N=9 H$ ) under pentobarbital anesthesia $(50 \mathrm{mg} / \mathrm{kg})$. Body and testis weights were recorded. Following a 2 week postoperative recovery, each male received $1.5 \mathrm{mg}$ B-estradiol-3benzoate sc, followed $42 \mathrm{~h}$ later with I $\mathrm{mg}$ progesterone. Beginning at 180 days of age, each experimental male was tested for feminine sexual receptivity with a stud male 4-6 $h$ following the progesterone injection. In each test session we recorded the following behaviors: I) number of times the animal was mounted, 2) lordosis, 3) ear wiggling, and 4) darting. Lordosis was scored as an all or none response, with lordosis defined as a clear raising of the head and arching of the back in response to a mount. We then calculated the lordosis quotient $(\mathrm{LQ}=$ lordosis/mounts $\times 100)$.

\section{RESULTS}

\section{Maternal and fetal weights}

Maternal weights on day 15,18 , and 21 were not significantly different between treatment groups. Moreover, at birth neonatal body weights were not significantly different between treatment groups. Data are shown inTable $\mathrm{I}$.

\section{Table I. Maternal gestational body weight and birth weight of offspring}

Maternal weight $(\mathrm{g}$ )

\section{EI5}

Control

Hypoxia
$242.5 \pm 6.3$

$234.7 \pm 3.7$
EI8

$270.0 \pm 8.1$

$266.2 \pm 3.6$
Birth weight ( $g$ )

E2I

E2I

$308.6 \pm 8.9$

$6.7 \pm 0.3$

$299.9 \pm 3.6$

\section{Maternal and fetal blood gases}

The hypoxic environment reduced maternal arterial oxygen partial pressure by approximately $65 \%$ to $31.3 \pm 1.2$ Torr, compared to $87.4 \pm 3.4$ Torr for controls $(p<0.001$ ). Fetal $\mathrm{PO}_{2}, \mathrm{O}_{2}$ saturation, and $\mathrm{O}_{2}$ content were sigificantly decreased in fetus whose mother was exposed to hypoxia ( Table 2). 
Table 2. Fetal blood gases and hemoglobin following intermittent acute hypoxia $\left(9 \% \mathrm{O}_{2}\right.$ ) from EI5 to E2I. Adult blood gases following 6 h acute hypoxia. Fetal measurements performed on E2I of gestation.

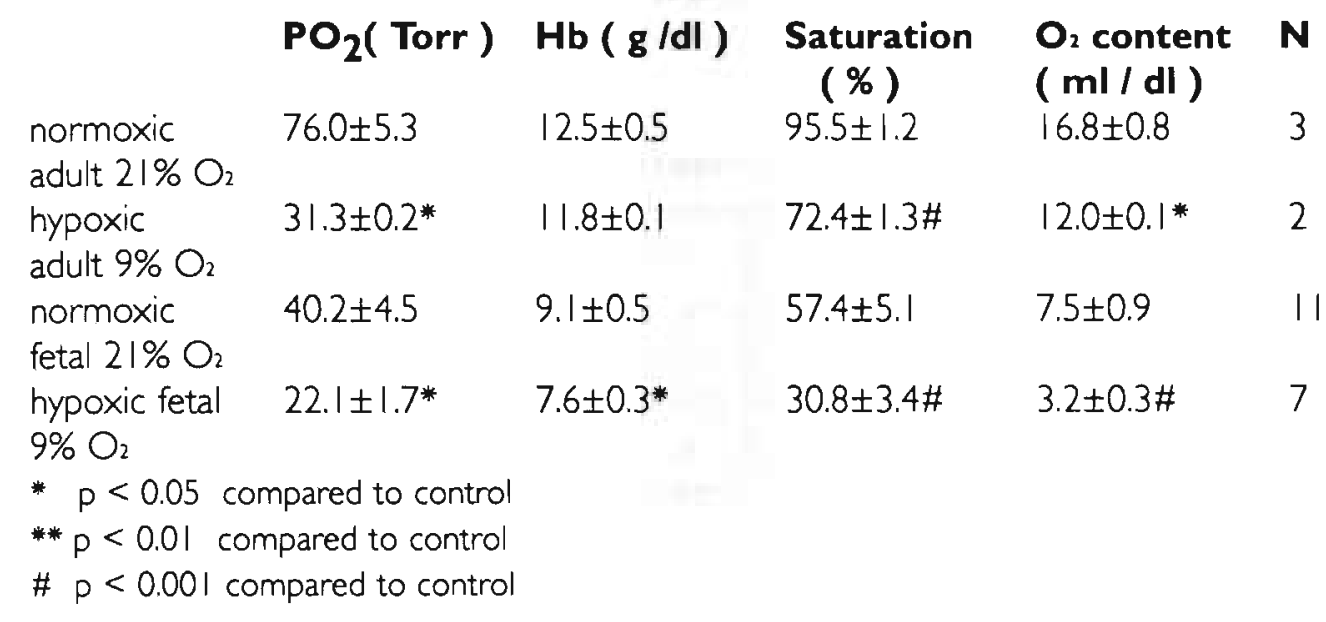

\section{Postnatal testosterone surge}

As shown in Fig. I, there was a significant reduction in the postnatal $T$ concen-

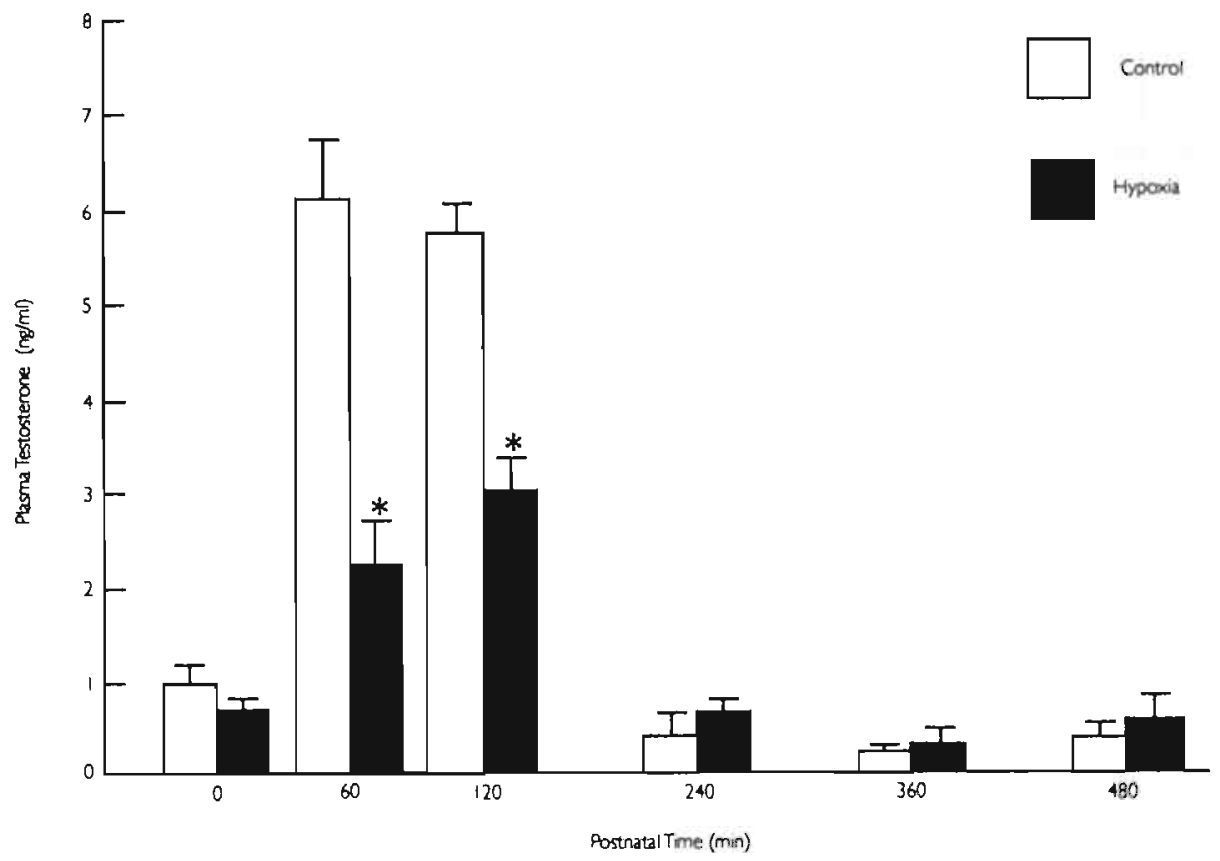

Fig 1. Plasma testosterone concentrations in male neonates from control dams and dams exposed to intermittent acute hypoxia ( $\left(9 \% \mathrm{O}_{2}, 6 \mathrm{~h} /\right.$ day from day 15 to 21 of gestation). Values are mean \pm SEM. ${ }^{*}=p<0.0001$ compared to controls. Control open bar, Hypoxic closed bor. 
trations of males exposed to intermittent hypoxia during the last week of gestation. The ANOV'A revealed a significant effect of treatment $(F[1,123]=33.47 ; p<0.0001)$, time $(F[5,123]=79.62 ; p<0.0001)$, and a treatment $x$ time interaction $(F[5,123]=16.34$; $\mathrm{p}<0.0001$ ) with respect to plasma testosterone concentrations. Immediately after birth (time 0 ), the plasma concentration of $\mathrm{T}$ in $\mathrm{C}$ and $\mathrm{H}$ pups did not differ significantly from each another. At 240,360 , and 480 min after birth, there also was no significant difference between treatment groups.

\section{Postnatal corticosterone concentrations}

Postnatal corticosterone concentrations were significantly depressed in hypoxic pups over the $480 \mathrm{~min}$ sampled (Figure 2). The ANOVA revealed a significant treatment effect $(F[1,112]=7.69 ; p<0.001)$, with overall plasma corticosterone concentrations of I $12.1 \pm 8.9 \mathrm{ng} / \mathrm{ml}$ for hypoxic animals, and $145.9 \pm 8.4 \mathrm{ng} / \mathrm{ml}$ for controls. At 60 and 120 min individual hypoxic values were significantly lower compared to controls $(p<0.05$, and $p<0.035$, respectively) The ANOVA revealed a marginal significance for time $(F[5,112]=1.97, P<0.089)$. No effect for treatment $x$ time interaction was measured.

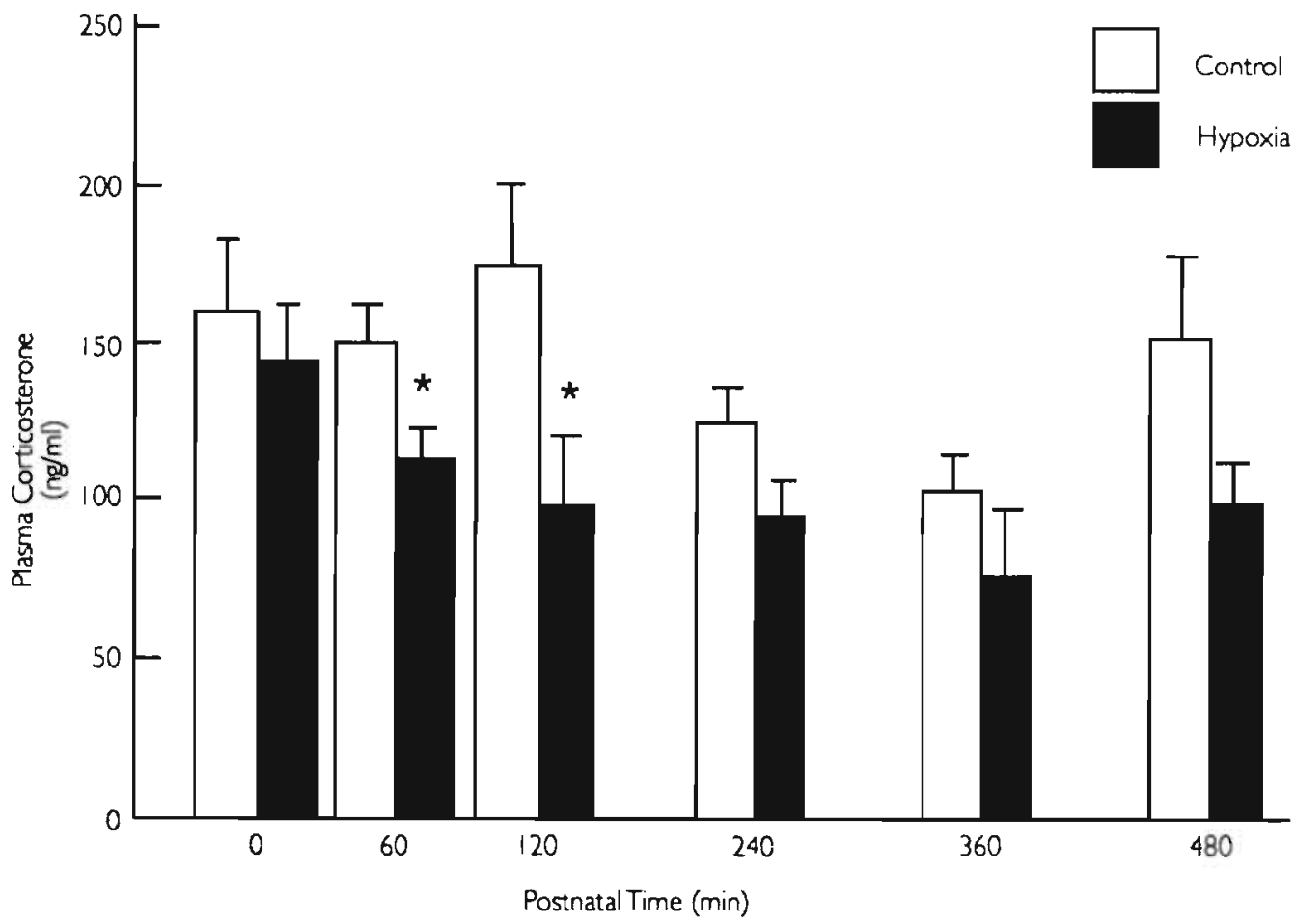

Fig 2. Plasma corticosterone concentrations in male neonates from control dams, and dams exposed to intermittent acute hypoxia. Values are mean $\pm S E M . *=p<0.05$ compared to controls at time points. Significantly lower corticosterone concentrations over the 480 min period measured $p<0.001$ by ANOVA. Symbols are the same as in Fig 1. 


\section{Saccharin intake}

Water intake over the 2 day baseline period did not differ significantly between treatment groups. Mean basal water intake averaged $13.6 \pm 0.5 \mathrm{ml} / \mathrm{g} /$ day in control males and $13.5 \pm 0.6 \mathrm{~m} / \mathrm{g} /$ day in those which were hypoxic. As shown in Fig. 3, we observed no significant differences in saccharin preference between control and hypoxic male rats.
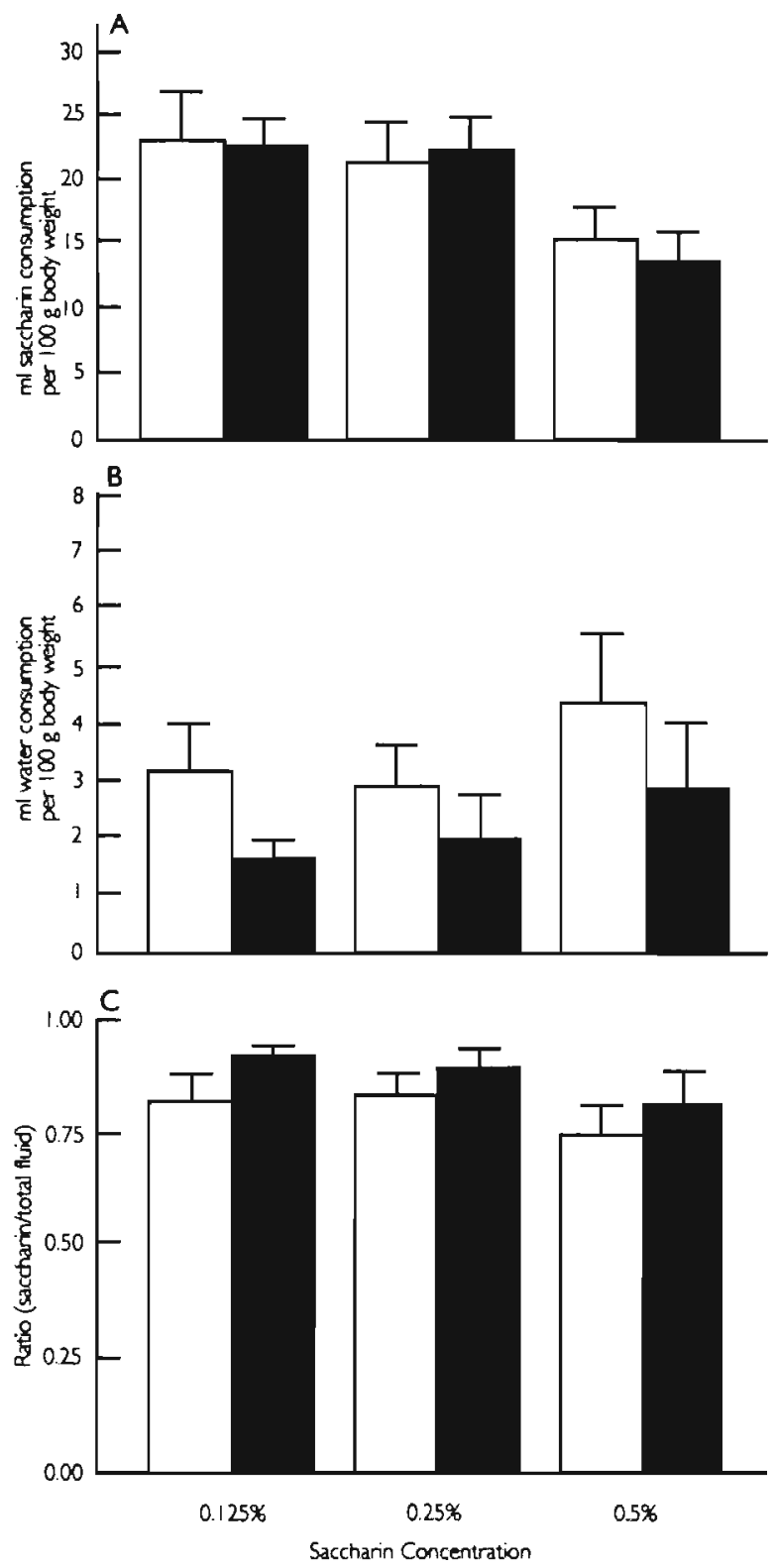

Fig 3. Saccharin $(0.125 \%, 0.25 \%$, and $0.5 \%)$ and water intake for male control and hypoxic rats. A. Consumption of saccharin solution per $100 \mathrm{~g}$ body weight per day. B. Water intake $(\mathrm{m} / \mathrm{l} / \mathrm{OOg} / \mathrm{day})$. C. Ratio of intake of saccharin solution to total fluid. Symbols are the same as in Fig 1 . 
With increasing saccharin concentrations the saccharin preference decreased equally in both groups. In addition, water intake and ratio of saccharin preference (saccharin intake / total fluid intake) were not significantly different at any concentration.

\section{Male sexual behavior}

As shown in Table 3, all indices of male sexual reproductive behavior when measured on trial 3 were not significantly altered following prenatal hypoxia.

Female Sex Behavior Potentials. The lordosis quotient for $\mathrm{H}(|4.0 \pm 1| .6)$ males was not statistically higher compared to controls $(26.1 \pm 1 \mathrm{l} .1)$. Body weights and testicular weights of animals at the time of castration were not significantly different between the groups.

\section{Table 3. Masculine male sexual behavior on third week of testing}

$\begin{array}{lllll} & \text { Control } & \text { N } & \text { Hypoxia } & \text { N } \\ \text { mounting latency } & 19.3 \pm 7.2 & 15 & 30.5 \pm 6.1 & 15 \\ \text { intromission latency } & 175.4 \pm 80.7 & 15 & 371.3 \pm 119.4 & 15 \\ \text { time to first event } & 19.3 \pm 7.1 & 15 & 25.7 \pm 5.8 & 15 \\ \text { ejaculation latency } & 918.8 \pm 84.8 & 15 & 866.4 \pm 96.8 & 15 \\ \text { number of mounts } & 11.3 \pm 1.8 & 15 & 11.0 \pm 1.6 & 15 \\ \text { number of intermissions } & 13.6 \pm 1.9 & 15 & 10.8 \pm 2.1 & 15 \\ \text { number of ejaculations } & 13.6 \pm 1.9 & 15 & 10.8 \pm 2.1 & 15 \\ \text { post ejaculatory interval } & 324.9 \pm 7.9 & 10 & 326.9 \pm 8.9 & 6\end{array}$

\section{DISCUSSION}

The present study demonstrates that exposure of pregnant dams to acute, intermittent hypoxia during the last week of gestation induces hormonal changes in the postparturition period in the male offspring. We observed a significant reduction in the postnatal testosterone surge, as well as decreased postnatal corticosterone concentrations. Control animals exposed to normoxic conditions during the last week of gestation exhibited a normal postnatal testosterone surge with plasma $T$ concentration increasing 5 to 8 fold at 60 to 120 min following parturition. In contrast, in hypoxic-exposed animals $T$ concentrations at 60 to 120 min were less than $50 \%$ of controls. We found no evidence for a delay of the T surge in hypoxic animals at later time points following delivery, compared to controls. By $4 \mathrm{~h}$ after birth, the plasma $T$ concentration dropped to values seen at $0 \mathrm{~min}$.

Numerous studies of neonatally castrated male rats have shown that complete masculinization and defeminization of adult male sexual behavior is dependent upon adequate levels of testosterone during the first few days of life (see Goy and McEwen, (I I) for review). The importance of the postnatal T surge to in this process has been demonstrated by Corbier et al. (7), who observed increased lordosis following estrogen and progesterone priming in adult males which had been castrated at the time of birth com- 
pared to intact animals. Animals castrated 6 or $12 \mathrm{~h}$ after birth were less receptive to other males than those castrated at 0 hours. Significant increases in lordosis behavior was not observed in males castrated at 0 hours and injected with testosterone propionate. Subsequently, this group demonstrated that adult males castrated at birth displayed a lower frequency of mounting behavior, but this effect was negated when castration was performed $24 \mathrm{~h}$ after birth, or when testosterone replacement therapy was given following castration at time 0 (27).

In adulthood, males exposed to prenatal hypoxia, exhibited normal masculine sexual behavior, although we observed a $50 \%$ decrease in the postnatal testosterone surge. Female sex behavior potentials in hypoxic males tended to be higher, but these differences were not found to be significant In addition, saccharin preference was not significantly altered compared to controls. Together these behavioral data indicate that the hypoxic-induced decrease in postnatal testosterone concentrations is not enough to disrupt masculinization and defeminization of the male brain.

Presently, the mechanisms by which prenatal hypoxia attenuates the postnatal surge are not known. However, it is reasonable to assume that stress related factors may be involved. Fetal cortisol (I), endorphins (33), and catecholamines (4), which are known to suppress the perinatal testosterone levels, are significantly elevated by hypoxia. Such factors could act directly on the placenta, the testis, or at higher levels of the hypothalamo-pituitary-gonadal (HPG) axis. Fetal glucocorticoid concentrations increase in response to hypoxia ( 1 ), suggesting the possibility that such elevation would continue into the immediate postparturition period and might suppress the $T$ surge. However, in the present study we observed no differences in plasma corticosterone concentrations immediately after parturition, in fact these levels were subsequently significantly reduced during the next few hours in pups exposed to prenatal hypoxia. This postnatal decrease in circulating corticosterone levels is in agreement with studies demonstrating reduced fetal and neonatal responsiveness of the HPA-axis in guinea pigs and sheep following maternal stress $(3,36)$. Moreover in humans, short-term, maternal dexamethasone has been shown to result in significantly lower neonatal ACTH levels during the first $24 \mathrm{~h}$ of life (15). It is generally assumed the decreased responsiveness reflects an increase in the negative feedback control of the HPA axis following extended exposure to stress (36). Together, these data suggest that the decreased corticosterone concentrations in these animals during the post partum period may result from exposure to hypoxic-induced elevated glucocorticoid in utero. Stylianapoulou (30) has reported that prenatal exposure to high levels of corticosteroids inhibits adult adrenal responsiveness to stress. This suggests the future studies should examine the stress responsiveness in adult: vrenatally exposed to hypoxia.

In contrast to the present findings with acute, intermittent hypoxia, we have previously shown that chronic prenatal hypoxia during this same period of gestation fails to interfere with postnatal testosterone surge. The prenatal T surge was also normal in hypoxic male fetuses in that study. Although hypoxic animals were found exhibited a significant delay in the initiation of sexual behavior accompanied by a decreased amount of ejaculations, all other aspects of male and female sex behavior potentials were found to be normal (13). 


\section{CONCLUSION}

In conclusion, it appears that, in the rat, acute, intermittent, prenatal hypoxia suppresses both the neonatal HPA and HPG axes during the first few hours after birth. However, no evidence was found to indicate that the degree of hormonal suppression following this prenatal hypoxic exposure regimen was enough to inhibit the normal development of sex behavior in the male rat. 


\section{REFERENCES}

1. Akagi, $K$ and I.R Challis. Threshold of homonal and biophysical responses to acute hypoxemia in fetal sheep at different gestational ages. Can. J. Physiol. Pharmacol. 68:549-555, 1990.

2. Beatty, W.W. Gonadal hormones and sex differences in non-reproductive behavior in rodents: Organizational and activational effects. Hormones \& Behavior 12:112-163, 1979.

3. Cadet, R, P. Pradier, M. Dalle, and P. Delost. Effects of prenatal matemal stress on the pituitary adrenocortical reactivity in guinea pigs. J. Develop. Physiol. 8:467-475, 1986.

4. Comline, R.S. J.A. Silver, and M. Silver. Factors responsible for the stimulation of the adrenal medulla duning hypoxia in the foetal lamb. J. Physiol. Lond. 178:211-238, 1965.

5. Corbier, P., L. Dehennin, M. Castanier, A. Mebazaa, D.A.Edwards, and J. Roffi. Sex differences in serum luteinizing hormone and testosterone in the human neonate during the first few hours after birth. J. Clin.Endocrin. Metabol. 71:1344-1348, 1990.

6. Corbier, P., B. Kerdelhue, R. Picon, and J. Roffi. Changes in testicular weight and serum gonadotropin and testosterone levels before, during, and after birth in the perinatal rat. Endocrinology 103:1985-1991, 1978.

7. Corbier, P., J. Roffi, and ]. Rhoda. Female sexual behavior in male rats: Effect of hour of castration at birth. Physiol. Behav. 30:613-616, 1983.

8. Corbier, P., D.A. Edwards, and J. Roffi. The neonatal testosterone surge: a comparative study. Arch. Int. Physiol. Biophys. 100:127-131, 1992.

9. Forest, M.G. and A.M. Cathiard. Pattem of plasma testosterone and androstenedione in normal newborns: Evidence for testicular activity at birth. J. Clin. Endocrinol Metab. 41:977-980, 1975.

10. Gamer, D., MeGivern, R, Jagels, G., and Laks, M.M. A new method of systolic and diastolic pressures in conscious rats using Vascular-Acess-Ports. Laboratory Animal Science 38:205-207, 1988.

11. Goy, RW. \& McEwen, B.S. Sexual Differentiation of the Brain. MIT Press, Cambridge, MA, 1980.

12. Habert, R and R. Picon. Control of testicular steroidogenesis in foetal rat: Effect of decapitation on testosterone and plasma luteinizing hormone-like activity. Acta Endocrinol. 99:466-473, 1982.

13. Hermans, R.H.M., W. Chen, RF. MCGivern, and L.D. Longo. Altered adult sexual behavior in the male rat following chronic prenatal hypoxia. Neurotoxicol. Teratol. 15:353-363, 1993.

14. Kakihana, R, J.C. Butte, and J.A. Moore. Endocrine effects of matemal alcoholization: Plasma and brain testosterone, dihydrotestosterone, estradiol, corticosterone. Alcoholism:

Clin. Exp.Res. 4:57-60, 1980

15. Kaupilla, A., S. Simila, O. Ylikorkala, M. Koivisto, and ). Haapalahthi. ACTH levels in matemal, fetal and neonatal plasma after short-term prenatal dexamethasone therapy. Br. J. Obst. Gynecol.

84: 124-128, 1976.

16. Lalau, J.D., M.L. Aubert, D.F. Carmignac, I. Gregoire, J.P. Dupouy, Reduction in testicular function in rats. II. Reduction by dexamethasone in fetal and neonatal rats. Neuroendocrinol. 51:289-293, 1990.

17. Lieberturg, I., Krey, L.C. and McEwen, B.S. Sex difference in senum testosterone and in exchangeable brain cell nuclear estradiol during the neonatal period in rats. Brain Res. 207-212, 1979.

18. Lichtensteiger, W. and M. Schlumpf. Prenatal nicotine affects fetal testosterone and sexual dimorphism of saccharin preference. Phamacol. Biochem. Behav. 23:439-444, 1985.

19. Longo, L.D. Respiratory gas exchange in the placenta. In Handbook of Physiology. Section 3: The respiratory System, Vol. IV. Gas Exchange. A.P. Fishman, L.E. Fahri, S.M. Tenney, S.R. Geiger, Editors. 35I-40I, 1987.

20. McGivem, RF.. Clancy, A.N.. Hill, M.A. \& Noble, E.P. Prenatal alcohol exposure aiters adult expression of sexually dimorphic behavior in the rat. Science 224:896-898. 1984.

21. McGivem, RF., G. Rose, C. Berka, A.N. Clancy, C.A. Sandman, and B.E.Beckwith. Neonatal exposure to a high level ACTH4-10 impairs adult leaming performance. Pharm. Biochem. Behav. 27:133-142, 1987. 
22. McGivem, RF., Holcomb, C. \& Poland, R.E. Effects of prenatal testosterone propionate treatment on saccharin preference of adult rats exposed to ethanol in utero.

Physiology \& Behavior 39:241-246, 1987.

23. McGivem, R.F., W.J. Raum, E. Salido and E. Redei. Lack of prenatal testosterone surge in fetal rats exposed to alcohol: Alterations in testicular morphology and physiology. Alcoholism: Clin. and Exp. Res. 12:243-247, 1988.

24. Naftolin, F. and MacLusky, N. Aromatization Hypothesis Revisited. In :Sexual Differentiation: Basic and Clinical Aspects., Serio, M. et al. (eds), pp. 79-91, 1984.

25. Pomerleau, O.F. Nicotine and the central nervous system: biobehavioral effects of cigarette smoking. Am. J.. Med. 93:2S-7S, 1992.

26. Redei, E. \& McGivem, RF. Attenuation of postnatal testosterone surge and decreased response to LH in fetal alcohol exposed males. Alcoholism: Clin. Exp. Res. 12:341, 1988.

27. Roff, J., F. Chami, P. Corbier, and D.A. Edwards. Testicular hormones during the first few hours after birth augment the tendency of adult male rats to mount receptive females. Physiol. Behav. 39:625-628, 1987.

28. Roffi, J., P. Corbier, and B. Kerdelhue. Stimulation de la secretion de LH et de FSH et augmentation du poids testiculare la naissance, chez le Rat. C.R Acad. Sc. Paris 284:1313-1316, Serie D, 1977.

29. Stahl, F., F. Gotz, I. Poppe, P. Amendt, and G. Domer. Pre- and early postnatal testosterone levels in rat and human. In: Homones and Brain Development. Domer, G. and M. Kawakami (eds), Elsevier/North-Holland Biomedical Press, 1978, pp 99-109.

30. Stylianapoulou, F. Prenatal exposure to high levels of corticosteroids affects adult adrenal response to stress. J. Steroid Biochem. 20: 1431, 1984.

31. Ward, I.L. Prenatal stress feminizes and demasculinizes the behavior of males. Science 175:82-84, 1972.

32. Ward, J.L., and J Weisz. Differential effects of matemal stress on circulating levels of corticosterone, progesterone, and testosterone in male and female rat fetuses and their mothers. Endocrinology, 1/4:1635-1644, 1984.

33. Wardlaw, S.L., RI. Stark, S. Daniel, and A.G. Frantz. Effects of hypoxia on beta-endorphin betalipoprotein release in fetal, newbom, and matemal sheep. Endocrinology. 108:1710-17/5, 1981.

34. Warren, D.W., G.C. Haltmeyer, and K.B. Eik-Nes. Testosterone in the fetal rat testis. Biol. Reprod. 8:560-565, 1973.

35. Weisz. J. and I.L. Ward. Plasma testosterone and progesterone titers of pregnant rats, their male and female fetuses, and neonatal offspring. Endocrinology 106:306-316, 1980.

36. Wood, C.E. and A.M. Rudolph. Can matemal stress alter fetal adrenocorticotropin secretion? Endocrinology. 115:298-301, 1984.

37. Zucker, I. Hormonal determinants of sex differences in saccharin preference, food intake and body weight. Physiol. Behav. 4:595-602, 1969. 


\title{
V. ALTERED ADULT SEXUAL BEHAVIOR IN THE MALE RAT FOLLOWING CHRONIC PRENATAL HYPOXIA
}

\author{
Hermans, R.H.M., W. Chen, R.F. McGivern, and L.D. Longo. \\ Neurotoxicology and Teratology, 15:353-363, 1993.
}

\section{ABSTRACT}

In the rat, the last week of gestation is a critical period for the sexual differentiation of the brain. Exposure to prenatal stress during this period has been shown to demasculinize and/or feminize adult male sexual behavior. Many of the neurochemical and endocrine responses to hypoxia are similar to that observed under stressful conditions such as restraint stress. Therefore, we examined the postnatal consequences on reproductive and nonreproductive sexually dimorphic behaviors in male offspring of dams exposed to chronic hypoxia during the last week of gestation. In addition, we examined sensorimotor development in offspring of both sexes. Pregnant Sprague-Dawley dams were exposed to continuous hypoxia ( $10.5 \% \mathrm{O}_{2}$ from gestational day 15 to 21 ). Offspring were weaned at 22 days of age and group housed. Behavioral tests were conducted with littermate representatives. In adulthood, male rats prenatally exposed to hypoxia had significantly delayed initiation latencies of masculine sexual behavior and decreased number of ejaculations, but did not display a significant increase in feminine sex behavior potentials. Developmentally, animals exposed to prenatal hypoxia did not differ significantly from controls with respect to day of eye or ear opening, or the in times of righting reflex, negative geotaxis or cliff avoidance. Wire hanging latencies in hypoxic exposed animals were significantly greater than control around the time of eye opening, but did not differ at earlier or later ages. A significant effect of hypoxia was detected on stride length at 95 days of age, but other aspects of gait patterns were similar to controls. No group differences in gait patterns were observed at 17 or 45 days of age. In addition, no significant differences were observed in open field activity, circadian locomotor activity, saccharin preference, or Morris water maze test. This hypoxia regimen did not influence the occurrence of the prenatal or postnatal surge of plasma testosterone. Overall, these results indicate that, in males, mild, chronic prenatal hypoxia can result in incomplete masculinization of adult reproductive behavior in the absence of overt changes in perinatal testosterone surges.

\section{INTRODUCTION}

Numerous studies have shown the fetus to be relatively resistant to hypoxia $(11,12,14,22)$. In spite of this, hypoxia during the fetal and/or newborn period is believed 
to be a major cause of central nervous dysfunction during childhood and adulthood. For example, chronic hypoxemia during development in children with cyanotic congenital heart disease is associated with impaired motor function, attention disorders, and relatively low academic achievement (37).

We have recently reported that acute, intermittent prenatal hypoxia in rats is associated with transient postnatal behavioral alterations (19). Specifically, acute intermittent hypoxia for 4 hours a day during the last week of gestation was associated with mild transient alterations in locomotor and sensorimotor development

In the present study, we tested the hypotheses that continuous, mild hypoxia from gestational days 15 to 20 (EI5-20) would have a more profound effect on cognitive, sensorimotor, and locomotor behavioral functions than intermittent hypoxia. Both short- and long-term behavioral alterations have been observed following either severe acute or less severe chronic antenatal hypoxia, many of which are dependent upon which type of prenatal hypoxic exposure is employed (see 19 for review).

In the rat, the last week of gestation is a critical period for the sexual differentiation of the brain (16). Complete masculinization of the rat brain requires elevated circulating testosterone concentrations, with intracellular aromatization of testosterone to estradiol $(24,36)$. Two perinatal testosterone surges provide the primary estrogen source for masculinization of the male brain during this period. In the rat fetus, a significant increase in circulating testosterone concentration [T] occurs on days 18 and 19 of gestation $(52,18,53,29)$. In the rat, as well as in humans, a second T surge occurs 2 to 4 hours after birth $(8,9)$. Environmental manipulations which interfere with testosterone secretion during this period, such as maternal restraint stress (49). exposure to alcohol $(26,27)$, cocaine (40), or nicotine (23) result in male offspring which exhibit incomplete masculinization of male behavioral patterns.

In many respects, hypoxia can be viewed as a stress to the pregnant dam and fetus. Hypoxic exposure results in elevated fetal levels of opioids (5I), glucocorticoids (2), and monamines (7). Therefore, the possibility exists that with chronic prenatal hypoxia exposure, incomplete masculinization with or without feminization will result in male offspring.

The present studies were undertaken to explore this possibility, as well as to compare such results with those which we recently obtained in males exposed to an acute intermittent hypoxic regimen during the last week of gestation. Since non-reproductive, sexually dimorphic behavior patterns such as locomotor activity in an open field, saccharin preference and maze learning are also dependent upon perinatal androgen status (see 6 for review), non-reproductive behaviors were studied in addition to reproductive behaviors. In separate studies, we measured the influence of this hypoxic regimen on the prenatal and postnatal surges of testosterone.

\section{METHODS}

Time pregnant, multiparous Sprague-Dawley rats (Charles River, Portage, MI) arrived in the laboratory on day 1 I of gestation. From days 15 to 20 of gestation (EI5E20), we exposed dams whose pups were to be used in the locomotor, sensorimotor. 
and cognitive test battery, to hypoxia $(H)$ for $24 \mathrm{~h}$ per day in an environmental chamber. Dams whose pups were to be used in sexual behavior and testosterone experiments were exposed from day 15 to 21 of gestation. The inspired oxygen $\left(\mathrm{O}_{2}\right)$ concentration was maintained at $10.5 \%$ by infusing nitrogen gas into the chamber. $\mathrm{O}_{2}$ concentration was continuously monitored by use of an $\mathrm{O}_{2}$ analyzer (Model OM-14, Beckman Instruments, Anaheim, CA).

We used a separate group of adult non-pregnant female rats to determine arterial oxygen partial pressure under these hypoxic conditions. These animals were implanted with arterial catheters placed in the carotid artery using procedures we have described previously (13). Following two days of recovery, some animals $(\mathrm{N}=7)$ were placed in the hypoxic chamber and a blood sample $(0.5 \mathrm{ml})$ was taken $4 \mathrm{~h}$ later. Eleven other animals served as controls and were sampled from their home cage. Blood gas values were subsequently measured using a respiratory blood gas analyzer (Radiometer, $A B L 2$, Copenhagen, Denmark) (9).

Eighteen additional pregnant rats were used to determine fetal oxygen levels. Dams were exposed to chronic hypoxia as described above, and subsequently sacrificed by cervical dislocation on day 21 of gestation. Fetuses were quickly harvested and blood of two fetuses was pooled and blood gas values were measured.

Control $(\mathrm{C})$ dams $(\mathrm{N}=22)$ were maintained in the same room where the chamber was located (Temp $=23^{\circ} \mathrm{C}$. Humidity $=45-55 \%$, and $12 \mathrm{~h}$ light-dark cycle, lights on at 0700). All rats were individually housed in translucent maternity cages, with free access to food and water. Nesting material was provided on day 18. Dams were weighed on days 15 and 21 of gestation.

We noted time of parturition to within $4 \mathrm{~h}$. Within $12 \mathrm{~h}$ after birth, we crossfostered hypoxic litters to untreated lactating dams, and fostered litters from control dams to other controls. Each foster dam received 4 male and 4 female pups. Ano-genital distance was measured at birth in males only. The distance was measured from the base of the phallus to the center of the anus using micrometer calipers.

Littermates were assigned to two groups for behavioral testing: one group for the preweaning studies (postnatal $(P)$ days; $P \mid$ to $P 2 I, N=6$ in both treatment groups), and the second for the postweaning studies ( $P 22$ to $P I 70, N=13$ in both treatment groups). With the exception of sexual behavior, all testing was conducted during the light phase of the light/dark cycle between $1000 \mathrm{~h}$ and $1400 \mathrm{~h}$. Animals tested for sex behavior were placed on a reverse day/night cycle on day P28 for the duration of the experiment. During all behavioral studies, the experimenter was blind as to the experimental group.

For measurements of sensorimotor development, the same animals were used at all time points ( $N=6$ litters per treatment group). The sensorimotor test battery used was based on that developed by Voorhees and co-workers (48). Animals used in the open field and Morris water tests were experimentally naive. Rats studied for sexual behavior were previously tested for saccharin preference.

Physical and sexual development. In the preweaning group, we recorded the time of eye and ear opening and recorded body weights at regular intervals. 


\section{PREWEANING STUDIES}

\section{Righting reflex}

The righting reflex is considered to be a reflection of subcortical maturation ( 3 , 43). For this test, we placed pups on their backs, and measured the time to turn over on all four feet. A maximum of $60 \mathrm{sec}$ per trial was allowed. The criterion of the mature righting response was righting within I sec, on each of 3 consecutive trials on a given day. We measured the latency of the response daily from $\mathrm{P} 3$ to Pl4 in all pups of both sexes from $6 \mathrm{H}$ and $6 \mathrm{C}$ dams. Data from both sexes in a litter were pooled to derive a litter mean. These pups were used in the additional developmental tests described below.

\section{Negative geotaxis}

This test is believed to test labyrinthine and cerebellar integration (17). We placed pups on an incline with their head pointing down the slope and measured the latency for the pup to turn and face up the incline. Pups were tested daily for $I$ min each on two inclines, $15^{\circ}$ (P2-P7) and $25^{\circ}$ (P2-P|0).

\section{Cliff avoidance}

The performance of the cliff avoidance test involves the integration of exteroceptive input (vibrissae) and locomotor output (3). Pups placed on the edge of a platform with their nose and forepaws over the edge, tend to move away by backing up or turning to the side (3). Avoidance was scored by reflex latency from the time of being placed on the edge and the first sign of an avoidance attempt. Latency was measured daily from $\mathrm{P} 2$ to $\mathrm{P} 1 \mathrm{l}$.

\section{Wire hanging maneuver}

This is a test of neuromuscular and locomotor development (4). Pups were suspended with their forelimbs from a horizontal rod $(2 \mathrm{~mm}$ thick, $70 \mathrm{~cm}$ long, between poles $50 \mathrm{~cm}$ high). Suspension latencies (i.e., duration in sec of hanging) were recorded. Animals were tested from PIO to P2I.

\section{POSTWEANING STUDIES}

\section{Gait analysis}

This is a test of cerebellar integrity ( 31$)$. Testing procedures and analysis were modified from Mullenix (35) and Meyer (31). The hindpaws of each rat were smeared with Vaseline. Subsequently, the animal was allowed to walk up a runway $(80 \times 10 \mathrm{~cm})$ covered with white paper, which was inclined at an angle of $10^{\circ}$, with a darkened homing cage at the upper end. For motivational purposes, a white light (60 Watt) was placed at the beginning of the ramp. The experimenter prevented the animal from back tracking during the test. Each animal was tested twice, and between each trial the paper cover was replaced. Subsequently, the record was dusted with charcoal revealing the footprint pattern. Measurements were made on 2 steps per trial. All measurements were made 
at the most proximal part of the second interdigital space. Six variables were measured using a distance scanner as follows: 1) distance between the successive placement of the same hindfoot, 2) distance between one hindfoot and the preceding print of the opposite hindfoot, 3) distance between one hindfoot and the succeeding print of the opposite hindfoot, 4) stride width, 5) step angle, and 6) gait symmetry. The weights of the $\mathrm{H}$ pups and $C$ pups were matched. Tests were conducted on PI7, P45, and P95 (C=10 males, 10 females; $\mathrm{H}=10$ males, 10 females) in separate naive groups of animals. Subjects were drawn from the pool of animals used in the preweaning tests, and at least I animal from each sex and each litter was tested. Animals were weight-matched before testing.

\section{Open field activity}

This test measures the activity and habituation response of animals in a novel environment. In addition, adult open field activity is a sexually dimorphic behavior, with females having higher activity levels compared to males $(6,19)$. On days P19, P27/28, $P 43 / 44$, and $P 8 I / 82$ the males and females $(N=10$ per sex, per treatment group) which were tested for open-field activity according to procedures we have reported previously (27). Briefly, we used two age-dependent sized circular open fields $(90 \mathrm{~cm}$ on P/9. P27, and $180 \mathrm{~cm}$ on P43 and P80) enclosed by white plastic walls (25 and $37 \mathrm{~cm}$ high. respectively) and illuminated by red light. Each field consisted of 19 equal area segments. Adult female rats were tested during the diestrous phase of the estrous cycle, which was determined by vaginal smear on the morning of the experiment. Each animal was subjected to a 6 min trial, in which measures were calculated for successive 2 min intervals. Each animal was placed in the center of the open field and the following observations recorded: 1) time to reach the field wall, 2) the number of grids crossed, 3) the number of rears, 4) periods of grooming, and 5) the number of boli excreted.

\section{Circadian activity}

Running wheel activity patterns reveal marked diumal activity rhythms (46). We studied wheel running simultaneously in male litter representatives for 5 consecutive days, beginning at $\mathrm{P} 64(\mathrm{C}=8, \mathrm{H}=8)$. Running wheel activity was continuously monitored and recorded by a computer system (Mini Mitter Co, Inc., Sun River, OR). Animals were acclimatized to the apparatus for 4 days prior to beginning of testing.

\section{Morris water test}

The Morris water test has been shown to be a useful tool to assess short-term memory (54). Ten male and female litter representative rats from each treatment group were tested on P28, P40, and P95. Animals were placed in a circular bath with a diameter of $180 \mathrm{~cm}$ and height of $70 \mathrm{~cm}$, half filled with opaque water at $25^{\circ} \mathrm{C}$. In this bath, a small platform $\left(11 \mathrm{~cm}^{2}\right)$ was placed $2 \mathrm{~cm}$ below the water surface. The latency to localize the platform was recorded for each rat up to a maximum of $120 \mathrm{sec}$. Rats failing to localize the platform within this period were removed and received a $120 \mathrm{sec}$ latency score. Each animal was given 10 trials. 


\section{Saccharin preference}

In the rat, saccharin preference is sexually dimorphic. When presented vith the choice between a saccharin solution and plain water, females consume significantly more saccharin solution than males (56). We measured saccharin preference beginning at 70 days of age in male rats $(N=\mid 5$ per treatment group). All animals were individually housed and simultaneously tested during 10 consecutive days.

During the first 5 days of testing, we measured daily baseline water intake by presenting the animals with a $250 \mathrm{ml}$ bottle containing tap water. Subsequently for the next 6 days, we presented the animals with a two-bottle choice between saccharin and tap water. The bottle positions of the two fluids were alternated daily. Saccharin solutions at three concentrations $(0.125 \%, 0.25 \%$, and $0.50 \%)$ were presented successively in ascending order. Each concentration was presented for two days.

Saccharin and water consumption were determined by measuring the difference in bottle weight over a $24 \mathrm{~h}$ period, and subsequently dividing both saccharin and water consumption by body weight. Body weights were measured every two days.

\section{Male sexual behavior}

Beginning at 130 days of age, we tested 15 males from each treatment group 4 times at weekly intervals for masculine sexual behavior, using procedures which we have published previously (27). Animals tested represented I-2 animals from a litter. Tests were conducted in the presence of a receptive female for 20 minutes in a circular Plexiglass arena under red light illumination. Sexual behavior tests were conducted between the 4th and 7th hour of the dark cycle. After each animal was tested, the bedding was changed and testing arena cleaned with an alcohol/acetic acid solution (50\% alcohol/water $v / v, 0.1 \%$ acetic acid).

Receptivity was induced in previously ovariectomized females chronically implanted with a silastic capsule containing slow releasing estrogen ( $2 \mathrm{~mm}$ 3-estradiol-3benzoate, Sigma, St Louis, MO). Four hours before testing, these females were injected with $500 \mathrm{mg}$ progesterone dissolved in $0.25 \mathrm{ml}$ sesame oil. The males were allowed to adapt to the mating arena for 5 min before the receptive female was introduced. During each test, the following behavioral parameters were recorded: I) number of mounts, 2) number of intromissions, 3) ejaculation, 4) mount latency (time to the first mount), 5) intromission latency (time to first intromission), 6) ejaculation latency (time to first ejaculation after first intromission), and 7) postejaculatory interval (time after ejaculation to the first intromission of a new series).

\section{Female sex behavior potentials}

Female sex behavior potentials were measured in a random selection of animals used in the male sex behavior study. Following the last test for masculine sexual behavior, we orchidectomized 10 males of each treatment group under Nembutal anesthesia $(50 \mathrm{mg} / \mathrm{kg}$ ). Body and testis weights were recorded. Following a 2 week postoperative recovery, each male received $1.5 \mathrm{mg} \mathrm{E} \mathrm{sc}$, followed $42 \mathrm{~h}$ later with I $\mathrm{mg}$ progesterone. Beginning at 180 days of age, each experimental male was tested for feminine sexual receptivity with a stud male 4-6 h following the progesterone injection. In each test ses- 
sion we recorded the following behaviors: 1) number of times the animal was mounted, 2) lordosis, 3) ear wiggling, and 4) darting. Lordosis was scored as an all or none response, with lordosis defined as a clear raising of the head and arching of the back in response to a mount. We then calculated the lordosis quotient $(L Q=$ lordosis/mounts $\times 100)$.

\section{PERINATAL TESTOSTERONE LEVELS}

\section{Prenatal testosterone surge}

On days 18, 19, and, 20 of pregnancy 5 pregnant dams per day and per treatment group underwent cervical dislocation. Dams were sacrificed between 1000 and $1500 \mathrm{~h}$ in rotating order, to control for the effects of time on the testosterone surge. All of the fetuses obtained via hysterotomy, were immediately decapitated, and blood collected from the neck vessels in heparinized capillary tubes (Baxter, Mc Gaw Park, IL). Subsequently, we determined the sex of each fetus by visualizing the testicles using a dissecting microscope (Zeiss, Model 475052, Thornwood, NY). We then eliminated the samples originating from female pups. To obtain sufficient blood volume for the radioimmunoassay, we pooled samples of several fetuses according to treatment group and gestational age. Subsequently, we centrifuged the samples and stored plasma samples at $-70^{\circ} \mathrm{C}$ until the time of assay.

\section{Postnatal testosterone surge}

On the morning of E2I (0800 to I $200 \mathrm{~h}$ ) we sacrificed I 4 pregnant female rats per treatment group by cervical dislocation. Pups were delivered by hysterotomy and the animals were sexed by visual assessment of anogenital distance. We then placed the male pups in a covered shaking water bath (Precision Scientific, Chicago, IL) to maintain temperature at $30^{\circ} \mathrm{C}$. At $0,60,120,240,360$, and 480 min after delivery we decapitated the pups (8-14 pups / time point / group), and collected trunk blood of each fetus in heparinized capillary tubes. Subsequently, we centrifuged the samples as above, and stored plasma samples at $-70^{\circ} \mathrm{C}$ until time of assay.

\section{Testosterone radioimmunoassay}

Testosterone extraction was performed by adding $5 \mathrm{~mL}$ diethylether and vortexing each sample. After settling, the organic phase was transferred to another tube and dried under a nitrogen stream. The extracted testosterone was then solublilized in buffer $(0.1 \mathrm{M}$ sodium phosphate, $0.1 \%$ gel, 0.1 M EDTA, $0.05 \%$ rabbit gamma globulin, $\mathrm{pH} 7.0$ ) at $37^{\circ} \mathrm{C}$ for I h. Aliquots were then taken for RIA. Recoveries were greater than $90 \%$.

For RIA, the primary antibody was raised against testosterone-19-carboxymethylester-BSA (ICN, Costa Mesa, CA, cat \#07-1891 16). After incubation of the sample with primary antibody and 20,000 cpm of [1- |25]-testosterone (ICN; cat \#07-189126) at $4^{\circ} \mathrm{C}$ overnight, we added $0.5 \mathrm{ml}$ of a $1: 9$ dilution of goat-anti-rabbit gamma globulin (Henninger, Provo, UT) which contained 5\% PEG, to each tube. The tubes were subsequently vortexed, and then centrifuged at $2000 \times \mathrm{g}$ for $20 \mathrm{~min}$ at $4^{\circ} \mathrm{C}$. The supernatant was aspirated and the pellet counted in a Micromedic 4/600 gamma counter with auto- 
matic data reduction software (RIA-AID; Robert Maciel and Assoc., Inc., Arlington, MA). Standard curves were calculated using the four parameter logistic option.

All samples displaced within the 80 to $20 \% \mathrm{~B} / \mathrm{Bo}$ and were run in one assay. The within-assay coefficient of variation for pools reading at the 80,50 and $20 \% \mathrm{~B} / \mathrm{Bo}$ were $4.5,6.8$, and $6.9 \%$, respectively. All quality control pools were within the two standard range of the ICN published concentrations.

Statistics. Behavioral data from the preweaning tests were analyzed by ANOVA using litter means. We analyzed postweaning and testosterone data by ANOVA with Duncan's posthoc multiple comparison. Repeated measures were used where appropriate.

\section{RESULTS}

\section{Animal weights and physical landmarks}

As shown in Table I, birth weights of hypoxic pups were significantly lower compared to control pups $(F[1,8] 10.1, p<0.01)$. During the rest of development, however, body weights of hypoxic pups did not differ significantly from controls. Anogenital distances and testicular weights of male rats did not significantly differ. We observed no differences between the treatment groups in day of eye or ear opening. Maternal weight gain from days 15 to 21 of gestation was not significantly different between hypoxic and controls ( $C=30.4 \pm 2.7 \%$; $H=31, I \pm 5.6 \%$ ).

\section{Table I. Weight and physical landmarks}

\section{Control}

\section{Hypoxia}

$\begin{array}{lll}\text { birth weight }(\mathrm{g}) & 6.9 \pm 0.2 & 6.0 \pm 0.2^{*} \\ \text { weight } \mathrm{p} 20(\mathrm{~g}) & 48.4 \pm 1.2 & 47.5 \pm 1.5 \\ \text { ear opening (day) } & 12 \pm 0.1 & 12.2 \pm 0.2 \\ \text { eye opening ( day) } & 14.4 \pm 0.2 & 14.4 \pm 0.2 \\ \text { male anogenital } & & \\ \text { distance }(\mathrm{mm} / \mathrm{g}) & 0.5 \pm 0.2 & 0.46 \pm 0.1 \\ { }^{*} p<0.01 & & \end{array}$

\section{Blood gases}

In chronically catheterized dams which inspired $10.5 \% \mathrm{O}_{2}$ arterial $\mathrm{PO}_{2}$ averaged

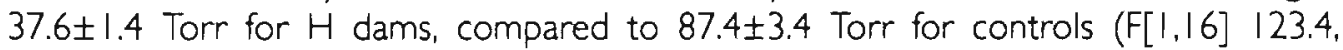
$p<0.001$ ) (9). Mixed $\mathrm{PO}_{2}$ in fetuses exposed to chronic hypoxia $(\mathrm{N}=7)$ averaged $23.8 \pm 1.3$ Torr, compared to 40.2 \pm 4.5 Torr for controls $(\mathrm{N}=11) \quad(p<0.01)$. Fetal $\mathrm{Hb}$ concentrations were not significantly different between hypoxic and control animals ( $C$ $[\mathrm{Hb}]=9 . \mathrm{I} \pm 0.5$, and $\mathrm{H}[\mathrm{Hb}]=9.2 \pm 0.4)$. 


\section{BEHAVIORAL STUDIES}

\section{Righting reflex}

Mean righting reflex latencies decreased from $12.9 \pm 3.2 \mathrm{sec}$ for control litters, and $13.0 \pm 2.4 \mathrm{sec}$ for hypoxic litters on P2 to $2.4 \pm 1.0 \mathrm{sec}$ and $1.3 \pm 0.4 \mathrm{sec}$ on PI2, respectively. At all time points hypoxic pups were not significantly different from controls.

\section{Negative geotaxis}

On both the $15^{\circ}$ and $25^{\circ}$ incline, no differences in performance were observed between treatment groups. Reaction latencies of $C$ pups decreased from $60 \mathrm{sec}$ on the 25 inclines on $\mathrm{P} 2$, to $14.6 \pm 0.7 \mathrm{sec}$ on $\mathrm{PI}$. Latencies for hypoxic pups decreased from $59.0 \pm 0.9$ on $P 2$ to $16.1 \pm 1.3 \mathrm{sec}$ on $P 10$

\section{Cliff avoidance}

In the cliff avoidance reaction, mean latencies for controls decreased from $13.6 \pm 0.5 \mathrm{sec}$ at $P 2$ to $6.1 \pm 0.7 \mathrm{sec}$ at $P 10$. Hypoxic reaction latencies decreased from $14.3 \pm 0.4 \mathrm{sec}$ on $\mathrm{P} 2$ to $5.9 \pm 0.7 \mathrm{sec}$ at PIO. Between treatment groups no significant differences were detected in mean latencies over the 8 days on which cliff avoidance was measured.

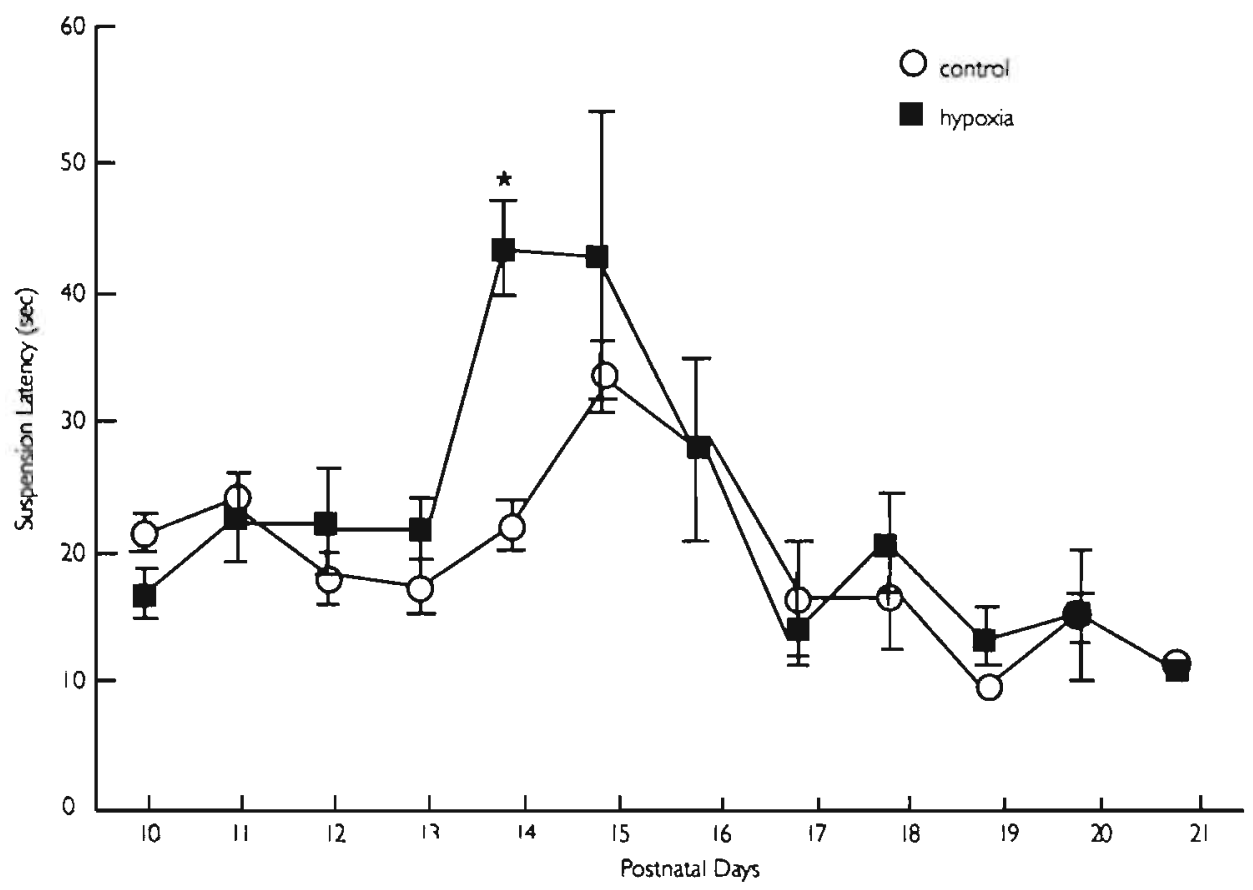

Figl. Development of reflex suspension from 10 to 21 days postnatally. Shown are mean \pm SEM suspension latencies in seconds for control and hypoxic pups. Significant increased latencies for hypoxic pups on P14, $p<0.0001$. 


\section{Reflex suspension}

Mean suspension latency times of controls increased from $21.4 \pm 1$ sec at $P 10$ to $32.8 \pm 3 \mathrm{sec}$ at PI5, thereafter declining to $8 \pm 1 \mathrm{sec}$ at P2I (Fig. I). There was significant increase in hanging latencies in both groups around the time of eye opening, but the latency was significantly greater on day 14 in hypoxic animals $(F[1,9] 34.3, p<0.0001$ ).

\section{Circadian activity}

Male locomotor activity increased strikingly after dark (1800 h), falling progressively to the end of the dark period $(0600 \mathrm{~h})$. Both groups exhibited a normal rise in nocturnal wheel running with no significant differences detected between treatment groups. Data are shown in Figure 2.

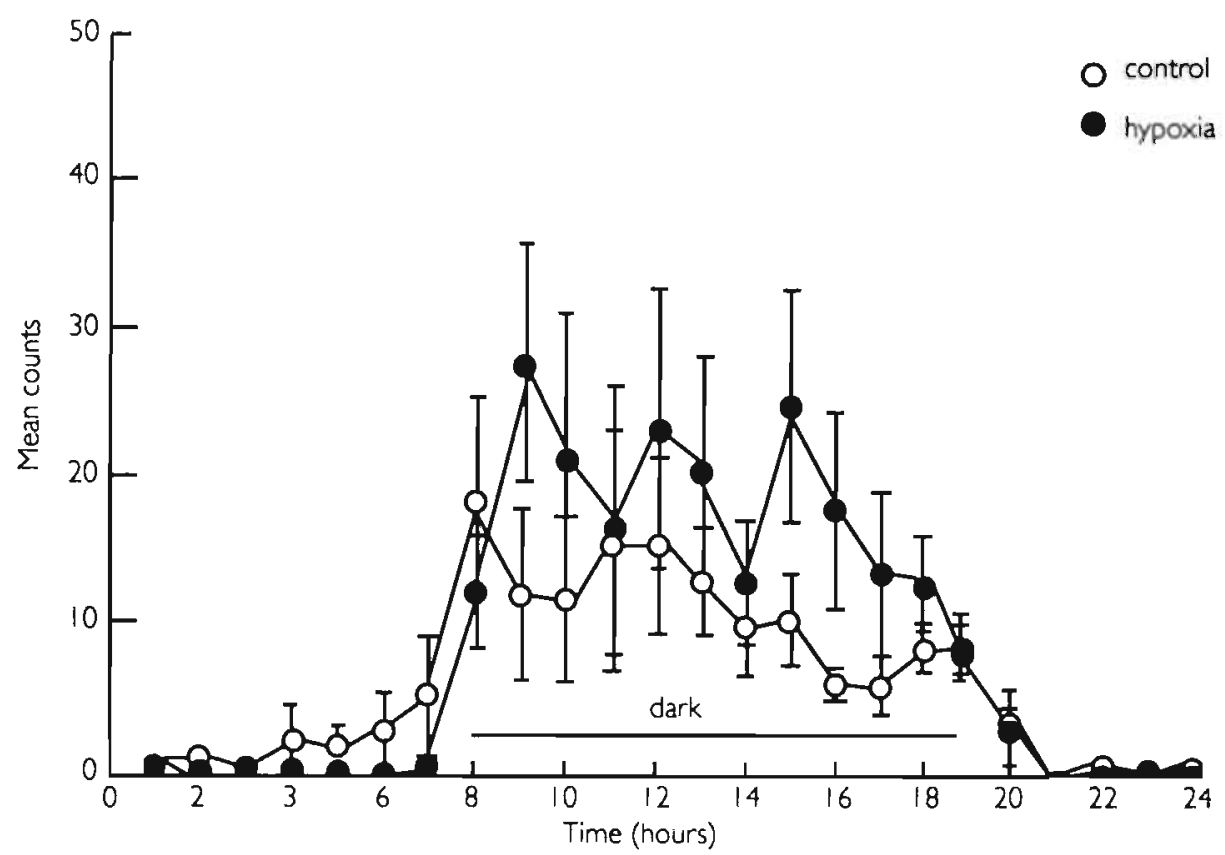

Fig 2. Circadian locomotor activity at 60 to 65 days of age. Shown are mean \pm SEM calculated wheel revolutions per 60 min over 5 days of male control and hypoxic rats.

\section{Gait analysis}

As shown in Table 2., on days 17 and 45 of life there were no significant treatment effects on gait patterns. On day 45 we observed a significant sex difference $(F[1,37] 4.99, p<0.03)$ in the distance between one hindfoot and the preceding print of the opposite hindfoot (distance $C_{\text {, in Fig }} 8$ of Hermans et al, 1992, and Table 2). On day 95 hypoxic animals had a significantly longer distance $C(F[I, 35] 13.41, p<0.001)$ and significantly longer distance $F$ reflected in larger gait symmetry value ( $F[1,35] 9.26, p<0.004)$ compared to controls (Table 2). Other indices like step angle and gait width were not altered. 
Table 2. Gait analysis

\section{Control Overall}

$\begin{array}{llll}8.7 \pm 0.1 & 8.6 \pm 0.2 & 8.8 \pm 0.24 & 8.7 \pm 0.19 \\ 31.6 \pm 0.9 & 32.4 \pm 1.1 & 30.8 \pm 1.5 & 32.9 \pm 1.1 \\ 2.7 \pm 0.1 & 2.7 \pm 0.1 & 2.6 \pm 0.1 & 2.8 \pm 0.1 \\ 0.97 \pm 0.02 & 0.98 \pm 0.01 & 0.97 \pm 0.05 & 0.98 \pm 0.02 \\ 5.1 \pm 0.1 & 5.1 \pm 0.1 & 5.17 \pm 0.1 & 5.2 \pm 0.09\end{array}$

$\begin{array}{ll}13.8 \pm 0.2 & 14.0 \pm 0.3 \\ 25.2 \pm 1.2 & 16.0 \pm 1.9 \\ 3.2 \pm 0.2 & 3.5 \pm 0.4 \\ 1.0 \pm 0.02 & 1.0 \pm 0.04 \\ 7.8 \pm 0.13 & 8.0 \pm 0.2\end{array}$

$15.8 \pm 0.4$
$23.5 \pm 1.8$
$3.2 \pm 0.2$
$1.05 \pm 0.03$
$8.6 \pm 0.2$

Postnatal day 45 stride length step angle stride width gait symmetry distance $\mathrm{C}$

Postnatal day 95 stride length step angle stride width gait symmetry distance $C$ * $p<0.03$ compared to controles $* p<0.003$ compared to males $\# p<0.001$ compared to controls
$16.6 \pm 0.3$
$24.5 \pm 1.3$
$3.4 \pm 0.2$
$1.0 \pm 0.02 \#$
$9.5 \pm 0.2 \#$

\section{Hypoxia}

Female Overall

Male

\section{Female}

$\begin{array}{ll}8.9 \pm 0.30 & 8.5 \pm 0.23 \\ 32.1 \pm 1.5 & 34.6 \pm 1.6 \\ 2.8 \pm 0.1 & 2.8 \pm 0.1 \\ 1.02 \pm 0.03 & 0.9 \pm 0.02 \\ 5.2 \pm 0.1 & 5.1 \pm 0.1\end{array}$

$\begin{array}{ll}13.6 \pm 0.2 & \mid 3.7 . \pm 0.3 \\ 24.4 \pm 1.7 & 27.2 \pm 1.1 \\ 3.0 \pm 0.2 & 3.2 \pm 0.1 \\ 1.0 \pm 0.03 & 1.05 \pm 0.04 \\ 7.6 \pm 0.2 & 7.8 \pm 0.2\end{array}$

$14.1 \pm 0.4$

$13.3 \pm 0.4$

$27.9 \pm 2.2$

$3.3 \pm 0.2$

$26.6 \pm 0.9$

$3.1 \pm 0.1$

$1.04 \pm 0.03$

$1.1 \pm 0.07$

$8.1 \pm 0.3$

$7.5 \pm 0.2 *$

$15.9 \pm 0.6$
$26.0 \pm 3.3$
$3.7 \pm 0.4$
$1.04 \pm 0.06$
$8.8 \pm 0.3$

$15.7 \pm 0.4$
$21.0 \pm 1.3$
$2.8 \pm 0.9 * *$
$1.05 \pm 0.03$
$8.4 \pm 0.3$

$16.7 \pm 0.4$
$22.6 \pm 1.6$
$3.0 \pm 0.2 * *$
$0.9 \pm 0.03$
$9.5 \pm 0.2$

$\begin{array}{ll}16.6 \pm 0.4 & 16.7 \pm 0.4 \\ 26.3 \pm 1.9 & 22.6 \pm 1.6 \\ 3.8 \pm 0.2 & 3.0 \pm 0.2 * * \\ 1.0 \pm 0.04 & 0.9 \pm 0.03 \\ 9.6 \pm 0.3 & 9.5 \pm 0.2\end{array}$




\section{Morris water test}

At all ages tested there were no significant differences between treatment or gender groups. Data from the second and the tenth trial are shown in Table 3.

\section{Table 3. Morris water performance}

$\begin{array}{lll}\text { P28 } & \text { P40 } & \text { P } 95\end{array}$

trial 2 trial 10 trial 2 trial 10 trial 2 trial 10

\section{Control}

$\begin{array}{lllllll}\text { male } & 558 \pm 15.0 & 15.4 \pm 4.5 & 13.1 \pm 9.0 & 5.7 \pm 3.1 & 9.5 \pm 1.2 & 7.6 \pm 2.2 \\ \text { female } & 30.5 \pm 14.9 & 8.7 \pm 2.0 & 14.1 \pm 2.8 & 6.9 \pm 1.9 & 16.3 \pm 4.1 & 9.5 \pm 2.8\end{array}$

\section{Hypoxia}

male $\quad 48.2 \pm 21.5$

$12.6 \pm 2.7$

$19.3 \pm 4.6$

$6.7 \pm 2.1$

$29.3 \pm 9.3$

$4.4 \pm 0.3$

female $57.4 \pm 4.8$

$9.1 \pm 1.9$

$12.0 \pm 4.0 \quad 7.1 \pm 1.0$

$19.3 \pm 10.6 \quad 4.9 \pm 0.5$

\section{Open field activity}

Open field activity measurements were analyzed over a 6 min testing period. Repeated measures ANOVA was performed on successive 2 min intervals within the 6 min trials. On day 19 no significant differences were detected in the behavior of $\mathrm{H}$ versus $\mathrm{C}$ animals. However, higher activity levels observed in $\mathrm{H}$ animals compared to controls reached marginal significance $(F[1,36] 3.86, p<0.057)$. Data are shown in Table 4. Sex differences in open field behavior were detected at this age. Male pups exhibited higher levels of grooming behavior and locomotor activity during the 6 min test period. Repeated measurement ANOVA demonstrated a main effect for sex in levels of grooming $(F[1,36] \mid I .84 p<0.001)$ and locomotor activity $(F[I, 36] 4.35 p<0.04)$.

No significant main effects or interactions were detected in the analyses of behavior measured at 27 days of age. On day 47, the females excreted significantly more boli compared to males $(F[1,36) 4.56 p<0.04)$. On day 81 , females secreted more boli, and displayed a higher crossing activity compared to males $(F[1,36] 9,87 p<0.003$ and $F[I, 36] 6.43 p<0.00$ I resp.). Rearing activity was higher in hypoxic animals, although with marginal significance (F[I.36] 3.83, $p<0.058)$.

\section{Saccharin intake}

Water intake over the five day baseline period did not significantly differ between the two treatment groups. Mean basal water intake averaged $13.7 \pm 0.4 \mathrm{~m} / 1 / 00 \mathrm{~g} / \mathrm{day}$ in controls and $14.4 \pm 0.6 \mathrm{~m} / / \mathrm{l00g} /$ day in hypoxic animals. As shown in Fig. 3, no significant differences were found in saccharin preference between control and hypoxic male rats. With increasing saccharin concentrations the saccharin preference decreased equally in both groups. In addition, water intake and ratio of saccharin preference (saccharin intake / total fluid intake) were not different at any saccharin concentration. 
Table 4. open field activity

\section{Activity}

crossings per 6 min rearings groomings thigmotaxis

crossings per $6 \mathrm{~min}$ rearings groomings

thigmotaxis

crossing per $6 \mathrm{~min}$ rearings groornings

thigmotaxis

crossings per $6 \mathrm{~min}$ rearings groomings thigmotaxis

* $p<0.003$

\section{Age Control}

19 Overall

$$
\begin{aligned}
& 93.9 \pm 6.3 \\
& 29.19 \pm .4 \\
& 3.1 \pm 0.5 \\
& 18.6 \pm 4.7
\end{aligned}
$$

27

$$
\begin{aligned}
& |3| .6 \pm 8.3 \\
& 28.1 \pm 3.8 \\
& 3.4 \pm 0.7 \\
& 4.6 \pm 0.5
\end{aligned}
$$

47

$137.0 \pm 11.2$
$17.7 \pm 2.6$
$1.8 \pm 0.4$
$9.8 \pm 1.4$

81

\section{Hypoxia}

\section{Male \\ Female}

$\begin{array}{ll}84.2 \pm 4.6 & 103.7 \pm 6.4 \\ 30.9 \pm 52.5 & 27.3 \pm 6.4 \\ 3.7 \pm 0.5 & 2.5 \pm 0.8 \\ 12.6 \pm 1.3 & 24.7 \pm 9.3\end{array}$

Overal

Male

$116.7 \pm 11.5$
$24.2 \pm 2.9$
$2.3 \pm 0.4$
$29.3 \pm 8.5$

$102.9 \pm 11.5$

$23.9 \pm 4$

$3.7 \pm 0.5$

$18.1 \pm 2.4$
$142.8 \pm 10.5$ $33.2 \pm 3.8$
$3.5 \pm 0.6$
$6.7 \pm 1$

$\begin{array}{ll}121.4 \pm 10.9 & |4| .8 \pm 12 \\ 22.7 \pm 2.7 & 33.5 \pm 6.1 \\ 3.0 \pm 1.3 & 3.8 \pm 0.7 \\ 5.47 \pm 0.8 & 3.8 \pm 0.6\end{array}$

$143.2 \pm 16.7$ $34.6 \pm 5.4$

$4.4 \pm 1$

$5.4 \pm 0.9$

$134.4 \pm 15.2$
$16.8 \pm 4.6$
$1.4 \pm 0.7$
$10.8 \pm 2.2$

$130.0 \pm 9.5$
$18.7 \pm 2.1$
$2.5 \pm 0.6$
$13.1 \pm 3.3$

$110.3 \pm 9.7$ $20.1 \pm 3.4$ $3.2 \pm 0.9$

$13.9 \pm 4.7$

$|49.7 \pm| 4 . \mid$
$\mid 7.3 \pm 2.6$
$\mid .7 \pm 0.6$
$\mid 2.2 \pm 4.9$

$142.4 \pm 13.9$ $31.7 \pm 5.6$ $2.5 \pm 0.7$ $7.9 \pm 1.7$

$130.5 \pm 16.1$

$25.4 \pm 4$

$0.9 \pm 0.3$

$40.3 \pm 16$

\section{$8.7 \pm 1.7$}

$\begin{array}{ll}70.6 \pm 23.6 & 135.8 \pm 12^{*} \\ 8.3 \pm 2.7 & 11.4 \pm 2.3 \\ 1.2 \pm 0.4 & 1.7 \pm 0.4 \\ 33.5 \pm 13.9 & 27.0 \pm 8\end{array}$

$111.8 \pm 13.5$
$15.7 \pm 2.3$
$1.5 \pm 0.5$
$25.2 \pm 8$

$136.5 \pm 16.8 *$ $103.2 \pm 14$ $1.5 \pm 0.3$ $30.3 \pm 8$
$17.5 \pm 4.1$ $1.3 \pm 0.5$ $37.4 \pm 15$ $13.8 \pm 2.3$ $1.6 \pm 0.5$ $13.3 \pm 3.2$
$87.1 \pm 18.8$ 

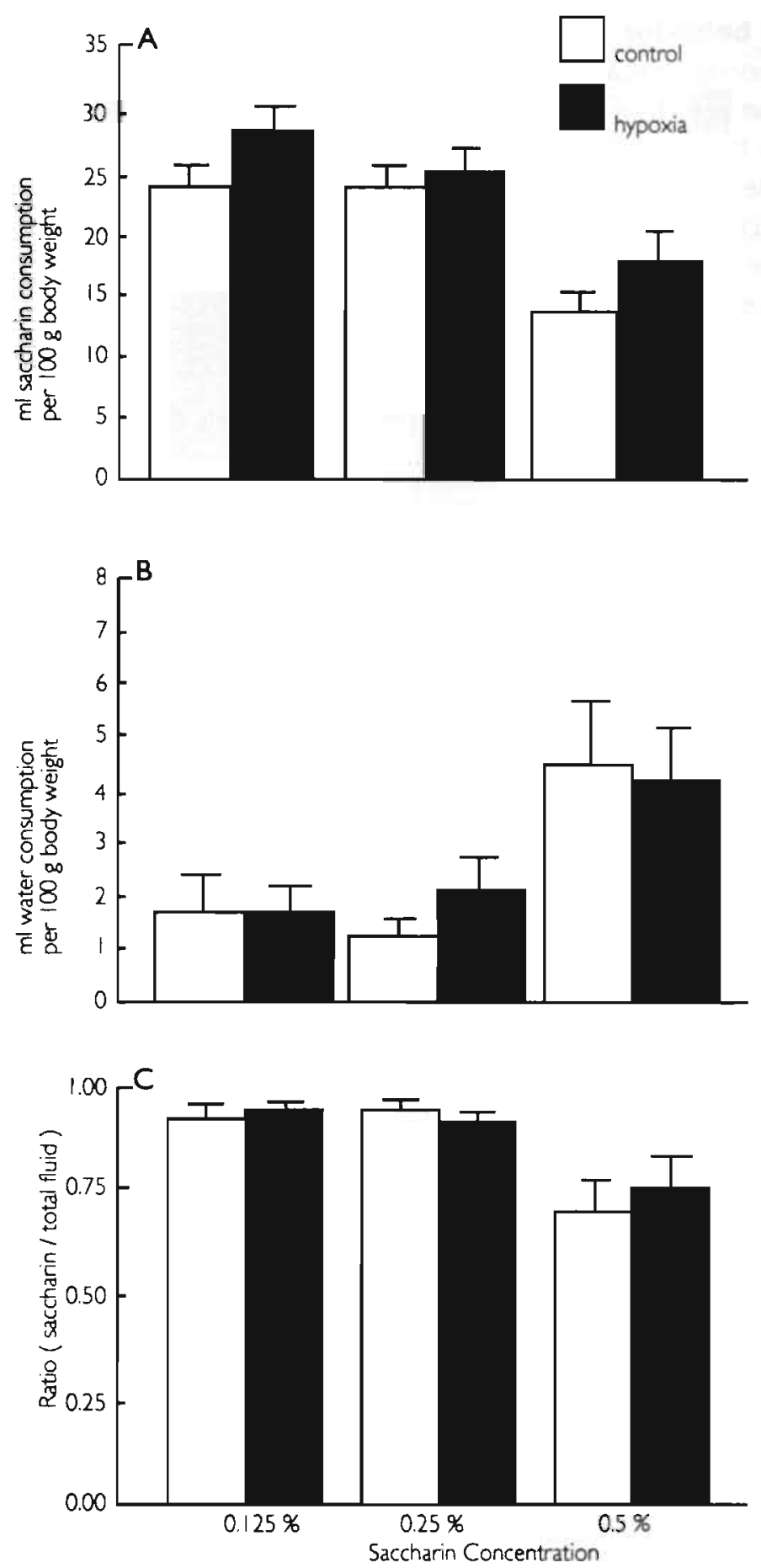

Fig 3. Saccharin $(0.125 \%, 0.25 \%$, and $0.5 \%)$ and water intake for male control and hypoxic rats. A. Consumption of saccharin solution per $100 \mathrm{~g}$ body weight per day. B. Water intake $(\mathrm{m} / / / \mathrm{OOg} / \mathrm{day})$. C. Rotio of intake of saccharin solution to total fluid. 


\section{Male sexual behavior}

Initiation of sexual behavior was significantly delayed in hypoxic males, as indicated by a main effect of treatment for mounting latency in the repeated measures ANOVA over the 4 week testing period ( $F[1,28] 8.88, p<0.006)$. Data for week 4 are shown in Table 5. Hypoxic males tested on week 4 also had a significantly decreased number of ejaculations over the 20 min testing period compared to controls $(F[1, \mid 8] 5.3$, $p<0.02$ ] (Table 5). Other indices of male sexual reproductive behavior did not differ significantly between treatment groups.

\section{Table 5. Results of male sexual behavior at week 4}

$\begin{array}{lll}\text { ejaculation lat. } & 563.3 \pm 63.8 & 659.5 \pm 95 \\ \text { intromission lat. } & 56.4 \pm 17.6 & 114.2 \pm 48.4 \\ \text { mounting lat. } & 26.1 \pm 7.3 & 93.6 \pm 27.5 * \\ \text { time to I event } & 23.9 \pm 6.9 & 68.1 \pm 25.7 \\ \text { number of ejaculations } & 1.9 \pm 0.2 & 1.3 \pm 0.2 * \\ \text { number of intermissions } & 26.8 \pm 1.4 & 24.9 \pm 1.6 \\ \text { number of mounts T } & 6.8 \pm 0.8 & 5.7 \pm 1.1 \\ \text { post ejaculatory interval } & 307.4 \pm 13.7 & 297.6 \pm 17.2 \\ \text { ratio (\#M/\#M+NI) } & 0.805 \pm 0.02 & 0.826 \pm 0.03 \\ { }^{*} P<0.02 & & \end{array}$

\section{Female sex behavior potentials}

The lordosis quotients of adult male animals following estrogen and progestero-

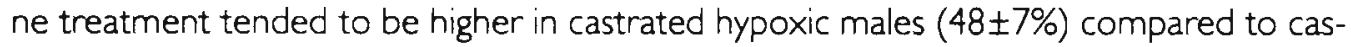

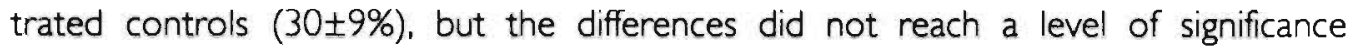
$(p<0.10)$.

\section{PERINATAL TESTOSTERONE LEVELS}

\section{Prenatal testosterone surge}

As shown in Fig. 4, both hypoxic and control fetuses experienced a $T$ surge on days 18 and 19 of gestation. The ANOVA revealed a significant effect for day $(F[1,23]$ $5.44, p<0.01$ ), indicating that both treatment groups experienced a surge. On day 20 , both control and hypoxic pups had significantly lower testosterone concentrations com pared to day 19 (Controls, F[I,8] 31.25, p<0.00I). (Hypoxic, F[I,8] $4.87 p<0.05$ ). Nonetheless, no significant differences were observed between control and hypoxic animals on the days 18, 19 or 20 of gestation. Mean body weights of male fetuses were not significantly different between these groups on days 18 to 20 of gestation (Table 1). 


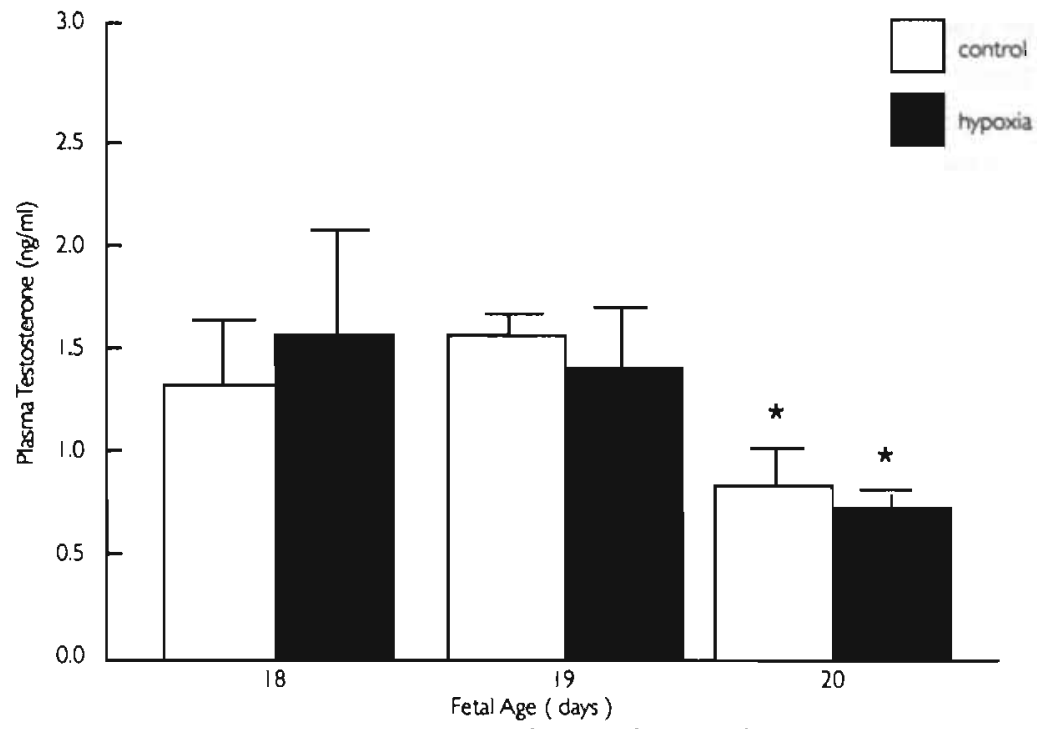

Fig. 4 Plasma testosterone concentrations of male fetuses from control and hypoxia exposed dams. Values are mean $\pm S E . *=p<0.01$ for day 20 compared to day 19 for each treatment group.

\section{Postnatal testosterone surge}

Both control and hypoxic pups exhibited a postnatal rise in testosterone concentrations (Fig. 5). Pups from both treatment groups exhibited a significant rise in cir

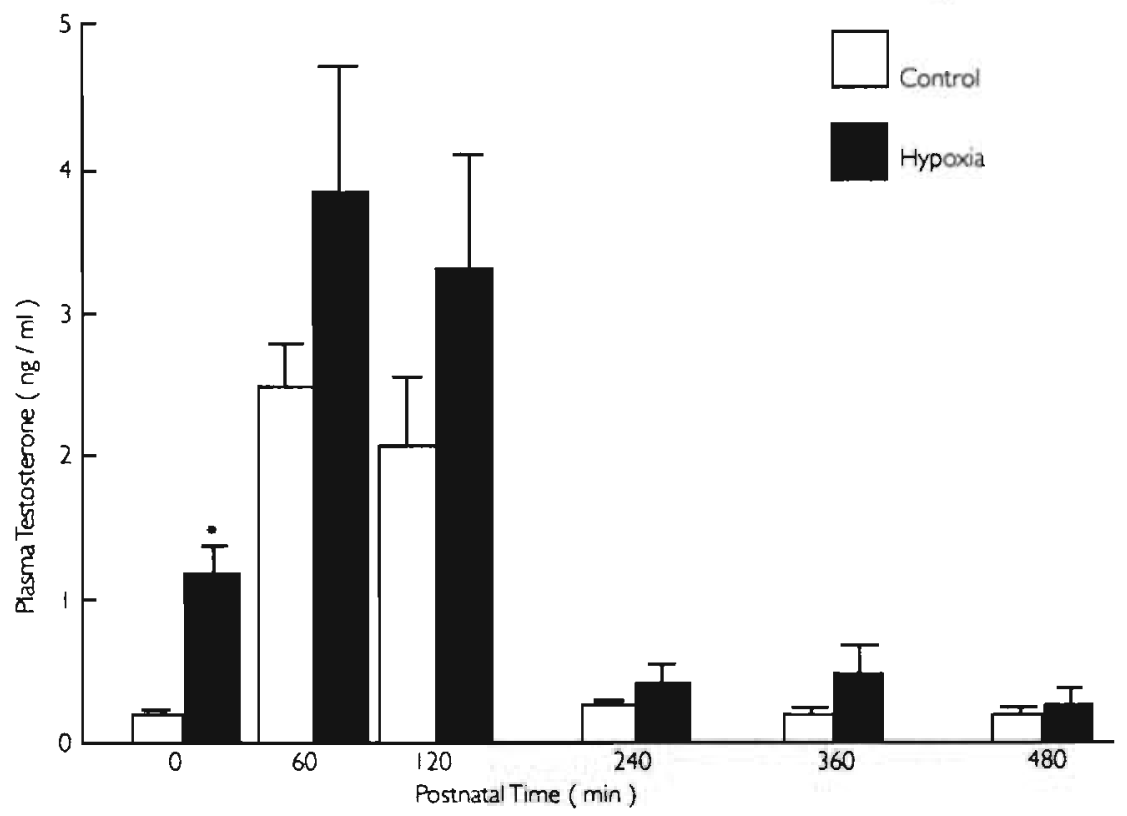

Fig 5. Postnatal plasma testosterone concentrations in male neonates from control dams and those exposed to chronic hypoxia. Values are mean \pm SEM. ${ }^{*}=p<0.001$ for hypoxic compared to controls. 
culating testosterone concentrations at 60 and $120 \mathrm{~min}(p<0.001)$ after birth compared to levels measured at $0 \mathrm{~min}$ (Fig 5). By $240 \mathrm{~min}$ after birth, plasma testosterone concentrations in both groups returned to a level at, or below, that measured immediately after birth. The analysis of treatment $X$ time revealed significant main effects of treatment $(F[1,97]=5.25 ; p<0.03)$ and time $(F[5,97]=16.95 ; p<0.0001)$, but no interaction. Post hoc analysis revealed that testosterone concentrations of hypoxic pups were significantly elevated at 0 min compared to controls $(H=1.14 \pm 0.2 \mathrm{ng} / \mathrm{ml}$ and $C=0.17 \pm 0.03$ $\mathrm{ng} / \mathrm{ml}, \mathrm{F}[\mathrm{l}, 20] 38.41 \mathrm{I}, \mathrm{p}<0.000 \mathrm{l})$. However, testosterone concentrations at the other time points were not significantly different between the two treatment groups.

\section{DISCUSSION}

Results from the present study demonstrate that relatively mild, chronic, prenatal hypoxia interferes with processes related to masculinization of sex behavior in male rats. Incomplete masculinization in hypoxia exposed males was evidenced by a significant delay in the initiation of sex behavior in the presence of a receptive female. This was accompanied by a significant decrease in the number of ejaculations during the test session, but this effect appears to be a consequence of the delay in initiation of sex behavior. This point is emphasized by the fact that the post-ejaculatory interval did not differ with respect to prenatal treatment. Other indices of masculine sexual behavior were not significantly affected. Female sex behavior potentials in hypoxia exposed males tended to be higher in hypoxia exposed males, compared to controls, but these differences did not prove to be significant. This trend suggests that further studies may be warranted to determine the effect of this hypoxic exposure regimen on the process of defeminization.

We observed no effect of prenatal hypoxia on the expression of non-reproductive sexually dimorphic behaviors, including open field activity and saccharin preference. However, sex differences in open field behavior were observed, consistent with results obtained by numerous other investigators (6).

Prenatally stressed males show both reduced levels of male copulatory behavior, and high rates of estrogen/progesterone-primed lordosis in adulthood $(49,10)$, indicating a disruption of masculinization and defeminization processes. However, the openfield behavior of such animals is not influenced by prenatal stress (30). This is similar to the lack of effect of hypoxia which we observed in the present study. Meisel et al. (30) suggested that the immediate postnatal period is the critical time for differentiation of open field behavior. This proposal is consistent with results from other investigators regarding the relationship between androgen status of the rat during late fetal and early newborn period and open field and saccharin preference behaviors (6).

The sympathetic and pituitary-adrenal hormonal responses to hypoxia and restraint stress are quite similar. Both treatments cause a marked elevation of maternal and fetal glucocorticoids $(2,50)$ and monoamines $(7,42)$. Therefore, it is not surprising that the behavioral results from the present study of hypoxia show some paraliel with the general pattern of results obtained from behavioral studies of offspring of dams exposed to prenatal stress.

In the present investigation, the prenatal and postnatal surges of testosterone 
were not significantly decreased by hypoxia. With respect to the postnatal testosterone surge, male pups from hypoxia-exposed dams had significantly elevated levels of testosterone levels at birth compared to normoxic controls. However, the subsequent amplitude of the surge, as well as its duration, was not significantly influenced by prenatal hypoxia exposure.

The lack of effect of hypoxia on the prenatal testosterone surge stands in contrast to the effect of prenatal stress.

A premature appearance of the prenatal testosterone surge on day 17 of gestation, and a subsequent lack of surge on day 18, has been reported in male fetuses exposed to light and restraint stress (53). This alteration is presumed to underlie the effects of prenatal stress on masculinization and defeminization of the male brain $(49,53)$. The postnatal surge of testosterone has not been studied in these animals.

Despite the apparently adequate plasma perinatal testosterone concentrations, chronic hypoxia decreased male adult sexual activity. This suggests the importance of other factors acting directly on the developing nervous system or indirectly to modify the organizational actions of steroid hormones. During late gestation and early postnatal period, catecholaminergic and cholinergic neurotransmitter systems undergo maturation. Results from a number of studies indicate the importance of monoamines in the sexual differentiation of the brain $(15,21,40,41,45)$. Adrenergic drugs are known to directly inhibit the incorporation of estradiol into hypothalamic nuclei in the neonatal rat $(39,40)$, a necessary step for complete masculinization of the brain. Hull (20) observed incomplete masculinization of male sexual behavior following prenatal treatment with the dopamine-related drugs, haloperidol, apomorphine, and X-methyl-p-tyrosine. Nonetheless, plasma [ 1$]$ was unaltered in haloperidol treated fetuses. Seidler and Slotkin (44) have demonstrated increased turnover of both norepinephrine and dopamine in neonatal rat midbrain and brainstem following hypoxia. Taken together, these results suggest that prenatal hypoxia may induce incomplete masculinisation effect through an influence on central catecholamine action.

The present results with chronic prenatal hypoxia show a number of similarities to the results which we recorded following exposure to intermittent hypoxia during this period of gestation (19). With acute, intermittent prenatal exposure to the same hypoxic conditions as used in the present investigation, we observed delays in the development of the righting reflex and hyperactivity in the open field 19 days of age, but not at later periods. In the present study of chronic hypoxia, we observed no evidence of a delay in sensorimotor development, but observed a similar trend toward hyperactivity at day 19 in both sexes. No effect of either chronic or acute, intermittent prenatal hypoxia was observed for cerebellar function, spatial learning, or circadian locomotor thythms, as well as open-field behaviors at 27,45 or 80 days of age.

However, clear evidence for differential effects of hypoxia on development which are dependent upon the frequency of in utero exposure comes from a separate study in which we examined the effect of the same intermittent, acute hypoxia exposure used previously (19) on postnatal testosterone levels and adult male sexual behavior. Animals exposed to intermittent hypoxia had a significantly attenuated postnatal testosterone surge. As adults, these animals displayed greater lordosis quotients, but these differen- 
ces proved not to be significant. We observed no significant differences in masculine behavior. (Hermans, Longo and McGivern, unpublished observations). Thus, in contrast to the chronic hypoxic regimen used in the present study, it appears that acute intermittent hypoxia disrupts the postnatal testosterone surge.

These results may help to elucidate the mechanisms involved in the disruption of neurobehavioral sexual differentiation by a number of different prenatal treatments. Prenatal exposure to maternal stress, nicotine, catecholamines, cocaine, and alcohol have all been shown to "interfere with masculinization" and/or feminize behavior of male offspring $(49,23,21,40,26,47)$. These treatment also induce fetal hypoxia. For instance, maternal psychological stress by restraint and bright illumination reduced uterine blood flow and fetal $\mathrm{O}_{2}$ tension in the baboon $(32,33)$. In the rat, Ohkawa and colleagues (38) showed that forced maternal immobilization reduced fetal blood $\mathrm{pH}$, suggesting fetal hypoxia.

Intravenous nicotine injection into pregnant ewes resulted in decreased uterine blood flow, leading to a transient fetal hypoxemia (25). In the mesus monkey, maternal epinephrine or norepinephrine administration induced uterine vasoconstriction, with fetal hypoxemia (1). In the sheep, cocaine also altered fetal oxygenation by reducing uterine blood flow and impairing placental $\mathrm{O}_{2}$ transfer (55). Muhkerjee and Hodgen (34) reported that intravenous administration of alcohol to pregnant monkeys caused a transient collapse of umbilical blood vessels in severe fetal hypoxia. Incubation of umbilical cord arteries and veins in solutions containing different concentrations of alcohol, demonstrated vessel contraction in the presence of low levels of alcohol (5).

Thus, hypoxia is an event common to all of these prenatal treatments, as is activation of the maternal/fetal hypothalamic-pituitary-adrenal (HPA) axis. At present, the current literature does not address whether behavioral effects common to these treatments are a result of elevated HPA activity, or result from direct effects of hypoxia on cellular function. However, since hypoxia activates the HPA axis, it seems reasonable to hypothesize that both indirect and direct actions of hypoxia may make a significant contribution to the disruptive effects of these treatments on neurobehavioral sexual differentiation. 


\section{REFERENCES}

1. Adamsons, K., E. Mueller-Heubach, and R. Myers. Production of fetal asphyxia in the thesus monkey by administration of catecholamines to the mother. Am. J. Obstet: Gynecol. 109:248-262, 1971.

2. Akagi, K, and J.R Challis. Threshold of hormonal and biophysical responses to acute hypoxemia in fetal sheep at different gestational ages. Can. J. Physiol. Pharmacol. 68:549-555, 1990.

3. Altman, J. and K Sudarsham. Postnatal development of locomotion in the laboratory rat. Anim. Behav. 23:896-920, 1975.

4. Altman, J., K. Sudarshan, G.D. Das, N. McCormick, and D. Barnes. The influence of nutrition on neural development: 3. Development of some motor, particularly locomotor pattems during infancy. Develop. Psychobiol. 4:97-1/4, 1970.

5. Altura, B.M., B.T. Altura, A. Carella, M. Chatterjee, M. Halevy, and S. Tejani. Alcohol produces spasms of human umbilical blood vessels: relationship to fetal alcohol syndrome (FAS). Eur. J. Pharmacol. 86:311-312, 1982.

6. Beatty, W.W. Gonadal hormones and sex differences in nonreproductive behaviors in rodents: Organizational and activational influences. Horm. Behav. 12:112-163, 1979.

7. Cheung, C.Y. Fetal adrenal medulla catecholamine response to hypoxia-direct and neural components. Am. J. Physiol. 258 :RI340-1346, 1990.

8. Corbier, P., L Dehennin, M. Castanier, A. Mebazaa, D.A. Edwards, and ). Roffi. Sex differences in serum luteinizing hormone and testosterone in the human neonate during the first few hours after birth. J. Clin Endocrin. Metabol. 71:1344-1348, 1990.

9. Corbier, P., B. Kerdelhue, R. Picon, and J. Roffi. Changes in testicular weight and serum gonadotropin and testosterone levels before, during, and after birth in the perinatal rat. Endocrinology 103:1985-1991, 1978.

10. Dahlöf, L-G., E. Hard, and K Larsson. Influence of matemal stress on offspring sexual behavior. Anim. Behav. 25:958-963. 1977.

II. Duffy, T.E. S.J. Kohli, and R.C. Vannucci. Carbohydrate and energ; metabolism in perinatal rat brain: Relation to survival in anoxia. J. Neurochem. 24:27।-276, 1975.

12. Fazekas, J.F., F.A.D. Alexander, and H.E. Himwich. Tolerance of the newborn to anoxia. Am. J. Physiol. 134, 281-287, 1941.

13. Gamer D, McGivem R. Jagels G, Laks MM 1989. A new method for direct measurement of systolic and diastolic pressures in conscious rats using vascular-access-ports. Laboratory Animal Science, 38:205

14. Glass, H.G., F.F. Snyder, and E. Webster. The rate of decline in resistance to anoxia of rabbits, dogs and guinea pigs from the onset of viability to adult life. Am. J. Physiol. 140:609-615. 1944.

15. Gorski, RA. Perinatal effects of sex steroids on brain development and function. Prog. Brain Res 39:149-162, 1973.

16. Goy, RW. and B.S. McEwen. Sexual differentiation of the brain. Cambridge, Mass. MIT Press, 1980. p88.

17. Grozier, W.J. and G. Pincus. The geotropic conduct of young rats. 1. Gen. Physiol. 10:257-269, 1926.

18. Habert, $R$ and $R$ Picon. Control of testicular steroid ogenesis in foetal rat: Effect of decapitation on testosterone and plasma luteinizing hormone-like activity. Acta Endocrinol. 99:466-473, 1982. Hermans, R.H.M., D.E. Hunter, R.F. McGivem, and L.D. Longo. Behavioral sequelae in young rats of acute intermittent antenatal hypoxia Neurotoxicol. Teratol. 14:119-129. 1992.

20. Hull, E., J.K. Nishita, and D. Bitran. Pennatal dopamine related drugs demasculinize rats. Science, 224:1011-1013,1984.

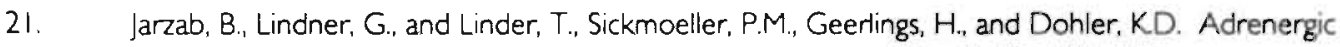
influences on sexual differentiation of the brain. Mon. Neural Sci. |2:191-196, 1986.

22. Jilék L., J. Fischer, L Kulich, and S. Trojan. The reaction of the brain to stagnant hypoxia and anoxia during ontogeny. Prog. Brain Res. 9:113-131, 1964. 

hism of saccharin preference. Pharmacol. Biochem. Behav. 23:439-444, 1985.

24. Lieberburg, I., Krey, L.C. and McEwen, B.S. Sex difference in serum testosterone and in exchangeable brain cell nuclear estradiol during the neonatal period in rats. Brain Res. 207-212, 1979.

25. Manning, F., D. Walker, and C. Feyerabend. The effect of nicotine on fetal breathing movements in conscious pregnant ewes. Obstet. Gynecol. 52:563-568, 1978.

26. McGivem, R.F., A.N. Clancy. M.A. Hill, and E.P. Noble. Prenatal alcohol exposure alters adult expression of sexually dimorphic behavior in the rat. Science 224:896-898, 1984.

27. McGivern, RF., C. Holcomb, and R.E. Poland. Effects of prenatal testosterone propionate treatment on saccharin preference: of adult rats exposed to ethanol in utero.

Physiol. Behav. 39:241-246, 1987.

28. McGivem, R.F., G. Rose, C. Berka, A.N. Clancy, C.A. Sandman, and B.E. Beckwith. Neonatal exposure: to a high level ACTH4-10 impairs adult leaming performance. Pharm. Biochem. Behav. 27:133-142, 1987.

29. McGivern, R.F., Raum, W.J., Salido, E. \& Redei, E. Lack of prenatal testosterone surge in fetal rats exposed to alcohol: Alterations in testicular morphology and physiology. Alcoholism: Clin. Exp. Res. 12:243-247, 1988.

30. Meisel, R.L., G.P. Dohanich, and I.L. Ward. Effects of prenatal stress on avoidance acquisition, open-field performance and lordotic behavior in male rats. Physiol. Behav. 22:527-530, 1979.

31. Meyer, L.S., L.E. Kotch, and E.P. Riley. Alterations in gart following ethanol exposure during the brain growth spurt in rats. Alcohol. Clin. Exp. Res. 14:23-27, 1990.

32. Morishima, H.O., H. Pedersen, and M. Finster. The influence of matemal psychological stress on the fetus. Am. J. Obstet. Gynecol. 131:286-290, 1978.

33. Morishima, H.O., Y. Ming-Neng, and L.S. James. Reduced uterine blood flow and fetal hypoxemia with acute matemal stress: experimental observation in the pregnant baboon. Am. J. Obstet. Gynecol. 134:270-275, 1979.

34. Mukherjee, A.B. and G. Hodgen. Maternal ethanol exposure induces transient impairment of umbilical circulation and fetal hypoxia in monkeys. Science. 218:700-702, 1982.

35. Mullenix. P., S. Norton and S. Culver. Locomotor damage in rats after X-irradiation. Exp. Neurol. 48:310-324, 1975.

36. Naftolin, F. and MacLusky, N. Aromatization Hypothesis Revisited. In: Sexual Differentiation: Basic and Clinical Aspects., Serio, M. et al. (eds), pp. 79-91, 1984.

37. O'Dougherty, M., F.S. Wright, R.B. Loewenson, and F. Torres. Cerebral dysfunction after chronic hypoxia in children. Neurology 35:42-46, 1985.

38. Ohkawa, T., S. Takeshita, T. Murase, A. Kambegawa, S. Okinago, and K. Arai. Ontogeny of the response of the hypothalamo-pituitary-adrenal axis to matemal immobilization stress in rats. Endocrinol. Japon. 38:187-194, 199|.

39. Raum, W.J., M. Marcano, and RS. Swerdloff. Nuclear accumulation of estradiol derived from aromatization of testosterone is inhibited by hypothalamic beta-receptor stimulation in the neonatal female rat brain. Biol. Reprod. 30:388-396, 1984.

40. Raum, W.J., RF. McGivem, M.A. Peterson, J.H. Shrne, and R.A. Gorski. Prenatal inhibition of hypothalamic sex steroid uptake by cocaine: effects on neurobehavioral sexual differentiation in male rats. Develop. Brain Res. 53:230-236, 1990.

41. Reznikov, A.G., and N.D. Nosenko. It is possible that noradrenaline is the biogenic monoamine responsible for androgen dependent sexual differentiation in brain. Exp. Clin. Endocrinol. 81:91-93, 1983.

42. Rhode, W., Onkawa, T., Dobashi, K, Arai, K, Okinaga, S. and Domer, G. Acute effects of matemal stress on fetal blood catecholamines and hypothalamic LH-RH content. Exp. Clin. Endocrin. 82:268-274, 1983.

43. Schönfelder, J. The postnatal development of rabbits air-righting reflex. Agressologie, 19:5-6, 1978.

44. Seidler, F.J., and T.A. Slotkin. Effects of acute hypoxia on neonatal rat brain: regionally selective, long-term atterations in catecholamine levels and tumover. Brain Res. Bull. 24:157-161, 1990. 
45. Sparber, S.B. Postnatal behavioral effects of in utero exposure to drugs which modify catecholamines and/or serotonin. In: Drugs and the Developing Brain, Vemadakis, A. \& Weiner, N. (Eds). pp. 81-102, Plenum Press, N.Y., 1974.

46. Stewart, KT., A.M. Rosenwasser, and N.T. Adler. Interaction between noctumal feeding and wheel running pattems in the rat. Physiol, and Behav. 34:601-608, 1985.

47. Udani, M., Parker, S., Gavaler, J. \& Van Thiel, D.H. Effects of in utero exposure to alcohol upon male rats. Alcoholism: Clin. Exp. Res. 9:355-359, 1985.

48. Vorthees, C.V., R.E. Butcher, R.L. Brunner, and T.J. Sobotka. A developmental test battery for neurobehavioral toxicity in rats: A preliminary analysis using monosodium glutamate, calcium carrageenan, and hydoxyurea. Toxicol. Appl. Pharmacol. 50:267-282, 1979.

49. Ward, I.L. Prenatal stress feminizes and demasculinizes the behavior of males. Science 175:82-84, 1972.

50. Ward, I.L. and Weisz, J. Differential effects of matemal stress on circulating levels of corticosterone, progesterone, and testosterone in male and female rat fetuses and their mothers. Endocrinology 1 |4:1635-1644, 1984

51. Wardlaw, S.L. RI. Stark, S. Daniel, and A.G. Frantz. Effects of hypoxia on beta-endorphin betalipoprotein release in fetal, newborn, and matemal sheep. Endocrinology. 108:1710-1715, 1981.

52. Warren, D.W. G.C. Haltmeyer, and K.B. Eik-Nes. Testosterone in the fetal rat testis. Biol. Reprod. 8:560-565, 1973.

53. Weisz, J. and I.L Ward. Plasma testosterone and progesterone titters of pregnant rats, their male and female fetuses, and neonatal offspring. Endocrinology, 106:306-315, 1980.

54. Whishaw, I.Q. Formation of a place leaming set by the rat. A new paradigm for neurobehavioral studies. Physiol Behav., 35:139-143, 1985.

55. Woods, J.R. M.A. Plessinger, and K.E. Clark Effect of cocaine on utenine blood flow and fetal oxygenation. JAMA, 257:957-961, 1987.

56. Zucker, I. Hormonal determinants of sex differences in sacchanin preference, food intake and body weight. Physiol. Behav. 4:595-602, 1969 


\title{
VI. THE POSTNATAL TESTOSTERONE SURGE IN THE MALE RAT: ROLE OF OPIOIDS AND N-METHYL-D-ASPARTATE EXCITATORY AMINO ACIDS
}

\author{
Hermans, R.H.M. and L.D. Longo. Submitted.
}

\section{ABSTRACT}

We have demonstrated that acute, intermittent, prenatal hypoxia attenuates the postnatal testosterone surge. In contrast, chronic, prenatal hypoxia failed to interfere with the onset or amplitude of the postnatal testosterone surge. Fetal hypoxia is known to increase levels of endogenous opioids and $\mathrm{N}$-methyl-D-aspartate excitatory amino acids. In the present study we tested the hypothesis that the opioid antagonist naltrexone, or the N-methyl-D-aspartate antagonist MK-80I would affect the postnatal testosterone surge either under normoxic control conditions or in response to prenatal hypoxia. Following chronic prenatal hypoxia, newborn plasma testosterone concentrations were significantly elevated compared to controls. Naltrexone treatment had no effect on the timing or magnitude of postnatal testosterone concentrations in either normoxic controls or in chronic hypoxic animals. Following acute, intermittent, prenatal hypoxia with or without MK-80I treatment, newborn plasma testosterone concentrations were significantly decreased. However, MK-80I alone significantly increased postnatal testosterone levels compared to controls. These results demonstrate that prenatal naltrexone treatment, with presumed inhibition of endogenous opioid action, did not affect the postnatal testosterone surge. In addition, MK-80I and presumed blockage of NMDA receptor activity, failed to antagonize the suppressing effects of prenatal hypoxia on postnatal testosterone concentrations.

\section{INTRODUCTION}

Both reproductive and nonreproductive sexually dimorphic behaviors have been demonstrated to be critically dependent on the organizational activity of perinatal androgen levels $(3,20)$. Complete masculinization of the rat brain requires elevated circulating testosterone concentrations with aromatization of testosterone to estradiol $(34,28)$. In the male rat, two perinatal surges of testosterone provide the primary source of estrogen for masculinization of the brain during this period. In the fetus, a significant increase in circulating testosterone concentration [T] occurs on days 18 and 19 of gestation $(21,48,49)$. A second postnatal T surge occurs 2 to 4 hours after birth $(11,37)$. However, there is little information on the regulation of the onset and amplitude of the testosterone surge by various factors. 
Ward (45) introduced the endogenous opioid hypothesis as a possible cause of the failure of masculinization, with feminization, of male rats following intermittent, maternal stress (immobilization accompanied by high intensity illumination three times a day). Maternal treatment with the opioid antagonist naltrexone before exposure to such stress blocked the subsequent feminization of the males (46). However, it is not known whether perinatal testosterone concentrations are altered following naltrexone treatment. In fetal sheep, hypoxia induces a marked increase of endogenous opioids (47). Quantitative autoradiographic studies by our group on brains of neonatal rats which had been exposed to chronic, prenatal hypoxia, revealed a significantly decreased number of mu-opioid receptors in the caudate-putamen, zona germinata, and in the lateral median and medial median preoptic areas of the hypothalamus (27). This suggests that during chronic hypoxia large amounts of endogenous opioids were released, which resulted in down-regulation of opioid receptors in the neonatal brain. However, we unexpectedly observed that chronic, prenatal hypoxia failed to suppress or shift the postnatal testosterone surge. Chronic, prenatal hypoxia, in fact, induced a significant rise in postnatal testosterone levels compared to controls. This, suggests that endogenous opioids are not involved in the regulation of the postnatal testosterone surge. Thus, we hypothesized that prenatal naltrexone, a potent long-acting opiate antagonist, would not interfere with the postnatal testosterone surge.

Recently, we also have shown that acute, intermittent, prenatal hypoxia attenuates the postnatal testosterone surge in male neonatal rats (22). Hypoxic/ischemic events induce an elevation of excitotoxic amino acid concentrations (44). N-methyl-Daspartate (NMDA) is known to raise adrenocorticotrophin and beta-endorphin levels in rats $(16,24)$. Activation of stress-related compounds such as endorphins, cortisol, and catecholamines are believed to be the major factors in mediating the suppression of perinatal testosterone concentrations in male rats following various treatments of the pregnant mother. The NMDA antagonist MK-80I, is known to block the effects of opioids (29) and to protect the developing brain against ischemic and hypoxic insults (17, 40). Thus, in addition, we tested the hypothesis that MK-80I would antagonize the effects of intermittent, prenatal, hypoxic exposure on the postnatal testosterone surge.

\section{METHODS}

\section{Chronic prenatal hypoxia and naltrexone treatment}

Sixty timed pregnant Sprague-Dawley rats (Charles River, Portage, MI) arrived in our laboratory on day II of gestation. We allotted these dams to four treatment groups. Group I $(H)$ was subjected to continuous hypoxia from day 15 to 21 of gestation ( $E|5-E 2|$ ). The inspired $O_{2}$ concentration was maintained at $10.5 \pm 0.5 \%$ by infusing nitrogen gas into the chamber. $\mathrm{O}_{2}$ concentration was continuously monitored by use of an $\mathrm{O}_{2}$ analyzer (OM-14, Beckman Inst, Anaheim, CA). Group 2 (C) consisted of control dams, maintained in the same room under normoxic conditions (temp $=23^{\circ} \mathrm{C}$, humidity $=45-55 \%$, and $12 \mathrm{~h}$ light dark cycle, lights on at 0700 ). We injected twenty eight pregnant hypoxic (group $3 \mathrm{H}-\mathrm{N}$ ) and normoxic control (group $4 \mathrm{C}-\mathrm{N}$ ) dams with $2 \mathrm{mg} / \mathrm{kg}$ naltrexone dissolved in sesame oil twice a day from 15 to 21 days of gestation. 
Naltrexone is a long-acting opioid antagonist, with a half-life of 4 to $10 \mathrm{~h}$, and a slow terminal elimination-phase half-life of $96 \mathrm{~h}$ (12). All the rats were individually housed in translucent maternity cages with free access to food and water.

\section{Acute intermittent hypoxia and MK-80I}

Sixty timed pregnant Sprague-Dawley rats (Charles River) were allotted to four treatment groups. Group I $(H)$ was subjected to $9 \% \mathrm{O}_{2}$ for $6 \mathrm{~h}$ a day (0830 to 1430 ) from EI5 to E2I of gestation.. Group 2 (C) served as normoxic controls. Group $3(\mathrm{H}$ MK) was injected daily with MK-80 I ( $\mathrm{mg} / \mathrm{kg}, \mathrm{sc}$ ) (Merck, West Point, PA) 10 min prior to being placed in the hypoxia chamber. $\mathrm{MK}-80 \mathrm{I}$ is a potent, selective, noncompetitive antagonist of NMDA receptors. Elimination half-life of MK- $80 \mathrm{I}$ is $2 \mathrm{~h}$ when injected intra peritoneally (42). MK-80I dosage was based on studies from the literature showing effectiveness with I $\mathrm{mg} / \mathrm{kg}$. Group 4 (C-MK) was injected daily with MK-80I and maintained under normoxic conditions.

\section{Postnatal testosterone surge}

On the morning of E2I (0800 to $1200 \mathrm{~h}$ ) we sacrificed I4 pregnant female rats per treatment group, by cervical dislocation. Pups were delivered by hysterotomy and the animals were sexed by visual assessment of anogenital distance. We then placed the male pups in cups in a covered shaking water bath (Precision Scientific, Chicago, IL) to maintain the temperature at $30^{\circ} \mathrm{C}$. At $0,60,120,240,360$, and 480 min after delivery, we decapitated the pups (8-14 pups / time point / group) and collected trunk blood of each fetus in heparinized capillary tubes. Subsequently, we centrifuged the samples and stored plasma samples at $-70^{\circ} \mathrm{C}$ until the time of assay.

\section{Testosterone radioimmunoassay}

Experiments were performed over a two year period, during which we changed methods. Samples originating from the chronic hypoxia and naltrexone experiment were subjected to an ether extraction procedure. Samples from the acute, intermittent acute hypoxia and MK-80I experiment were assayed directly. Testosterone extraction was performed by adding $5 \mathrm{ml}$ diethyl-ether and vortexing each sample. After settling, the organic phase was transferred to another tube and dried under a nitrogen stream. The extracted testosterone was then solubilized in buffer $(0.1 \mathrm{M}$ sodium phosphate, $0.1 \%$ gel, $0.1 \mathrm{M}$ EDTA, $0.05 \%$ rabbit gamma globulin, $\mathrm{pH} 7.0$ ) at $37^{\circ} \mathrm{C}$ for $\mathrm{Ih}$. Aliquots were taken for RIA. The primary antibody was raised against testosterone-19-carboxymethylester-BSA (ICN, Costa Mesa, CA 92626; cat \#07-189116). After incubation of the sample with primary antibody and $20,000 \mathrm{cpm}$ of [1-125]-testosterone (ICN; cat $\# 07-189 / 26)$ at $4^{\circ} \mathrm{C}$ overnight, $0.5 \mathrm{ml}$ of a $1: 9$ dilution of goat-anti-rabbit gamma globulin (Henninger, Provo, UT) which contained 5\% PEG, was added to each tube. The tubes were subsequently vortexed, and then centrifuged at $2000 \times \mathrm{g}$ for $20 \mathrm{~min}$ at $4^{\circ} \mathrm{C}$. The supernatant was aspirated and the pellet counted in a gamma counter (Micromedic 4/600) with automatic data reduction software (RIA-AlD; Robert Maciel and Assoc., Inc., Arlington, MA). Standard curves were calculated using the four parameter logistic option. All samples displaced within the 80 to $20 \% \mathrm{~B} / \mathrm{Bo}$ and were run in one assay. The 
within-assay coefficient of variation for pools reading at the 80,50 and $20 \% \mathrm{~B} / \mathrm{Bo}$ were $4.5,6.8$, and $6.9 \%$, respectively in the naltrexone study, and $4.8,6.5$, and $6.7 \%$ in the MK80 l study. All quality control pools were within the two standard range of the ICN published concentrations.

\section{Statistics}

Data expressed were analyzed by ANOVA, followed by Tukey`s posthoc multiple comparison test.

\section{RESULTS}

\section{Chronic hypoxia and naltrexone treatment}

As shown in Fig la and b, pups from each of the four treatment groups experienced a significant rise in circulating testosterone concentrations 60 and $120 \mathrm{~min}$ after birth. Treatment $x$ drug $x$ time $\times$ result ANOVA on all four groups, showed a significant effect for treatment $(F[1,190]=5.064 ; p<0.026)$ with hypoxic animals having higher overall testosterone concentrations, and time $(F[5,190]=37.55 ; p<0.0001)$. However, no significant drug effect was observed among treatment groups.

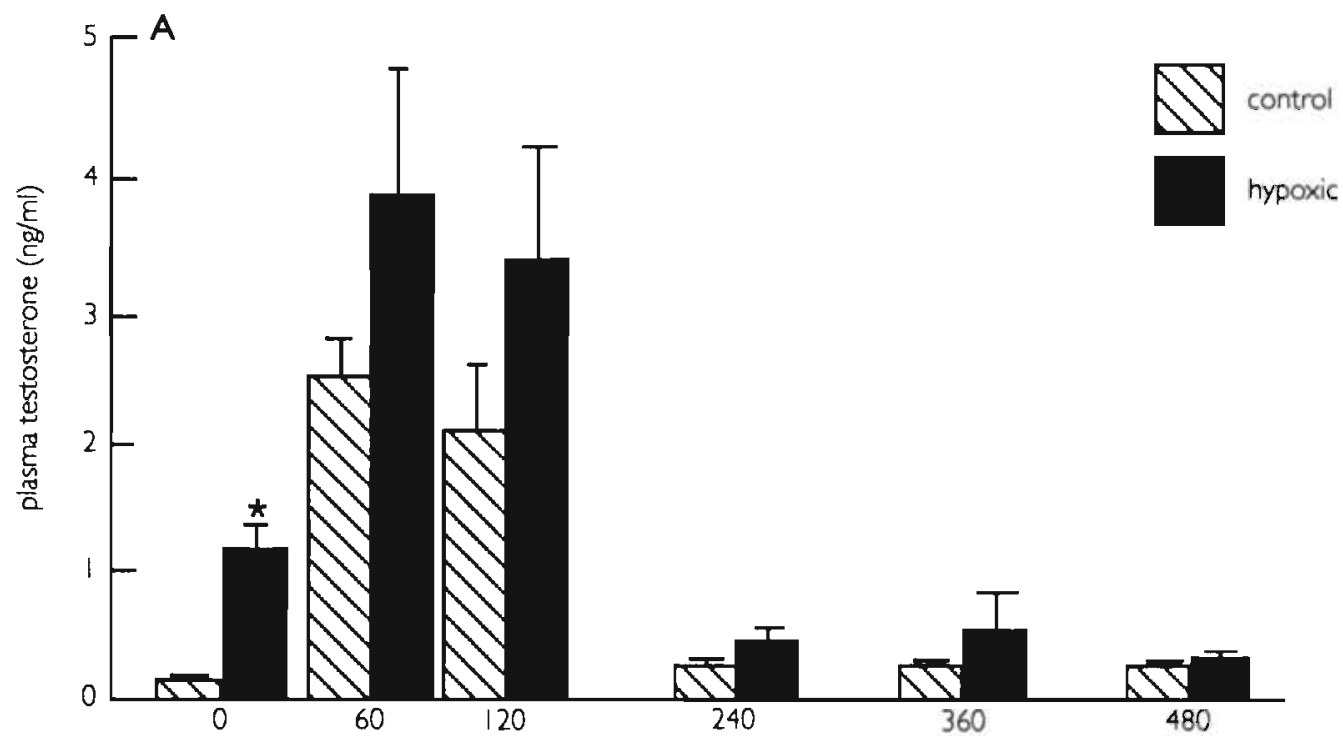

Fig IA. Plasma testosterone concentrations in male neonates from normoxic control dams (hatched bars) and those exposed to chronic hypoxia ( $10.5 \% \mathrm{O}_{2}$ from day 15 to 20 of gestation)(solid bars). Values are mean $\pm S E M$. * indicates $p<0.001$ for hypoxia compared to controls. 


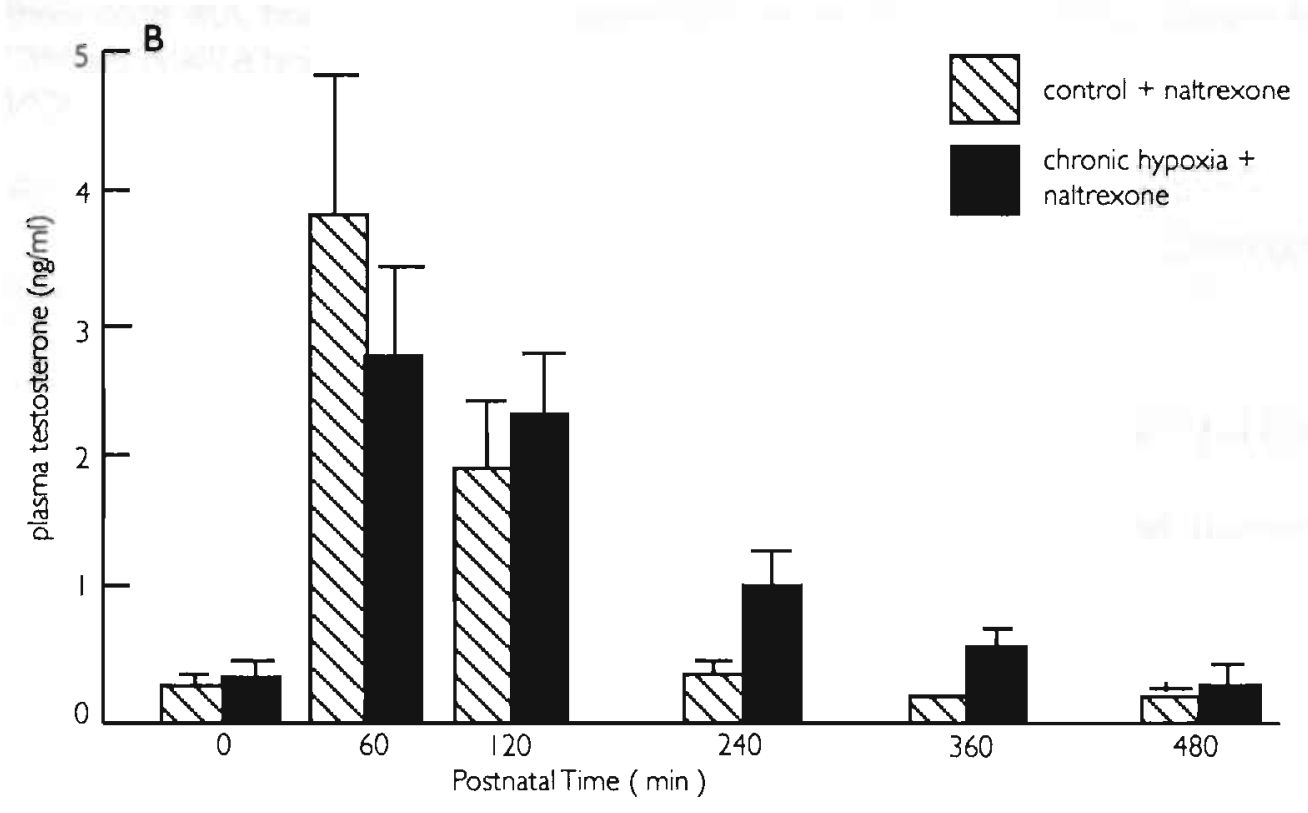

Fig IB. Plasma testosterone concentrations in male neonates from normoxic naltrexone ( $2 \mathrm{mg} / \mathrm{kg}$ twice a day) (hatched bars) treated dams, and those exposed to naltrexone and chronic hypoxio ( $10.5 \% \mathrm{O}_{2}$ from day 15 to 20 of gestation) (solid bars). Values are mean \pm SEM. * indicates $p<0.05$ for naltrexone compared to controls.

In normoxic pups ( $\mathrm{Fig} . \mathrm{Ia}$ ), plasma testosterone concentrations rose from $0.17 \pm 0.03 \mathrm{n} / \mathrm{ml}$ at $0 \mathrm{~min}$ to $2.5 \pm .3 \mathrm{n} / \mathrm{ml}$ at $60 \mathrm{~min}(\mathrm{~F}[\mathrm{I}, 20]=76.413 \mathrm{P}<0.000 \mathrm{I}$ ). By 240 min testosterone concentrations decreased to a similar level as that measured 0 min after birth. In contrast, in hypoxic pups testosterone concentrations were almost sixfold increased at $0 \mathrm{~min}$, compared to controls (hypoxia $=1.14 \pm 0.2 \mathrm{n} / \mathrm{ml}$ and control $=0.17 \pm 0.03$ $\mathrm{n} / \mathrm{ml},(F[3,37]=17.43 ; \mathrm{p}<0.000 \mathrm{I}))$. These increased at 60 and $120 \mathrm{~min}$ to $3.8 \pm 1.0$ and $3.3 \pm 0.9$ respectively (n.s.)

Plasma testosterone concentrations in naltrexone treated normoxic animals did not differ significantly from saline injected animals over the 480 min sampled (Fig /b). The testosterone concentrations of naltrexone treated hypoxic pups at $0 \mathrm{~min}$ also did not differ significantly from that of normoxic control pups (Fig. Ib). Nonetheless, their testosterone concentrations were lower than the untreated hypoxic pups at time 60 and 120 min. At 240 and 360 min after birth the testosterone concentrations of hypoxicnaltrexone pups were significantly higher compared to the three other treatment groups (Fig Ib). By 480 min no significant differences were observed among these groups.

\section{Acute intermittent hypoxia and MK80I treatment}

As shown in Fig. 2a, the postnatal T surge of males exposed to acute, intermittent hypoxia during the last week of gestation was significantly reduced as compared to controls. This effect was observed in males exposed to intermittent hypoxia alone, as 

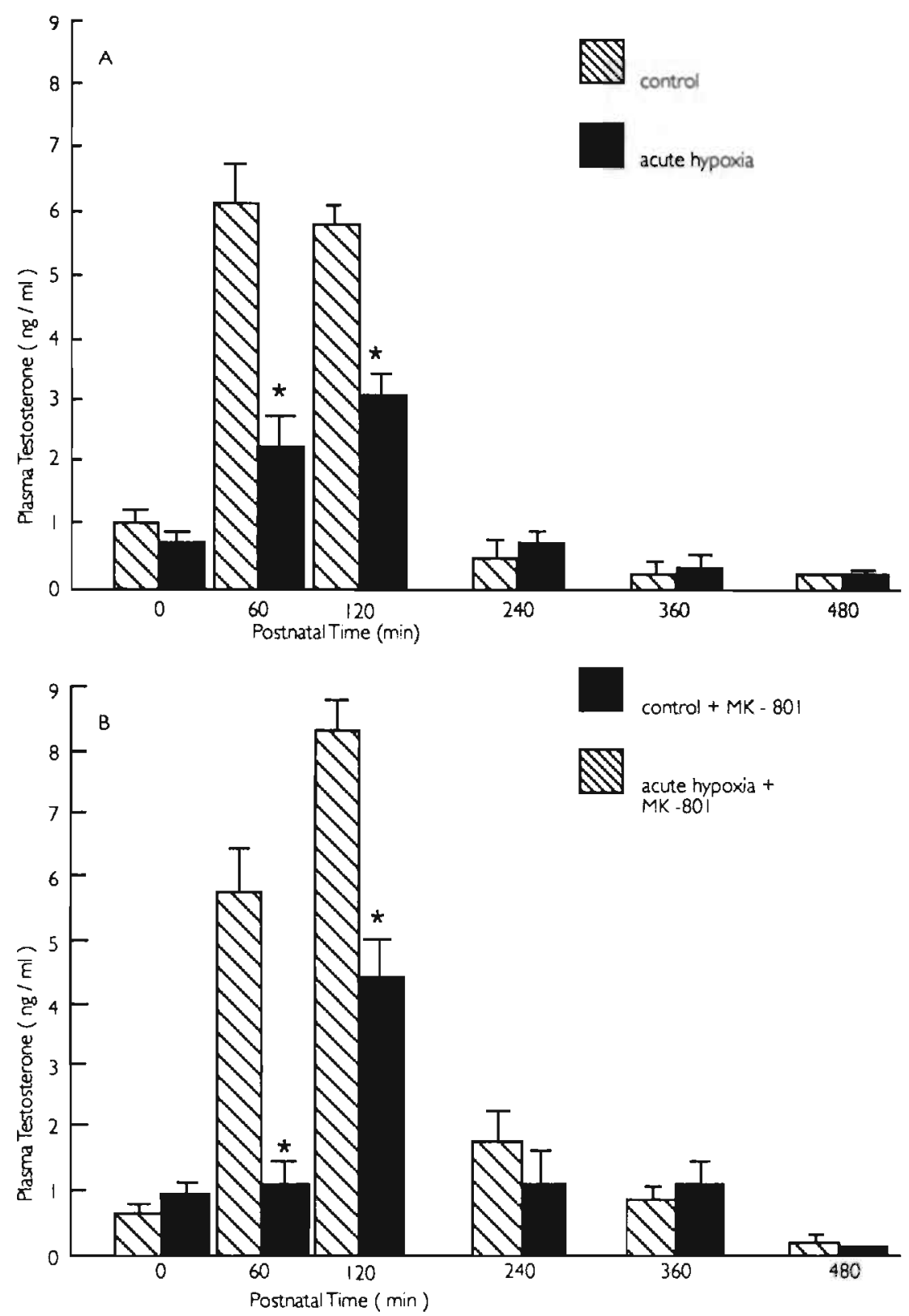

Fig 2A. Plosma testosterone concentrations in male neonates from normoxic control (hatched bars) dams and dams exposed to intermittent acute hypoxia ( $9 \% O_{2} 6$ h/day from day 15 to 21 of gestation) (solid bars). Values are mean \pm SEM. * indicates $p<0.0001$ compared to controls.

Fig 2B. Plasmo testosterone concentrations in male neonates from normoxic control dams exposed to MK-80I (I mg/kg) (hatched bars), and hypoxic ( $9 \% \mathrm{O}, 6 \mathrm{~h} /$ day from day 15 to 21 of gestation) dams treated with MK-80I (solid bars). Values are mean $\pm S E M$. * indicates $p<0.0001$. 
well as hypoxic males treated with MK80 ( $F i g$. 2b). The ANOVA revealed a significant effect of treatment $(F[1,248]=66.06 ; p<0.000 I)$, drug with MK-80I treated pups having higher []$(F[I, 248]=6.44 ; p<0.012)$ time $(F[5,248]=|35.47 ; p<0.000|)$, a treatment $x$ time interaction $(F[15,248]=12.41 ; p<0.0001)$, and a drug $\times$ time interaction $(F[5,248]=7,27 ; p<0.0001)$ with respect to plasma testosterone concentrations. No treatment $\times$ drug $\times$ time interaction was detected. Immediately after birth (time 0 ), the plasma [ $\square$ in $\mathrm{C}$ and $\mathrm{H}$ pups did not differ significantly from one another. However, in $\mathrm{H}$ and $\mathrm{H}-\mathrm{MK}$ pups [T] was significantly lower compared to $C$ and $C-M K$ animals, respectively at $60 \mathrm{~min}$ (Treatment, $F[3,41]=19.98 ; p<0.0001)$ and at $120 \mathrm{~min}(F[3,46]=23.04$; $p<0.0001$ ). In addition, at 120 min C-MK pups had significantly higher $\square]$ compared to untreated controls $(p<0.001$ ). At 240,360 , and 480 min after birth, no significant differences were detected among treatment groups.

\section{DISCUSSION}

The present study demonstrates that acute, intermittent, prenatal hypoxia significantly attenuates the postnatal testosterone surge. In contrast, chronic prenatal hypoxia failed to exert a suppressive effect on postnatal testosterone concentrations. It is postulated that the suppressive effect of a number of maternal interventions such as nicotine, alcohol, and stress, is mediated by stress-related factors. Thus, activation of the hypothalamo-pituitary-adrenal (HPA) axis and other systems, results in elevated cortisol, catecholamine, and endogenous opioid levels. These substances are also known to suppress gonadal output by inhibition of the hypothalamo-pituitary-gonadal (HPG) axis. We postulate that during chronic, prenatal stress both the maternal and fetal system adapt to the ongoing stress, thus failing to interfere with the postnatal testosterone surge. Supportive data for this hypothesis is provided by Harvey and colleagues (unpublished data) who demonstrated both decreased adrenal responsiveness and decreased sensitivity to negative feed-back in long-term hypoxic fetal sheep.

\section{Endogenous opioids}

In the present study, we have demonstrated that chronic prenatal injections with naltrexone failed to interfere with the amplitude or onset of the postnatal testosterone surge of male newborn rats. The lack of effect of naltrexone on the onset of the testosterone surge suggests that endogenous opioids are not involved in its onset or amplitude. Because, mu- and $\varepsilon$-opioid receptors are both highly sensitive to low doses of naltrexone, while relatively large doses are required to antagonize the $\delta$ - or $\kappa$-receptors, we cannot exclude that the testosterone surge may be mediated via the latter opioid receptors. Additional evidence is provided by the fact that autoradiographic studies demonstrated a significant reduction of $\mu$-opioid receptor number in the caudate-putamen, zona germinata, and in the lateral median and medial median preoptic areas of the hypothalamus following chronic hypoxia (27). This suggests down-regulation of opioid receptors following exposure to high opioid levels. These reduced $\mu$-receptor numbers were measured in neonates which experienced a normal testosterone surge. However, in both humans, and rats opioid antagonists elevates plasma ACTH, and corticosterone con- 
centrations $(13,30,43)$. Opiate receptors have a role in the negative feedback system controlling the HPA-axis, and opiate antagonists disinhibit the system resulting in stimulation. Thus, naltrexone elevates both corticosterone and opioids, which may account for the lack of effect on the postnatal testosterone surge.

Perinatal exposure to opioids or peptide opioid agonists results in behavioral effects suggesting a role of endogenous opioids in the mechanisms of sexual differentiation of the brain. For example, neonatal B-endorphin administration ( $\mathrm{PI}$ to $\mathrm{P} 5$ once/day) resulted in lower mounting frequencies when tested for adult sexual behavior (32). Prenatal B-endorphin treatment increased feminine potentials in male offspring, and lower preference for estrous females (25). Prenatal exposure to morphine resulted in lowered frequency and quality of lordosis behavior of the female offspring (4I). However, male sexual behavior was not affected by prenatal morphine. In contrast, Ward (45) observed reduced ejculatory behavior and increased lordosis behavior in male offspring of pregnant dams treated with morphine. Naltrexone treatment of male and female neonates ( $\mathrm{PI}$ to $\mathrm{PIO}$ ) failed to alter either adult male copulatory or exploratory behavior (33). In contrast, females displayed enhanced lordosis and exploratory behavior following neonatal naltrexone treatment. Ward and colleagues (46) demonstrated that naltrexone blocked the effects of prenatal stress on sexual behavior in male rats. Male offspring of rats exposed to restraint stress during pregnancy showed increased lordotic behavior when tested in adulthood. When mothers were injected with naltrexone prior to stress exposure, the male offspring were protected against the feminizing effect of stress (46).

In adult male rats and other species, it has been clearly established that serum testosterone concentrations are markedly depressed following acute or chronic narcotic administration. A number of studies have demonstrated that endogenous opiates inhibit LH output, which results in reduced testicular steroidogenesis $(7,8,9)$. In the adult rat, endogenous opioids may mediate gonadotrophin secretion during acute stress, but not during chronic stress (19). For instance, chronic restraint stress inhibited plasma $\mathrm{LH}$, $\mathrm{FSH}$, and lowered hypothalamic $\mathrm{GnRH}$ content. This decline was not reversed by naltrexone. However in acutely stressed rats, naltrexone increased plasma $L H$ concentrations (19). Several observations suggest that the opioid antagonist naloxone is not capable of releasing the opiate inhibition of $\mathrm{LH}$ prior to the onset of puberty $(23,26)$. Shiskina and colleagues (38) demonstrated that chronic ß-endorphin administration did not affect the concentrations of sex hormones in male and female neonates. However: prenatal methadone treatment to pregnant dams from $\mathrm{E} / 4$ to 19 , significantly reduced basal serum testosterone levels at E2O in male rats (39). Opioids have also been shown to alter steroidogenesis at the gonadal level. Intratesticular enkephalin administration in 5 day old neonates, suppressed basal testosterone secretion. Naloxone treatment prior to enkephalin treatment prevented this suppression (18). Fabri and colleagues (15) showed that in culture the fetal Leydig cell produces B-endorphins. However, acute or chronic B-endorphin treatment failed to affect in vitro testosterone production by the fetal testis (14). 


\section{NMDA receptors}

Acute, intermittent hypoxia, markedly inhibited the magnitude of the postnatal testosterone surge (Fig. 2a). Nonetheless, the inhibitory effect of hypoxia on postnatal testosterone secretion was not antagonized by MK80I. The amount of testosterone secreted by H-MK pups in the first two hours after birth did not differ significantly from that secreted by H pups. MK80I treatment alone did not inhibit postnatal testosterone secretion and, in fact, produced a significant enhancement of the testosterone surge over the 480 min test period, as compared to controls (Fig 2b). This suggests that NMDA receptors are not involved in the suppressive effect of acute, intermittent hypoxia on the testosterone surge. Hypoxic/ischemic events induce an elevation of excitotoxic amino acids (EAA) concentrations (44). N-methyl-D-aspartate (NMDA) is known to raise adrenocorticotrophin and beta-endorphin levels in rats $(16,24)$. Activation of stressrelated compounds such as endorphins, cortisol, and catecholamines are believed to be major factors in mediating the suppression of perinatal testosterone concentrations in male rats following environmental treatments of pregnant mother. In addition, MK-80I is known to block the effects of opioids (29) as well as NMDA receptors, and to protect the developing brain against ischemic and hypoxic insults $(17,40)$. Thus, the lack of effect of MK-80I treatment following hypoxia may provide indirect evidence of the lack of opioid involvement in the regulation of the postnatal testosterone surge.

In adult animals it is well recognized that following acute administration, excitatory amino acids are involved in gonadal function, through the activation of $\mathrm{LH}$ secretion (4.35). Conversely, in adults MK-80I significantly decreased LH production (3I). There is evidence that the EAA effect on gonadotrophins can be reversed in the absence of gonadal steroid regulation. In ovariectomized immature female rats, NMDA inhibited LH secretion, whereas in adult proestrus females, it stimulated $\mathrm{LH}$ secretion (5). In longterm ovariectomized thesus monkeys, NMDA decreased plasma LH concentrations, but increased plasma cortisol concentrations. Pretreatment with CRF antiserum or naloxone, prevented the decrease in $\mathrm{LH}(36)$. The authors suggested that, activation of the HPA-axis by NMDA inhibited LH secretion in ovariectomized monkeys (36). In fetal and neonatal rats the majority of estrogen is bound to alpha fetoprotein, creating a low estrogen environment. Further studies need to determine the exact role of NMDA and MK801 in the regulation of the testosterone surge. However, the hypoxia-induced attenuation in postnatal testosterone concentrations appears not to be mediated by NMDA receptors. There appears to be age dependent sensitivity to NMDA antagonists, which may contribute to the lack of effect by MK-80I (2). Bardgett and colleagues (2) observed that systemic NMDA treatment of neonatal rats at 9 and 20 days of life resulted in significant increased $\mathrm{ACTH}$ concentrations. Pretreatment with the competitive NMDA antagonist ( \pm )-3-(2-carboxypiperazin-4-yl)-propyl-1-phosphonic acid (CPP) failed to attenuate the $\mathrm{ACTH}$ response in the younger rats, yet reduced the response in older ones (2). 


\section{CONCLUSIONS}

We conclude that chronic intermittent naltrexone treatment fails, to interfere significantly with the postnatal testosterone surge: in the rat. Prenatal MK- $80 \mathrm{I}$ treatment increased postnatal testosteone concentartions compared to controls. Further studies need to elucidate the systems regulating onset and magnitude of the postnatal testosterone surge. In addition, studies need to explore the involvement. of stress related factors in the suppressive effect of prenatal hypoxia on the postnatal testosterone surge.

\section{SPECULATION}

We speculate that some placental or maternal factor is involved in the onset of the testosterone surge. The concentration in neonatal blood of multitude of peptides and hormones from maternal origin rapidly decrease in the first hours after birth. Withdrawal of such a factor may trigger the testosterone surge. 


\section{REFERENCES}

I. Ahluwalia, B.S... J.F. Clark Westney, D.M. Smith, M. James, S. Rajgun. Amniotic fluid and umbilical artery levels of sex hormones and prostaglandines in human cocaine users. Reprod Toxicol. 6:5762. 1992.

2. Bardgett, M.E., G.T. Taylor, and I.M. Farah. Systemic NMDA treatment increases plasma ACTH in the neonatal female and male rat. Develop. Brain. Res. 68:289-293, 1992.

3. Beatty, W.W. Gonadal hormones and sex differences in non-reproductive behavior in rodents: Onganizational and activational effects. Hormones \& Behavior 12:112-163, 1979.

4. Bourgignon, J.P., A. Gerard, ML. Alvarez-Gonzalez, L Fawe, P. Franchimont. Gonadal-independent developmental changes in activation of $\mathrm{N}$-methyl-D-aspartate receptors involved in gonadotropinreleasing hormone secretion. Neuroendocrinology. 55:634-641, 1992.

5. Bran, D.W., and V.B. Mahesh. Excitatory amino acid regulation of gonadotropin secretion: modulation by steroid hormones. J. Steroid Biochem. Mol. Biol. 41:847-850, 1992.

6. Cicero, T.J. Opiate-mediated control of luteinizing homone in the male: physiological implications. In: Opioid modulation of endocrine function, Eds G. Delitala et al. Raven Press New York, $211-222,1984$.

7. Cicero, T.J., B.A. Schainker, and ED. Meyer. Endogenous opioids participate in the regulation of the hypothalamic-pituitaryluteinizing hormone axis and testosterone's negative feedback control of luteinizing hormone. Endocrinology. 104:1286-1291, 1979.

8. Cicero, T.J., RD. Bell, E.R Meyer, and I. Schweitzer. Narcotics and the hypothalamic-pituitarygonadal axix. acute effects on luteinizing hormone, testosterone and androgen-dependent. systems. J. Pharmacol. Exp. Ther. 201:76-83, 1977.

9. Cicero. T.j., E.R Meyer, RD. Bell, and G.A. Koch. Effects of morphine and methadone on serum testosterone and luteinizing hormone levels and on the secondary sex organs of the male rat Endocrinology. 98:367-72, 1977.

10. Corbier, P., L. Dehennin, M. Castanier, A. Mebazaa, D.A. Edwards, and I. Roffi. Sex differences in serum luteinizing hormone and testosterone in the human neonate during the first few hours after birth. J. Clin. Endocrin. Metabol. 71:1344-1348, 1990.

II. Corbier, P., B. Kendelhue, R. Picon, and J. Roffi. Changes in testicular weight and senum gonadotropin and testosterone levels before, during, and after birth in the perinatal rat. Endocrinology 103:1985-1991. 1978.

12. Crabtree, B.L. Review of naltrexone, a long-acting opiate anatagonist. Clin. Pharm. 3:273-280, 1984.

13. Eisenberg. RM. Effects of nattrexone on plasma corticosterone in opiate-naive rats: a central action. Life Science. 34:1185-1191, 1984.

14. Fabri, A. and M.L. Dufau. Hormonal regulation of beta-endorphin in the testis. J. Steroid Biochem. 30:347-352, 1988.

15. Fabri, A., G. Knox, E. Buckzo, and M.L Dufau. Beta-endorphin production by the fetal Leydig cell: regulation and implications for paracrine control of Sertoli cell funtion. Endocrinology.

122:749-755, 1988.

16. Farah, J.M. T.S. Rao, S.J. Mick J. Michel, and S. lyengar.N-methyl-D-aspartate acid treatment increases circulating ACTH and immunoreactive betaendorphin in rats. Endocr. Soc. Abstr. 71:180, 1989.

17. Ford, L.M., P.R. Sandberg, A.B. Norman, and M.H. Fogelson. MK-80I prevents hippocampal neurodegeneration in neonatal hypoxic-ischemic rats. Arch. Neurol, 46:1090-1096, 1989.

18. Gerendai, I., A. Nemeskeri, and V. Csemus. Intratesticular injection of [D-Met2-Pro5] enkephalinamide suppresses testosterone secretion of the testis of immature rat. Regul. Pept. 27:107.115, 1990.

19. Gonzalez-Quijano, M.I., C. Anznavarrettam, A.l. Martin, J.A.F. Treguerres, and A. Lopez-Calderon. Naltrexone does not reverse the inhibitory effect of chronic restraint on gonadotropin secretion in intact male rat. Neuroendocrinology 54:447-453, 1991. 
Goy, RW. \& McEwen, B.S. Sexual Differentiation of the Brain. MIT Press, Cambridge, MA. 1980. Habert, R and R Picon. Control of testicular steroidogenesis in foetal rat: Effect of decapitation on testosterone and plasma luteinizing hormonelike activity. Acta Endocrinol. 99:466-473, 1982. Hermans, RH.M., R.F. McGivem, L.D. Longo. Decreased postnatal testosterone and corticosterone concentrations in rats following acute intermittent prenatal hypoxia without alterations in adult male sexual behavior. Neurotoxicol. Teratol. in press.

23. leiri, T., H.T. Chen, J. Meites. Effects of morphine and naloxone on serum levels of luteinizing hormone and prolactin in prepubertal male and female rats. Neuroendocrinology 29:288-292, 1979.

24. Jezova, D., C Olivier, and J. Jurcovicova. Stimulation of adrenocorticotropin but not prolactin and catecholamine release by N-methyl-aspartic acid. Neuroendocrinology 54:488-492, 1991.

25. Kashon, M.L., O. Byron Ward, W. Grisham, and I. Ward. Prenatal ß-endorphin can modulate some aspects of sexual differentiation in rats. Behav. Neurosci. 106:555-562, 1992.

26. Kalra, S.P.,and P.S. Kalra. Opioid-adrenergic-steroid connection in regulation of luteinizing hormone secretion in the rat. Neuroendocrinology, 38:418-424, 1984.

27. Kraczkowski, J.J., F.M. Leslie, and L.D. Longo. Chronic prenatal hypoxia decreases mu-opioid receptor binding in newbom rat brain: quantitative autoradiographic analysis. Society for Gynecologic Investigation 40th annual meeting, Program: Abstract PI68, 1993.

Lieberburg, I., Krey, L.C and McEwen, B.S. Sex difference in serum testosterone and in exchangeable brain cell nuclear estradiol during the neonatal period in rats. Brain Res. 207-212, 1979.

Lipa, S.M. and Kavaliers, M. Sex differences in the inhibitory effects of the NMDA antagonist, MK-80I on morphine and stress-induced analgesia. Brain Res. Bull. 24:627-30, 1990.

30. Lymangrover, J.R, L.A. Dokas, A. Kong, R. Martin, and M. Saffran. Naloxone has a direct effect on the adrenal cortex. Endocrinology, 109:1132-1137. 1981.

31. Meijs-Roelofs, H.M., P. Kramer, E.C. van Leeuwen. The N-methyl-D-aspartate receptor antagonist MK- 80 I delays the onset of puberty and may acutely block the first spontaneous $\mathrm{LH}$ surge and ovulation in the rat. J. Endocrinol. 131:435-441, 1991.

32. Meyerson, B.J. Neonatal B-endorphin and sexual behavior. Acta Physiol. Scand. 1/15:159-160. 1982.

33. Meyerson, B.J., M. Berg, B. Johansson. Neonatal naltrexone treatment: effects on sexual and exploratory behavior in male and female rats. Pharmacol. Biochem. Behav. 31:63-67, 1988.

34. Naftolin, F. and MacLusky, N. Aromatization Hypothesis Revisited. In: Sexual Differentiation: Basic and Clinical Aspects., Serio, M. et al. (eds), pp. 79-91, 1984.

35. Price, M.T., J.W. Olney, T.J. Cicero. Acute elevation of serul luteinizing hormone induced by kainic acid, N-methyl-aspartic acid and homocisteic acid. Neuroendocrinology. 26:352-358, 1976.

36. Reyes, A., J. Luckhaus, and M. Ferin. Unexpected inhibitory action of n-methyl-d,l- aspartate on luteinizing hormone release in adult ovariectomized rhesus monkeys: a role of the hypothalamicadrenal axis. Endocrinology, 127:724-729, 1990.

37. Roffi, J., P. Corbier, and B. Kerdelhue. Stimulation de la secretion de LH et de FSH et augmentation du poids testiculare la naissance, chez le Rat. C.R. Acad. Sc. Paris 284:1313 1316, Serie: D. 1977.

38. Shiskina, I.V., V.N. Babichev, and I. Pankov. Effects of endogenous opioids on the development of reproductive function in rats. Biull. Eksp. Biol. Med. I 12:232-234, 1991.

39. Singh, H.H., V. Purohit, and B.S. Ahluwalia. Effect of methadone treatment during pregnancy on the fetal rat testes and hypothalamus in rats. Biol. Reprod. 22:480-485, 1980.

40. Speiser, Z., J. Uziel, R. Deffin-Assa, S. Gitter, and G. Urca. Different behavioral deficits are induced by anoxia/hypoxia in neonatal and senescent rats: blockade by MK-80I. Behav. Brain Res. 42:181.186, 1991 .

41. Vathy, I.U., A.M. Etgen, and R. Barfield. Effects of prenatal exposure to morphine on the development of sexual behavior in rats. Pharmacol. Biochem. Behav. 22:227-232, 1985.

42. Vezzani, A., R Serafini, M. Stasi, S. Caccia, I. Conti, R Tridico, and R Samanin. Kinetics of MK-80। and its effect on quinolinic acid-induced seizures and neurotoxicity in rats. J. Pharmacol. Exp. Ther. 249:278-283, 1989. 
43. Volavka, J., D. Cho, A. Mallya, and J. Bauman. Naloxone increases ACTH and cortisol in man. N. Eng. J. Med. 300:1056-1057, 1979.

44. Vomov, J.J. and J.T. Coyle. Enhancement of NMDA receptor-mediated neurotoxicity in the hippocampal slice by depolarization and ischemia. Brain Res. 555:99-106, 1991.

45. Ward, O.8. J.M. Orth, and J. Weisz A possible role of opiates in modifying sexual differentiation. In M. Schlumpf and W. Lichtensteiger (Eds), Drugs and Hormones in Brain Development. Basel: Karger, 1983.

46. Ward, O.B., E.P. Monaghan, and I.L Ward. Naltrexone blocks the effects of prenatal stress on sexual behavior differentition in male rats. Pharmacol. Biochem. Behav. 25:573-576, 1986.

47. Wardlaw, S.L. RI. Stark, S. Daniel, and A.G. Frantz. Effects of hypoxia on beta-endorphin betalipoprotein release in fetal newbom, and matemal sheep. Endocrinology. 108:1710-1715, 1981.

48. Warren, D.W., G.C. Haltmeyer, and K.B. Eik-Nes. Testosterone in the fetal rat testis. Biol. Reprod. 8:560-565, 1973.

49. Weisz, J. I.L. Ward. Plasma testosterone and progesterone titers of pregnant rats, their male and female fetuses, and neonatal offspring. Endocrinology 106:306-316, 1980.

50. Westney, L; Bruney, R; Ross, B.; Clark J.F; Rajguru, S.; Ahluwalia, B. Evidence that gonadal hormone levels in amniotic fluid are decreased in males born to alcohol users in humans. AlcoholAlcohol. 26:403-407:1991. 


\title{
VII. THE POSTNATAL TESTOSTERONE SURGE IS NOT PRECE- DED BY A POSTNATAL RISE IN PLASMA LHB IN THE RAT
}

\author{
McGivern, R.F., R.H.M. Hermans, B. Handa and LD. Longo. Submitted
}

\section{ABSTRACT}

Results of the role of $\mathrm{LH}$ in the initiation of the postnatal surge of testosterone in the male rat have produced ambiguous results based upon a radioimmunoassay employing an $\mathrm{LH}$ antibody which is not specific for the biologically active beta subunit of the peptide. We examined the pattern of postnatal LHß secretion in the newborn male rat coincident with plasma testosterone levels, using a specific antibody. In an attempt to block LH secretion immediately after parturition, some animals were injected with a $\mathrm{GnRH}$ antagonist, an $\mathrm{LH}$ antibody, or progesterone. Male offspring from time-pregnant Sprague-Dawley dams were delivered by cesarean section on day 22 of gestation and immediately injected with saline, $\mathrm{GnRH}$ antagonist (5 $\mu \mathrm{g}, 60 \%$ saline and $40 \%$ propylene glycol s.C.), LH-antibody ( $1: 187$ dilution in saline, s.c.), progesterone ( $10 \mathrm{ng}, 60 \%$ ethanol solution, s.c.), or the ethanol vehicle $(60 \%$ solution), each in $50 \mu$ volume. Following injection, the pups were kept in a humidified incubator maintained at $30^{\circ} \mathrm{C}$ until they were killed by decapitation at 60, 120,240,360 or $480 \mathrm{~min}$ after delivery. Plasma from individual animals was subsequently measured for $\mathrm{LH}$ and testosterone by RIA. Results revealed a postnatal surge of testosterone in all groups which peaked at 2 hours after delivery. The postnatal surge of testosterone was not accompanied by a surge of LHB in any group. Administration of the $\mathrm{GnRH}$ antagonist or the ethanol vehicle produced a transient drop of approximately $25 \%$ in LHB levels at 60 min, but did decrease the postnatal testosterone surge in the same animals. Additional studies in untreated males and females born by cesarian section or natural birth also failed to reveal a postnatal rise in plasma LHß during the first 3 hours after birth. Plasma levels in both sexes were significantly lower in animals delivered by cesarian section compared to natural birth. Overall, these results indicate that the postnatal surge of testosterone occurs without a corresponding surge of $L H B$ in the male rat.

\section{INTRODUCTION}

In the male rat, the perinatal organization of both reproductive and nonreproductive sexually dimorphic behaviors has been demonstrated to be critically dependent on androgen levels $(4,14)$. Complete masculinization of the rat brain requires elevated circulating testosterone ( 1 ) concentrations, and subsequent aromatization of testosterone to estradiol $(21,25)$. Two perinatal surges of $\mathrm{T}$ in the male provide the primary source of estrogen for masculinization of the brain during this period. In the rat fetus, a significant increase in circulating T concentration occurs on days 18 and 19 of gestation ( 18 , $23,37,39)$. A corresponding prenatal surge of $T$ also occurs in humans during the second trimester (35). In several species including humans, rats, mice, and horses a 
second T surge peaks 2 to 12 hours after birth (see 9 for review). In the rat, suppression or abolition of this postpartum surge is associated with long-term decreases in reproductive and non-reproductive sexually dimorphic behaviors in males $(10,22,24)$.

Currently, there is limited information regarding factors which regulate the onset or amplitude of the postnatal T surge. However, it has been generally assumed that this regulation involves gonadotropin stimulation of the fetal and neonatal testes which operates in the fetus and neonate in a fashion similar to that in the adult (e.g. 1, 7, 10,20, 26). This assumption is supported by data demonstrating sharp rises in pituitary $\mathrm{LH}$ content on days 17 and 18 of gestation (26) and at birth (1,26). In addition, fetal testicular $\mathrm{LH}$ receptors are detectable by day 15.5 of gestation (38) and testosterone secretion of fetal and neonatal testes exhibit a marked rise in response to gonadotropin stimulation in vivo and in vitro $(35,24,16,17,29)$. In the original study of Corbier et al (1), LH was observed to exhibit a dramatic postnatal rise coincident with the $T$ surge in animals from natural delivery. A much smaller rise in $\mathrm{LH}$ was also observed by Pang et al (27).

Data inconsistent with a regulatory role for $\mathrm{LH}$ in the perinatal surges of $\mathrm{T}$ comes from several studies. Slob et al, (34) failed to observe any elevation in $\mathrm{LH}$ to accompany the postnatal $T$ surge in a study using pooled samples from males delivered by natural birth. In spite of a minimal rise in postnatal LH levels, Corbier and coworkers ( 1 ) observed a postnatal rise in plasma $T$ in males delivered on day 20 by cesarian section which equalled that of natural birth males. In addition, the interpretation of the LH data from this study of both natural and cesarian sectioned males is limited by the fact that $\mathrm{LH}$ data at critical time points $(0-2 \mathrm{~h}$ postnatally) were derived from only a single measurement of a pooled sample.

An ambiguous role for $\mathrm{LH}$ in the stimulation of $T$ secretion during the perinatal period in normal human fetal males is indicated by the fact hCG failed to stimulate adenylate cyclase activity or T secretion from homogenates of fetal testes (40).

Due to technical limitations, previous studies of the postnatal $T$ surge in rats have been forced to measure $\mathrm{LH}$ in blood samples pooled from several animals $(11,27,34)$. Further, the antibodies available for radioimmunoassay could not discriminate between the alpha and beta subunits of the peptide. Advances in recent years have demonstrated that $L H B$ is the biologically active subunit (6). The present study was therefore designed to measure $\mathrm{LH} B$ and $T$ in plasma samples from individual animals to determine whether the biologically active subunit of the $L H$ protein, $L H B$, exhibited a rise in plasma which was coincidental with the postnatal $T$ surge. To further examine the stimulatory role of $\mathrm{LH}$ in this surge, some animals were treated with a $\mathrm{GnRH}$ antagonist or an $\mathrm{LH}$ antibody at the time of delivery. In addition, we also explored a potential role for progesterone as a maternal factor involved in the regulation of the postnatal $T$ surge. Progesterone concentration decreases $80 \%$ in the first hour after birth in the rat $(30)$. In adult males, progesterone decreases circulating $T$ concentrations through an inhibitory action on the level of the pituitary and/or gonads (2). In neonatal rats, this steroid has been proposed to have a general inhibitory effect on limbic electrophysiological activity (5). Taken together, these data suggest that progesterone may be a maternal or placental factor regulating the postnatal $T$ surge. 


\section{METHODS}

Forty Sprague Dawley rats (Charles River, Portage, MI) were time mated by the breeder and arrived in our laboratory on day || of gestation. The day of conception was defined as Day I of gestation. All the rats were individually housed in translucent maternity cages with free access to food and water. The animals were housed in a separate climate controlled vivarium room (temperature $=23^{\circ} \mathrm{C}$, humidity $=45-55 \%$ ) under a $12 \mathrm{~h}$ light dark cycle with lights on at $0700 \mathrm{~h}$.

\section{Postnatal concentrations of testosterone and LHß in males following C-section}

On the morning of E22 (0800 to 1200 h), we sacrificed pregnant female rats by cervical dislocation. Pups were subsequently delivered by hysterotomy within 5 min after cervical dislocation and sexed by visual assessment of anogenital distance. Male pups were immediately injected with saline, $\mathrm{GnRH}$ antagonist $(5 \mu \mathrm{g}, 60 \%$ saline and $40 \%$ propylene glycol s.c.), LH-antibody ( $1: 187$ dilution in saline, s.c.), progesterone ( $10 \mathrm{ng}, 60 \%$ ethanol solution, s.C.), or ethanol (60\% solution), each in $50 \mu$ volume. Males within a litter were assigned to different treatment groups. Animals which were used to determine the hormone levels at parturition were drawn from these same litters which supplied littermates for the drug treatments. Animals injected with the ethanol vehicle were sacrificed at 60, 120, 240 or 360 minutes after injection. The GnRH antagonist [AcD2Nal',DCpa $\left.{ }^{2}, \mathrm{DTrp}^{3}, \mathrm{DArg}^{6}\right] \mathrm{GnRH}-\mathrm{HOAc}$ was synthesized at the Salk Institute under Contract NOI-HD-7-2907 with the NIH, and made available by the Contraceptive Development Branch, Center for Population Research, NICHD. The LH antibody was made available by Dr. Al Parlow through support provided by NIDDK, Center for Population Research of the NICHD, and the Agricultural Research Service of the U.S. Dept. Agriculture. Immediately following injection, the pups were placed in plastic weigh boats in an environmental chamber (Fisher Scientific, Tustin CA, low temperature incubator, Model 307) maintained at $30^{\circ} \mathrm{C}$ and $60 \%$ humidity, similar to the procedures of Roffi et al. (31). At $0,60,120,240,360$, and 480 min after delivery, we decapitated the pups (8-14 pups/time point/treatment) and collected trunk blood of each fetus in heparinized capillary tubes. Collection tubes were kept on ice and subsequently centrifuged at $4^{\circ} \mathrm{C}$. Plasma samples were stored $3-4$ weeks at $-70^{\circ} \mathrm{C}$ until the time of assay.

\section{Postnatal LHB concentrations in males and females following natur- al delivery or C-section}

Time pregnant Sprague-Dawley dams from Charles River (Portage, MI) arrived in the laboratory on day 5 of pregnancy. The animals were housed as described as above with food and water available ad libitum. On the morning of the 22nd day of gestation, the animals from 5 dams were delivered by $\mathrm{C}$-section and housed in an incubator as described as above. Animals were killed immediately upon delivery, or at 1, 2 or 3 hours later.

An additional 5 dams were monitored at 15 min intervals until they gave birth naturally. Some pups were removed for sacrifice within 15-30 minutes after the first pup 
of the litter delivered. Additional pups were removed from each litter at 2, 3, and 4 hours after delivery began. Trunk blood was collected as described above.

\section{Testosterone radioimmunoassay}

The primary antibody was raised against testosterone-19-carboxymethylesterBSA (ICN Biomedicals, Costa Mesa, CA). After incubation of the sample with primary antibody and 20,000 cpm of [1-125]-testosterone (ICN; cat \#07-189126) at $4^{\circ} \mathrm{C}$ overnight, $0.5 \mathrm{ml}$ of a $1: 9$ dilution of goat-anti-rabbit gammaglobulin (Henninger, Provo, UT) which contained $5 \%$ PEG, was added to each tube. The tubes were subsequently vortexed, and then centrifuged at $2000 \times \mathrm{g}$ for $20 \mathrm{~min}$ at $4^{\circ} \mathrm{C}$. The supernatant was aspirated and the pellet counted in a gamma counter (Micromedic/4/600, ICN) with automatic data reduction software (RIA-AID; Robert Maciel and Assoc., Inc, Arlington, MA). Standard curves were calculated using the four parameter logistic option.

All samples displaced within the 80 to $20 \% \mathrm{~B} / \mathrm{Bo}$ and were run in one assay. The within-assay coefficients of variation for pools reading at the 80,50 and $20 \% \mathrm{~B} / \mathrm{Bo}$ were $4.5,6.8$, and $6.9 \%$, respectively. All quality control pools were within the two standard range of the ICN published concentrations.

\section{LH radioimmunoassay}

Luteinizing hormone was measured in plasma samples using an anti-bovine $\mathrm{LH} B$

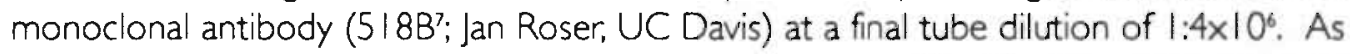
a tracer hormone, NIDDK-rLH-I-6 was radiolabelled with $\left.\right|^{125}$ using chloramine $T$. NIDDK-rLH-RP-3 was used as the reference preparation. The standard curve ranged from 10 to $2000 \mathrm{pg} /$ tube. Incubation was overnight at room temperature and separation of bound and free was accomplished using a goat ant-mouse gamma: globulin (Antibodies Inc., Davis, CA) in 5\% polyethylene glycol. The sensitivity of the assay was approximately $40 \mathrm{pg} /$ tube. Intra-assay variance was $2.1 \%$. All samples; were processed in a single assay to prevent inter-assay variance from biasing the data.

\section{Statistics}

Testosterone data were analyzed using a 4 (treatment) $\times 5$ (time) ANOVA. Post hoc comparisons were made using Student's T-tests. Planned comparisons were made at the $60,120,240,360$ and 480 time points after injection. LHB data were similarly analyzed with the exception that the group administered $\mathrm{LH}$ antibody was not included in the overall analysis since detectable LH levels were not evident after 120 min post injection. This group was subsequently compared to saline and $\mathrm{GnRH}$ antagonist treated animals in a separate ANOVA using the 60 and 120 min time points. Animals administered ethanol alone were compared to saline injected animals in separate analyses. Values from animals measured for comparison of LHB levels between natural and cesarian section delivery were analyzed by a 2 (delivery) $\times 2$ (sex) $\times 4$ (time) ANOVA. 


\section{RESULTS}

A clear surge of $T$ which peaked at approximately 2 hours after parturition was evident in all treatment groups. Data from animals administered saline, $\mathrm{GnRH}$, progesterone or the ethanol vehicle are shown in Figures I-5. A similar T surge was evident in animals treated with the $\mathrm{LH}$ antibody at birth. However, absorption of the antibody, as measured by interference with the binding $\mathrm{LH} 3$ in the RIA, took 2-3 hours, making the treatment ineffective in blocking $\mathrm{LH}$ prior to the occurrence of the surge. The ANOVA revealed a significant main effects for treatment $(F[4,200]=7.06 ; p<0.00001)$ and time $(F[4,200]=68.14 ; p<0.00001$, as well as a significant interaction between the two factors $(F[14,200]=4.76 ; p<0.00001)$. Compared to saline treated animals, no effect of the ethanol vehicle was observed on plasma $T$ at any time point.

Compared to saline treated animals, significant elevations in $T$ levels were observed at $60 \mathrm{~min}$ in $\mathrm{GnRH}$ antagonist $(p<0.01)$ and in progesterone treated animals $(p<0.01)$. At $120 \mathrm{~min}, T$ levels in progesterone treated animals were significantly elevated above saline treated animals $(p<0.05)$.

The analysis of $\mathrm{LH}$ concentrations revealed a significant main effect of treatment $(F[3,127]=9.66)$. Post hoc analyses using planned comparisons revealed that $\mathrm{LH}$ levels were significantly suppressed in $\mathrm{GnRH}$ antagonist treated animals $(p<0.01)$ and ethanol treated animals $(p<0.05)$ at 60 min compared to saline treated animals. Data are shown in Figures $1-5$.

The analysis of $L H B$ in untreated animals delivered by cesarian or natural birth revealed a significant main effect of birth $(F[1,65]=9.09 ; p<0.004)$. Animals delivered by cesarian section had significantly reduced levels of plasma LHß during the first 3 hours after birth than animals delivered by natural birth. There was no significant effect of time or sex, but there was a significant effect between treatment and time $(\{[3,65]=3.023$; $p<0.03$ ). The interaction derived from the decrease in $L H B$ levels at 120 minutes in cesarian animals, was not observed in natural birth animals. Data are shown in Table I.

\section{Table I. LHB values ( $\mathrm{ng} / \mathrm{ml}$ ) in plasma of neonates. Data are mean and SEM. Number of animals sampled at each time point is shown in parentheses}

$\begin{array}{lccccc}\text { Group } & \text { sex } & \mathbf{1 5} \mathbf{- 3 0} \mathbf{~} \mathbf{m i n} & \mathbf{6 0} \mathbf{~} \mathbf{m i n} & \mathbf{I 2 0} \mathbf{~ m i n} & \mathbf{1 8 0} \mathbf{~} \mathbf{8 i n} \\ \text { Cesarian } & M & 0.801 \pm 0.105 & 0.507 \pm 0.075 & 0.596 \pm 0.168 & 0.757 \pm 0.076 \\ \text { Delivery } & & (7) & (5) & (6) & (4) \\ & F & 0.803 \pm 0.81 & 0.723 \pm 0.193 & 0.523 \pm 0.146 & 1.09 \pm 0.172 \\ & & (8) & (5) & (4) & (5) \\ \text { Natural } & M & 1.11 \pm 0.71 & 0.843 \pm 0.14 & 1.03 \pm 0.28 & 0.623 \pm 0.375 \\ \text { Delivery } & & (5) & (5) & (5) & (4) \\ & F & 1.18 \pm 0.112 & 0.861 \pm 0.118 & 1.22 \pm 0.108 & 0.945 \pm 0.158 \\ & & (7) & (5) & (2) & (4)\end{array}$



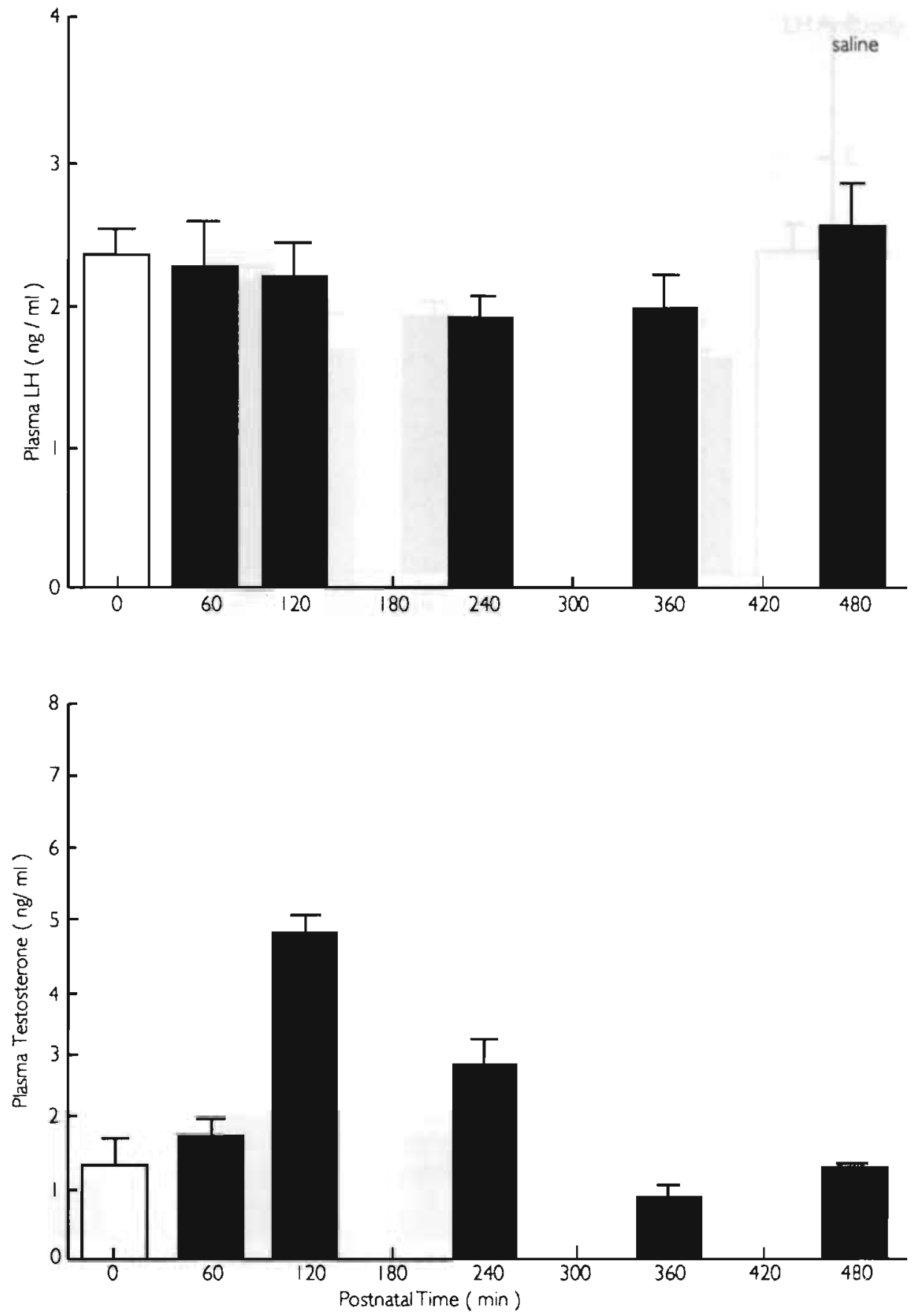

Fig 1. Upper Panel: Plasma LHB concentrations in male neonates injected with saline within 5 min after delivery. Values are mean \pm SEM. Reference standard is LH-RP-3. Lower Panel: Plasma testosterone concentrations in male neonates injected with saline. Values are mean \pm SEM. 

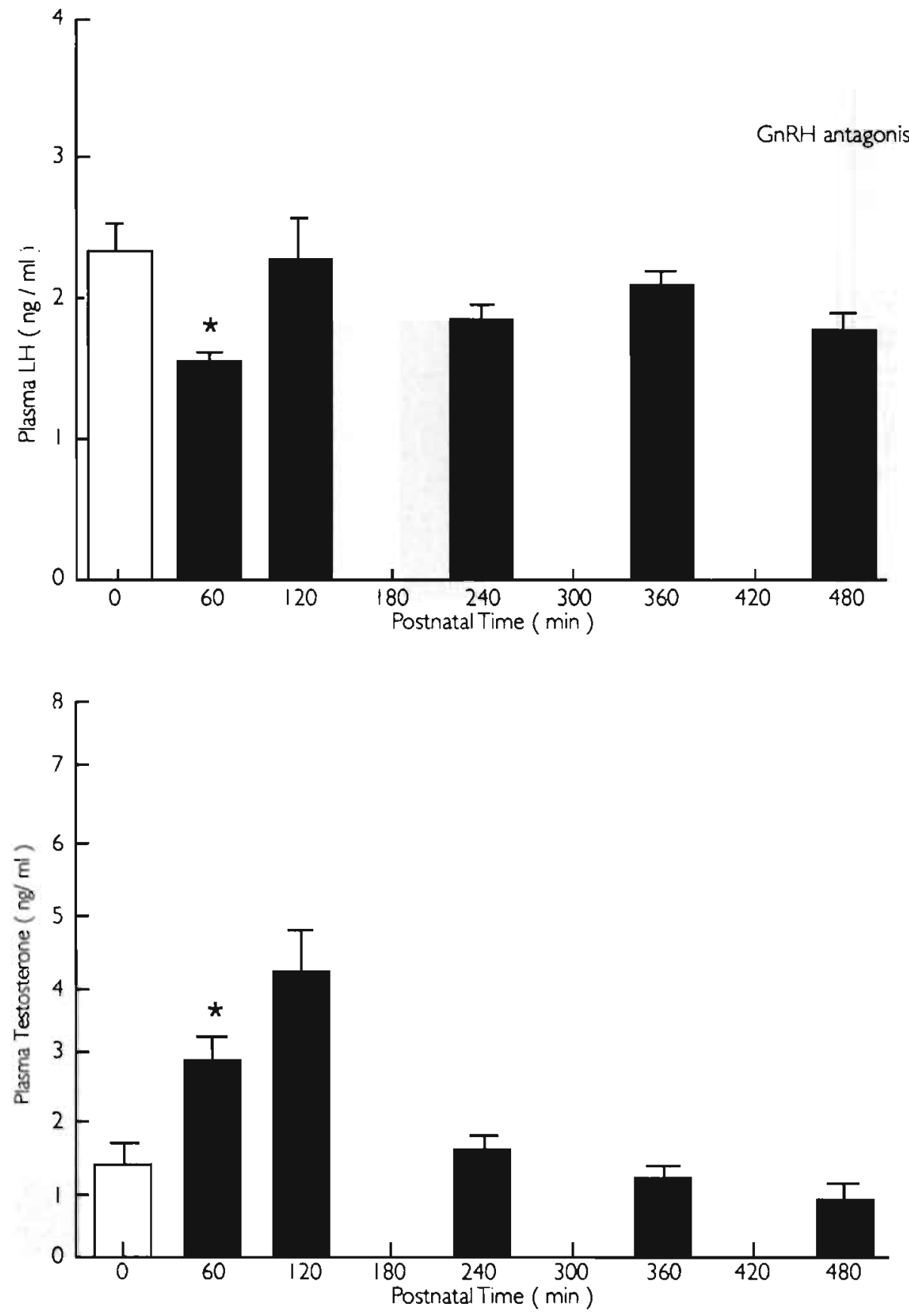

Fig 2. Upper Panel: Plasma $L H B$ concentrotions in male neonates injected with GnRH antogonist within 5 min after delivery. Values are mean $\pm S E M . ~ *=p<0.05$ compared to controls. Reference standard is LH-RP-3. Lower Panel: Plasma testosterone concentrotions in male neonates injected with GnRH antagonist. Values are mean $\pm S E M .{ }^{*}=p<0.01$ compared to controls. 

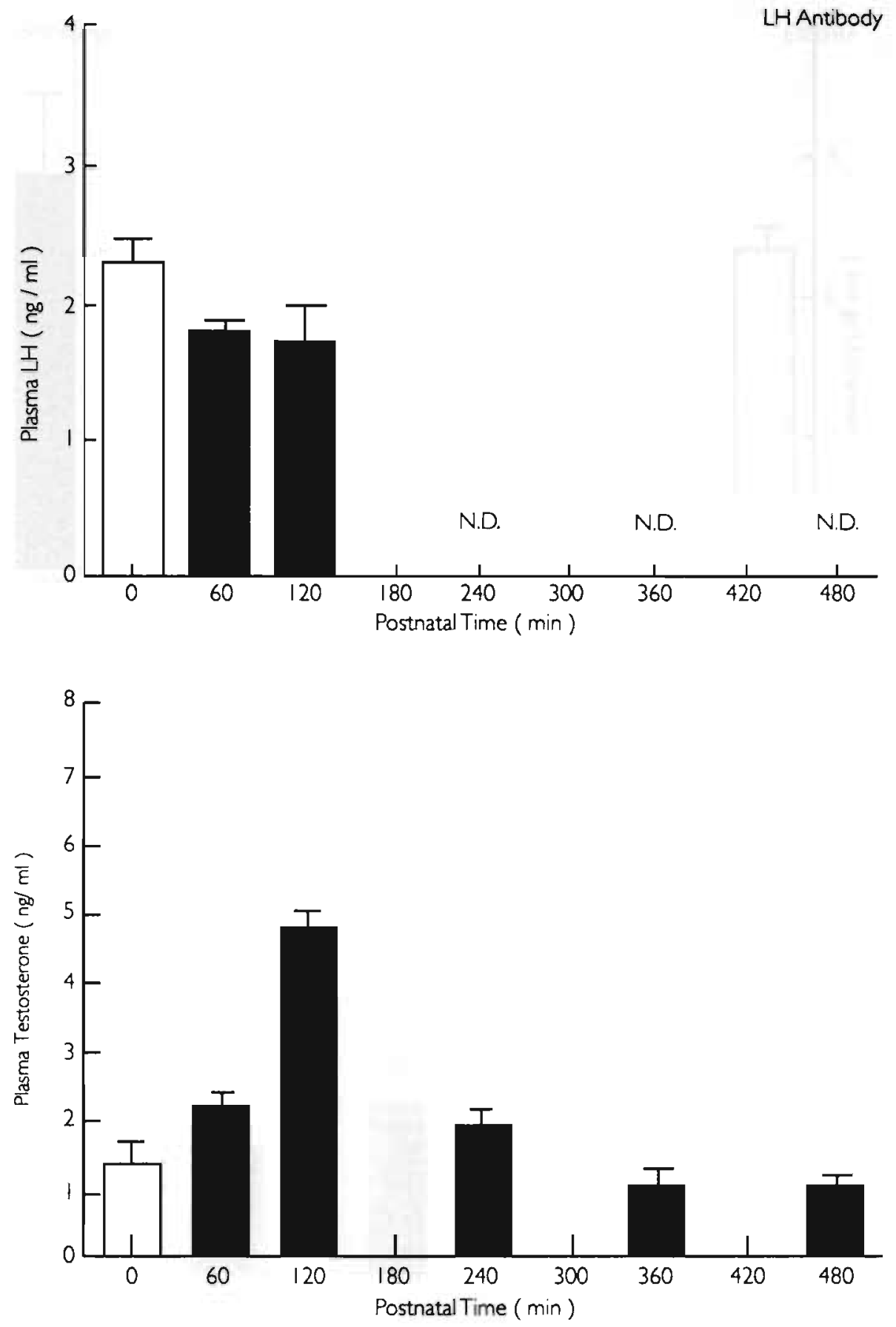

Fig 3. Upper Panel: Plasma $\mathrm{LHB}$ concentrations in male neonates injected with $\mathrm{LH}$ antibody within 5 min after delivery. Values are mean \pm SEM. Reference standard is LH-RP-3. Lower Panel: Plasma testosterone concentrations in male neonates injected with $\mathrm{LH}$ antibody. Values are mean \pm SEM. N.D. $=$ non-detectable. 

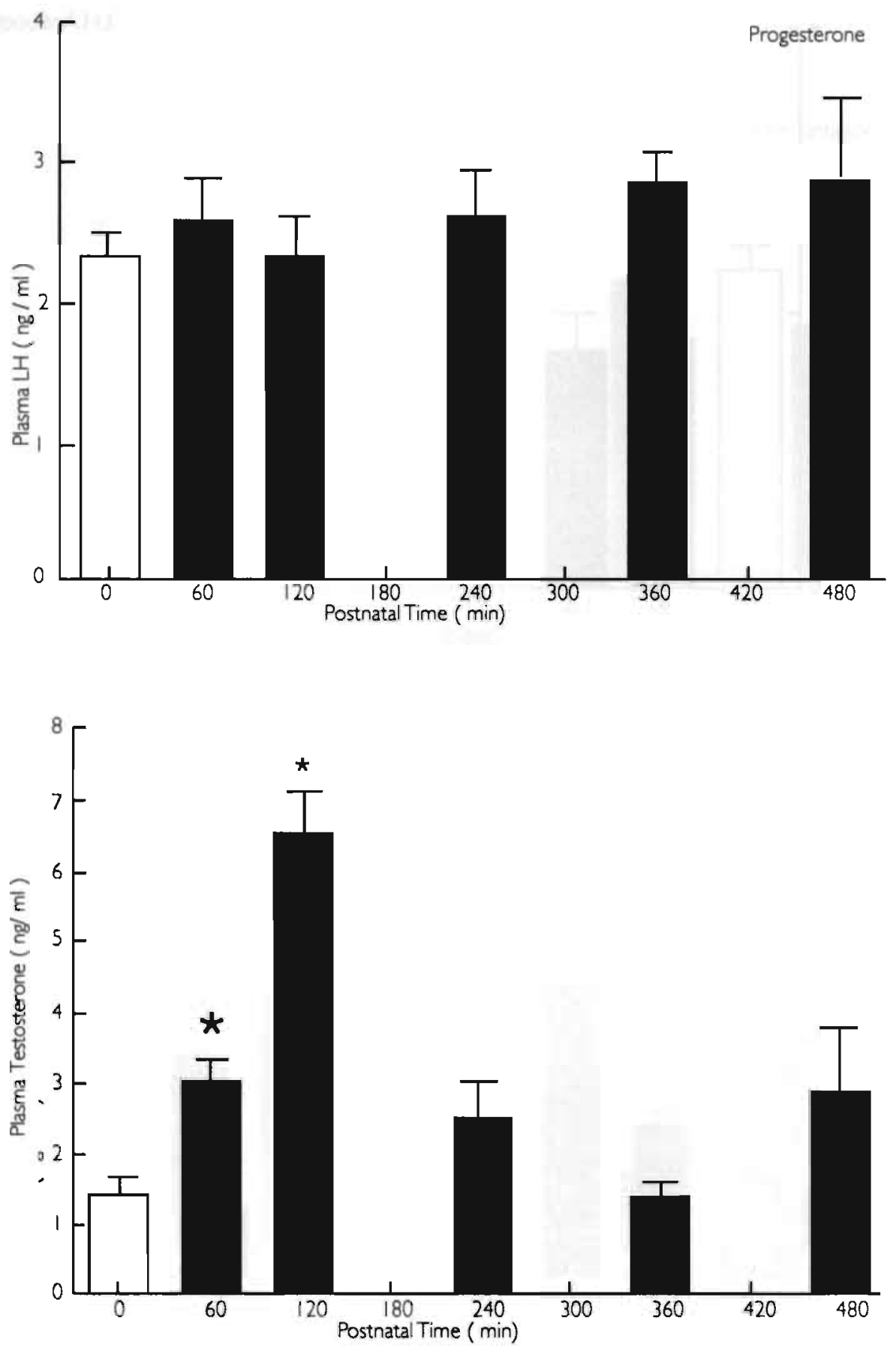

Fig 4. Upper Panel: Plasma LHB concentrations in male neonates injected with progesterone within 5 min after delivery. Values are mean \pm SEM. Reference standard is LH-RP-3. Lower Panel: Plasma testosterone concentrations in male neonates injected with progesterone. Values are mean \pm SEM. ${ }^{*}=p<0.01$ compared to controls. 

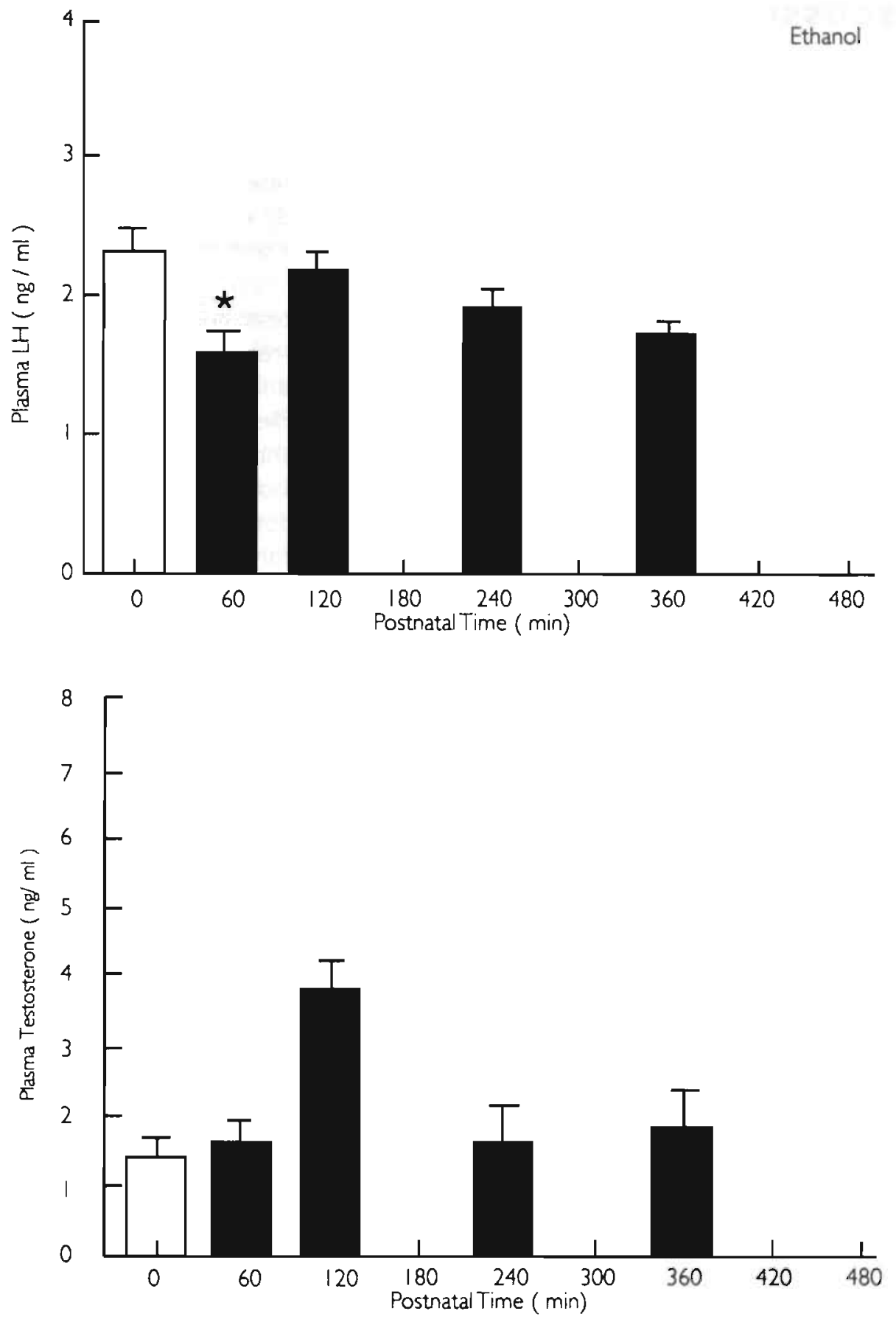

Fig 5. Upper Panel: Plasma LHB concentrations in male neonates injected with ethanol within 5 min after delivery. Values are mean $\pm S E M .{ }^{*}=p<0.05$ compared to controls. Reference standard is LH-RP-3. Lower Panel: Plasma testosterone concentrations in male neonates injected with ethanol. Values are mean \pm SEM. 
A clear postnatal surge of plasma $T$ was observed in males from all treatment groups. This surge peaked at two hours after delivery and the timing of its occurrence was the same in all treatment groups. There was no detectable postnatal surge of $L H ß$ which corresponded to the $T$ surge or preceded it in theses same animals. We also observed no postnatal surge of $\mathrm{LH}$ in an additional study which compared individual plasma levels from males and females delivered by cesarian section with those from normal delivery.

The present study is the first measuring postnatal testosterone and $L H B$ levels in the rat in individual samples from the same animals. Our results give no indication that there is a postnatal rise in $\mathrm{LH} B$ regardless of whether the animal is delivered by cesarian section or naturally. As reviewed above, results from earlier studies of the association between $\mathrm{LH}$ and $\mathrm{T}$ during the first few hours after birth have been inconsistent. This inconsistency may reflect the less specific and sensitive antibodies available at the time, as well as the necessity of having to use pooled samples to obtain enough plasma for hormone measurement. Alternatively, the pattern of results for $\mathrm{LH}$ secretion may be dissimilar to that of $\mathrm{LH} B$ which we observed in the present study during the postnatal period.

LHB levels in cesarian sectioned animals were significantly lower overall during the first 3 hours compared to animals which delivered naturally 3-5 hours later. There was also a difference in $\mathrm{LH} B$ levels over time regardless of the type of delivery. In saline treated males, as well as males and females from cesarian and natural delivery birth, $L H B$ levels were generally higher at birth than at 60- | 80 minutes later. This is similar to the pattern which Slob and colleagues (34) reported for $\mathrm{LH}$ concentrations during the first 12 hours after birth. Fernale plasma LH levels in that were also significantly elevated in that study compared to males during the postnatal period. Pang and coworkers (27) observed similar sex related elevations of $\mathrm{LH}$ during the first 30-120 minutes after birth in plasma of female neonates compared to males. We did not observe a sex difference in plasma $L H B$ in the present study, although females were higher on average than males in both the cesarian and natural birth groups. Given the relatively sample small size at some points in the present study, further work will be necessary to establish whether this lack of a sex difference is related to differences in $L H$ versus $L H \beta$ or simply due to lack of statistical power.

In the human, a sex difference in plasma $\mathrm{LH}$, opposite to that which we describe, has been observed at birth ( 12 ). This clear evidence of pulsatile secretion of LH was observed in male infants which was associated with elevated levels of T during the first few hours after birth. In contrast, levels in female infants were below the limits of detection for the assay during this same period (12). The contribution of $\mathrm{LH}$ pulsatility to the postnatal $T$ surge in the rat cannot be assessed due to the technical difficulties of obtaining repeated blood samples from neonatal rats. However, in the present investigation, the small standard errors associated with the group means for LHßlevels at each postnatal time point across the two studies, suggests that pulsatile secretion of $\mathrm{LH}$ probably is not making a significant contribution to the present results.

This lack of a postnatal rise in $\mathrm{LH} B$ does not address whether the amount of $\mathrm{LH}$ 
present at birth is enough to stimulate the testicular steroidogenesis at birth. Habert $(16,17)$ has proposed that the existence of a possible inhibitory factor(s) of maternal origin, whose absence would hypothetically increase the stimulatory capacity of the amount of $\mathrm{LH}$ present at birth. this concept of inhibitory factors is similar to that proposed to operate in the control of LH stimulatory activity of mouse and ovine testes ( 15 , 28). Steroidogenic responsiveness of fetal Leydig cells to $\mathrm{LH}$ stimulation decreases around the time of birth both in vitro $(16,29)$ and in vivo $(17)$. This effect stands in marked contrast to the age related increases in bioactive and immunological concentrations of $\mathrm{LH}$ in fetal plasma during this period $(15,34)$, supporting the possibility of extragonadotropic regulations of $T$ secretion in late fetal life as suggested by others (16).

Administration of the $\mathrm{GnRH}$ antagonist at birth failed to diminish the amplitude of the $T$ surge compared to saline administration, in spite of a decrease of approximately $25 \%$ in the level of $L H B$ at 60 min after birth. The corresponding level of $T$ at this time point was significantly higher than saline animals. However, no suppression of LHB was observed at any of the other time during the $8 \mathrm{~h}$ in which samples were obtained after birth. The reasons for this lack of effect may be due to an inadequate dose. This appears unlikely based upon studies where we have administered the same dose $(5 \mu \mathrm{g})$ of this batch of the $\mathrm{GnRH}$ antagonist to 7 days old animals. In these animals, which weigh significantly more than neonates, we observed a marked suppression of LHB at $2 \mathrm{~h}$ after administration (unpublished observations). Other unpublished studies in our laboratory have found that in the adult animal, a weight equivalent dose of the same GnRH antagonist will suppress $L H B$ in the castrated animals for many hours after injection. Therefore, one potential explanation for the lack of effect which we observed for the $\mathrm{GnRH}$ antagonist on $\mathrm{LH}$ levels in the neonate may be developmental immaturity of the $\mathrm{GnRH}$ system.

We failed to observe any inhibitory effect of progesterone on the postnatal $T$ surge. In fact, administration of progesterone at birth significantly increased the amplitude of the $T$ surge at $\mathrm{I}$ and $2 \mathrm{~h}$ after delivery compared to saline administration. These data provide little support for hypothetical actions of progesterone on T biosynthesis in the neonatal testis of negative feedback on $\operatorname{LH}(2,34)$ The significant elevation in the peak of the $T$ surge suggests that progesterone may have significantly increased the available substrate for conversion to $T$ as suggested by Habert (17).

A significant reduction in $\mathrm{LH}$ was observed at $60 \mathrm{~min}$ in animals injected with ethanol vehicle alone which was not observed with progesterone administration. However, no effect of ethanol vehicle was detected on the amplitude of timing of the postnatal $T$ surge. The approximate dose of ethanol administered to these animals was $3-4 \mathrm{~g} / \mathrm{kg}$, a dose known to suppress both $\mathrm{LH}$ and $\mathrm{T}$ in the adult male rat $(8,36)$. Little is known regarding the effects of alcohol on the neonatal hypothalamic-pituitary-gonadal axis of the rat. Results from one study showed an inhibitory influence of ethanol administration ( 1 or $2 \mathrm{~g} / \mathrm{kg}$, ip) on T concentrations in samples comprising a single time point taken from $3-5 \mathrm{~h}$ after birth in males by Kelce et al. (19). However, since $3-5 \mathrm{~h}$ after birth falls within the normal postnatal period for the occurrence of the T surge $(11,24$, 32), depending upon the ambient environmental temperature (32), their results may reflect activity associated with the surge, rather than an effect of ethanol. The present 
results suggest that a higher dose of ethanol is capable of a transient suppression of $\mathrm{LH}$, but does not influence $T$ secretion during the first few hours of postnatal life.

The administration of an $\mathrm{LH}$ antibody was also ineffective in altering the timing or amplitude of the postnatal T surge. However, the antibody concentration in blood did not reach a level high enough to interfere with the measurement of plasma. LHB in these animals until 2-4 $\mathrm{h}$ after administration, indicating that a significant amount of antibody absorption occurred only after the peak of the T surge. The slow rate of absorption suggests that subcutaneous, and probably intraperitoneal administration, are not effective routes of antibody administration to block $\mathrm{LH}$ actions within the first hour after birth. An additional point should also be made with respect to these data. Although the levels of T measured at 240,360 and 480 min, when the antibody completely interfered with LHB measurement, were in the same range as saline treated animals, is not clear from these data whether this reflects a lack of $L H B$ stimulation in the neonate or simply inadequate titers of plasma antibody to significantly interfere with $L H$ stimulation in vivo. The most likely explanation for the inability to measure $L H B$ is that the antibody absorbed into the plasma resulted in an excess of antibody in the RIA.

The postnatal occurrence of the peak of the T surge is known to be influenced by environmental temperature, with colder environmental temperatures delaying both the timing of the T peak postnatally, as well as the clearance rate (32). The consistent peak of $\mathrm{T}$ at $2 \mathrm{~h}$ following cesarian section in the present study, as well as the relatively consistent clearance rate of the steroid appears to reflect the general stability of the environmental temperature within the incubator. Slob et al. (34) have suggested that the postnatal surge of $T$ might simply result from the dramatic decrease in metabolic clearance rates of $T$ subsequent to the separation of the fetus from the dam. However, this appears unlikely to account fully for the 3-5 fold increase in plasma $T$ which can occur during the first 60-120 min postnatally. Moreover, a decreased postpartum steroid clearance would likely produce a relative 'surge' of $T$ in the female during the first few hours postnatally as well, a finding which has not been observed. However, subsequent work from this group has shown a postnatal decrease in metabolic rate occurs and likely plays an important role in extending the exposure of the male to the masculinizing effects of T (3).

Corbier et al. ( 10$)$ have reported that maternal estradiol may be an important inhibitory factor in suppressing the postnatal T surge. Like progesterone, estradiol levels fall dramatically in the newborn. Injection of large doses $(5 \mu \mathrm{g})$ of estradiol into the neonate at birth blocked the expression of the postnatal $T$ surge. These results suggest that estradiol may play a disinhibiting role on the postnatal T surge. However, it remains to be determined whether estradiol operates in a similar fashion at physiological concentrations or whether such an inhibitory action influences $\mathrm{LH}$ receptor sensitivity in the neonatal testis. The lack of evidence in the present study for a regulatory role for LHB in the postnatal T surge supports the suggestion that factors of maternal of placental origin play a significant role in the stimulation of this surge $(16,17,27)$. 
I. Aubert. M.L., M. Begeot, B.P. Winiger, G. Morel, P.C. Sizonenka, P.M. Dubois. Ontogeny of hypo thalamic luteinizing hormone-releasing hormone $(\mathrm{GnRH})$ and pituitary $\mathrm{GnRH}$ receptors in fetal and neonatal rats. Endocrinology 116:1565-1576, 1985.

2. Barbieri, R.L. and K.J. Ryan. Direct effects of medroxyprogestarone acetate (MPA) and megestro! acetate (MGA) on rat testicular steroidogenesis. Acta Endocrinologica 94:419-425, 1980.

3. Baum, M.J., T. Brandt, M. Ooms, J.T.M. Vreeburg, A.K. Slob. Immediate postnatal rișe in whole body androgen content in male rats: Correlation with increased testicular content and reduced body clearance of testosterone. Biol. Reproduc. 38:980-986, 1988.

4. Beatty, W.W. Gonadal homones and sex differences in non-reproductive behavior in rodents: Organizational and activational effects. Hormones \& Behavior 12:112-163, 1979.

5. Beyer, C. and H.H. Feder. Sex steroids and afferent input: Their roles in brain sexual differentia tion. Ann. Rev. Physiol. 49:349-364, 1987.

6. Bousefield, G.R, W.M. Perry, D.N. Ward. Gonadotropins: Chemistry and biosynthesis. In: The Physiology of Reproduction. E.Knobil, J.D. Neil (eds), 1749-1792, Raven Press, NY, 1993.

7. Chowdurry, M., and E. Steinberger. Piturtary and plasma levels of gonadotrophins in foetal and newbom male and female rats. J. Endocr. 69:381-384, 1976.

8. Cicero, T.J. Multiple Effects of Ethanol on the Hypothalamic-Piturtary Gonadal Axis in the Male In: Biological Effects of Alcohol, Begleiter H (Ed). pp 463-478, 1980.

9. Corbier, P., D.A. Edwards, J. Roff. The neonatal testosterone surge: a comparative study. Arch. Int. Physiol. Biophys. 100:127-131. 1992.

10. Cortier, P., N. Allioli, J. Roffi. Variations in the testicular responsiveness to hCG during the perinatal period in the rat: influence of estroges. Arch. Int. Physiol. Biophys. 100:389-397, 1992.

II. Cortier, P., B. Kerdelhue, R. Picon, J. Roffi. Changes in testicular weight and serum gonadotropin and testosterone levels before. during, and after birth in the perinatal rat. Endocrinology 103:1985-1991, 1978.

12. De Zegher, F., H. De Vlieger, J.D. Veldhuis. Pulsatile and sexually dimorphic secretion of luteinizing hormone in the human infant on the day of birth. Pediatr. Res. 32:6015-607, 1992.

13. Ding, Y.Q., I.T. Huhtaniemi. Human senum inhibitor(s): behavior and contribution to in vitro bioassay of LH using dispersed mouse Leydig cells. Acta Endocrinol. 121:46-54, 1989.

14. Gorski, RA. Sexual Differentiation of the Endocrine Brain and tis Control. In: Brain Endocrinology, Second Edition, Motta,M. (Ed), pp.7I-104, Raven Press, New York, 1991.

15. Habert, R, R Picon. Control of testicular steroidogenisis in foetal rat: effect of decapitation on testosterone and plasma luteinizing homone-like activity. Acta Endodocrinol. 99:466-473, 1982.

16. Habert, R. and P. Brignaschi. Developmental changes in in vituro production by dispersed Leydig cells during fetal life in rats. Arch. Andrology 27:65-71, 1991.

17. Habert, $R$ In vivo acute testicular testosterone response to injection of luteinizing hormone in the rat fetus. Acta Endocrinologica 128:268-273, 1993.

18. Hermans, RH.M., R.F. McGivem, W. Chen, L.D. Longo. Attered adult sexual behavior in the male rat following chronic prenatal hypoxia. Neurotoxicol. Teratol. 15:353-363, 1993.

19. Kelce, WR V.K Ganjam, P.K Rudeen. Inhibition of testicular steroidogenisis in the neonatal rat following acute ethanol exposure. Alcohol, 7:75-80. 1990.

20. Lalau, J-D. M.L. Aubert. D.F. Carmignac, I. Gregoire, J.P. Dupouy. Reduction in testicular function in rats. I. Reduction by a specific gonadotropin-releasing homone antagonist in fetal rats. Neuroendocrinology 51:284-288, 1990.

21. Lieberburg, I., L.C. Krey, B.S. McEwen. Sex difference in serum testosterone and in exchangeable brain cell nuclear estradiol during the neonatal period in rats. Brain Res. 207-212, 1979.

22 McGivem, RF., RJ. Handa, E. Redei. Decreased postnatal testosterone surge in male rats exposed to ethanol during the last week of gestation. Alcoholism; Clin. Exp. Res. 1993 in press.

23. McGivern, RF., W.J. Raum, E. Salido, E.Redei. Lack of prenatal testosterone surge in fetal rats exposed to alcohol: Alterations in testicular morpholog); and physiology. Alcoholism: Clin. Exp.

Res. 12:243-247, 1988. 
24. Montelica-Heino, I., D.A. Edwards, J. Roffi. Intermale agression in mice: Does hour of castration after birth influence adult behavior. Physiol. Behav. 53:1017-1019, 1993.

25. Naftolin, F. and N. MacLusky. Aromatization Hypothesis Revisited. In: Sexual Differentiation: Basic and Clinical Aspects.; Serio, M. et al. (eds), pp. 79-91. 1984.

26. Nemeskeri, A., M. Kurcz, B. Halász. Changes in hypophyseal luteinizing hormone (LH) content during fetal and early postnatal life, and capacity of fetal and early postnatal piturtaries to synthesize and release LH in vitro. Neuroendocrinology 38:393-396, 1984.

27. Pang, S.F. A.R Caggiula, V.L. Gay, RL Goodman, C.S.F. Pang. Serum concentrations of testosterone, oestrogens, luteinizing hormone and follicle stimulating hormone in male and fema le rats during the critical period of neural sexual differentiation. J. Endocr. 80:103-1 10, 1979.

28. Papadoupoulos, V., P. Kamtchouing, N. Boujrad, C. Pisselet, C.Perrau, A. Locatelli. Evidence for LH-inhibiting activity in ovine peripheral and testicular blood. Acta. Endocrinol. 123:345-352, 1990.

29. Picon, R, A. Ktorza. Effect of $\mathrm{LH}$ on testosterone production by fetal rat testes in vitro. FEBS Lett. 68:19-22, 1976.

30. Rhoda, J., P. Cortier, J. Roffi. Gonadal steroid concentrations in serum and hypothalamus of the rat at birth: aromatization of testosterone to 17 B-estradiol. Endocrinology |14:1754-1760, 1984.

31. Roffi, J., F. Chami, P. Corbier, D.A. Edwards. Testicular hormones during the first few hours after birth augment the tendency of adult male rats to mount receptive females. Physiol. Behav.

39:625-628, 1987.

32. Roffi, J., F. Chami, P. Corbier, D.A. Edwards. Influence of the environmental temperature on the post-partum testosterone surge in the rat. Acta. Endocrinol. 115:478-482, 1987.

33. Salisbury, R. . S.D. Dudley, J. Weisz. Effect of gonadotrophin-releasing hormone on circulating levels of immunoreactive luteinizing hormone in fetal rats. Neuroendocrinology 35:265-269, 1982.

34. Slob, A.K., M.P. Ooms, J.T.M. Vreeburg. Prenatal and early postnatal sex differences in plasma and gonadal testosterone and plasma luteinizing hormone in female and male rats. J. Endocr. 87:81-87, 1980.

35. Stahl, F., F. Gotz, I. Poppe, P. Amendt, G. Domer. Pre- and Early Postnatal Testosterone Levels in Rat and Human. In: Hormones and Brain Development, G. Domer and M. Kawakami (Eds), pp. 99-109, Flsevier, North Holland, 1978.

36. Van Thiel, D.H. Ethanol: its adverse effects upon the hypothalamic-pituitary-gonadal axis. J. Lab. Clin. Med.101:21-33, 1983.

37. Warren, D.W, C.G. Hattmeyer, KB. Eik-Nes. Testosterone in the fetal rat testis. Biol. Reprod. 8:560-565, 1973.

38. Warren, D.W., I.T. Huhtaniemi, ]. Tapanainen, M.L. Dufau, KJ. Catt Ontogeny of gonadotropin receptors in the fetal and neonatal rat testis. Endocrinology 114:470-476, 1984.

39. Weisz, J. and I.L. Ward. Plasma testosterone and progesterone titers of pregnant rats, their male and female fetuses, and neonatal offspring. Endocrinology 106:306-316, 1980.

40. Word, RA., F.W. George, J.D. Wilson, B.R. Carr. Testosterone synthesis and adenylate cyclase activity in the early human fetal testis appear to be independent of human chorionic gonadotropin control. J. Clin. Endocrinol. Metab. 69:204-208, 1989. 


\section{ALTERED CATECHOLAMINERGIC BEHAVIORAL AND- HORMONAL RESPONSES IN RATS FOLLOWING EARLY POST- NATAL HYPOXIA}

Hermans, R.H.M. and L.D. Longo. Physiology and Behovior, 55: 469-475, 1994.

\section{ABSTRACT}

We have previously reported alterations in a battery of behavioral functions in the rat following both intermittent and chronic prenatal hypoxia. In this species, the critical brain growth spurt for the catecholaminergic neurotransmitter system takes place in the late gestational and early postnatal period. In addition, postnatal stress can modify adult hypothalamic-pituitary-adrenal responsiveness. Following a given stress, administration of dopaminergic/adrenergic agonists/antagonists may elucidate subtle changes which are not apparent in routine behavioral and endocrine tests. To test the hypothesis that early postnatal hypoxia affects development of the catecholaminergic system, and thus alters functional outcome, we performed the following study. We exposed 25 litters of Sprague-Dawley rats, each consisting of 10 male pups to hypoxia (10.5\% inspired $\mathrm{O}^{2}$ ) for h/day (0900 to $1500 \mathrm{~h}$ ) from postnatal day (P) 2 to 10 . We also had 25 control (C) litters. We then performed a series of behavioral tests in immature and mature animals. Body weights were significantly decreased in hypoxic $(H)$ animals from PIO to PI00. At P2I we tested locomotor activity in an open field paradigm with drug challenge (apomorphine, a dopamine receptor agonist, 0.025 and $0.1 \mathrm{mg} / \mathrm{kg}$; or haloperidol, a dopamine receptor antagonist, 0.2 and $0.4 \mathrm{mg} / \mathrm{kg}$ ). Grooming activity was significantly decreased in $\mathrm{H}$ animals at both apomorphine concentrations, compared to controls. Moreover, rearing activity was significantly increased in $\mathrm{H}$ animals under basal conditions and when challenged with $0.1 \mathrm{mg} / \mathrm{kg}$ apomorphine. Apomorphine $(1.0 \mathrm{mg} / \mathrm{kg})$-induced stereotypy at $\mathrm{P} 39$ was significantly increased in $\mathrm{H}$ animals compared to controls. Open field activity at 80 days revealed no significant differences in drug responsiveness between $\mathrm{H}$ and $\mathrm{C}$ animals. The corticosterone response to clonidine at $\mathrm{P} / 50$ showed significantly earlier rise of corticosterone concentrations in the $\mathrm{H}$ animals. However, restraint stress showed no difference in corticosterone responsiveness between the two treatment groups. We conclude that relatively mild, early, postnatal hypoxia can result in altered activity of the dopaminergic and adrenergic neurotransmitter systems, which affect pharmacologic responses.

\section{INTRODUCTION}

In the rat, we have shown that both acute, intermittent hypoxia (9), and chronic hypoxia (10) during late pregnancy altered responses to behavioral tests in both the newborn and the adult. In these studies we tested animals exposed to prenatal hypoxia 
in a longitudinal test battery for learning and spontaneous locomotor activity. Little is known, however, about the role of specific neurotransmitter systems, e.g., dopaminergic and noradrenergic systems, in hypoxic-induced behavioral sequelae. In the rat, the critical brain growth spurt for the catecholaminergic neurotransmitter system takes place: in the late gestational and early postnatal period (23). Seidier and Slotkin (25) showed that acute hypoxia on the first day of life induced a long-lasting increase in dopamine and norepinephrine turnover in the rat midbrain and brainstem. In addition, following severe but brief hypoxia on day one of life, tyrosine hydroxylase and tryptophan hydroxylase activities were decreased in whole brains of 28 day old pups (8). Thus, hypoxia may alter development of central catecholaminergic systems closely involved with locomotor behavior. Challenge of these neurotransmitter systems by administration of agonists and antagonists may elucidate hypoxic-induced alterations $(3,6)$.

In addition, postnatal handling (4), or pre- $(E \mid 6,17,18)$ and postnatal injections of corticosteroids (12,21), or alcohol (19) have been shown to modulate prepubescent and adult behavioral and endocrine responsiveness to stress (for review see 20). As adults, these animals displayed a decreased responsiveness during and following exposure to several stressors. Moreover, catecholamines are intimately involved in the function of the hypothalamic-pituitary-adrenal (HPA) axis (27). The present study was designed to test the null hypothesis that postnatal hypoxia does not induce catecholamine-related behavioral or hormonal changes.

\section{METHODS}

Fifty timed, pregnant Sprague-Dawley rats (Charles River, Portage, MI) arrived in our laboratory on day II of gestation. All rats were individually housed in translucent cages, with free access to food and water. Within $12 \mathrm{~h}$ after birth we culled the litters to 8 male pups. Subsequently, we exposed 19 litters to $10.5 \%$ inspired oxygen $\left(\mathrm{O}_{1}\right)$ for $6 \mathrm{~h}$ a day from days 2 to 10 of life in an environmental chamber. The inspired $\mathrm{O}_{2}$ was maintained at $10.5 \%$ by infusing nitrogen gas into the chamber. Oxygen concentration was continuously monitored by use of an $\mathrm{O}_{2}$ analyzer (Model OM-14. Beckman inst, Anaheim, $C A$ ). In the hypoxic adults arterial $O_{2}$ partial pressure averaged $37.6 \pm 1.4$ Torr, compared to $87.4 \pm 3.4$ Torr for normoxic controls (9). Control rats were maintained in the same room where the chamber was located (Temp $23^{\circ} \mathrm{C}$, humidity $45-55 \%$, and $\mid 2$ $\mathrm{h}$ light dark cycle, lights on at 0700). Subsequently, we used the rats for behavioral and endocrine determinations. Each animal was only used once in a given experiment and injected with one drug dosage, after which it was sacrificed. All behavioral tests were observed by two experimenters blinded as to treatment group.

\section{Stereotypy}

At 39 days of age, hypoxic and control rats received the dopamine receptor agonist apomorphine (Sigma Chem., St Louis, MO) freshly dissolved in $\mathrm{NaCl}$ at $1.0 \mathrm{mg} / \mathrm{kg}$ i.p. We estimated stereotypic behavior according to the method of Costall and Naylor (2), using a scoring system from 0 to 5 as follows: 0 ) the animal is asleep or stationary, 1) the animal is active, 2) the animal is predominantly active, but with bursts of stereotyped snif- 
fling and rearing, 3) the animal displays constant stereotyped behavior, sniffling, rearing, or head bobbing, but with locomotor activity still present, 4) the animal shows constant stereotypy but with bursts of licking, gnawing, and/or biting, 5) the animal displays continuous licking, biting, and/or gnawing. For the observations we used lucite cages measuring $30 \times 30 \times 30 \mathrm{~cm}$. Rats were placed in the observation cages $24 \mathrm{~h}$ before drug treatment, to allow adaptation to the new environment. Each group consisted of 10 animals. Stereotypy was scored over a $60 \mathrm{~min}$ period at $10 \mathrm{~min}$ intervals.

\section{Open field test}

This test measures the activity and habituation response of animals on placement in a novel environment. The mild stress of this test may activate the dopaminergic system (29). We used low dosages of the dopamine receptor agonist apomorphine $(0$, 0.025 or $0.1 \mathrm{mg} / \mathrm{kg}$ on $\mathrm{P} 2 \mathrm{I}$, and an additional $0.4 \mathrm{mg} / \mathrm{kg}$ dose on P8I) and the DI, D2 receptor antagonist haloperidol $(0,0.2$, or $0.4 \mathrm{mg} / \mathrm{kg}$ ) to examine involvement of the dopaminergic system. In rats, low apomorphine dosages induce hypoactivity (18). On days 21 and $80 / 8$ I we tested the animals for open field activity, according to procedures we have reported previously (9). Briefly, we used two age-dependent sized circular open fields ( $90 \mathrm{~cm}$ on P2I and $180 \mathrm{~cm}$ on P80) enclosed by white plastic walls ( 25 and $37 \mathrm{~cm}$ high, respectively), and illuminated by red light. Each field consisted of 19 equal area segments. Each animal was subjected to a 6 min trial in which measures were calculated for successive $2 \mathrm{~min}$ intervals. The animal was placed in the center of the open field and the following observations recorded by two observers: time to reach the field wall (thigmotaxis time), the number of grids crossed, the number of rears, periods of grooming, and the number of boli excreted.

\section{Corticosterone responsiveness to clonidine or restraint stress}

Under anesthesia (Nembutal $60 \mathrm{mg} / \mathrm{kg}$ i.p.), we chronically catheterized the external jugular vein of hypoxic $(n=6)$ and control $(n=4)$ rats with a small silastic catheter $(0.5 \mathrm{~mm}$ i.d.) and passed the tip into the superior vena cava. The catheter was exteriorized with a access-port (Norfolk Medical, Skokie, IL) connected to the dorsal neck region. Following surgery, we placed the animals in individual vision blocked cages which allowed unrestrained and unstressful blood sampling. To maintain catheter patency during the three day period between surgery and blood sampling, we flushed daily with a 50 $\mathrm{U} / \mathrm{ml}$ heparin solution which contained $2 \mathrm{mg}$ gentamycin. On the day of the experiment, we connected an extension catheter to the access port, and collected a baseline blood sample. Subsequently, we injected clonidine $(5 \mu \mathrm{g} / \mathrm{kg})$ in $0.1 \mathrm{ml}$ saline to each rat. We then withdrew blood samples $(0.15 \mathrm{ml}$ in $10 \mathrm{ml}$ EDTA) at $15,30,60,90$, and $120 \mathrm{~min}$, and maintained catheter patency by flushing with a $5 \mathrm{U} / \mathrm{ml}$ heparin solution. Blood was collected in heparinized tubes, the blood samples were centrifuged at $300 \mathrm{~g}$, and the separated plasma was stored at $-80^{\circ} \mathrm{C}$.

Ten other animals ( 5 control and 5 hypoxic) of both treatment groups were catheterized as described above. Following recovery, animals were exposed to restraint stress. After we obtained baseline samples, animals were tightly wrapped in towels for 
a 30 min period. Samples for corticosterone determination were obtained as described above, at $0,10,20,30,60$, and $90 \mathrm{~min}$.

\section{Radioimmunoassay}

Corticosterone concentrations were measured in unextracted plasma, using $\left[{ }^{125} \mid\right]$-corticosterone radioimmunoassay (RIA). Specific rabbit antiserum (ICN Biomedicals, Carson, CA), raised against corticosterone-3-carboxymethyloxime:BSA, was used. The antiserum bound $50 \%$ of [ $\left.{ }^{125}\right]$-3-carboxymethyloxime: BSA at equilibrium. Corticosterone antiserum cross-reactivity has less then $0.01-0.3 \%$ with deoxycorticosterone, progesterone, testosterone, aldosterone, or cortisol. ED ${ }^{50}$ was $121 \mathrm{ng} / \mathrm{ml}$, and intra-assay coefficient of variation was $1.8 \%$

\section{Statistics}

Behavioral and endocrine data were subjected to analysis of variance (ANOVA). When appropriate, data were analyzed with repeated measurements or single ANOVA.

\section{RESULTS}

\section{Animal weights}

As shown in Table I, body weights of hypoxic pups over a 100 day period were significantly decreased compared to controls (P|O0 F[1,28] $9.19 p<0.005$ ).

\section{Table I. Animal weights ( $g$ )}

\section{Postnatal day}

10

30

100

${ }^{*} p<0.005$
Control

$19.0 \pm 0.3$

$226.0 \pm 4.2$

$476.9 \pm 9.7$

\section{Hypoxia}

$17.2 \pm 0.3^{*}$

$202.2 \pm 4.1 *$

$435 \pm 9.8^{*}$

\section{Stereotypy}

In hypoxic rats at 39 days of age, the stereotypic behavioral score following apomorphine challenge was significantly greater compared to control animals (Fig 1). Repeated measurement ANOVA over the $60 \mathrm{~min}$ period showed a significant treatment effect $(F[I, \mid 8] 8.34 \mathrm{p}<0.01$ ), with hypoxic animals having higher scores compared to controls. 


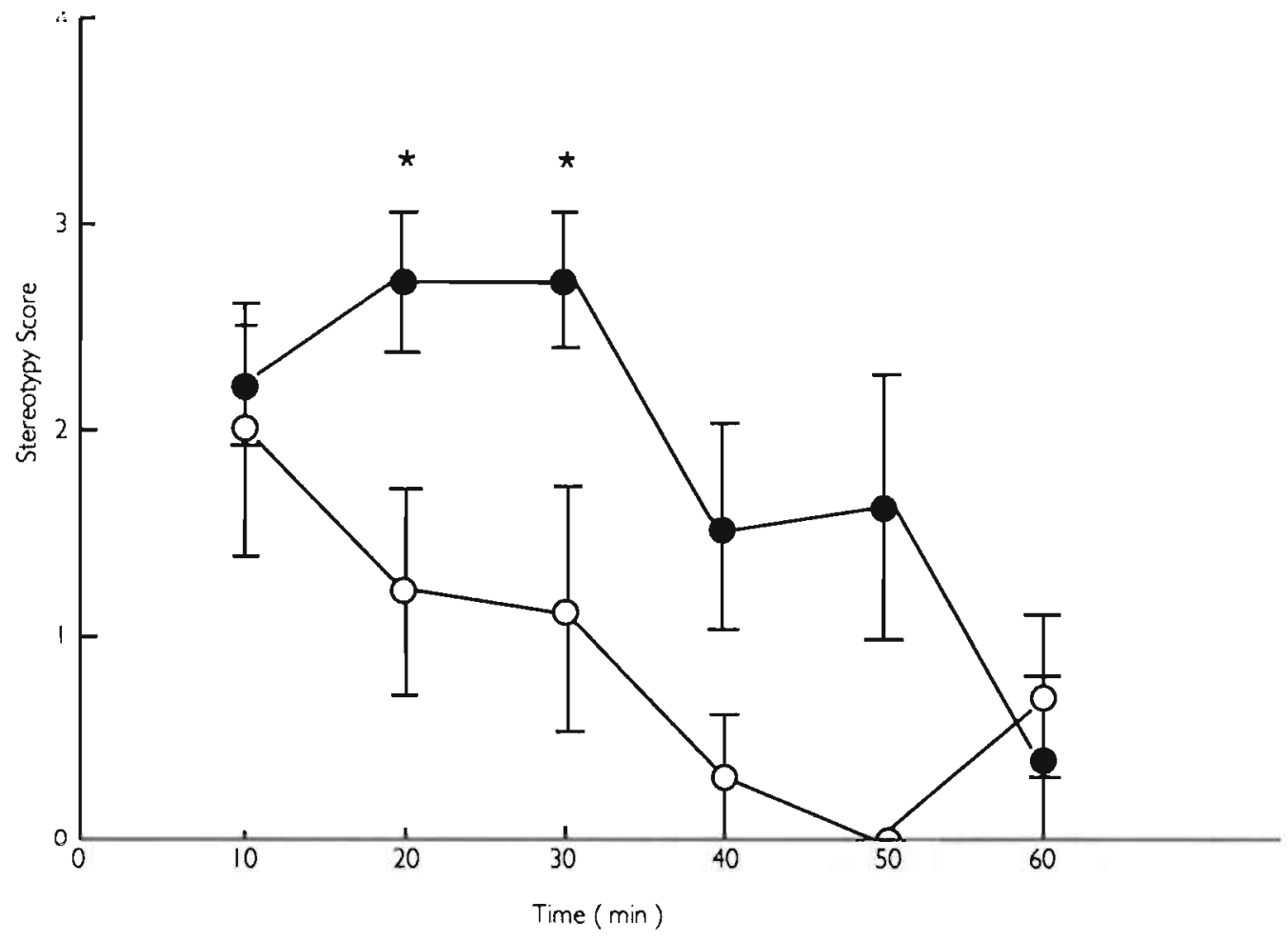

Fig 1 Stereotypy performance for control (0), and hypoxic ( 0 ) male rats at 39 days of age. Stereotypy scores $10 \mathrm{~min}$ following apomorphine injection (DA receptor agonist, $1.0 \mathrm{mg} / \mathrm{kg}$ i.p.). Shown are the mean score $\pm S E M . *=p<0.01$. Significant increased stereotypy scores in hypoxic pups compared to controls by repeated ANOVA, $p<0.01$.

\section{Open field behavior}

To examine habituation rates to a novel environment, we quantified crossings, rearings, and grooming over a 6 min testing period. As shown in Fig 2, at 21 days of life neither crossing behavior (upper panel), nor number of groomings (lower panel) were significantly different between saline injected hypoxic and control animals. Rearing acti-

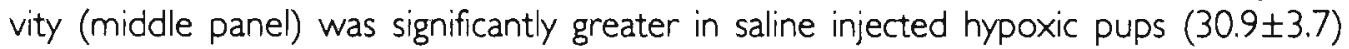

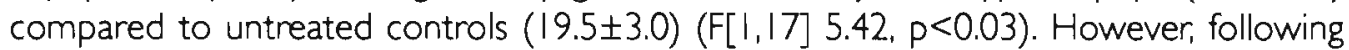
0.2 or $0.4 \mathrm{mg} / \mathrm{kg}$ haloperidol, the number of rearings decreased in both groups, so that differences were no longer significant In addition, at both dosages haloperidol-injected hypoxic pups showed no differences in crossing and grooming activity, compared to controls (Fig. 2). 

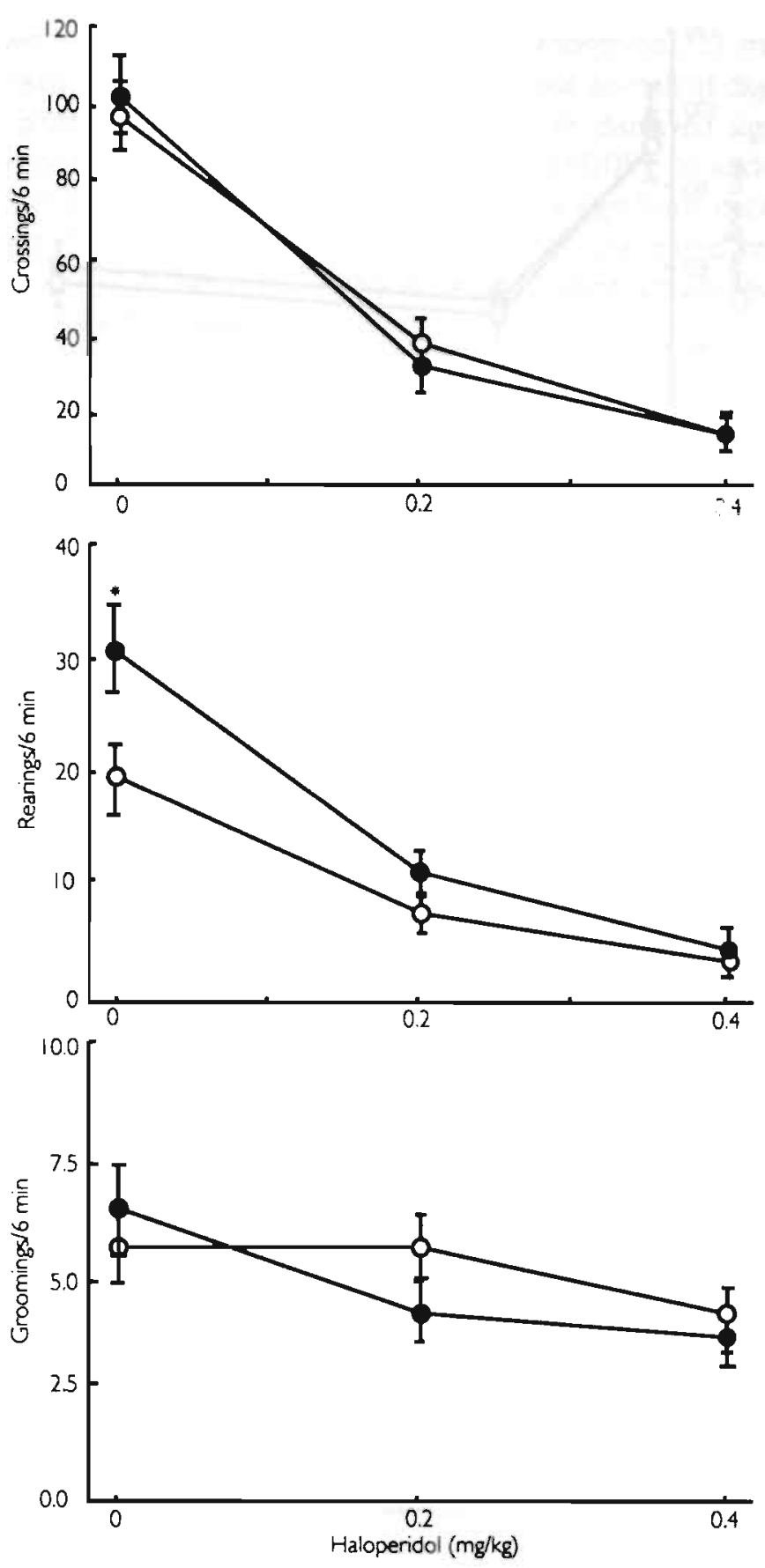

Fig 2 Open field activity at 21 days of age, following holoperidol injection (DA receptor ontogonist 0, 0.2, $0.4 \mathrm{mg} / \mathrm{kg}$ i.p.) Upper Panel. Number of crossings per 6 min. Middle Panel. Number of rearings per 6 min. Lower Panel. Number of groomings per $6 \mathrm{~min}$. ${ }^{*}=p<0.05$ compared to controls. Symbols are the same as in Fig. I. 

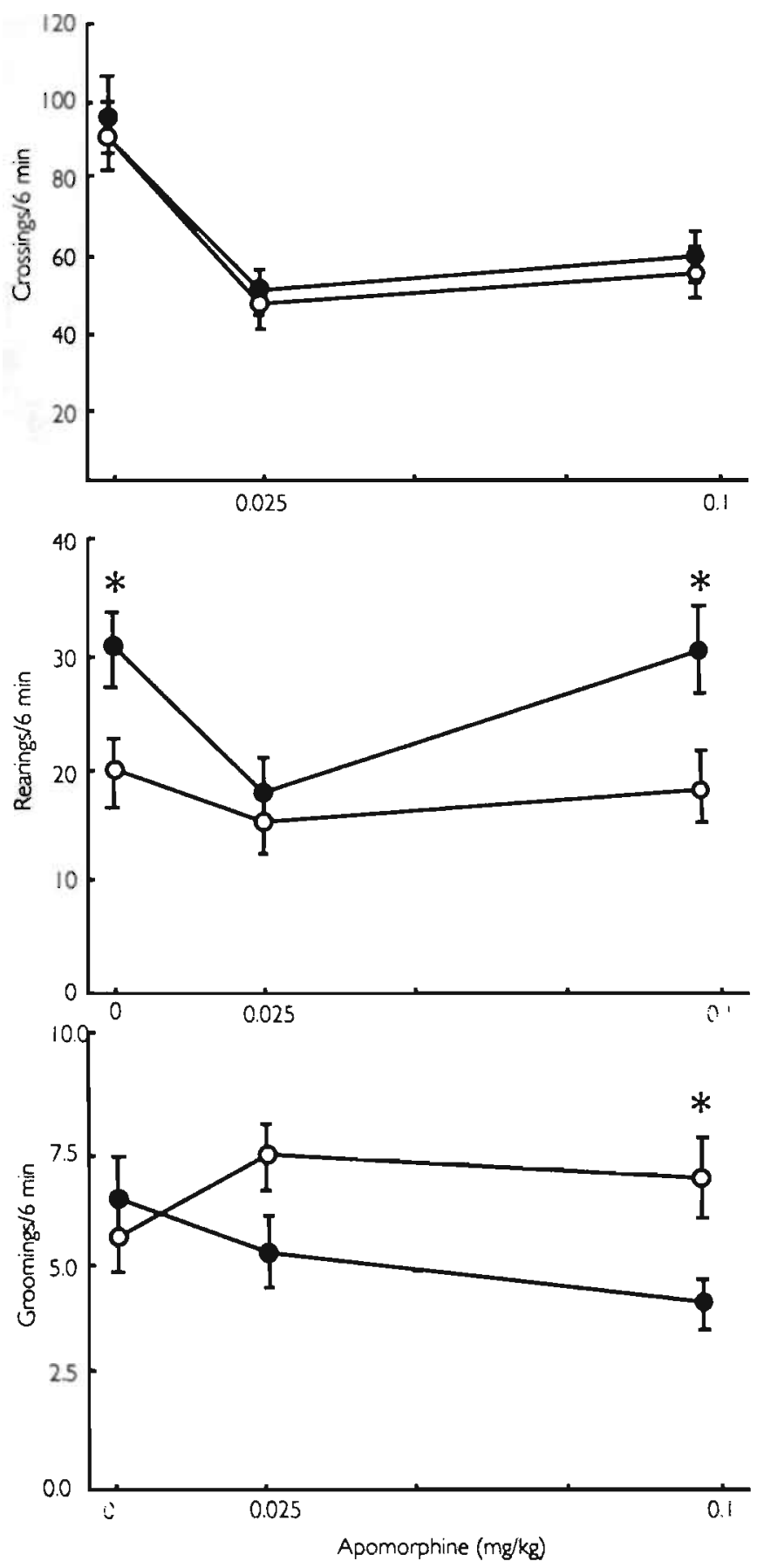

Fig 3 Open field activity at 21 days of age, following apomorphine injection (DA receptor agonist 0, 0.025, $0.1 \mathrm{mg} / \mathrm{kg}$ s.c.) Upper Panel. Number of crossings per $6 \mathrm{~min}$. Middle Panel. Number of rearings per $6 \mathrm{~min}$. Lower Panel. Number of groomings per $6 \mathrm{~min}$. $*=0<05$ compared to controls at a given concentration. 
As shown in Fig. 3 (lower panel), following apomorphine $(0.1 \mathrm{mg} / \mathrm{kg})$ challenge, grooming responses were significantly depressed in hypoxic animals at day 21 (treatment, $F[1,18]=6.14, p<0.02$ ). Saline injected hypoxic animals displayed significantly higher rearing activities compared to controls $(F[1,18]=5.42, p<0.05)$. In addition, in hypoxic animals injection of $0.025 \mathrm{mg} / \mathrm{kg}$ apomorphine induced a significant decrease in rearing activity $(17.8 \pm 3.1)(T[1,17]=3.44, p<0.003)$ (middle panel) compared to saline injected hypoxic animals $(30.9 \pm 3.7)$, returning to the elevated baseline activity level in those animals at the higher dose $(0.1 \mathrm{mg} / \mathrm{kg})$.

\section{Table 2. Open field activity at 80 days}

\section{Saline}

\section{Control Hypoxia Control Hypoxia}

$\begin{array}{lllll}\text { crossing } & 149.8 \pm 8.1 & 134.3 \pm 7.4 & 31.7 \pm 7.9 & 36.7 \pm 7.9 \\ \text { rearing } & 31.1 \pm 3.6 & 21.3 \pm 2.3^{*} & 9.6 \pm 1.8 & 10.6 \pm 1.7 \\ \text { grooming } & 1.0 \pm 0.3 & 0.5 \pm 0.3 & 2.0 \pm 0.5 & 3.4 \pm 1.3 \\ \text { thigmotaxis } & 15.0 \pm 3.1 & 9.3 \pm 1.0 & 87.1 \pm 41.1 & 11.3 \pm 1.2 \\ \text { boli } & 0.5 \pm 0.3 & 1.1 \pm 0.6 & 1.2 \pm 0.4 & 1.3 \pm 0.6\end{array}$

\section{Apormorphine}

\section{Control Hypoxia Control Hypoxia}

$\begin{array}{lllll}\text { crossing } & 23.1 \pm 4.9 & 16.0 \pm 2.7 & 42.6 \pm 9.5 & 62.2 \pm 9.6 \\ \text { rearing } & 7.9 \pm 2.2 & 7.0 \pm 1.9 & 6.5 \pm 1.5 & 8.7 \pm 2.0 \\ \text { grooming } & 1.8 \pm 0.4 & 2.0 \pm 0.5 & 0.3 \pm 0.3 & 1.1 \pm 0.6 \\ \text { thigmotaxis } & 98.4 \pm 45 & 148.2 \pm 48 & 25.8 \pm 6.7 & 18.2 \pm 5.6 \\ \text { boli } & 0.8 \pm 0.4 & 0.1 \pm 0.1 & 0.6 \pm 0.3 & 0.8 \pm 0.4\end{array}$

* $p<0.05$ compared to controls

As shown in Table 2, at 80 days of life, the numbers of control crossings and rearings increased as compared with those activities at $\mathrm{P} 21$. Following, saline injection, the number of rearings were significantly depressed in hypoxic animals, compared to controls (F[I, I8] 5.24, p<0.03). Following apomorphine challenge at 80 days of life, grooming activity tended to be increased in the hypoxic group, but not significantly so. No differences were noted in thigmotaxis time or the number of crossings, rearings, or boli excreted. 


\section{Corticosterone responsiveness to clonidine}

As shown in Fig. 4, upper panel, following $5 \mu \mathrm{g} / \mathrm{kg}$ clonidine, in control animals corticosterone concentrations increased from $90.8 \pm 10$ to $143 \pm 18 \mathrm{ng} / \mathrm{ml}$ at $15 \mathrm{~min}$, and then continued to increase to peak levels of $271 \pm 67$ by $90 \mathrm{~min}$ (Fig. 4). in contrast, cor
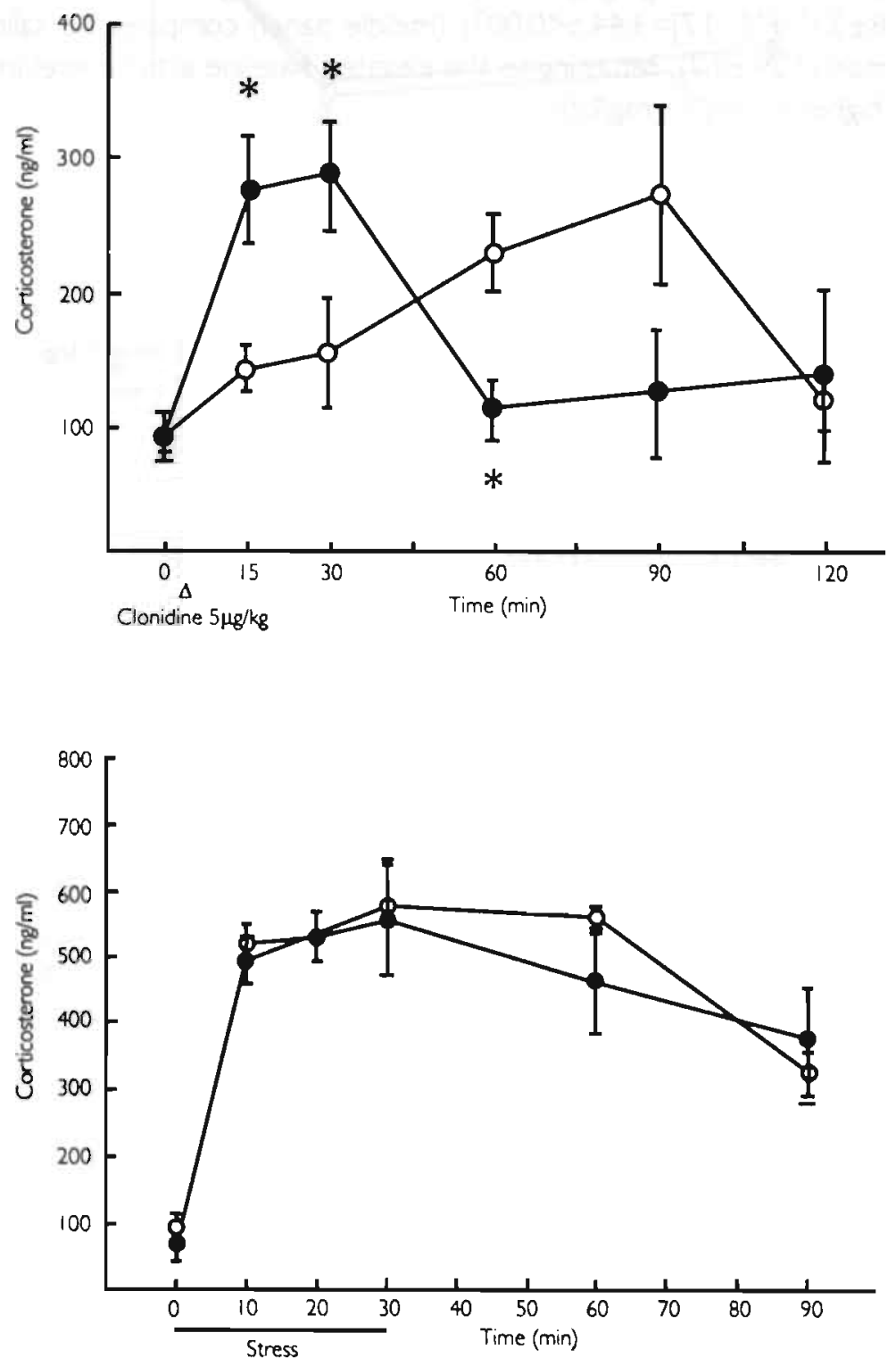

Fig 4 Upper Panel. Corticosterone response to bolus injection of clonidine (alpha 2receptor agonist, $5 \mu \mathrm{g} / \mathrm{kg}$ i.v.) at 150 days of life. $*=p<0.05$ compared to controls at a given time point. Lower Panel. Corticosterone response to restraint stress at 160 days of life. Symbols are the same in Fig. I. 
ticosterone concentrations in the hypoxic animals rapidly rose from $93 \pm 18$ to $277 \pm 41$ $\mathrm{ng} / \mathrm{ml}$ at $15 \mathrm{~min}(\mathrm{~F}[\mathrm{I}, 8]=6.48, \mathrm{p}<0.03$ compared to controls). By 120 min corticosterone concentrations had returned to baseline levels. An orthogonal trend analysis revealed significant differences in the cubic component for treatment $(F[1,8] 10.8, p<0.01)$.

Following a 30 min period of restraint stress, plasma corticosterone concentrations in control animals increased from $93 \pm 22$ to $576 \pm 7 \mid \mathrm{ng} / \mathrm{ml}$ (Fig. 4, lower panel). After $90 \mathrm{~min}$, corticosterone concentrations decreased to $319 \pm 34 \mathrm{ng} / \mathrm{ml}$. Hypoxic animals did not differ in their adrenal responsiveness compared to controls.

\section{DISCUSSION}

During late prenatal and early postnatal life neurotransmitter systems of the developing nervous system undergo rapid maturation (23). Environmental and chemical insults during this critical period can alter subsequent endocrine, neurochemical, and behavioral functions $(3,6,19)$. The present study demonstrates that in rodents exposed to postnatal hypoxia, challenge with dopaminergic and adrenergic drugs reveals altered behavioral responses which were not necessarily apparent in the absence of these agonists/antagonists.

Postnatal hypoxia has been shown to have long-term effects on brain catecholamines. Hedner and colleagues (8) exposed one day old rat pups to $6 \% \mathrm{O}_{2}$ for 4.5 hours. On day 28 of life following aromatic L-amino acid decarboxylase inhibition, brain concentrations of dihydroxyphenylalanine (DOPA) and 5-hydroxytryptophan (5-HT) decreased in these animals, which suggested inhibition of the enzymes tyrosine hydroxylase and tryptophan hydroxylase, respectively. These authors suggested that impaired development of central catecholamine pathways may have accounted for the behavioral deficiencies (8). Lun and colleagues have explored a number of aspects of developmental neurochemistry in relation to hypoxia. In hypoxic Wistar rat pups $\left(\sim 11.8 \% \mathrm{O}_{2}\right.$ for I I h/day from P 2 to $P$ 10), in addition to significantly decreased body (48\%) and brain (30\%) weights, cerebral cortical protein to DNA ratio and acetylcholine esterase activity were decreased. At age 3 months the dopamine fractional efflux rate was increased in the hypoxic animals, and even more so in those treated with piracetam (a nootropic drug used to improve learning and memory function) (14). In adult rats which had been made hypoxic as pups ( $10 \mathrm{~h} /$ day from $P 2$ to $P 6$ or $P 10)$, there was an absence of the expected marked decrease in stimulated dopamine fractional efflux rate from corpus striatum slices, i.e., the efflux rates were greater (15). These changes could be blocked by administering L-dopa ( 2.5 to $50 \mathrm{ug} / \mathrm{g}$ ) during the hypoxic exposure (17). Further, pyritinol administration, either before or following hypoxia, also prevented both the potassium-stimulated dopamine release and the learning deficits at 5 to 8 weeks of age (16). In further studies, Odarjuk and colleagues (22) demonstrated long-lasting changes in dopamine release and uptake in rats subjected to hypoxia from $P 2$ to $P 11$. Three months later, $\mathrm{K}+$-stimulated dopamine release was increased, and its uptake reduced due to decreased affinity of the uptake carrier system. The authors postulated increased dopaminergic function of the nigrostrial system, an alteration associated with plasticity of the developing brain (22). 
At 39 days of age, our hypoxic animals showed a significantly greater stereotypic response to apomorphine, compared to controls (Fig. 2). Apomorphine-induced stereotypy is thought to be mediated by direct stimulation of dopamine receptors in the neostriatum, and increased stereotypy is the result of dopaminergic supersensitivity (30). Our data are in accordance with that of Bjelke and colleagues ( 1 ) who reported increased apomorphine responsiveness following neonatal asphyxia. In contrast, in adult animals Grammate and Schmidt (5), failed to show alterations in apomorphine-induced stereotypy following postnatal hypobaric hypoxia. Thus, age may play a role in altered stereotypic responsiveness following postnatal hypoxia, as we tested prepubescent animals. Adult animals exposed to $8 \%$ inspired $\mathrm{O}_{2}$, also showed increased apomorphine-induced stereotypic behavior 50 days following the hypoxic treatment (28). The increase in responsiveness to apomorphine, suggests an increased receptor sensitivity in hypoxic animals brought about by either an increased number of dopamine receptors or by a loss of inhibitory neural systems controlling the dopaminergic systems involved in stereotypy. These alterations could be located in one or various central dopaminergic pathways. In this context it is known that apomorphine-induced stereotyped behavior is mainly dependent on the progressive activation of dopaminergic receptors of the nigrostriatal pathways (24).

The open field response at 21 days of age revealed increased rearing activity in the hypoxic pups (Fig. 2 and 3). In addition, challenge with low dosage apomorphine induced a significantly decreased grooming activity, and a more rapid decrease in the rearing response of hypoxic pups. In the hypoxic animals, injection with the higher dosage of apomorphine increased rearing activity levels similar to the saline injected subjects. The ambulation (crossings) levels following apomorphine administration decreased and did not differ from controls. Administration of low dosages of apomorphine inhibits open field activity. It is disputed if this effect is mediated by presynaptically localized autoreceptors, or postsynaptic sub-receptor populations with a high affinity for the agonist (18). Auto receptors have been identified on the neurons of the nigrostriatal and mesolimbic dopaminergic neurons. Apparently, stimulation of these receptors affects grooming, and postnatal hypoxia alters apomorphine responsiveness of the systems involved. Moreover, the altered grooming activity following postnatal hypoxia appears to be transient, as adult animals do not significantly differ from controls when challenged with apomorphine. Presynaptic dopamine autoreceptors do not seem to be functionally mature until 28 days postnatally (7). Thus, postnatal hypoxia may delay the maturation of dopaminergic systems. The basal ganglia play an important role in motor control and seem particularly sensitive to oxygen deprivation. The mesolimbic and the mesotriatal DA pathways, are strongly involved in the control of locomotor activity in the rat. Enhancement of dopaminergic neurotransmission in these systems results in increases of various aspects of locomotor activity. The present open field results show that postnatal hypoxia induced a transient rise in rearing, although locomotion was not altered. Following low doses of apomorphine both rearing and grooming activity were reduced. This suggests that postnatal hypoxia may alter the balance in the dopaminergic mediation of locomotor activity, rearing, and grooming. Haloperidol injection prior to open field testing reduced crossing and rearing activity in both treatment groups. The lack of effect 
of postsynaptic receptor blocking by haloperidol, suggests that the observed alterations following apomorphine injection are mediated by presynaptic autoreceptors.

Acute administration of the centrally acting agonist clonidine, induced a markedly shifted corticosterone response in the postnatally hypoxic animals (Fig. 4 upper panel). Smythe and colleagues (26) suggested that increases in serum glucose and corticosterone following clonidine administration are mediated by central adrenoreceptors that inhibit neuronal norepinephrine release. However, clonidine is also believed to act peripherally by direct noradrenergic agonism (26). Thus, alterations in peripheral and/or central receptors may play a role in the enhanced corticosterone responsiveness to clonidine following postnatal hypoxia. Postnatal hypoxia has been shown to increase beta-adrenergic receptors in brains of 60 days old rats exposed to 25 min of anoxia on PI of life (I I). Further studies are needed to evaluate adrenergic and dopaminergic receptor status following postnatal hypoxia.

Postnatal handling, and stress have been shown to decrease the adult HPA responsiveness following immobilization stress (20). In contrast, Levine and Mullins (13) showed that animals stimulated in infancy by being picked up daily, placed in another cage for $3 \mathrm{~min}$, and then returned, showed a more rapid and greater steroid response to a brief electric shock in adulthood, than that shown by animals not handled in this way. However, in our study at 150 days of age the corticosterone response of hypoxic animals to restraint stress did not differ from controls (Fig. 5, lower panel). This suggests, that the response of the hypothalamic-adrenal axis to an emotional stress stimulus is not altered.

\section{CONCLUSIONS}

In the present study, postnatal hypoxia altered responsiveness to dopaminergic and noradrenergic drugs. This may have been mediated by oxygen dependent neurotransmitter enzymes such as tyrosine hydroxylase which alter brain neurotransmitter status during hypoxia. Moreover, the period during which we exposed the neonates to hypoxia is characterized by synaptogenesis, gliogenesis, myelination, neurogenesis, and migration.

Overall, we observed both short-, and long-term alterations in response to dopaminergic and adrenergic drugs. Extrapolation of the present data obtained in rats to humans is difficult. However, it suggests that perinatal exposure to hypoxia can alter subsequent drug responsiveness in humans.

Further studies are needed to examine the effect of hypoxia on receptor systems. For example, studies of site-specific dopamine release, dopamine turnover, dopamine induced signal transduction following postnatal hypoxia could help to elucidate behavioral output. 


\section{REFERENCES}

I. Bjelke, B., K. Andersson, S.V. Ogren, and P. Bolme. Asphycticlesion: proliferation of tyrosine hydroxylase-immunoreactive nerve cell bodies in the rat substantia nigra and functional changes in dopamine neurotransmission. Brain.Res. 543:1-9, 1991.

2. Costall, B. and R.J. Naylor. On the mode of action of apomorphine. Eur. J. Pharm. 21:350-361, 1973.

3. Cuomo, V., R. Cagiano, 1. Mocchetti, E. Coen, F. Cattabeni, and G. Racagni. Behavioral and biochemical effects in the adult rat after prolonged postnatal administration of clozapine.

Psychopharmacology 81:239-243, 1983.

4. Femandez-Teruel, A., RM. Escorihuela, P. jiminez, and A. Tobena. Infantile stimulation and perinatal administration of Ro 15-1788: additive anxiety-reducing effects in rats. Eur. J. Pharmacol. 191:111-114, 1990.

5. Grammate, Th. and J. Schmidt. The effect of early postnatal hypoxia on the effectiveness of drugs influencing locomotor behavior in adult rats. Biomed. Biochim. Acta 45: 1069-1074, 1986.

6. Hannigan, J.H. The ontogeny of SCH 23390 -induced catalepsy in male and female rats exposed to ethanol in utero. Alcohol 7:11-16,1990.

7. Hedner, T. and P. Lundborg. Development of dopamine autoneceptors in the postnatal rat. J. Neural Transmiss, 62:53-63, 1985.

8. Hedner, T., Lundborg, P., and J. Engel. Brain biochemical and behavioral changes in 4-weeks old rats after neonatal oxygen deprivation. Pharmacol. Biochem. Behav. 10:647-650, 1979.

9. Hermans, RH.M., D.E. Hunter, RF. McGivem, C.D. Cain, and LD. Longo. Behavioral sequelae in young rats of acute intermittent antenatal hypoxia. Neurotoxicol. Teratol. 14:119-129, 1992.

10. Hermans, R.H.M. R.F. McGivem, W. Chen, and L.D. Longo. Attered adult sexual behavior in the male rat following chronic prenatal hypoxia. Neurotoxicol. Teratol. 15:353-363, 1993.

11. Hershkowitz. M., V.E. Grimm, and Z. Speiser. The effects of postnatal anoxia on behavior and on the muscarinic and beta-adrenergic receptors in the hippocampus of the developing rat. Dev. Brain Res. 7:147-155, 1983.

12. Krieger, D.T. Effects of neonatal hydrocortisone on corticosteroid circadian periodicity, responsiveness to ACTH and stress in prepuberal and adult rats. Neuroendocrinology 16:355-363, 1974.

13. Levine, S. and RF. Mullins. Hormonal influences on brain organization in infant rats. Science 152:1585-1592, 1966.

14. Lun, A, H.D. Fischer, C. Wustmann, R Pohle, R. Moller, J. Gross, and J. Schmidt. Effects of piracetam in brain development in newbom rats exposed to hypoxia Biomed. Biochim. Acta 43:789-795, 1984.

15. Lun, A. J. Gross, M. Beyer, H.D. Fischer, C. Wustmann, J. Schmidt, and K Hecht. The vulnerable period of perinatal hypoxia with regard to dopamine release and behavior in adult rats. Biomed. Biochem. Acta 45:619-627, 1986.

16. Lun, A., H. Gruetzmann, C. Wustmann, L Szuesz, B. Dominick G. Horvath, H.D. Fischer, I. Nagy, and J. Gross. Effect of pyritinol on the dopaminergic system and behavioral outcome in an anima! model of mild chronic postnatal hypoxia. Biomed. Biochem. Acta 48:5237-\$242, 1989.

17. Lun, A., C. Wustmann, C. Bemdt, H.D. Fischer, J. Gross, K Hecht, G. Stamminger, and ]. Schmidt. Postnatal administration of L-DOPA normalizes hypoxia-induced long-term changes in dopamine release from striatum slices and in avoidance leaming. Biomed. Biochim. Acta 10:1277-1283, 1986.

18. Lynch, M.R Dissociation of autoreceptor activation and behavioral consequences of low-dose apomorphine treatment. Prog. Neuropsychophamacol. Biol. Psychiatry 5:689-698, 1991.

19. McGivem, R.F., RE. Poland, I.P. Noble, and L.A. Lane. Influence of prenatal ethanol exposure on homonal responses to clonidine and naloxone in prepubescent male and female rats.

Psychoneuroendocrinology 11:105-1 10, 1986.

20. Meaney, J.M., V. Viau, S. Bhatnagar, K. Betito, L.J. Iny. D. O Odonell, and J.B.Mitchell. Cellular mechanisms underlying the development and expression in the hypothalamic-pituitary-adrenal stress response f. Steroid Biochem. Molec. Biol. 39:265-274, I991. 
21. Naumenko, E.V. and N.N. Dygalo. Noradrenergic brain mechanisms and emotional stress in adult rats after prenatal hydrocortisone treatment. In: Biogenic Amines in Development. 1980. Amsterdam, Elsevier Biomedical Press. Eds Parvez H. and S. Parvez, pp 373-388.

22. Odarjuk, J. L. Hetey, and J. Gross. Synaptosomal uptake and release of dopamine in rat striatum after hypoxia. J. Neurochem. 48:1115-1120, 1987.

23. Pradhan S.N. and S. Pradhan. Development of central neurotransmitter systems and ontogeny of behavior. In:Biogenic Amines in Development, 1980. Amsterdam, Elsevier Biomedical Press. Eds Parvez H. and S. Parvez, pp 641-662.

24. Randrup, A. and I. Munkwad. Pharmacology and physiology of stereotyped behavior. J. Psychiatry II:I-10, 1974.

25. Seidler, F.J. and T.A. Slotkin. Effects of acute hypoxia on neonatal rat brain: regionally selective, long-term alterations in catecholamine levels and turnover. Brain Res. Bull. 24:157-161, 1990.

26. Smythe, G.A., J.E. Bradshaw, R.M. Gleeson, H.S. Grunsten, and M.V. Nicholson. The central vs. peripheral effects of clonidine on $\mathrm{ACTH}$, corticosterone and glucose release. Eur. J. Pharm. III:401-403, 1985.

27. Smythe, G.A., J.E. Bradshaw, and RF. Vining. Hypothalamic monoamine control of stress-induced adrenocorticotropin release in the rat. Endocrinology 113:1062-1071, 1983.

28. Speiser, Z.j. Amitzi-Zonder, R Ashkenazi, S. Gitter, and S. Cohen. Central catecholaminergic dysfunction and behavioral disonders following hypoxia in adult rats. Behav. Brain. Res. 37:19-27. 1990.

29. Van den Buuse, M. and W. De Jong. Differential effects of dopaminergic drugs on open-field behavior of spontaneously hypertensive rats and normotensive Wistar-Kyoto rats. J. Pharmacol. Exp. Ther. 248: I 189- I195, 1989.

30. Weissman, E.M., A.B. Norman, S.F. Calderon, E.M. Zubrycki, M.M. El-Elteri, M.T.Shipley, and P.R Sandberg. The effect of prenatal treatment with MPTP or MPP+ on the development of dopamine-mediated behaviors in rats. Pharmacol. Biochem. Behav. 34:545-551, 1989. 


\section{GENERAL DISCUSSION}

\section{PRENATAL HYPOXIA AND POSTNATAL BEHAVIOR}

\section{Behavioral sequelae as measured with longitudinal test battery}

Both acute, intermittent and chronic prenatal hypoxia in the rat had only a moderate effect on subsequent behavior as measured in our test battery. The main effects were detected at early ages e.g., prior to puberty, 40-50 days. During subsequent development hypoxic animals did not differ significantly from controls. Thus, moderate prenatal hypoxia, whether intermittent (daily $4 \mathrm{~h}$ exposure to $10.5 \% \mathrm{O}_{2}, 0.5$ atm, equivalent to $\mathrm{PO}_{2}$ at 5,490 meters or 18,000 feet elevation) or chronic as employed in our paradigm, failed to have a lasting and sizeable impact on behavioral tests. These data may testify for the relative resistance of the fetus to prenatal hypoxia, and/or the plasticity of the developing brain to recover from insults.

Also, compared to previous reports (Table I, and 2 Chapter 1.), behavioral effects demonstrated in our studies were relatively minor. Several factors may account for this phenomenon. The strain of rat, exposure paradigms, gestational age at time of treatment, foster procedures, and test methods differed markedly among the reported studies. More specifically, several studies employed a carbon monoxide exposure paradigm which may have a toxic effect on its own.

Our results suggest that for hypoxic stress to induce lasting alterations in overt behavior; the developing rat fetus has to be exposed to severe hypoxia. In addition the point in time of exposure to hypoxia may be of importance. Nonetheless, as demonstrated in chapter 8 , behavioral differences may be quite subtle, and only detectable when the system is challenged with drugs that interfere with regulators of behavior, i.e. specific neurotransmitters. Described alterations following drug challenge demonstrate that perinatal hypoxia interferes with the development of neurotransmitter systems. However, the described alterations are inconclusive about exact mechanisms involved.

\section{Sexual dimorphic nonreproductive and reproductive behaviors following prenatal hypoxia}

In the rat, acute intermittent hypoxia significantly attenuated the postnatal testosterone surge. Nonetheless, the hypoxic-induced decrease in postnatal testosterone concentrations appear to provide sufficient amounts of substrate for masculinization and defeminization of the male brain. In adulthood these animals exhibited normal masculine sexual behavior, lordotic behavior in response to estrogen and progesterone priming, open field behavior and saccharin preference. Based on this study, one can assume that a reduction in $T$ of more than $50 \%$ is probably needed to affect sexually dimorphic behavior. A study employing a dose response curve in neonatally castrated rats with testosterone replacement may define the threshold concentration for the masculinizing properties of testosterone.

Chronic prenatal hypoxia failed to attenuate the postnatal testosterone surge relative to normoxic controls. However, in adulthood, animals exposed to chronic prenatal hypoxia displayed a significant delay in the initiation of masculine sexual behavior. 
with a lower number of ejaculations. The significance and causes of the delayed initiation of sexual behavior is unclear. Other nonsteroidal influences may be acting directly on the developing nervous system or indirectly to modify the organizational actions of steroid hormones. Compared to behavioral sequelae observed following other environmental insults such as alcohol, and stress these changes are relatively minor. Lordosis behavior, open field behavior, and saccharin preference were not significantly altered compared to controls.

In chapter 2 we described the demasculinizing and feminizing effects of a multitude of maternal and neonatal treatments. Relative to these studies, prenatal hypoxia had a minor effect on sexual differentiation. There appear to be significant strain differences in vulnerability of the central nervous system to perinatal "stressors" Moreover, the hypoxic paradigm employed by us was of moderate severity. Thus, more severe acute hypoxia may have a more profound effect on adult sexually dimorphic, nonreproductive and reproductive behaviors. Further studied are needed to address this aspect.

\section{PRENATAL HYPOXIA AND THE PRENATAL AND POSTNATAL TESTOSTERONE SURGE}

In the present thesis we assessed the effect of prenatal hypoxia on the postnatal testosterone surge. In addition, we performed several experiments designed to study the mechanisms involved in the regulation of the testosterone surge. Acute, intermittent prenatal hypoxia suppressed the amplitude of the postnatal testosterone surge. In contrast, chronic prenatal hypoxia failed to interfere with either the prenatal or postnatal testosterone surge. As shown in chapter 2 (Tables 1-5), the effect of several maternal and neonatal treatments on the pre- and postnatal surges have been studied. However, it is not clear which factors determines onset and amplitude of the testosterone surge, and how maternal treatments influence it.

In the following paragraphs we will speculate on possible regulating and suppressive factors of the testosterone surge.

\section{Hypothalamic-pituitary-gonadal axis}

In chapter 7 we demonstrated that in the rat the postnatal testosterone surge is not associated with a significant rise in plasma $L H$. In addition, elevated testosterone levels failed to exert negative feedback on plasma $\mathrm{LH}$ concentrations. Treatment of male pups within 5 min after caesaren section with an $\mathrm{GnRH}$ antagonist, or $\mathrm{LH}$ antibody decreased plasma $\mathrm{LH}$ concentrations, but failed to interfere with postnatal testosterone concentrations. These results suggest that mechanisms other than a rise in $\mathrm{GnRH}$ and $\mathrm{LH}$ must be involved in the regulation of the testosterone surge. Factors involved must have a disinhibiting effect on testicular steroidogenesis, most likely by an direct effect on the gonads. Possible candidates are a multitude of substances of maternal and placental origin, the concentrations of which rapidly decline in the newborn following birth. These include, follicle stimulating homone, growth hormone, prolactin, estrogen, etc. Neonatal progesterone failed to alter onset or suppress the amplitude of the testosterone surge.

Recently, Corbier and colleagues (8) demonstrated that at the end of gestation, 
the male rat fetus is unresponsive to hCG treatment. However, hCG injected at either 4 or $48 \mathrm{~h}$ after birth increases serum testosterone concentrations. In addition, administration of a high dose of 17 beta estradiol immediately after birth, blocked the testosterone surge (8). A lower dose of 17 beta estradiol failed to produce this effect. The authors suggested that both the fall in plasma estrogens and the increased testicular sensitivity to hCG may be important regulators of the testosterone surge. However, further studies using physiological estrogen dosages need to confirm these phenomena.

\section{Hypothalamic-pituitary-adrenal axis}

Common to the majority of treatments like alcohol, stress, or hypoxia is the activation of the HPA-axis. It is well known that plasma concentrations of glucocorticoids increase during hypoxia and stress. As discussed in chapter 2 , maternal stress, ACTH, or dexamethasone treatment attenuate the postnatal testosterone surge. Adrenal glucocorticoids may mediate the effects of stress on testicular steroidogenesis by acting directly on the testis to suppress gonadal function. For example, ACTH or corticosterone infusions to adult male rats reduce serum testosterone concentrations, but fail to interfere with serum $\mathrm{LH}$ concentrations (13). In vitro incubation of testicular interstitial cells with dexamethasone or corticosterone suppresses hCG-stimulated testosterone secretion in a dose dependent manner (19). Coincubation with the antiglucocorticoid RU486 blocked the glucocorticoid effect, indicating that these agents act through a glucocorticoid receptor (20). Glucocorticoid receptors have been localized on rat Leydig cells (23).

As shown in Fig.2. (chapter 4) following acute, intermittent, prenatal hypoxia plasma corticosterone concentrations of male pups were suppressed over the $480 \mathrm{~min}$ measured. Previous studies have shown that in utero elevated levels of glucocorticoids are followed by decreased neonatal glucocorticoid concentrations $(6,10)$. Moreover, in vivo dexamethasone treatment of immature rats (21-23 days) for 5 days decreases subsequent in vitro secretion by testicular cells in response to hCG stimulation, and LH/hCG receptor content (3). Thus, activation of the HPA-axis during prenatal intermittent acute hypoxia may decrease hCG sensitivity, and consequently testicular steroidogenesis.

\section{Opioids}

Ward and colleagues (25) suggested that in response to stress, opioids may mediate alterations in sexual differentiation by suppressing testosterone secretion through the hypothalamic-pituitary system, or through gonadal opioid receptors. As shown in chapter 5 neither the prenatal or postnatal testosterone surge were suppressed following chronic, prenatal hypoxia. However, studies by our group have shown that chronic prenatal hypoxia significantly down-regulated mu-opioid receptors in neonatal brains ( $\mid 1)$. In fact, these brains were harvested from neonates used in the testosterone surge experiments described in this thesis. Thus, during chronic hypoxia large amounts of opioids were probably secreted, and subsequently opioid receptors were down regulated. Surprisingly, following acute, intermittent prenatal hypoxia no significant differences were detected in opioid receptor densities in the several brain regions of male rats. This suggests that the magnitude of opioid release following acute, intermittent hypoxia was less than that after chronic hypoxia. Nonetheless, the testosterone 
surge was suppressed with this paradigm. In addition, prenatal treatment. with the opioid antagonist naltrexone failed to alter postnatal testosterone concentrations. It can not be ruled out that opioids interfere with steroidogenesis at a gonadal level.

\section{Estrogen}

In the first hours after birth plasma estradiol concentrations fall progressively. Neonatal estrogen treatment blocks the postnatal testosterone surge ( 8 ). Fetal hypoxemia is associated with dramatic increased plasma estrone, and estradiol concentrations (24). In addition, in neonatal rats, dexamethasone treatment inhibits serum alpha-fetoprotein, increasing serum estrogen concentrations (9). The possibility exists that hypoxiainduced elevations in plasma estradiol interfere in a similar fashion with the postnatal testosterone surge. Further studies are needed to explore this hypothesis.

\section{NMDA}

In chapter 6 we showed that MK-80 I treatment failed to block the suppressive effect of intermittent, acute hypoxia on the postnatal testosterone surge. In neonatal rats (9-10 and 20-21 days) systemic NMDA treatment increases plasma ACTH concentrations (4). However, pretreatment with the competitive NMDA antagonist CPP failed to attenuate the ACTH response to NMDA in the 10 day old rats, whereas in 20 day old pups CPP blocked this effect. This suggests that the ACTH response is not sensitive to NMDA antagonists during the early neonatal period. This may be a factor in the lack of effect of MK-80I pretreatment in our experiment. Thus, NMDA can not be excluded as a possible mediator in the suppressive action of acute intermittent hypoxia on the postnatal testosterone surge.

\section{Liver}

Steroids are predominately metabolized in the liver prior to excretion. Studies by Baum and colleagues (5) showed that relatively slow metabolism of testosterone in the early postnatal period may be a factor in the postnatal rise in circulating testosterone. Consequently, the same could be true for corticosterone which is also metabolized in the liver. However, as shown in chapter 4 we did not observe an corticosterone surge in the first eight hours following birth. Moreover, a decreased postpartum steroid clearance would likely produce a relative 'surge' of $T$ in the female during the first hours postnatally as well, a finding which has not been observed.

\section{Intermittent versus chronic hypoxia}

In the present thesis we described the paradoxical effect of prenatal, chronic hypoxia and acute, intermittent, prenatal hypoxia on the testosterone surge of the newborn male rat Hypoxia is known to activate the HPG-axis of both the pregnant dam and fetus. Nonetheless, several studies in sheep and rats suggest that following chronic stress or hypoxia both adults and fetus can "adapt" to the ongoing stimulation (unpublished data Harvey and Ducsay). Prolonged exposure to high circulating concentrations may be detrimental to fetal growth and well-being (18). Harvey and colleagues (unpublished data) suggested that maintenance of plasma cortisol concentrations within range 
of the normoxic fetus may serve as an adaptive mechanism during exposure to chronic hypoxia. Thus, compensation of the fetal HPA-axis may occur, ultimately resulting in unaltered pre- and postnatal testosterone concentrations following chronic hypoxia.

In summary, the onset and amplitude of the postnatal testosterone surge in the male rat are not regulated by $\mathrm{GnRH}$ and $\mathrm{LH}$. Possibly a combined effect of decreasing plasma estradiol and increased hCG sensitivity of the neonatal testis, induces the increased steroidogenesis. Acute, intermittent hypoxia may interfere directly with the latter process through elevated estradiol, $\mathrm{ACTH}$, and/or corticosterone concentrations.

\section{Hypoxia as co-factor}

Prenatal treatment paradigms such as stress, nicotine, catecholaminergic drugs, cocaine, and alcohol that have shown to demasculinize and feminize male offspring, also may induce fetal hypoxia. In the baboon, maternal psychological stress by illumination and restraint reduces uterine blood flow and fetal $\mathrm{PO}_{2}(15,16)$. Onkawa and colleagues (19) showed in the rat that forced maternal immobilization reduced fetal blood $\mathrm{pH}$, suggesting fetal hypoxia. Intravenous injection of nicotine into pregnant ewes resulted in a fall of uterine blood flow, leading to a transient fetal hypoxemia (14). In the rhesus monkey maternal administration of epinephrine and norepinephrine induced vasoconstriction in the uterine circulation, with fetal hypoxemia $(1)$. Prenatally administered cocaine is known to demasculinize male adult rats (22). In the sheep, cocaine alters fetal oxygenation by reducing uterine blood fiow and impairing oxygen transier to the fetus (26). Muhkeriee and Hodgen (17) reported that high dosages of intravenous alcohol to pregnant monkeys caused a transient collapse of umbilical vasculature that resulted in severe fetal hypoxia. Incubation of umbilical cord arteries and veins in solutions containing different concentrations of alcohol, demonstrated vessel contraction in the presence of low levels of alcohol (2). These studies suggest that hypoxia may contribute to the demasculinizing and feminizing actions of these treatments

\section{The testosterone surge in humans}

There is abundant evidence for the occurrence of a postnatal testosterone surge in male newborn humans. For instance, Corbier et al (7), reported that at birth serum testosterone in males increased dramatically during the first $3 \mathrm{~h}$ after birth and remains elevated between 3 and $12 \mathrm{~h}$ after birth. Subsequently, another increase in testosterone concentrations occurs during the first months of life. However, it is not clear what the significance of this surge is for the sexual differentiation of the human brain, and adult behavior. In addition, no studies have demonstrated an effect of an environmental factor on the postnatal testosterone surge in humans. Alcohol use by pregnant mothers of male fetus, decreased basal amniotic fluid concentrations of testosterone levels, without altering gonadotrophin concentrations (12). Further studies need to determine the physiological significance of the postnatal testosterone surge in humans. As fetal, and neonatal hypoxia is a relative frequent event in humans, it is of interest if such an insult alters the onset or amplitude of the testosterone surge. 


\section{CONCLUSION}

The present thesis demonstrates that in the rat relatively mild prenatal hypoxia. induces minor functional alterations in the developing offspring, In addition, acute intermittent prenatal hypoxia suppresses the testosterone surge in male neonates without alterations in adult sexual behavior. Further studies are needed to determine the effects of more severe prenatal hypoxia and different time points of exposure on the perinatal androgen status, and subsequent function. The onset and amplitude of the neonatal testosterone surge appears not to be regulated by the hypothalamus and/or pituitary. Mechanisms regulating the normal and abnormal testosterone surge are not clear. Factors of maternal or placental origin may play a significant role in the stimulation of the postnatal testosterone surge. Interestingly, the postnatal testosterone surge occurs in male rats, dogs, horses, and humans. However, little is known about the physiological importance of this phenomenon for humans. 


\section{REFERENCES}

1. Adamsons, K, E. Mueller-Heubach, and R Myers. Production of fetal asphyxia in the thesus monkey by administration of catecholamines to the mother. Am. J. Obstet. Gynecol. 109:248-262, 1971.

2. Altura, B.M., B.T. Altura, A. Carella, M. Chatterjee, M. Halevy, and S. Tejani. Alcohol produces spasms of human umbilical blood vessels: relationship to fetal alcohol syndrome (FAS). Eur. 1. Phamacol. 86:311-312, 1982.

3. Bambino, T.H., A.J.W. Hsueh. Direct inhibitory effect of glucooticoids upon tetsicular luteineizing homone receptor and steroidogenisis in vivo and in vitro. Endocrinology 108:2142-2148, 1981.

4. Bardgett, M.E., G.T. Taylor, and J.M. Farah Jr. Systemic NMDA treatment increases plasma ACTH in the neonatal rat. Develop. Brain. Res. 68:289-293, 1992.

5. Baum, M.j., T. Brandt, M. Ooms, J.T.M. Vreeburg, A.K Slob. Immediate postnatal rise in whole body androgen content in male rats: Correlation with increasedtesticular content and reduced body clearance of testosterone. Biol. Reproduc. 38:980-986, 1988.

6. Cadet, R. P. Pradier, M. Dalle, and P. Delost. Effects and prenatal matemal stress on the pituitary adrenocortical reactivity in guinea pigs. J. Develop. Physiol. 8:467-475, 1986.

7. Corbier, P., L Dehennin, M. Castanier, A. Mebazaa, D.A. Edwards, and J. Roffi. Sex differences in serul luteinizing hormone and testosterone in the human neonate duning the first few hours after birth. Clin. Endocrinol. Metab. 71:1344-1348, 1990.

8. Corbier, P., N. Allioli, and J. Roffi. Variations in the testicular response to HCG during the perinatal period in the rat: influence of estrogen. Arch. Int. Physiol. Biochim. Biophys. 100:389-397, 1992.

9. Huang, D.P. G.J. Cote, RJ. Massari, and J.F. Chiu. Dexamethasone inhibits alfa-fetoprotein gene transcription in neonatal rat liver and isolated nuclei. Nucleic. Acids. Res. 13:3878-3890, 1985.

10. Kaupilla, A., S. Simila, O. Ylikorkala, M., M. Koivisto, and J. Haapalathi. ACTH in maternal, fetal and neonatal plasma after short-term prenatal dexamethasone therapy. Br. 1. Obset. Gynecol. 84:124128, 1976.

11. Kraczkowski, .J.. F.M. Leslie, and L.D. Longo. Chronic prenatal hypoxia decreases mu-opioid receptor binding in newborn rat brain: quantitative autoradio-graphic analysis. Society for Gynecologic Investigation 40th annual meeting, Program: Abstract P168, 1993.

12. Westney, L., R Bruney, B. Ross, J.F. Clark. S. Rajguru and B. Ahluwalia. Evidence that gonadal hormone levels in amniotic fluid are decreased in males born to alcohol users in humans. Alcohol \& Alcoholism. 26:403-407, 1991.

13 Mann, D.R, C. Free, C. Nelson, C. Scott and D.C. Collins. Mutually independent effects of adrenocorticotropin on luteinizing hormone and testosterone secretion. Endocrinology. 120:1542-1550, 1987.

14. Manning, F., D. Walker, and C. Feyerabend. The effect of nicotine on fetal breathing movements in conscious pregnant ewes. Obstet. Gynecol. 52:563-568, 1978.

15. Morishima, H.O., H. Pedersen, and M. Finster. The influence of matemal psychological stress on the fetus. Am. J. Obstet. Gynecol. 131:286-290, 1978.

16. Morishima, H.O., Y. Ming-Neng, and LS. James. Reduced uterine blood flow and fetal hypoxemia with acute maternal stress: experimental observation in the pregnant baboon. Am. J. Obstet Gynecol. 134:270-275, 1979.

17. Mukheriee, A.B. and G. Hodgen. Matemal ethanol exposure induces transient impairment of umbilical circulation and fetal hypoxia in monkeys. Science. 218:700-702, 1982.

18. Munck A., P.M. Guyre, and N.J. Hollbrook. Physiological functions of glucocorticoids in stress and the relations to pharmacological actions. Endocrin. Rev. 5:25-44, 1984.

19. Ohkawa, T., S. Takeshita, T. Murase, A. Kambegawa, S. Okinago, and K. Arai. Ontogeny of the response of the hypothalamo-pituitary-adrenal axis to matemal immobilization stress in rats. Endocrinol. Japon. 38:187-194, 1991.

20. Or, E., D.R Mann. Role of glucocorticoids in the stress-induced suppression of testicular 
steroidogenisis in adult male rats. Horm. Behav. 26:350-363, 1992.

21. Orr, T.E. D.R. Mann. Effects of restraint stress on plasma $\mathrm{LH}$ and testosterone concentrations, leydig cell $\mathrm{LH} / \mathrm{HCG}$ receptors, and in vitro testicular steroidogenisis in adult rats. Horm. Behav. 24:324-341, 1990.

22. Raum, W.J., RF. McGivem, M.A. Peterson, J.H. Shryne, and R.A. Gorski. Prenatal inhibition of hypothalamic sex steroid uptake by cocaine: effects on neurobehavioral sexual differentiation in male rats. Develop. Brain Res. 53:230-236, 1990.

23. Stalker, A, L Hermo, and T. Antakly. Covalent affinity labelin, radioautography, and immunocytochemistry localize the gluco corticoid receptor in rat testicular Leydig cells. Am. I. Anat. 386:369-377, 1989.

24. Stepherd, RW., F.C. Stanczyk, C.L. Bethea, and M.J. Novy. Fetal and matemal endocrine responses to reduced uteroplacental blood flow. J. Clin. Endocrinol. Metab. 75:301-307, 1992.

25. Ward, B.O., J.M. Orth, J. Weisz. A possible role of opiates in modifying sexual differentiation. Monogr. Neural Sci. 9:194-200, 1983.

26. Woods, J.R, M.A. Plessinger, and K.E. Clark. Effect of cocaine on utenne blood flow and fetal oxygenation. JAMA, 257:957-961, 1987. 


\section{SUMMARY}

The aim of the experiments described in this thesis was to investigate the behavioral and endocrine sequelae of perinatal hypoxia in the rat.

Chapter I reviews the literature on the effects of perinatal hypoxia on subsequent behavior. In the rat, the late gestational and early postnatal period is of critical importance for the developing brain. This period is characterized by cellular migration, cell proliferation, differentiation, synaptogenesis, gliogenisis, myelinization, and functional organization. Thus, perinatal insults during this period may profoundly impact subsequent development and behavior. Studies of hypoxia, asphyxia, and ischemia in fetal and newborn rats resulted in a wide spectrum of sequelae, particularly with respect to subsequent learning and locomotor behavior.

Chapter 2 reviews the effects of prenatal stress on sexual differentiation of the brain and behavior. The perinatal period is a critical period for the sexual differentiation of the rat brain. Complete masculinization of the rat brain requires elevated circulating testosterone concentrations, and subsequent aromatization of testosterone to estradiol. Two perinatal surges of testosterone provide the primary source of testosterone and estradiol for masculinization. In the rat fetus, a significant increase in circulating testosterone concentration occurs on days 18 and 19 of gestation. In several species, including humans and rats, a second testosterone surge peaks 2 to 12 hours after birth. The studies described provided evidence for altered perinatal androgen status, and subsequent modification of sexually dimorphic behaviors by maternal exposure to stress per se, or substances such as alcohol, nicotine or cocaine.

Chapter 3 presents the effect of acute, intermittent, mild prenatal hypoxia on neurobehavioral development, as well as on the neurochemical changes. Previous studies by our group showed that this hypoxic paradigm markedly altered and polyamine concentrations and ornithine decarboxylase activity, its rate limiting enzyme in fetal and newborn rat brains. Polyamines are intimately associated with cellular growth and differentiation. Rats exposed to acute, intermittent, antenatal hypoxia displayed some functional alterations during development. However, with maturation these abnormal behaviors disappeared, which testifies to the neuroplasticity of the developing nervous system. It remains to be established whether these behavioral changes reflect the neurochemical alterations which occurred in association with hypoxia.

Subsequently, we examined the influence of intermittent hypoxic exposure during gestation on the postnatal testosterone surge and corticosterone concentrations, and subsequent development of adult reproductive and non-reproductive behaviors Relative to normoxic controls, acute, intermittent prenatal hypoxia significantly suppressed the postnatal testosterone surge. Postpartum corticosterone levels in these animals were also suppressed. In adulthood, these animals exhibited normal masculine sexual behavior. In addition, lordosis behavior and saccharin preference (the latter being a nonreproductive sexually dimorphic behavior) were not significantly influenced by prenata! hypoxic exposure. We concluded that the degree of hormonal suppression following this prenatal hypoxic exposure regimen was not enough to interfere with normal development of sexual behavior in the male rat. 
We then hypothesized whether the effects of chronic, prenatal hypoxia on perinatal androgen status and subsequent behavioral development would differ from that of acute intermittent hypoxia (chapter 5). We showed that mild, chronic, prenatal hypoxia affected several aspects of adult reproductive behavior in the absence of overt changes in either the pre- or postnatal testosterone surge. Specifically, rats exposed to chronic prenatal hypoxia had significantly increased latencies to initiate male sexual behavior and a decreased number of ejaculations compared to controls. However, other indices of masculine sexual behavior, lordosis behavior, and saccharin preference were not affected. In addition, we observed only moderate effects of chronic prenatal hypoxia on sensorimotor development.

Acute, fetal hypoxia has been shown to increase levels of endogenous opioids and $\mathrm{N}$-methyl-D-aspartate excitatory amino acids. In chapter 6 we tested the hypothesis that the opioid antagonist naltrexone, or the $\mathrm{N}$-methyl-D-aspartate antagonist MK801 would affect the postnatal testosterone surge, either under normoxic control conditions or in response to prenatal hypoxia. Naltrexone treatment had no effect on the timing or magnitude of postnatal testosterone concentrations in either normoxic control or in chronicly hypoxic animals. Following acute intermittent prenatal hypoxia with or without MK-80 I treatment, newborn plasma testosterone concentrations were significantly decreased. However, MK-80 I alone significantly increased postnatal testosterone levels compared to controls. These results demonstrated that prenatal naltrexone treatment, with presumed inhibition of endogenous opioid action, did not affect the postnatal testosterone surge. In addition, MK-80I, with presumed blockage of NMDA receptor activity, failed to antagonize the suppressing effects of prenatal hypoxia on postnatal testosterone concentrations.

We do not know the mechanism by which the amplitude and onset of normal testosterone surge is regulated, nor do we know how acute hypoxia suppresses the postnatal testosterone surge. However, it has been generally assumed that this regulation involves gonadotropin stimulation of the fetal and neonatal testes, which operates in a fashion similar to that of the adult Our data demonstrated that, in the rat, the postnatal testosterone surge is not preceded by a postnatal rise in plasma LHß (chapter 7). Administration of a GnRH antagonist resulted in transient drop in LHB level, but did not decrease the postnatal testosterone surge in the same animals. This suggests that the hypothalamo-pituitary axis may not be involved in the regulation of the postnatal testosterone surge.

In the rat, the critical brain growth spurt for the catecholaminergic neurotransmitter system takes place in the late gestational and early postnatal period. In chapter 8 we hypothesized that early postnatal hypoxia would affect the development of the catecholaminergic system and thus alter functional outcome. Animals exposed to postnatal hypoxia had significantly increased stereotypic behavior in response to apomorphine compared to controls. In addition, the corticosterone response following clonidine injection was significantly altered in these animals. 


\section{SAMENVATTING}

Met de in dit proefschrift beschreven experimenten hebben we getracht de invloed van perinatale hypoxie op de perinatale hormoonhuishouding te beschrijven en de eventuele gevolgen hiervan op het latere gedrag van de rat.

Hoofdstuk I bevat een literatuuroverzicht over de gevolgen van perinatale hypoxie op gedrag. Het laatste deel van de zwangerschap en de vroege postnatale periode zijn cruciaal voor de ontwikkeling van de hersenen van de rat Deze periode wordt gekarakteriseerd door cellulaire migratie, celproliferatie, differentiatie, synaptogenese, gliogenese, en de functionele organisatie van de hersenen. Daarom kunnen insulten tijdens deze periode een vergaande invloed hebben op de verdere ontwikkeling en gedrag. Blootstelling van foetus en pasgeborenen aan hypoxie, asphyxie en ischemie veroorzaakten een breed scala aan gedragsveranderingen. Vooral veranderingen in leer- en motorisch gedrag werden waargenomen.

Hoofdstuk 2 behandelt de effecten van prenatale stress op de sexuele differentiatie van de hersenen en gedrag. De perinatale periode is van groot belang voor de sexuele differentiatie van de hersenen van de rat. De masculinisatie van de hersenen van de rat vereist in die periode verhoogde testosteronconcentratie met daarop volgend aromatisatie tot estradiol. In de perinatale periode vertoont de testosteronconcentratie twee pieken die de belangrijkste bron zijn voor testosteron en estradiol bij de inductie van de masculinisatie van de hersenen. Op dag 18 en 19 van de zwangerschap treedt in de mannelijke rat foetus een significante stijging in de circulerende testosteronconcentraties op. Bij zowel de mens als de rat treedt een tweede testosteronstijging op welke een piek bereikt tussen 2 en 12 uur na de geboorte. De beschreven studies tonen aan dat maternale blootstelling aan psychogene stress of stoffen zoals alcohol, nicotine en cocaine, de perinatale androgenenhuishouding en sexueel dimorf gedrag kunnen veranderen.

Hoofdstuk 3 beschrijft de effecten van acute intermitterende milde prenatale hypoxie op de ontwikkeling van gedrag en op het verloop in de weefselconcentraties van ornithine decarboxylase in de hersenen. Voorafgaande studies door onze groep hebben aangetoond dat een dergelijke blootstelling aan hypoxie de ornithine decarboxylase en polyamineconcentraties verandert. Ornithine decarboxylase is de "rate limiting" factor bij de aanmaak van polyamines. Polyamines zijn van belang voor celgroei en -differentiatie. Ratten blootgesteld aan acute intermitterende prenatale hypoxie toonden enkele functionele ontwikkelingsveranderingen. De geobserveerde afwijkingen waren echter van tijdelijke aard, vermoedelijk vanwege de plasticiteit van de hersenen. Of deze gedragsafwijkingen gecorreleerd zijn aan neurochemische veranderingen is onduidelijk.

Vervolgens onderzochten wij de invloed van intermitterende acute prenatale hypoxie op de postnatale testosteronpiek, corticosteronconcentraties, en volwassen sexueel dimorf gedrag. Zowel de postnatale testosteronpiek als postnatale corticosteronconcentraties waren significant verlaagd in mannelijke neonaten, die als foetus waren blootgesteld aan acute intermitterende hypoxie. Volwassen dieren toonden echter een normaal mannelijk sexueel gedrag.

Bovendien bleek het lordosis gedrag en de saccharinepreferentie (een nonre- 
productief sexueel dimorf gedrag) niet beïnvloed te zijn door prenatale hypoxie. basis van deze resultaten werd geconcludeerd, dat de mate van hormoonsuppressie volgend op acute prenatale hypoxie onvoldoende was om de sexuele differentiatie van de mannelijke rat te verstoren.

In hoofdstuk 5 bestudeerden we of chronische hypoxie de perinatale androgeenhuishouding en het volwassen sexueel gedrag anders zou beïnvloeden dan acute prenatale hypoxie. Chronische hypoxie bleek geen remmende werking uit te oefenen op zowel de prenatale als de postnatale testosteronpiek. Desondanks viel het ons op dat de latentiefase, die voorafgaat aan het eerste sexueel gedrag verlaagd was en dat het aantal ejaculaties in vergelijking met controle-dieren verlaagd was. Andere aspecten van mannelijk sexueel gedrag, lordosis gedrag en de saccharinepreferentie-test waren niet significant veranderd. Tenslotte bleek chronische prenatale hypoxie de motorische ontwikkeling in geringe mate te beïnvloeden.

Tijdens acute foetale hypoxie is de concentratie van het endogene opioid en die van N-methyl-D-aspartate (excitatory) aminozuur verhoogd. In hoofdstuk 6 onderzochten wij de invloed van de opioid antagonist naltrexon, en die van de $\mathrm{N}$-methyl-Daspartate antagonist MK-80I op de postnatale testosteronpiek onder zowel normoxische als hypoxische condities. Maternale behandeling met naltrexon had in geen van beide groepen invloed op het tijdstip en de hoogte van de testosteronpiek. Acute prenatale hypoxie al dan niet met MK-80I-behandeling resulteerde in significant verlaagde postnatale testosteronconcentraties. Behandeling met MK-80I induceerde een significant verhoogde postnatale testosteronpiek. Deze resultaten tonen aan dat prenatale naltrexonbehandeling met veronderstelde opioid inhibitie, geen invloed uitoefent op de postnatale testosteronpiek Bovendien bleek dat MK-80I geen effect had op de onderdrukkende werking van acute prenatale hypoxie op de postnatale testosteronpiek.

Het is onbekend welke factoren het tijdstip en de hoogte van de postnatale testosteronpiek bepalen. Eveneens is het onbekend, hoe omgevingsfactoren zoals hypoxie en stress de postnatale testosteronpiek kunnen onderdrukken. Men neemt aan dat net als bij volwassen dieren gonadotrophinen betrokken zijn bij de stimulatie van de foetale en neonatale testis. In de studies beschreven in hoofdstuk 7 werd aangetoond dat bij de rat, voorafgaande aan de postnatale testosteronpiek geen stijging optreedt van het $L H B$. Postnatale toediening van een $\mathrm{GnRH}$ antagonist resulteerde in een voorbijgaande daling van de LHß-concentratie zonder dat het tijdstip en de hoogte van de testosteronpiek werd veranderd. Deze resultaten suggereren, dat de hypothalamus en hypofyse niet betrokken zijn bij de regulatie van de postnatale testosteronpiek.

De groeispurt van het catecholaminergische neurotransmittersysteem vindt bij de rat met name in het laatste deel van de zwangerschap en de vroege postnatale periode plaats. In hoofdstuk 8 toetsten we de hypothese, dat postnatale hypoxie de ontwikkeling van het catecholaminergische neurotransmittersysteem en daaraan gelieerd gedrag zou veranderen. Ratten blootgesteld aan postnatale hypoxie vertoonden een versterkt "stereotypisch" gedrag, na injectie met apomorphine. Bovendien was de corticosteron response na injectie met clonidine significant verandert. 


\section{ACKNOWLEDGEMENT}

The research reported in this thesis was performed at the Loma Linda University and San Diego State University under the supervision of professors Larry Longo and Bob McGivern. I wish to thank them for their warm encouragements, friendship, and mentorship. I would further like to express my gratitude to the staff members, technicians and research fellow's at the Loma Linda University for their various contributions to the realization of this thesis.

Furthermore, I thank dr. Louis Peeters and prof.dr. Jelte de Haan for encouraging me to undertake the adventure of performing research in the U.S.A., and for assisting in the raising of financial support for my endeavours.

Last but not least / wish to thank Miriam and my family for their continuous love and support. 


\section{CURRICULUM VITAE}

\section{Personal Information:}

Born:

September 30, 1964,

Kerkrade, The Netherlands.

\section{Education:}

Secondary

School:

Sancta Maria College,

Kerkrade,The Netherlands. 1976-1983.

Medical

School:

Medical School of the University of Limburg

Maastricht, The Netherlands. 1983-1990.

Intership Gynecology and Obstetrics. St. Elisabeth Hospital,

Willemstad Curaçao, Netherlands Antilles 1989.

Postdoctoral

Fellowship:

Division of Perinatal Biology, Departments of

Physiology and Obstetrics/Gynecology.

School of Medicine Loma Linda University

Loma Linda, California U.S.A. 1990-1993.

Residency

Obstetrics \&

Gynecology:

Division of Obstetrics and Gynecology,

Academisch Ziekenhuis Maastricht. 1994-present.

\section{LIST OF PUBLICATIONS}

I. Hermans, R.H.M., D.E. Hunter, RF. McGivern, C.D. Cain and L.D. Longo, Behavioral sequelae in young rats of acute intermittent antenatal hypoxia. Neurotoxicology and Teratology, 14:1 19-129, 1992.

2. Longo L.D. and R.H.M. Hermans. Behavioral and neurochemical sequelae in young rats of antenatal hypoxia. Early Human Development, 29:83-90, 1992. 
3. Hermans, R.H.M., L.D. Longo and R.F. McGivern. Decreased postnatal testosterone and corticosterone concentrations and unaltered sexual behaviors in male rats following acute intermittent prenatal hypoxia. Neurotoxicology and Teratology, 16:201-206, 1994.

4. Hermans, R.H.M. and L.D. Longo. Altered catecholaminergic behavioral and endocrine response in rats following early postnatal hypoxia. Physiology and Behavior, 55: 469-475, 1994.

5. Hermans, R.H.M., W. Chen, R.F. McGivern and L.D. Longo. Altered sexual behavior in the male rat following chronic prenatal hypoxia. Neurotoxicology and Teratology, 15:353-363, 1993.

6. McGivern, R.F, R.H.M. Hermans, B. Handa and L.D. Longo. Postnatal testosterone surge and plasma $\mathrm{LH}$ concentrations in the male rat following treatment with a GnRH antagonist, LH antibody and progesteron. Submitted.

7. Hermans, R.H.M. and L.D. Longo. The postnatal testosterone surge in the male rat: apparent lack of role of opioids and $\mathrm{N}$-methyl-D-aspartate excitatory amino acids. Submitted.

\section{ABSTRACTS}

1. Hermans, R.H.M., D.E. Hunter, R.F. McGivern and L.D. Longo. Behavioral sequelae in young rats of acute intermittent hypoxia. 38th Annual Meeting of the Society for Gynecologic Investigation, San Antonio, 1991, \#54.

2. Hermans, R.H.M., R.F. McGivern and L.D. Longo. Demasculinization and other behavioral sequelae in male rats following chronic antental hypoxia. 39th Annual Meeting of the Society for Gynecologic Investigation, San Antonio, 1992, \# 109.

3. Hermans, R.H.M., R.F. McGivern and L.D. Longo. Attered dopaminergic response in rats after early postnatal hypoxia. 39th Annual Meeting of the Society for Gynecologic Investigation, San Antonio, 1992, \# I 10.

4. Hermans, R.H.M., W. Chen, R.F. McGivern and L.D. Longo. Altered sexual behavior in the male rat following chronic prenatal hypoxia. 40th Annual Meeting of the Society for Gynecologic Investigation,Toronto, 1993, \# I 80.

5. Hermans, R.H.M., R.F. Handa, RF. McGivern and L.D. Longo. Postnatal testosterone surge and plasma $\mathrm{LH}$ concentrations in the male rat following treatment with a GnRH antagonist or LH antibody. 4 Ith Annual Meeting of the Society for Gynecologic Investigation, Chicago 1994, \#53.

\section{AWARD}

Society for Gynecologic Investigation president's poster award 1993. 
Publication of this thesis was financially supported by Harry and Bella Hermans, Ciba Geigy B.V., Cilag B.V., Duphar B.V., Ferring B.V., Glaxo B.V., Organon B.V., Pfizer B.V., Schering B.V. and Wyett B.V. 

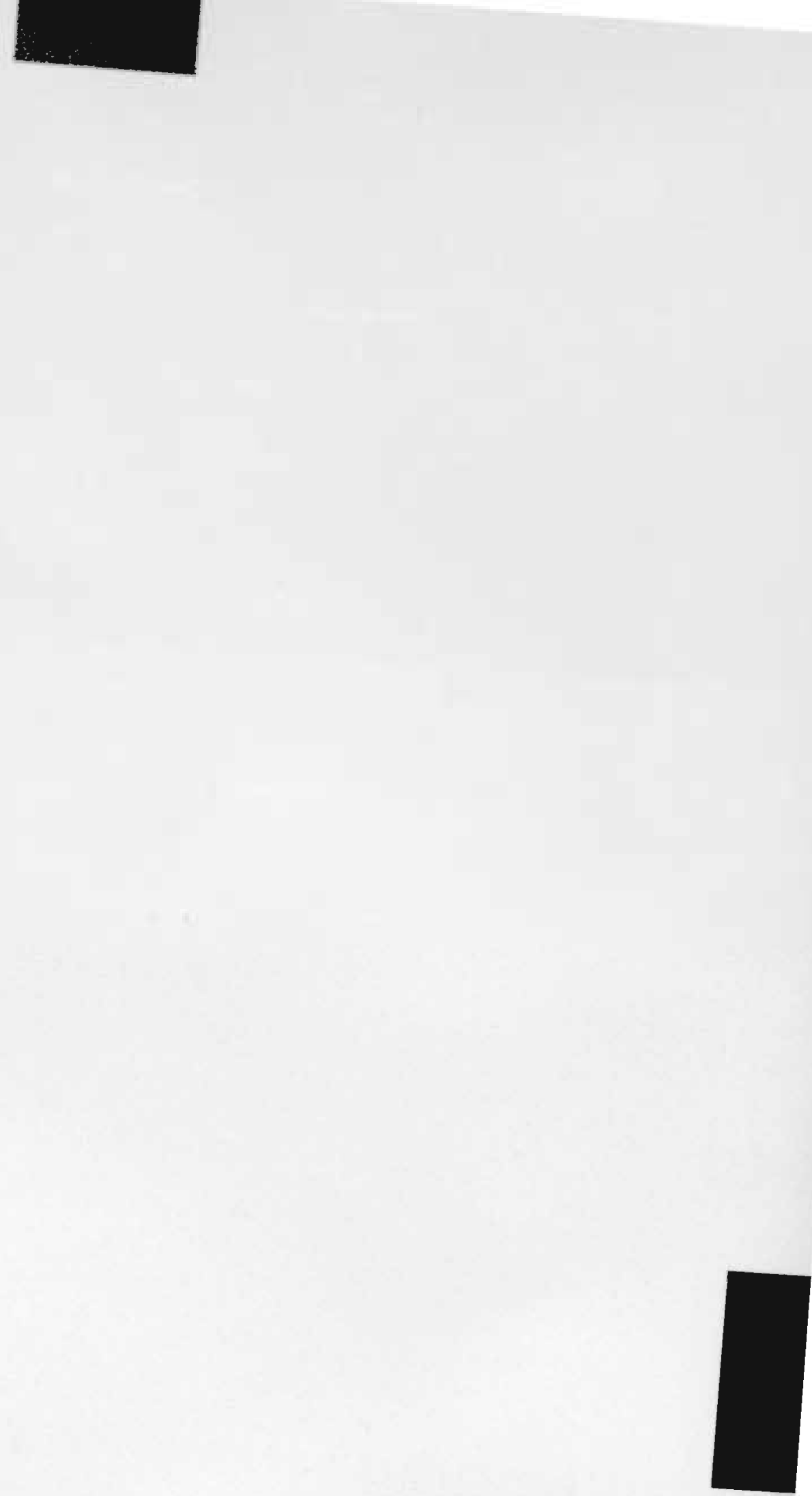